\title{
Growth versus inflammation : lung development after antenatal inflammation and corticosteroids
}

Citation for published version (APA):

Collins, J. J. P. (2012). Growth versus inflammation : lung development after antenatal inflammation and corticosteroids. [Doctoral Thesis, Maastricht University]. BOXPress. https://doi.org/10.26481/dis.20121219jc

Document status and date:

Published: 01/01/2012

DOI:

10.26481/dis.20121219jc

Document Version:

Publisher's PDF, also known as Version of record

\section{Please check the document version of this publication:}

- A submitted manuscript is the version of the article upon submission and before peer-review. There can be important differences between the submitted version and the official published version of record.

People interested in the research are advised to contact the author for the final version of the publication, or visit the DOI to the publisher's website.

- The final author version and the galley proof are versions of the publication after peer review.

- The final published version features the final layout of the paper including the volume, issue and page numbers.

Link to publication

\footnotetext{
General rights rights.

- You may freely distribute the URL identifying the publication in the public portal. please follow below link for the End User Agreement:

www.umlib.nl/taverne-license

Take down policy

If you believe that this document breaches copyright please contact us at:

repository@maastrichtuniversity.nl

providing details and we will investigate your claim.
}

Copyright and moral rights for the publications made accessible in the public portal are retained by the authors and/or other copyright owners and it is a condition of accessing publications that users recognise and abide by the legal requirements associated with these

- Users may download and print one copy of any publication from the public portal for the purpose of private study or research.

- You may not further distribute the material or use it for any profit-making activity or commercial gain

If the publication is distributed under the terms of Article $25 \mathrm{fa}$ of the Dutch Copyright Act, indicated by the "Taverne" license above, 
Growth versus

Inflammation

Lung Development after

Antenatal Inflammation

and Corticosteroids

Jennifer J.P.Collins 

Growth versus inflammation Lung development after antenatal inflammation and corticosteroids 
Copyright Jennifer J.P. Collins, 2012

Cover design Sarah E. Butler

Lay-out Daniël A. de Wolf

Printed by Uitgeverij BOXPress, 's-Hertogenbosch

Sponsors Stichting Kindergeneeskunde

Chiesi Pharmaceuticals B.V. 


\section{Growth versus inflammation Lung development after antenatal inflammation and corticosteroids}

DISSERTATION

to obtain the degree of Doctor at Maastricht University, on the authority of the Rector Magnificus,

Prof. dr. L.L.G. Soete, in accordance with the decision of the Board of Deans, to be defended in public on Wednesday December $19^{\text {th }} 2012$ at 10 o'clock 


\section{Promotors}

Prof. dr. B.W.W. Kramer

Prof. dr. L.J.I. Zimmermann

Prof. dr. S.G. Kallapur (University of Cincinnati, Ohio, United States of America)

\section{Assessment Committee}

Prof. dr. F.C.S. Ramaekers (chairman)

Prof. dr. S. Bambang Oetomo (Eindhoven University of Technology)

Prof. dr. B. Kremer

Prof. dr. I.K.M. Reiss (Erasmus University Rotterdam)

Prof. dr. E.F.M. Wouters 


\section{Table of Contents}

Chapter 1 General Introduction and Outline of this Thesis

Chapter 2 Intra-amniotic LPS and antenatal betamethasone:

23

inflammation and maturation in preterm lamb lungs

Am J Physiol Lung Cell Mol Physiol. 2012 Feb;302(4):L380-9.

Chapter 3 Inflammation in fetal sheep from intra-amniotic injection of

43

Ureaplasma parvum

Am J Physiol Lung Cell Mol Physiol. 2010 Dec;299(6):L852-60.

Chapter 4 Antenatal inflammation reduces Cav-1 expression and influences multiple signaling pathways in preterm fetal lungs Am J Respir Cell Mol Biol. 2011 Nov;45(5):969-76.

Chapter 5 Antenatal glucocorticoids counteract LPS changes in TGF $\beta$ pathway and Caveolin-1 in ovine fetal lung Submitted

Chapter 6 Repetitive intra-uterine exposures to inflammatory stimuli attenuated transforming growth factor $\beta$ signaling in the ovine fetal lung

Submitted

Chapter 7 LPS-induced chorioamnionitis and antenatal corticosteroids modulate Wnt and Shh signaling in the ovine fetal lung Published in part:

Am J Physiol Lung Cell Mol Physiol. 2012 Sep 7 Epub

Chapter 8 Summary \& Discussion

Vereenvoudigde Nederlandse samenvatting

Curriculum Vitae

List of Publications 

General Introduction and Outline

\section{of this Thesis}




\section{Preterm birth}

In the Western world 5 to 13 percent of all babies are born preterm, defined as less than 37 completed weeks (259 completed days) of gestation [1, 2]. In the Netherlands 7.7 percent of infants were born preterm between 22 and 36 weeks of gestation in 2008 [3]. Preterm birth is the most important cause of perinatal morbidity and mortality, causing nearly $75 \%$ of neonatal deaths in the Netherlands in 2008 [3, 4]. Since 1990 there has been a steady increase in the preterm birth rate in several developed countries, which has been accompanied by an increased survival of these preterm babies $[2,3$, $5,6]$. For a large part this increase in survival and decrease in mortality and morbidity can be explained by the introduction of new therapeutic interventions, such as the administration of maternal corticosteroids and surfactant replacement therapy [7]. Corticosteroids are given to mothers when there is an imminent risk for preterm delivery [7]. Both corticosteroids and surfactant replacement therapy serve to facilitate lung function in the preterm neonate to improve neonatal outcome.

\section{Causes of preterm birth}

The onset of preterm birth can be subdivided in three distinct categories: 1) preterm labor with intact membranes, 2 ) preterm premature rupture of the membranes (PPROM) and 3 ) labor induction or cesarean delivery based on medical indications of maternal or fetal health $[4,8]$. Preterm labor and PPROM are both classed as spontaneous preterm birth, whereas the third category is classed as indicated preterm birth $[4,8]$.

A great variety of maternal risk factors for preterm birth have been identified, ranging from demographic risk factors (such as ethnicity, socioeconomic and educational status) and genetic predispositions to environmental exposures (such as smoking and nutrition) $[4,9,10]$. There are many different causes that can trigger biological pathways leading to spontaneous preterm birth. Most commonly these pathways are 1) activation of the maternal/fetal hypothalamic-pituitary-adrenal (HPA) axis (for instance by maternal stress), 2) infection and inflammation, 3) placental dysfunction and 4) uterine overdistension (for instance during a multiple pregnancy) [4, 11]. Of these pathways, infection and inflammation is likely one of the most common mechanisms as bacterial infection of the intra-uterine environment present in many cases of preterm birth [11, $12]$, likely up to $50 \%[11,13]$. Intra-uterine infection often does not affect the mother and is therefore clinically silent, but is diagnosed by histological examination of the fetal membranes and microbial analysis of the amniotic fluid. If the chorionic and amniotic membranes are inflamed, this is referred to as chorioamnionitis, a term which is often used to indicate the fetal inflammatory response following an intra-uterine infection. Bacterial presence in the amniotic cavity does not necessarily induce preterm birth 
[14-16], although the percentage of diagnosed intra-uterine infections is much higher in very preterm infants compared to near term and term infants $[13,17,18]$. It is not clear when during pregnancy these infections start and manifest themselves, although different routes of microbial invasion have been described in literature and studied in animal models. The most common route is thought to be ascent through the vagina and cervix, with bacteria penetrating the fetal membranes $[13,19]$. Other possible invasion routes include transfer from the maternal circulation through the placenta, descent from the fallopian tubes or by invasive procedures $[13,20]$. A wide variety of bacteria have been identified in the amniotic fluid and membranes of preterm infants [21-23], yet the bacteria most frequently associated with intra-uterine infection and preterm birth are Ureaplasma spp. [24-26]. Not only can intra-uterine infection lead to preterm birth; there is a growing body of epidemiological studies which link chorioamnionitis and even intra-uterine exposure to specific bacteria to the development of multiple diseases of prematurity [27-32]. This link is even stronger in infants who showed signs of having mounted an inflammatory response to the intra-uterine infection, the fetal inflammatory response syndrome (FIRS) [28, 33, 34].

\section{Consequences of preterm birth}

The severity of the outcome of the preterm neonate after preterm birth is first and foremost dependent on the gestational age at birth. Nearly all infants born before 24 weeks gestational age (GA) die in the neonatal period (first 28 days), yet survival rates increase dramatically with increasing GA and weight at birth [35]. If these infants do survive, they often require medical treatments to support their immature organs to function outside the protected environment of the womb, without the placental circulation to provide oxygen, nutrients and immunological support. The first problem these infants face is breathing, as the surface area of their lungs is not large enough yet to absorb enough oxygen. Most preterm children will have been treated with maternal corticosteroids before birth, leading to a maturational response of the lung, which will improve breathing by enhancing surfactant production and facilitating gas exchange. In addition, preterm infants are ventilated to ensure that sufficient oxygen enters the systemic circulation. Other organs however also struggle to cope with life outside the uterus. Because of immature epithelial barriers (skin, lungs and intestinal system) and an immature immune system, the majority of preterm infants suffer from infections and sepsis. Major risk factors for these infections are the very instruments that aid survival: ventilation tubes and intravenous catheters needed for nutritional support. Depending on the gestational age, the epithelial barriers of the intestines are too immature to cope with food and the emerging gut flora. The developmental immaturity of the organs and their incapacity to deal with the challenges of life outside the womb, mostly oxygen and 


\section{Chapter 1}

inflammation, leads to the development of diseases of prematurity. The most common diseases are Respiratory Distress Syndrome (RDS) and Bronchopulmonary Dysplasia (BPD), or Chronic Lung Disease of prematurity (CLD), in the lung (discussed in more detail in the section "Lung Development"), Necrotizing Enterocolitis (NEC) in the gut, white matter injury and Periventricular Leukomalacia (PVL) in the brain, Patent Ductus Arteriosus (PDA) in the circulation and Retinopathy of Prematurity (ROP) in the eyes (Figure 1) [28].

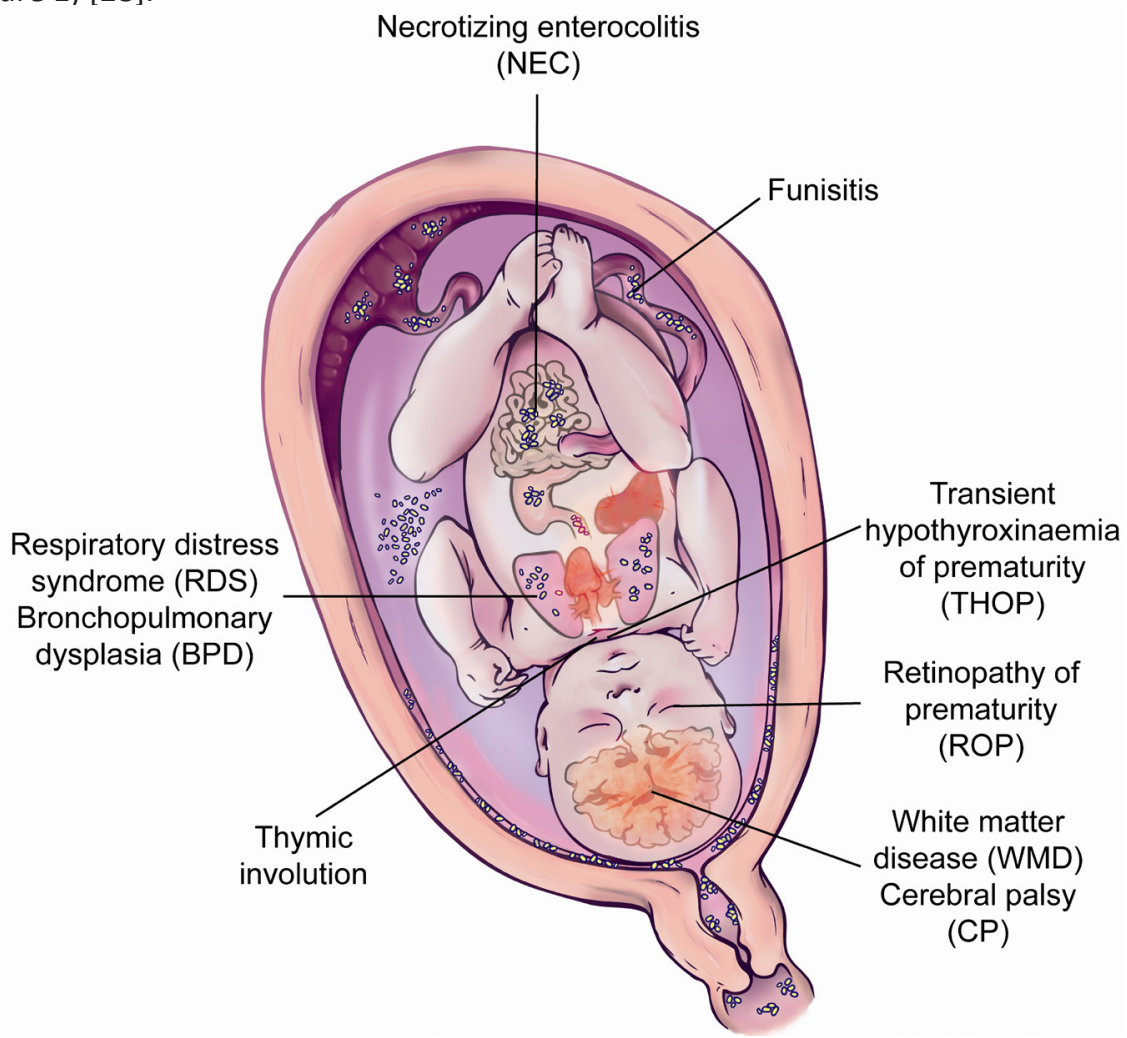

Figure 1: Diseases of prematurity associated with chorioamnionitis [28]

From infancy until young adulthood, children who were born preterm continue to have a higher morbidity and develop more disabilities that those born at term. The prevalence and severity of these problems is generally inversely related with gestational age at birth. The most frequently reported long term outcomes are of a neurodevelopmental nature, including severe outcomes like Cerebral Palsy (CP) and mental retardation, but also auditory and visual impairments, learning disabilities, attention deficit-hyperactivity disorder (ADHD) minor neuromotor dysfunction, behavioral and socio-emotional difficulties [35-37]. Children who had been born preterm and developed BPD are frequently admitted to hospitals with respiratory infections $[38,39]$. As these children 
grow older, they usually have a poor lung function [38] and more frequently develop a wheezing phenotype and asthma compared to age-matched children born at term [40]. Other long term consequences which have been observed in survivors of preterm birth include growth retardation $[35,41]$ and an increased risk for the development of cardiovascular and kidney disease [42].

\section{Lung development}

In postnatal life, the lungs fulfill a crucial role in the development of the other organs, as they supply the oxygen which the newborn needs to grow and develop into a healthy adult. Within a limited amount of space within the human body, the lung needs a large surface area, of around $140 \mathrm{~m}^{2}$ in the adult lungs, for gas exchange to supply enough oxygen to the circulation [43]. To achieve such a large gas exchange area, the lung is made up of efficiently branched airways in a tree-like structure, in which all airways are flanked by capillaries which carry the red blood cells for oxygen transport. For life inside the uterus, the lungs are however not necessary, as the fetus receives oxygen through the placental circulation. For this reason, the fetal circulation partially bypasses the lung through the ductus arteriosus, which connects the pulmonary artery to the aorta. Nonetheless, the lung needs to grow and develop in utero so that it can support the newborn as soon as it is born.

\section{Overview of lung morphogenesis}

Human lung morphogenesis starts around the 4th week of embryonic development when the lung arises from endodermal cells of the foregut and starts to grow into the surrounding mesenchyme. At the end of the embryonic phase, tubes have formed the mainframe of the main structures in the lung, including the trachea and the major bronchi which will grow into the separate lung lobes. Subsequent developmental processes in the lung can be divided into four phases: the pseudoglandular phase (7-17 weeks), canalicular phase (16-27 weeks), saccular phase (24-36 weeks) and alveolar phase (36 weeks-postnatal) (Figure 2) [43-45]. These phases overlap somewhat, as the rostral side of the lungs develops slightly faster than the caudal side. During the pseudoglandular phase, the major bronchi divide and branch up to 20 generations to form the terminal bronchioli [46]. The terminal bronchioli sprout several canaliculi during the canalicular phase, which grow to become respiratory bronchioli and alveolar ducts. These structures will form the functional respiratory part of the lungs. Once the alveolar ducts are formed they grow a multitude of little sacs during the saccular stage. Meanwhile, the vast capillary network which has developed in parallel with the respiratory structures, grows into the mesenchyme of the saccular walls (called the primary septa) to provide the basis 


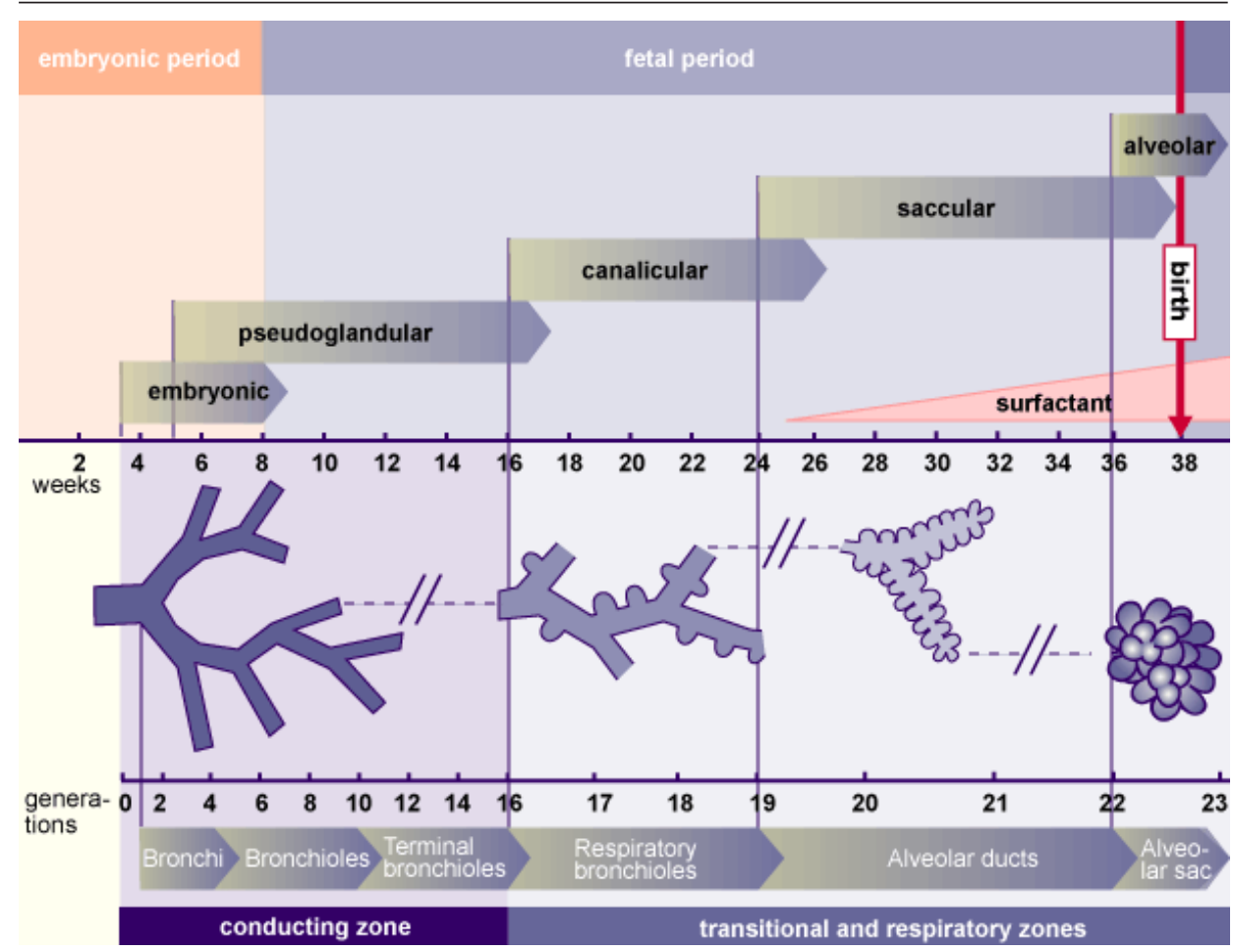

Figure 2: Stages of lung development [43]

for the gas exchange with the circulation. The cells lining the primary septa differentiate into epithelial alveolar type I cells, which will facilitate gas exchange into the capillaries, and the secretory alveolar type II cells. From this stage on, the degree of lung maturation is clinically dependent on the extent of surfactant production and secretion by the alveolar type II cells, which allows the lungs to expand during breathing cycles without collapsing. Towards the end of gestation, the alveolar sacs are divided into alveoli by the outgrowth of secondary septa, which drastically increases the surface area for gas exchange. This process is orchestrated by myofibroblasts, which produce focal deposits of elastin and from there direct the outgrowth of the secondary septa by closely interacting with surrounding epithelial and endothelial cells [47-49]. This process marks the start of the alveolar phase, also called alveologenesis or alveolarization. Once alveoli have formed the septa undergo a stage of maturation for optimal function. During this maturation, the alveolar septa undergo mesenchymal thinning to shorten the distance between the air and circulation compartments [44, 45]. Furthermore, the initial double capillary network residing in the septa mature into a single capillary system, which further optimizes the gas exchange from the alveoli into the circulation [44, 45]. There is currently no consensus among scientists on when or even whether alveolarization ends 
at all, as there is evidence that it may continue well into adulthood $[44,50]$.

\section{Regulation of lung development}

By the time the lungs are fully formed, on average they will have around 23 generations of conducting and respiratory airway branches and around 500 million alveoli, consisting of numerous specialized cell types $[43,51]$. Despite the large body of knowledge concerning the morphogenesis of the lung, the intercellular communications that regulate growth, migration and differentiation during lung development are still a topic of ongoing research. There is however a general consensus that many different signals are needed to drive lung development, including transcription factors, growth factors, cell-cell interactions and even fluid pressure in the lungs [52]. At the heart of this complex network there are several peptide growth factors and their downstream signaling components, which form a toolkit for growth and are used for autocrine and paracrine signaling in cells.

Among some of the best characterized growth factors and their signaling components in early lung development are the evolutionary conserved Fibroblast Growth Factor (FGF), Transforming Growth Factor $\beta$ (TGF $\beta$ ), Bone Morphogenic Protein (BMP), Sonic Hedgehog (Shh) and Wingless-Int (Wnt). At the very start of lung morphogenesis, the outgrowth of primary lung buds from the early trachea is directed by FGF10 [53, 54]. Throughout the branching process of the airway tree, FGF10 is expressed in the distal tips of the outgrowing buds in what has been called the "distal tip signaling center" [52]. In this distal tip signaling center there is a fine balance in the expression of not only FGF9 and FGF10, but also TGF $\beta$, BMP, Shh and Wnt signaling pathway components and inhibitors [55-60]. By crosstalk between these pathways, and by different spatiotemporal expression of pathway components between the epithelium and the mesenchyme, outgrowth and branching morphogenesis is meticulously regulated [52, 56, 57, 61]. More specifically, FGF10 and BMP4 stimulate outgrowth respectively from the mesenchyme and epithelium [56], and are regulated by Shh and Wnt signaling components Wnt2, Wnt5a and Wnt7b [58-60, 62]. TGF 31 functions as a negative regulator of branching, inhibits FGF10 expression, and is highly expressed at the bifurcation site between branches where it stimulates the production of extracellular matrix proteins like collagen I and III [63-65]. The three isoforms of TGF $\beta$ (1, 2 and 3) are produced in different tissue compartments during lung development [66]. Although all three isoforms are needed for normal lung development, their functional differences have not yet been elucidated [67-70].

Much less is known about the intercellular communications that direct the saccular and alveolar phase of lung development. Multiple studies have demonstrated that FGF 
signaling is crucial for myofibroblast differentiation and subsequent onset of secondary septation [71-74]. Wnt, BMP and TGF $\beta$ signaling components have also been implicated to play a role in fibroblast differentiation during alveolarization [75-77]. Additionally, correct deposition of extracellular matrix (ECM) proteins by myofibroblasts, like elastin and collagen, plays a crucial role during secondary septation [78, 79]. These and other ECM components may exert their role in lung development by functioning as a scaffold for the growth factors to coordinate the growth interactions of cells [80].

\section{Bronchopulmonary dysplasia}

When infants are born preterm, their lungs have just progressed into the saccular phase of development, and may even partially still be in the canalicular phase in the case of very preterm infants. The maternal administration of corticosteroids prior to preterm birth leads to thinning of the primary septa, which narrows the air blood barrier, and stimulates the production of surfactant, which stabilizes the alveolar sacs and prevents collapse after exhalation. Although this improves neonatal outcome and survival of the infant, the antenatal corticosteroids have the unwanted side-effect of inhibiting secondary septation and impairing microvasculature development [81-84]. Exposure to intra-uterine inflammation, postnatal sepsis, ventilation and hyperoxia all lead to inflammation and lung injury affecting the immature lung. One of the most common complications seen in these children, especially the very premature, is the development of BPD, defined as a requirement for oxygen at 36 weeks of postmenstrual age [8587]. Histologically, the lungs of BPD patients have fewer but very large alveoli, increased levels of elastin and an impaired microvasculature $[88,89]$. Although there is a clear association between the above mentioned adverse events and the development of BPD, the mechanistic link remains unclear. There is some evidence that TGF $\beta$ is involved, as it is elevated in the bronchoalveolar lavage fluid of infants that develop BPD [90, 91]. Findings from several different animal models of BPD support the role of TGF $\beta$ signaling in lung simplification [92-95], and have also hinted at the involvement of Wnt signaling [96]. Furthermore, infants that develop BPD are often deficient in vitamin A, whose derivative retinoic acid regulates FGF10 and Shh, and is needed for secondary septation [72, 74, 97-99]. Because the basic molecular mechanisms underlying saccular and alveolar development remain unclear, more research is needed to understand how inflammation, corticosteroids, injury and repair may disturb normal lung development in the preterm infant.

\section{Outline of this thesis}

Even though a healthy, functional developing lung is paramount for a good outcome of 
preterm infants, hardly anything is known about how inflammation and corticosteroids affect the molecular mechanisms that direct saccular and early alveolar development in the fetal lung. Knowledge of these processes is necessary for a better understanding of the development of BPD, and more importantly, for the development of prevention and treatment options for BPD. The main focus of this thesis was therefore to give insight into how the developing lung and the pathways that orchestrate lung development are affected by antenatal stimuli, such as inflammation and corticosteroids. For this purpose preterm lambs were used, as the timing of their lung development in utero is highly similar to human fetal lung development (Figure 3).

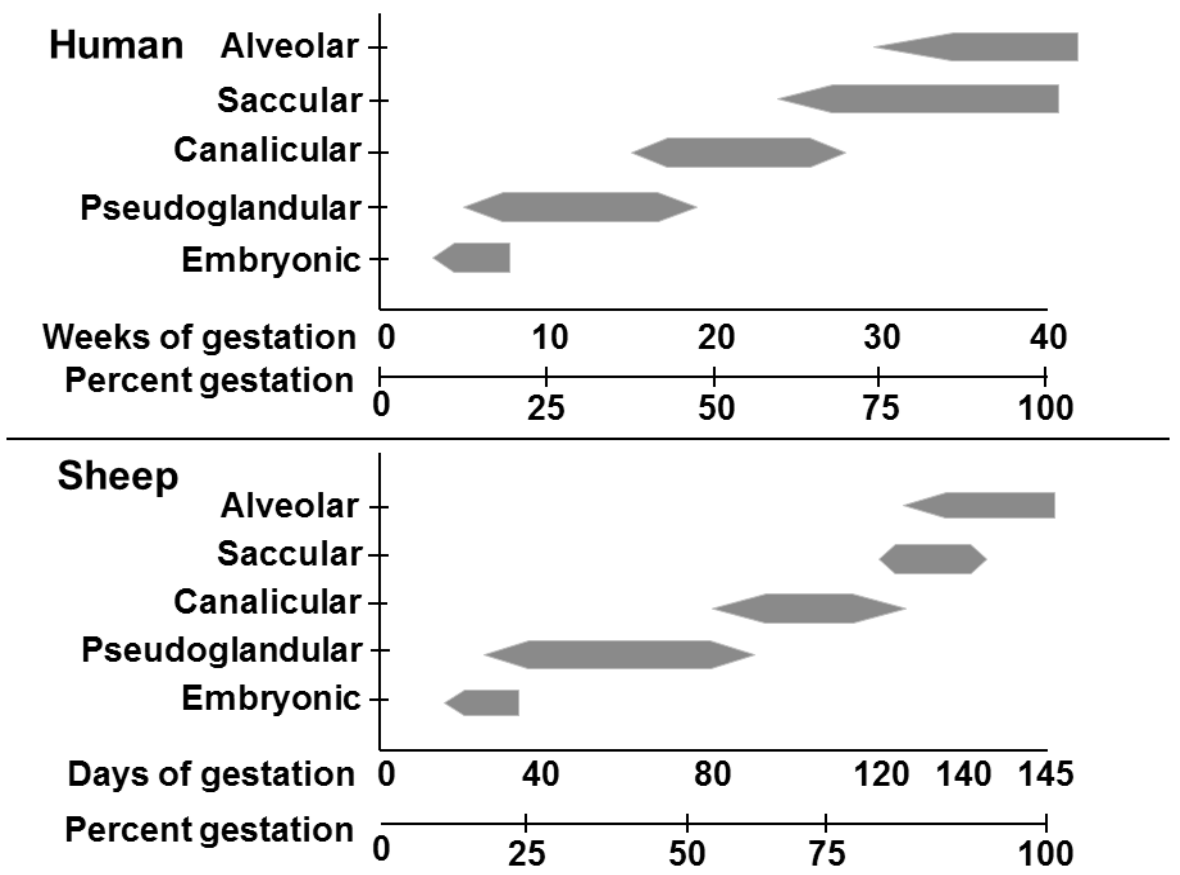

Figure 3: Sheep versus human lung development [100]

Many preterm infants likely have been exposed to both chorioamnionitis and antenatal corticosteroids. Therefore we assessed how the fetal lung responds to sequential exposure to a pro-inflammatory stimulus (LPS) and antenatal corticosteroids with respect to inflammation and maturation in chapter 2 .

The inflammation mounted by the fetal lung, as a response to chorioamnionitis, is probably one of the factors that initiate the development of BPD. In chapter $\mathbf{3}$ we exposed fetal lambs to Ureaplasma parvum, the bacteria most commonly found in histologic chorioamnionitis, to confirm that these bacteria can trigger an immunologic response and affect the developing lung in utero. 
TGF $\beta$ signaling is involved both in inflammation and in lung development and repair; therefore we evaluated the changes of TGF $\beta$ signaling components in several models of antenatal events. In chapter 4 we assessed fetal lungs exposed to a single or repeated exposure to a pro-inflammatory stimulus (LPS) and its effects on Caveolin-1, a negative regulator of TGF $\beta$ signaling, the TGF $\beta$ induced Smad, Stat and acid-sphingomyelinase/ ceramide pathways and heme oxygenase ( $\mathrm{HO})-1$. In chapter 5 we studied the effects of sequential exposure to LPS and antenatal corticosteroids on TGF $\beta$ signaling and its downstream regulated genes CTFG and Caveolin-1. To evaluate the effects of polymicrobial exposure on TGF $\beta$ signaling, we exposed fetal lambs sequentially to LPS and Ureaplasma parvum in chapter 6.

In chapter $\mathbf{7}$ we explored whether other pathways important for lung development, Wnt and Shh signaling and their downstream mediators FGF10 and BMP4, were affected by exposure to LPS-induced inflammation and antenatal corticosteroids.

To conclude, chapter $\mathbf{8}$ provides a discussion of the presented research, clinical perspectives and a recommendation for future research towards understanding how the developing lung responds to injury and repair.

\section{References}

1. Internal classification of diseases and related health problems, 1992, World Health Organization: Geneva.

2. Chapter 1: Introduction, in Preterm birth: causes, consequences and prevention, R.E. Behrman and A. Stith Butler, Editors. 2007, National Academies Press: Washington. p. 31-52.

3. Perinatale zorg in Nederland 2008, 2011, Stichting Perinatale Registratie Nederland: Utrecht.

4. Goldenberg, R.L., Culhane, J.F., lams, J.D., and Romero, R., Epidemiology and causes of preterm birth. Lancet, 2008. 371(9606): p. 75-84.

5. Preterm births: United States 1990-2008, 2012, National Center for Health Statistics.

6. Beck, S., Wojdyla, D., Say, L., Betran, A.P., Merialdi, M., Requejo, J.H., Rubens, C., Menon, R., and Van Look, P.F., The worldwide incidence of preterm birth: a systematic review of maternal mortality and morbidity. Bulletin of the World Health Organization, 2010. 88(1): p. 31-8.

7. Section III Chapter 9: Diagnosis and treatment of conditions leading to spontaneous preterm birth, in Preterm birth: causes, consequences and prevention, R.E. Behrman and A. Stith Butler, Editors. 2007, National Academies Press: Washington. p. 261-307.

8. Section II Chapter 5: Medical and pregnancy conditions associated with preterm birth, in Preterm birth: causes, consequences and prevention, R.E. Behrman and A. Stith Butler, Editors. 2007, National Academies Press: Washington. p. 148-168.

9. Section II Chapter 4: Sociodemographic and community factors contributing to preterm birth, in Preterm birth: causes, consequences and prevention, R.E. Behrman and A. Stith Butler, Editors. 2007, National Academies Press: Washington. p. 124-147.

10. Section II Chapter 7: Role of gene-environment interactions in preterm birth, in Preterm birth: causes, consequences and prevention, R.E. Behrman and A. Stith Butler, Editors. 2007, National Academies Press: Washington. p. 207-228. 
11. Section II Chapter 6: Biological pathways leading to preterm birth, in Preterm birth: causes, consequences and prevention, R.E. Behrman and A. Stith Butler, Editors. 2007, National Academies Press: Washington. p. 169-206.

12. Knox, I.C., Jr. and Hoerner, J.K., The role of infection in premature rupture of the membranes. American journal of obstetrics and gynecology, 1950. 59(1): p. 190-4, illust.

13. Goldenberg, R.L., Hauth, J.C., and Andrews, W.W., Intrauterine infection and preterm delivery. N Engl J Med, 2000. 342(20): p. 1500-7.

14. Perni, S.C., Vardhana, S., Korneeva, I., Tuttle, S.L., Paraskevas, L.R., Chasen, S.T., Kalish, R.B., and Witkin, S.S., Mycoplasma hominis and Ureaplasma urealyticum in midtrimester amniotic fluid: association with amniotic fluid cytokine levels and pregnancy outcome. Am J Obstet Gynecol, 2004. 191(4): p. 1382-6.

15. Iwasaka, T., Wada, T., Kidera, Y., and Sugimori, H., Hormonal status and mycoplasma colonization in the female genital tract. Obstet Gynecol, 1986. 68(2): p. 263-6.

16. Steel, J.H., Malatos, S., Kennea, N., Edwards, A.D., Miles, L., Duggan, P., Reynolds, P.R., Feldman, R.G., and Sullivan, M.H., Bacteria and inflammatory cells in fetal membranes do not always cause preterm labor. Pediatric research, 2005. 57(3): p. 404-11.

17. Mueller-Heubach, E., Rubinstein, D.N., and Schwarz, S.S., Histologic chorioamnionitis and preterm delivery in different patient populations. Obstetrics and gynecology, 1990. 75(4): p. 622-6.

18. Russell, P., Inflammatory lesions of the human placenta. III. The histopathology of villitis of unknown aetiology. Placenta, 1980. 1(3): p. 227-44.

19. Romero, R. and Mazor, M., Infection and preterm labor. Clinical obstetrics and gynecology, 1988. 31(3): p. 553-84.

20. Romero, R., Espinoza, J., Kusanovic, J.P., Gotsch, F., Hassan, S., Erez, O., Chaiworapongsa, T., and Mazor, M., The preterm parturition syndrome. BJOG, 2006. 113 Suppl 3: p. 17-42.

21. DiGiulio, D.B., Romero, R., Kusanovic, J.P., Gomez, R., Kim, C.J., Seok, K.S., Gotsch, F., MazakiTovi, S., Vaisbuch, E., Sanders, K., Bik, E.M., Chaiworapongsa, T., Oyarzun, E., and Relman, D.A., Prevalence and diversity of microbes in the amniotic fluid, the fetal inflammatory response, and pregnancy outcome in women with preterm pre-labor rupture of membranes. Am J Reprod Immunol, 2010. 64(1): p. 38-57.

22. DiGiulio, D.B., Romero, R., Amogan, H.P., Kusanovic, J.P., Bik, E.M., Gotsch, F., Kim, C.J., Erez, O., Edwin, S., and Relman, D.A., Microbial prevalence, diversity and abundance in amniotic fluid during preterm labor: a molecular and culture-based investigation. PLoS One, 2008. 3(8): p. e3056.

23. Hillier, S.L., Martius, J., Krohn, M., Kiviat, N., Holmes, K.K., and Eschenbach, D.A., A casecontrol study of chorioamnionic infection and histologic chorioamnionitis in prematurity. $\mathrm{N}$ Engl J Med, 1988. 319(15): p. 972-8.

24. Schelonka, R.L. and Waites, K.B., Ureaplasma infection and neonatal lung disease. Semin Perinatol, 2007. 31(1): p. 2-9.

25. Yoon, B.H., Chang, J.W., and Romero, R., Isolation of Ureaplasma urealyticum from the amniotic cavity and adverse outcome in preterm labor. Obstet Gynecol, 1998. 92(1): p. 7782.

26. Witt, A., Berger, A., Gruber, C.J., Petricevic, L., Apfalter, P., Worda, C., and Husslein, P., Increased intrauterine frequency of Ureaplasma urealyticum in women with preterm labor and preterm premature rupture of the membranes and subsequent cesarean delivery. Am J Obstet Gynecol, 2005. 193(5): p. 1663-9.

27. Been, J.V., Rours, I.G., Kornelisse, R.F., Lima Passos, V., Kramer, B.W., Schneider, T.A., de Krijger, R.R., and Zimmermann, L.J., Histologic chorioamnionitis, fetal involvement, and antenatal steroids: effects on neonatal outcome in preterm infants. Am J Obstet Gynecol, 2009. 201(6): p. 587 e1-8. 
28. Gantert, M., Been, J.V., Gavilanes, A.W., Garnier, Y., Zimmermann, L.J., and Kramer, B.W., Chorioamnionitis: a multiorgan disease of the fetus? J Perinatol, 2010. 30 Suppl: p. S21-30.

29. Been, J.V., Kramer, B.W., and Zimmermann, L.J., In utero and early-life conditions and adult health and disease. N Engl J Med, 2008. 359(14): p. 1523-4; author reply 1524.

30. Watterberg, K.L., Demers, L.M., Scott, S.M., and Murphy, S., Chorioamnionitis and early lung inflammation in infants in whom bronchopulmonary dysplasia develops. Pediatrics, 1996. 97(2): p. 210-5.

31. Viscardi, R.M., Ureaplasma species: role in diseases of prematurity. Clin Perinatol, 2010. 37(2): p. 393-409.

32. Thomas, W. and Speer, C.P., Chorioamnionitis: important risk factor or innocent bystander for neonatal outcome? Neonatology, 2010. 99(3): p. 177-87.

33. Gotsch, F., Romero, R., Kusanovic, J.P., Mazaki-Tovi, S., Pineles, B.L., Erez, O., Espinoza, J., and Hassan, S.S., The fetal inflammatory response syndrome. Clinical obstetrics and gynecology, 2007. 50(3): p. 652-83.

34. Yoon, B.H., Romero, R., Kim, K.S., Park, J.S., Ki, S.H., Kim, B.I., and Jun, J.K., A systemic fetal inflammatory response and the development of bronchopulmonary dysplasia. Am J Obstet Gynecol, 1999. 181(4): p. 773-9.

35. Saigal, S. and Doyle, L.W., An overview of mortality and sequelae of preterm birth from infancy to adulthood. Lancet, 2008. 371(9608): p. 261-9.

36. Section IV Chapter 11: Neurodevelopmental, health, and family outcomes for infants born preterm, in Preterm birth: causes, consequences and prevention, R.E. Behrman and A. Stith Butler, Editors. 2007, National Academies Press: Washington. p. 313-345.

37. Eikenes, L., Lohaugen, G.C., Brubakk, A.M., Skranes, J., and Haberg, A.K., Young adults born preterm with very low birth weight demonstrate widespread white matter alterations on brain DTI. Neuroimage, 2011. 54(3): p. 1774-85.

38. Greenough, A., Long term respiratory outcomes of very premature birth (<32 weeks). Seminars in fetal \& neonatal medicine, 2012. 17(2): p. 73-6.

39. Doyle, L.W., Ford, G., and Davis, N., Health and hospitalistions after discharge in extremely low birth weight infants. Seminars in neonatology : SN, 2003. 8(2): p. 137-45.

40. Fawke, J., Lum, S., Kirkby, J., Hennessy, E., Marlow, N., Rowell, V., Thomas, S., and Stocks, J., Lung function and respiratory symptoms at 11 years in children born extremely preterm: the EPICure study. American journal of respiratory and critical care medicine, 2010. 182(2): p. 237-45.

41. Wood, N.S., Costeloe, K., Gibson, A.T., Hennessy, E.M., Marlow, N., and Wilkinson, A.R., The EPICure study: growth and associated problems in children born at 25 weeks of gestational age or less. Archives of disease in childhood. Fetal and neonatal edition, 2003. 88(6): p. F492-500.

42. Abitbol, C.L. and Rodriguez, M.M., The long-term renal and cardiovascular consequences of prematurity. Nature reviews. Nephrology, 2012.

43. Schöni-Affolter, F., Dubuis-Grieder, C., and Strauch, E. Embryology.ch Module 18 Respiration tract. Embryology.ch [cited 2012 April 22nd]; Available from: http://embryology.ch/anglais/ rrespiratory/phasen01.html.

44. Burri, P.H., Structural aspects of postnatal lung development - alveolar formation and growth. Biol Neonate, 2006. 89(4): p. 313-322.

45. Warburton, D. and Shi, W., Genetic Mechanisms of Lung Development and Bronchopulmonary Dysplasia: An Integrative View, in Bronchopulmonary Dysplasia, S.H. Abman, Editor 2010, Informa Healthcare USA, Inc.: New York. p. 1-39.

46. Kitaoka, H., Burri, P.H., and Weibel, E.R., Development of the human fetal airway tree: analysis of the numerical density of airway endtips. The Anatomical record, 1996. 244(2): p. 207-13. 
47. Bostrom, H., Willetts, K., Pekny, M., Leveen, P., Lindahl, P., Hedstrand, H., Pekna, M., Hellstrom, M., Gebre-Medhin, S., Schalling, M., Nilsson, M., Kurland, S., Tornell, J., Heath, J.K., and Betsholtz, C., PDGF-A signaling is a critical event in lung alveolar myofibroblast development and alveogenesis. Cell, 1996. 85(6): p. 863-73.

48. Lindahl, P., Karlsson, L., Hellstrom, M., Gebre-Medhin, S., Willetts, K., Heath, J.K., and Betsholtz, C., Alveogenesis failure in PDGF-A-deficient mice is coupled to lack of distal spreading of alveolar smooth muscle cell progenitors during lung development. Development, 1997. 124(20): p. 3943-53.

49. Wilkinson, G.A., Schittny, J.C., Reinhardt, D.P., and Klein, R., Role for ephrinB2 in postnatal lung alveolar development and elastic matrix integrity. Dev Dyn, 2008. 237(8): p. 2220-34.

50. Narayanan, M., Owers-Bradley, J., Beardsmore, C.S., Mada, M., Ball, I., Garipov, R., Panesar, K.S., Kuehni, C.E., Spycher, B.D., Williams, S.E., and Silverman, M., Alveolarization continues during childhood and adolescence: new evidence from helium-3 magnetic resonance. American journal of respiratory and critical care medicine, 2012. 185(2): p. 186-91.

51. Ochs, M., Nyengaard, J.R., Jung, A., Knudsen, L., Voigt, M., Wahlers, T., Richter, J., and Gundersen, H.J., The number of alveoli in the human lung. American journal of respiratory and critical care medicine, 2004. 169(1): p. 120-4.

52. Morrisey, E.E. and Hogan, B.L., Preparing for the first breath: genetic and cellular mechanisms in lung development. Dev Cell, 2010. 18(1): p. 8-23.

53. Min, H., Danilenko, D.M., Scully, S.A., Bolon, B., Ring, B.D., Tarpley, J.E., DeRose, M., and Simonet, W.S., Fgf-10 is required for both limb and lung development and exhibits striking functional similarity to Drosophila branchless. Genes \& development, 1998. 12(20): p. 315661.

54. Sekine, K., Ohuchi, H., Fujiwara, M., Yamasaki, M., Yoshizawa, T., Sato, T., Yagishita, N., Matsui, D., Koga, Y., Itoh, N., and Kato, S., Fgf10 is essential for limb and lung formation. Nature genetics, 1999. 21(1): p. 138-41.

55. Pepicelli, C.V., Lewis, P.M., and McMahon, A.P., Sonic hedgehog regulates branching morphogenesis in the mammalian lung. Curr Biol, 1998. 8(19): p. 1083-6.

56. Weaver, M., Dunn, N.R., and Hogan, B.L., Bmp4 and Fgf10 play opposing roles during lung bud morphogenesis. Development, 2000. 127(12): p. 2695-704.

57. Li, M., Li, C., Liu, Y.H., Xing, Y., Hu, L., Borok, Z., Kwong, K.Y., and Minoo, P., Mesodermal deletion of transforming growth factor-beta receptor II disrupts lung epithelial morphogenesis: crosstalk between TGF-beta and Sonic hedgehog pathways. J Biol Chem, 2008. 283(52): p. 3625764.

58. Rajagopal, J., Carroll, T.J., Guseh, J.S., Bores, S.A., Blank, L.J., Anderson, W.J., Yu, J., Zhou, Q., McMahon, A.P., and Melton, D.A., Wnt7b stimulates embryonic lung growth by coordinately increasing the replication of epithelium and mesenchyme. Development, 2008. 135(9): p. 1625-34.

59. Shu, W., Jiang, Y.Q., Lu, M.M., and Morrisey, E.E., Wnt7b regulates mesenchymal proliferation and vascular development in the lung. Development, 2002. 129(20): p. 4831-42.

60. Li, C., Hu, L., Xiao, J., Chen, H., Li, J.T., Bellusci, S., Delanghe, S., and Minoo, P., Wnt5a regulates Shh and Fgf10 signaling during lung development. Dev Biol, 2005. 287(1): p. 86-97.

61. Minoo, P. and Li, C., Cross-talk between transforming growth factor-beta and Wingless/Int pathways in lung development and disease. Int J Biochem Cell Biol, 2010. 42(6): p. 809-12.

62. Goss, A.M., Tian, Y., Tsukiyama, T., Cohen, E.D., Zhou, D., Lu, M.M., Yamaguchi, T.P., and Morrisey, E.E., Wnt2/2b and beta-catenin signaling are necessary and sufficient to specify lung progenitors in the foregut. Developmental cell, 2009. 17(2): p. 290-8.

63. Heine, U.I., Munoz, E.F., Flanders, K.C., Roberts, A.B., and Sporn, M.B., Colocalization of TGFbeta 1 and collagen I and III, fibronectin and glycosaminoglycans during lung branching morphogenesis. Development, 1990. 109(1): p. 29-36. 
64. Lebeche, D., Malpel, S., and Cardoso, W.V., Fibroblast growth factor interactions in the developing lung. Mech Dev, 1999. 86(1-2): p. 125-36.

65. Beer, H.D., Florence, C., Dammeier, J., McGuire, L., Werner, S., and Duan, D.R., Mouse fibroblast growth factor 10: CDNA cloning, protein characterization, and regulation of $M R N A$ expression. Oncogene, 1997. 15(18): p. 2211-8.

66. Pelton, R.W., Saxena, B., Jones, M., Moses, H.L., and Gold, L.I., Immunohistochemical localization of TGF beta 1, TGF beta 2, and TGF beta 3 in the mouse embryo: expression patterns suggest multiple roles during embryonic development. The Journal of cell biology, 1991. 115(4): p. 1091-105.

67. Serra, R., Pelton, R.W., and Moses, H.L., TGF beta 1 inhibits branching morphogenesis and $\mathrm{N}$-myc expression in lung bud organ cultures. Development, 1994. 120(8): p. 2153-61.

68. Sanford, L.P., Ormsby, I., Gittenberger-de Groot, A.C., Sariola, H., Friedman, R., Boivin, G.P., Cardell, E.L., and Doetschman, T., TGFbeta2 knockout mice have multiple developmental defects that are non-overlapping with other TGFbeta knockout phenotypes. Development, 1997. 124(13): p. 2659-70.

69. Kaartinen, V., Voncken, J.W., Shuler, C., Warburton, D., Bu, D., Heisterkamp, N., and Groffen, J., Abnormal lung development and cleft palate in mice lacking TGF-beta 3 indicates defects of epithelial-mesenchymal interaction. Nature genetics, 1995. 11(4): p. 415-21.

70. Liu, J., Tseu, I., Wang, J., Tanswell, K., and Post, M., Transforming growth factor beta2, but not beta1 and beta3, is critical for early rat lung branching. Developmental dynamics : an official publication of the American Association of Anatomists, 2000. 217(4): p. 343-60.

71. Weinstein, M., Xu, X., Ohyama, K., and Deng, C.X., FGFR-3 and FGFR-4 function cooperatively to direct alveogenesis in the murine lung. Development, 1998. 125(18): p. 3615-23.

72. Snyder, J.M., Jenkins-Moore, M., Jackson, S.K., Goss, K.L., Dai, H.H., Bangsund, P.J., Giguere, V., and McGowan, S.E., Alveolarization in retinoic acid receptor-beta-deficient mice. Pediatric research, 2005. 57(3): p. 384-91.

73. Liebeskind, A., Srinivasan, S., Kaetzel, D., and Bruce, M., Retinoic acid stimulates immature lung fibroblast growth via a PDGF-mediated autocrine mechanism. American journal of physiology. Lung cellular and molecular physiology, 2000. 279(1): p. L81-90.

74. Perl, A.K. and Gale, E., FGF signaling is required for myofibroblast differentiation during alveolar regeneration. Am J Physiol Lung Cell Mol Physiol, 2009. 297(2): p. L299-308.

75. Boucherat, O., Franco-Montoya, M.L., Thibault, C., Incitti, R., Chailley-Heu, B., Delacourt, C., and Bourbon, J.R., Gene expression profiling in lung fibroblasts reveals new players in alveolarization. Physiological genomics, 2007. 32(1): p. 128-41.

76. Nakanishi, H., Sugiura, T., Streisand, J.B., Lonning, S.M., and Roberts, J.D., Jr., TGF-betaneutralizing antibodies improve pulmonary alveologenesis and vasculogenesis in the injured newborn lung. American journal of physiology. Lung cellular and molecular physiology, 2007. 293(1): p. L151-61.

77. Alejandre-Alcazar, M.A., Shalamanov, P.D., Amarie, O.V., Sevilla-Perez, J., Seeger, W., Eickelberg, O., and Morty, R.E., Temporal and spatial regulation of bone morphogenetic protein signaling in late lung development. Developmental dynamics : an official publication of the American Association of Anatomists, 2007. 236(10): p. 2825-35.

78. Burri, P.H., The postnatal growth of the rat lung. 3. Morphology. The Anatomical record, 1974. 180(1): p. 77-98.

79. Brody, J.S. and Kaplan, N.B., Proliferation of alveolar interstitial cells during postnatal lung growth. Evidence for two distinct populations of pulmonary fibroblasts. The American review of respiratory disease, 1983. 127(6): p. 763-70.

80. Neptune, E.R., Frischmeyer, P.A., Arking, D.E., Myers, L., Bunton, T.E., Gayraud, B., Ramirez, F., Sakai, L.Y., and Dietz, H.C., Dysregulation of TGF-beta activation contributes to pathogenesis in Marfan syndrome. Nature genetics, 2003. 33(3): p. 407-11. 
81. Bourbon, J., Boucherat, O., Chailley-Heu, B., and Delacourt, C., Control mechanisms of lung alveolar development and their disorders in bronchopulmonary dysplasia. Pediatr Res, 2005. 57(5 Pt 2): p. 38R-46R.

82. Willet, K.E., McMenamin, P., Pinkerton, K.E., Ikegami, M., Jobe, A.H., Gurrin, L., and Sly, P.D., Lung morphometry and collagen and elastin content: changes during normal development and after prenatal hormone exposure in sheep. Pediatric research, 1999. 45(5 Pt 1): p. 61525.

83. Willet, K.E., Jobe, A.H., Ikegami, M., Kovar, J., and Sly, P.D., Lung morphometry after repetitive antenatal glucocorticoid treatment in preterm sheep. American journal of respiratory and critical care medicine, 2001. 163(6): p. 1437-43.

84. Bunton, T.E. and Plopper, C.G., Triamcinolone-induced structural alterations in the development of the lung of the fetal rhesus macaque. American journal of obstetrics and gynecology, 1984. 148(2): p. 203-15.

85. Jobe, A.H. and Bancalari, E., Bronchopulmonary dysplasia. Am J Respir Crit Care Med, 2001. 163(7): p. 1723-9.

86. Farstad, T., Bratlid, D., Medbo, S., and Markestad, T., Bronchopulmonary dysplasia prevalence, severity and predictive factors in a national cohort of extremely premature infants. Acta paediatrica, 2011. 100(1): p. 53-8.

87. Section IV Chapter 10: Mortality and acute complications in preterm infants, in Preterm birth: causes, consequences and prevention, R.E. Behrman and A. Stith Butler, Editors. 2007, National Academies Press: Washington. p. 313-345.

88. Husain, A.N., Siddiqui, N.H., and Stocker, J.T., Pathology of arrested acinar development in postsurfactant bronchopulmonary dysplasia. Human pathology, 1998. 29(7): p. 710-7.

89. Toti, P., Buonocore, G., Tanganelli, P., Catella, A.M., Palmeri, M.L., Vatti, R., and Seemayer, T.A., Bronchopulmonary dysplasia of the premature baby: an immunohistochemical study. Pediatr Pulmonol, 1997. 24(1): p. 22-8.

90. Kotecha, S., Wangoo, A., Silverman, M., and Shaw, R.J., Increase in the concentration of transforming growth factor beta-1 in bronchoalveolar lavage fluid before development of chronic lung disease of prematurity. The Journal of pediatrics, 1996. 128(4): p. 464-9.

91. Lecart, C., Cayabyab, R., Buckley, S., Morrison, J., Kwong, K.Y., Warburton, D., Ramanathan, R., Jones, C.A., and Minoo, P., Bioactive transforming growth factor-beta in the lungs of extremely low birthweight neonates predicts the need for home oxygen supplementation. Biology of the neonate, 2000. 77(4): p. 217-23.

92. Gauldie, J., Galt, T., Bonniaud, P., Robbins, C., Kelly, M., and Warburton, D., Transfer of the active form of transforming growth factor-beta 1 gene to newborn rat lung induces changes consistent with bronchopulmonary dysplasia. Am J Pathol, 2003. 163(6): p. 2575-84.

93. Vicencio, A.G., Lee, C.G., Cho, S.J., Eickelberg, O., Chuu, Y., Haddad, G.G., and Elias, J.A., Conditional overexpression of bioactive transforming growth factor-beta1 in neonatal mouse lung: a new model for bronchopulmonary dysplasia? Am J Respir Cell Mol Biol, 2004. 31(6): p. 650-6.

94. Kunzmann, S., Speer, C.P., Jobe, A.H., and Kramer, B.W., Antenatal inflammation induced TGF-b1 but suppressed CTGF in preterm lungs. Am J Physiol Lung Cell Mol Physiol, 2006. 292: p. 223-231.

95. Viscardi, R.M., Atamas, S.P., Luzina, I.G., Hasday, J.D., He, J.R., Sime, P.J., Coalson, J.J., and Yoder, B.A., Antenatal Ureaplasma urealyticum respiratory tract infection stimulates proinflammatory, profibrotic responses in the preterm baboon lung. Pediatr Res, 2006. 60(2): p. 141-6.

96. Dasgupta, C., Sakurai, R., Wang, Y., Guo, P., Ambalavanan, N., Torday, J.S., and Rehan, V.K., Hyperoxia-induced neonatal rat lung injury involves activation of TGF-\{beta\} and Wht signaling and is protected by rosiglitazone. Am J Physiol Lung Cell Mol Physiol, 2009. 296(6): 
Chapter 1

p. L1031-41.

97. Shenai, J.P., Chytil, F., and Stahlman, M.T., Vitamin A status of neonates with bronchopulmonary dysplasia. Pediatr Res, 1985. 19(2): p. 185-8.

98. Mendelsohn, C., Lohnes, D., Decimo, D., Lufkin, T., LeMeur, M., Chambon, P., and Mark, M., Function of the retinoic acid receptors (RARs) during development (II). Multiple abnormalities at various stages of organogenesis in RAR double mutants. Development, 1994. 120(10): p. 2749-71.

99. Riddle, R.D., Johnson, R.L., Laufer, E., and Tabin, C., Sonic hedgehog mediates the polarizing activity of the ZPA. Cell, 1993. 75(7): p. 1401-16.

100. Kramer, B.W., Chorioamnionitis - new ideas from experimental models. Neonatology, 2011. 99(4): p. 320-5. 


\section{2}

\section{Intra-amniotic LPS and antenatal}

\section{betamethasone: inflammation and maturation in preterm lamb lungs}

Kuypers E*, Collins JJP*, Kramer BW, Ofman G, Nitsos I,

Pillow JJ, Polglase GR, Kemp MW, Newnham JP, Gavilanes AWD, Nowacki R, Ikegami M, Jobe AH, Kallapur SG Am J Physiol Lung Cell Mol Physiol. 2012 Feb;302(4):L380-9. 
Abstract

The pro-inflammatory stimulus of chorioamnionitis is commonly associated with preterm delivery. Women at risk of preterm delivery receive antenatal glucocorticoids to functionally mature the fetal lung. However, the effects of the combined exposures of chorioamnionitis and antenatal glucocorticoids on the fetus are poorly understood. Time-mated ewes with singleton fetuses received an intra-amniotic injection of lipopolysaccharide (LPS) either preceding or following maternal intra-muscular betamethasone 7 or 14 days before delivery, and the fetuses were delivered at 120 days gestational age (GA) (term=150 days GA). Gestation matched controls received intra-amniotic and maternal intramuscular saline. In comparison with saline controls, intra-amniotic LPS increased inflammatory cells in the bronchoalveolar lavage and myeloperoxidase (MPO), Toll-like receptor 2 and 4 mRNA, PU.1, CD3, and Foxp3-positive cells in the fetal lung. LPS induced lung maturation measured as increased airway surfactant and improved lung gas volumes. Intra-amniotic LPS induced inflammation persisted until 14 days after exposure. Betamethasone treatment alone induced modest lung maturation, but when administered before intra-amniotic LPS, suppressed lung inflammation. Interestingly, betamethasone treatment after LPS did not counteract inflammation but enhanced lung maturation. We conclude that the order of exposures of intra-amniotic LPS or maternal betamethasone had large effects on fetal lung inflammation and maturation.

\section{Introduction}

Chorioamnionitis, defined as inflammation of the fetal membranes, complicates up to $70 \%$ of preterm deliveries before 30 weeks of gestation [1]. The epidemiological associations of preterm infants exposed to chorioamnionitis are fetal systemic inflammation and lung, brain and gastrointestinal injury [2,3]. Lung inflammation may initiate a progressive injury that results in bronchopulmonary dysplasia [4]. However, the exposure of the fetal lung to inflammation associated with chorioamnionitis also increases surfactant proteins and lipids with salutary effects on respiratory distress syndrome [5-7].

Antenatal corticosteroids are a standard treatment given to mothers at risk of imminent preterm birth to induce lung maturation [8]. Lung maturation induced by corticosteroids results from the simultaneous induction and suppression of multiple genes that have the net effects of increasing surfactant lipids, surfactant proteins and thinning of the lung mesenchyme to increase the potential airspaces [9-11]. Clinical studies and experimental evidence suggest that antenatal corticosteroids are also efficacious in the setting of chorioamnionitis [12-14]. The delivery of many women given corticosteroids is delayed for several days to weeks [15], and chorioamnionitis is clinically silent in a 
Fetal lung exposure to LPS and corticosteroids

majority of women [5]. Therefore, the combined exposures of antenatal corticosteroids and chorioamnionitis are common in the preterm fetus, but the order of exposures can vary.

We reported previously that simultaneous exposure of the preterm sheep fetus to antenatal corticosteroids and lipopolysaccharide (LPS) suppressed the pulmonary inflammation for 1 to 2 days after the exposure but amplified the inflammatory response to chorioamnionitis 5 to 15 days after the exposure $[16,17]$. However, it is not known if the order of exposure is important in mediating lung inflammation and maturation. Therefore, we aimed to study the interactive effects of chorioamnionitis and antenatal corticosteroids on the inflammatory and maturational response in the fetal lungs in a clinically relevant preterm sheep model of chorioamnionitis [18]. We tested the hypothesis that the order of exposure to maternal betamethasone and intra-amniotic LPS will differentially impact lung surfactants and inflammatory responses in the preterm fetus. Fetal sheep were exposed in utero to intra-amniotic LPS or antenatal maternal intra-muscular betamethasone, with an interval of 7 days between the two interventions. Furthermore, we asked if the order of exposure to antenatal corticosteroids and intraamniotic LPS altered fetal lung outcomes.

\section{Materials and methods}

\section{Animal model and sampling protocol}

All studies were approved by the Animal Ethics Committees at The University of Western Australia and Cincinnati Children's Hospital Medical Center. Time-mated ewes with singleton fetuses were randomly assigned to one of six treatment groups to receive an intra-amniotic (IA) injection of lipopolysaccharide (LPS) (10 mg Escherichia Coli 055:B5, Sigma Chemical, St. Louis, MO, USA), intra-muscular (IM) injection of betamethasone (Beta) (Celestone Soluspan, Schering-Plough, North Ryde, New South Wales (NSW), Australia, $0.5 \mathrm{mg} / \mathrm{kg}$ maternal weight) or an equivalent injection of saline (controls) at 107 days and/or 114 days GA in different permutations and combinations (Figure 1). All ewes in this study received a single intra-muscular injection of $150 \mathrm{mg}$ medroxyprogesterone acetate (Depo-Provera, Kenral, NSW, Australia) at 100 days GA to prevent preterm birth induced by betamethasone treatment [19]. Lambs were surgically delivered at 120 days GA (term = 150 days GA) and euthanized with $100 \mathrm{mg} / \mathrm{kg}$ pentobarbital. The fetus was weighed and fetal cord blood was collected. Following opening of the chest, a deflation air pressure-volume curve was measured from static inflation of the lung to $40 \mathrm{~cm}$ $\mathrm{H}_{2} \mathrm{O}$ airway pressure [20]. The lungs were removed, separated and weighed prior to a bronchoalveolar lavage of the left lung with $0.9 \% \mathrm{NaCl}[20]$. The bronchoalveolar lavage 
fluid (BALF) was used for differential cell counts and surfactant measurements. Lung tissue from the right lower lobe (RLL) was snap frozen and the right upper lobe (RUL) was inflation-fixed in $10 \%$ buffered formalin for 24 hours.

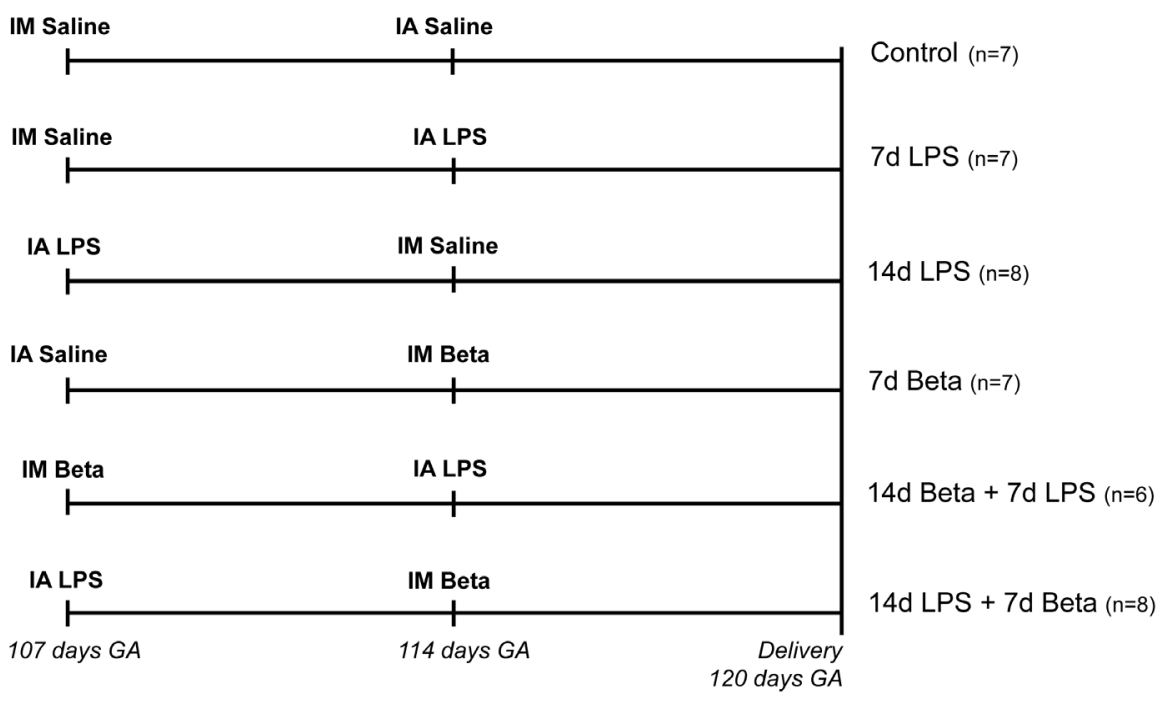

Figure 1: Study design.

Pregnant ewes received an intra-amniotic injection of lipopolysaccharide (LPS) and/or an intramuscular injection of betamethasone (Beta) and/or an equivalent injection of saline for control animals at 107 days and/or 114 days gestation (GA). Lambs were delivered preterm by cesarean section at 120 days $\mathrm{GA}$ (term $=150$ days $\mathrm{GA}$ ).

\section{Surfactant proteins and cytokine mRNA quantitation}

Total RNA was isolated from frozen lung tissue of the RLL using a modified Chomzynski method and mRNA quantitation was performed using real-time PCR [21]. Gene expression was measured for surfactant proteins and cytokines: SP-A, SP-B, SP-C, IL-1B, IL-6, IL-8, CP-1 and Serum amyloid A3. The mRNA was reverse transcribed to yield a single-strand cDNA (verso cDNA kit, Thermoscientific, UK), which was used as a template with primers and Taqman probes (Applied Biosystems, Carlsbad CA, USA) specific to sheep sequences [22]. The values for each cytokine were normalized to the internal 18S rRNA. Data were expressed as fold increased over control values.

\section{Toll-like receptor mRNA quantitation}

For the Toll like receptor (TLR) mRNA measurements, total RNA was extracted from frozen lung tissue of the RLL using the SV Total RNA Isolation system (Z3100, Promega, Madison, USA) according to the manufacturer's instructions. Genomic DNA contamination was removed by treatment with RQ1 DNase (M610A, Promega) and the RNA was tested 
Fetal lung exposure to LPS and corticosteroids

for the presence of genomic GAPDH. Briefly, PCR amplification for the detection of genomic DNA was performed with DNA Taq Polymerase (M124B, Promega) at $95^{\circ} \mathrm{C}$ for 5 minutes followed by 40 cycles at $95{ }^{\circ} \mathrm{C}$ for 30 seconds, $55^{\circ} \mathrm{C}$ for 45 seconds and $72{ }^{\circ} \mathrm{C}$ for 30 seconds. Total RNA was used as a template. PCR products were analyzed on 1.5 $\%$ agarose gels. Total RNA was reverse transcribed with the First Strand cDNA synthesis kit (4379012001, Roche-Applied, Mannheim, Germany) according to manufacturer's instructions using anchored oligo-primers. Primers for real time PCR (RT-PCR) were constructed based on published ovine or bovine cDNA sequences (Table 1). Dilution

Table 1: Primers used for RT-PCR

\begin{tabular}{|c|c|c|c|c|}
\hline Gene & Sequence $\left(5^{\prime}-3^{\prime}\right)$ & $\begin{array}{l}\text { Amplicon } \\
\text { size }\end{array}$ & $T^{m}$ & $\begin{array}{l}\text { Accession code } \\
\text { (RefSeq) }\end{array}$ \\
\hline \multirow[t]{2}{*}{ TLR2 } & Fw: GGCTGTAATCAGCGTGTTCA & $160 \mathrm{bp}$ & $64^{\circ} \mathrm{C}$ & NM_001048231.1 \\
\hline & Rv: GATCTCGTTGTCGGACAGGT & & & \\
\hline \multirow[t]{2}{*}{ TLR4 } & Fw: GAGAAGACTCAGAAAAGCCTTGCT & $200 b p$ & $65^{\circ} \mathrm{C}$ & NM_001135930.1 \\
\hline & Rv: GCGGGTTGGTTTCTGCAT & & & \\
\hline \multirow[t]{2}{*}{ TLR9 } & Fw: CCCTGGAGAAGCTGGACAT & $175 b p$ & $60^{\circ} \mathrm{C}$ & NM_001011555.1 \\
\hline & Rv: GACAGGTCCACGAAGAGCAG & & & \\
\hline
\end{tabular}

experiments were performed to ensure similar PCR amplification efficiency of the primers. RT-PCR reactions were performed in duplicate with the LightCycler 480 SYBR Green I Master mix (4707516001, Roche-Applied) on a LightCycler 480 Instrument according to the manufacturer's instructions. RT-PCR results were normalized to cyclophilin $A$, a household gene, and mean fold changes in mRNA expression were calculated by the $\Delta \Delta$ Ct-method [23].

\section{Surfactant saturated phosphatidylcholine (Sat PC) and SP-D}

SP-D in the BALF was measured with a sandwich ELISA using rabbit anti-ovine SP-D as coating antibody and guinea pig anti-ovine SP-D a secondary antibody [24, 25]. Sat PC was isolated from the BALF using organic solvent extraction, osmium tetroxide and neutral alumina followed by a phosphorus measurement [26].

\section{Immunohistology}

The following antibodies were used to identify different cell types: CD3 - T cells, Myeloperoxidase - activated neutrophils and monocytes, PU.1 - maturation marker for myeloid cells, Pro-Surfactant protein-C (SP-C) - maturation marker for alveolar type II cells, thyroid transcription factor-1 (TTF-1) - alveolar type II cells, Foxp3 - Regulatory T-cells. Paraffin embedded RUL lung sections ( $4 \mu \mathrm{m}$, transverse) were stained for CD3 
(DAKO A0452, Dakocytomation, Glostrup, Denmark), myeloperoxidase (MPO) (DAKO A0398, Dakocytomation) PU.1 (sc-352, Santa Cruz Biotechnology, Santa Cruz, USA), Foxp3 (14-7979, eBioscience, San Diego, USA), thyroid transcription factor-1 (TTF-1) (WRAB-1231, Seven Hills Bioreagents, Cincinnati OH, USA) or Pro-SP-C (WRAB-9337, Seven Hills Bioreagents). Briefly, the sections were deparaffinized in an ethanol series and endogenous peroxidase-activity was blocked by incubation with $0.3 \% \mathrm{H}_{2} \mathrm{O}_{2}$ in $1 \mathrm{x}$ phosphate buffered saline (PBS, pH 7.4) or methanol (for TTF-1 and Pro-SP-C). Antigen retrieval was performed by incubating the sections in heated citrate buffer (10 mM, pH 6.0) for 30 minutes. In order to block nonspecific binding, the slides were incubated with $20 \%$ normal goat serum (NGS) in PBS (for MPO and Foxp3), $5 \%$ bovine serum albumin (BSA) in PBS (for CD3 and PU.1) or $2 \%$ NGS in PBS (for TTF-1 and Pro-SP-C). Sections were incubated overnight at $4{ }^{\circ} \mathrm{C}$ with the diluted primary antibody (CD3 1:200, MPO 1:500, PU.1 1:400, Foxp3 1:30, TTF-1 1:100, Pro-SP-C 1:1500). After incubation with a goat-anti-mouse biotin labeled (for Foxp3) (DAKO E0433, Dakocytomation) or swine-anti rabbit biotin labeled secondary antibody (DAKO E0353, Dakocytomation), immunostaining was enhanced with Vectastain ABC peroxidase Elite kit (PK-6200, Vector Laboratories, Burlingame, USA) and stained with nickel sulfate-diaminobenzidine (NiDAB). Subsequently, the sections were rinsed in Tris/saline and incubated with Tris/ cobalt. After counterstaining with $0.1 \%$ Nuclear Fast Red, the sections were washed, dehydrated and cover-slipped.

Since the air-space expansion and tissue characteristics were different in the different groups, we measured tissue area in the lung sections. Blinded measurements of tissue fractions (expressed relative to the total lung area) were performed in 5 random nonoverlapping fields (20x objective) for each animal and for at least 4 animals/group using the color threshold function of the program metamorph v6.1r0 (Molecular devices/ Universal imaging corp., Sunnyvale CA). The average measurement from each lamb was used to compute a group average. The tissue fractions in different experimental groups were normalized to the control group average to obtain a correction factor. For example, if the tissue fraction in an experimental group was 1.2 times control, then the cells counted per microscopic field were divided by 1.2. Thus the expressed cell counts per microscopic field incorporated this correction factor.

Evaluation was performed by light microscopy (Axioskop 40, Zeiss, Germany) with LeicaQWin Pro v.3.4.0 software (Leica Microsystems, Germany). MPO-, CD3-, PU.1- and Pro-SP-C positive cells were counted in three representative high power fields at 200x magnification by a blinded observer and averaged per animal. Because Foxp3 positive cells were unevenly distributed throughout the lung tissue, sections were scored for positive signal for Foxp3 with a semi-quantitative scoring system by a blinded observer: 
1 - little staining, 2 - light staining, 3 - heavy staining. For TTF-1, a computer aided manual count of 5 random fields at 200x magnification per animal was performed, using the computer program metamorph (Image-Pro Plus v7.0). The MPO, CD3 and TTF-1 cell counts per microscopic field incorporated the correction factor for tissue fraction. The SP-C positive cells were expressed relative to TTF-1 positive cells to assess if changes were due to increased expression in each of the alveolar type II cell vs. increased numbers of alveolar type II cells in different groups.

\section{Data Analysis}

Results are given as means \pm standard error of means (SEM). The groups were compared using one-way ANOVA with Tukey's test for post-hoc analysis as appropriate. Statistical analysis was performed by GraphPad Prism v5.0. Significance was accepted at $p<0.05$.

\section{Results}

\section{Description of animals}

The experiments were prospectively designed to test the interactions of antenatal corticosteroids and intra-amniotic LPS exposure. Despite the medroxyprogesterone acetate treatment, animals exposed to maternal betamethasone experienced fetal losses, such that we reassigned animals from the group which only received betamethasone 14 days before delivery to other treatment groups as our priority was to test the interaction of betamethasone and LPS. The intra-amniotic LPS injections were not associated with fetal losses, but fetal deaths identified by ultrasound and fetal losses were frequent in the betamethasone treated groups (Table 2). All animals had comparable birth weights except for a lower birth weight for animals with combined exposure to LPS 14 days and betamethasone 7 days before delivery. Cord blood pH values and lung to body weight ratios were comparable across all groups.

Table 2: Variables at birth

\begin{tabular}{l|ccccccc} 
Treatment group & \multicolumn{3}{|c}{ Fetal outcomes } & $\begin{array}{c}\text { Birth } \\
\text { weight }\end{array}$ & $\begin{array}{c}\text { Cord } \\
\text { blood }\end{array}$ & $\begin{array}{c}\text { Sex } \\
\text { Lung } \\
\text { Wt/ } \\
\text { Body Wt }\end{array}$ \\
\cline { 2 - 9 } & $\begin{array}{c}\text { Fetal } \\
\text { death }\end{array}$ & Abortion & Alive & kg & pH & M/F & g/kg \\
\hline Control & 1 & - & 7 & $2.7 \pm 0.2$ & $7.24 \pm 0.03$ & $3 / 4$ & $32.7 \pm 0.9$ \\
$7 d$ LPS & - & - & 7 & $2.5 \pm 0.1$ & $7.26 \pm 0.02$ & $3 / 4$ & $33.6 \pm 1.2$ \\
$14 d$ LPS & - & - & 8 & $2.5 \pm 0.1$ & $7.27 \pm 0.02$ & $5 / 3$ & $37.1 \pm 1.8$ \\
$7 d$ Beta & 2 & 1 & 7 & $2.7 \pm 0.2$ & $7.20 \pm 0.04$ & $4 / 3$ & $36.7 \pm 0.8$
\end{tabular}


Chapter 2

\begin{tabular}{c|cccccccc}
\hline Treatment group & \multicolumn{3}{|c}{ Fetal outcomes } & $\begin{array}{c}\text { Birth } \\
\text { weight }\end{array}$ & $\begin{array}{c}\text { Cord } \\
\text { blood }\end{array}$ & $\begin{array}{c}\text { Sex } \\
\text { Lung } \\
\text { Wt/ } \\
\text { Body Wt }\end{array}$ \\
\cline { 2 - 8 } & $\begin{array}{c}\text { Fetal } \\
\text { death }\end{array}$ & Abortion & Alive & kg & pH & M/F & g/kg \\
\hline $14 d$ Beta $+7 d$ LPS & - & 3 & 6 & $2.7 \pm 0.1$ & $7.25 \pm 0.04$ & $1 / 5$ & $36.2 \pm 2.4$ \\
$14 d$ LPS $+7 d$ Beta & 1 & 1 & 8 & $2.1 \pm 0.1 *$ & $7.25 \pm 0.03$ & $4 / 4$ & $39.9 \pm 2.7$
\end{tabular}

Data expressed as mean \pm SEM. ${ }^{*} \mathrm{p}<0.05$ vs. controls using a one-way ANOVA with Tukey's post hoc test. LPS- Lipopolysaccharide, Beta- Betamethasone, GA- Gestational age, Wt- weight, M male, $\mathrm{F}$ - female.

\section{Lung inflammation}

Pulmonary inflammation resulting from LPS and the anti-inflammatory effect of betamethasone exposures were assessed by differential cell counts on the BALF (Figure 2). Neutrophil levels were modestly increased 7 days after the exposure to LPS and significantly increased 14 days after LPS exposure (Figure 2A). This increase did not occur in lambs exposed to maternal betamethasone 7 days after intra-amniotic LPS. In this group, however, there was a 10-fold increase in monocytes, which was not seen in the groups exposed to LPS only (Figure 2B). Lymphocyte numbers did not differ in experimental groups compared to controls (Figure 2C).

Figure 2: Differential cell count of the bronchoalveolar lavage.

A: Neutrophil levels increased 14 days after the exposure to LPS. B: Combined exposure to LPS for 14 days and betamethasone for 7 days increased monocytes in the bronchoalveolar lavage. C: The lymphocyte count did not differ in any of the treatment groups compared to controls. ${ }^{*} p<0.05$ versus controls using a oneway ANOVA with Tukey's post hoc test.
A

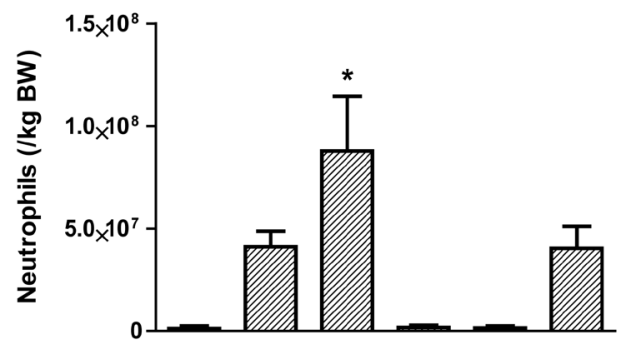

B

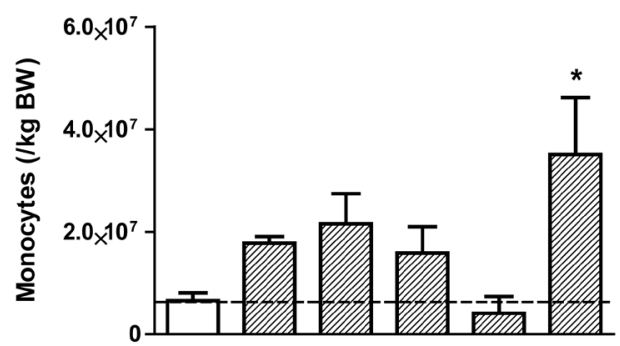

C

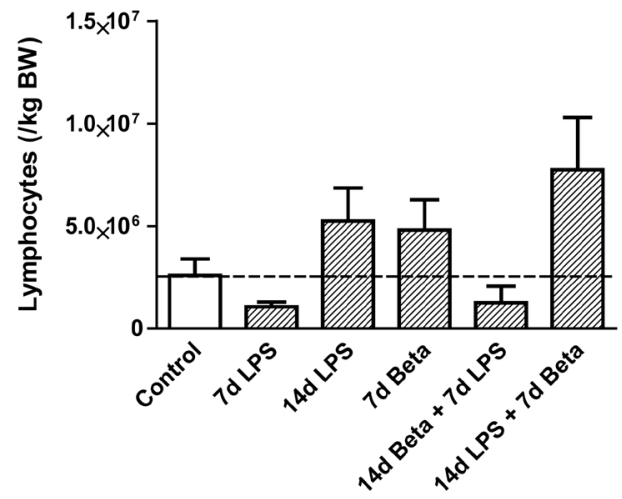


Lung inflammation was further characterized by identifying markers for activation of inflammatory cells (Figure 3). MPO-positive cells were significantly increased 14 days after LPS exposure (Figure 3A-D). Betamethasone pre-treatment 7 days before the LPS exposure prevented the increase of MPO-positive cells in the fetal lung. However, betamethasone given 7 days after LPS only partially inhibited the influx of LPS-mediated MPO-positive cells. PU.1 expression, which is a transcription factor that indicates maturation of monocytes [27], increased 7 days after LPS exposure in the fetal lung (Figure 3E-H). This increase in PU.1 positive-cells could be prevented by pretreatment with betamethasone 7 days before the LPS exposure. However, exposure to 14 days LPS followed by betamethasone for $7 d$ increased PU.1 expressing cells in the lung. LPS exposure for either 7 or 14 days increased the number of CD3-positive cells in the fetal lung (Figure 3I). The groups exposed to both betamethasone and LPS did not show a significant increase in CD3-positive cells compared to controls indicating that betamethasone pre- and post-treatment both countered the LPS-induced influx of CD3-positive cells. Foxp3-positive cells only increased in the lung tissue 7 days after LPS exposure (Figure 3J), which was inhibited by betamethasone pre-treatment.

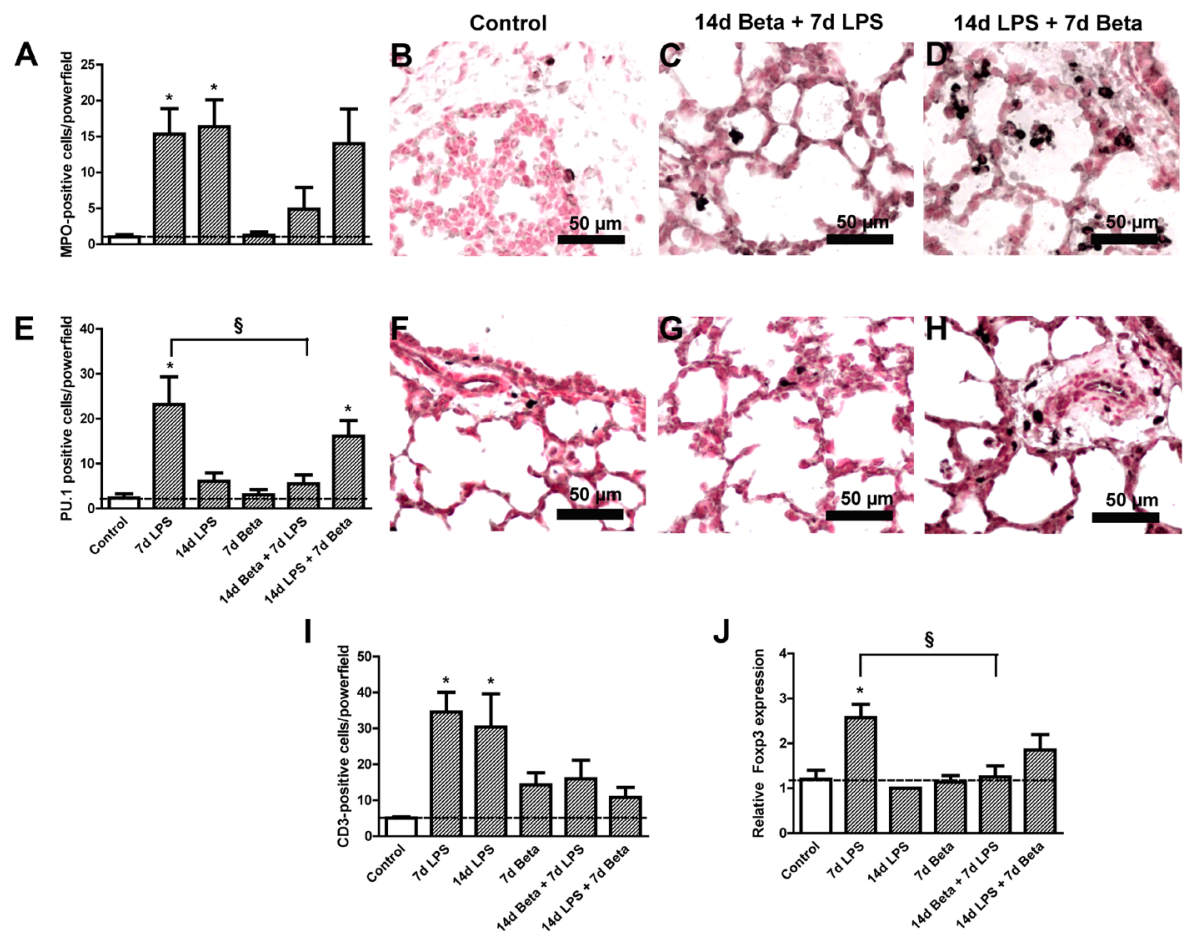

Figure 3: Characterization of inflammatory cells in the fetal lung tissue.

A: Quantitation of myeloperoxidase expressing cells in lung sections per microscopic field corrected for the tissue fraction (see methods for details). Representative photomicrographs 
of immunostaining against myeloperoxidase using lung sections from B: Controls C: $14 \mathrm{~d}$ Bethamethasone + 7d LPS D: 14d LPS + 7d Betamethasone. Myeloperoxidase (MPO) -positive cells increased in the lung tissue 14 days after LPS exposure compared to controls. E: Quantitation of PU.1 expressing cells in lung sections per microscopic field. Representative photomicrographs of immunostaining against PU.1 using lung sections from F: Controls G: $14 d$ Bethamethasone $+7 d$ LPS H: 14d LPS + 7d Betamethasone. LPS exposure for 7 days and combined exposure to LPS for 14 days and betamethasone for 7 days increased the number of PU.1-positive cells in the fetal lung. Betamethasone treatment 7 days before the LPS exposure prevented this increase. I: The number of CD3-positive cells increased significantly 7 and 14 days after LPS exposure compared to controls. J: Foxp3 expression increased 7 days after LPS exposure compared to controls. Betamethasone treatment before the LPS exposure prevented this increase. ${ }^{*} p<0.05$ versus controls $\S p<0.05$ between experimental groups using a one-way ANOVA with Tukey's post hoc test.

Consistent with our previous observation of maximal induction of cytokines $2 \mathrm{~d}$ after exposure $[28,29]$, the mRNA expression of $I L-16, I L-6, I L-8$ and $M C P-1$ were only modestly increased 7days after LPS exposure compared to controls (Table 3). Combined exposure to LPS and betamethasone had no significant effect on lung cytokine mRNA expression. The mRNA levels of Serum amyloid A, an acute phase reaction protein expressed in the lung and liver [30], increased 7 days after the LPS exposure compared to controls. Betamethasone pre-treatment prior to the LPS exposure suppressed this increase. The

Table 3: Cytokine and acute phase reactant expression in the fetal lung

\begin{tabular}{l|ccccc} 
Treatment group & $\begin{array}{c}\text { IL-1 } \beta \\
\text { mRNA (fold } \\
\text { increase) }\end{array}$ & $\begin{array}{c}\text { IL-6 mRNA } \\
\text { (fold } \\
\text { increase) }\end{array}$ & $\begin{array}{c}\text { IL-8 mRNA } \\
\text { (fold } \\
\text { increase) }\end{array}$ & $\begin{array}{c}\text { MCP-1 } \\
\text { mRNA (fold } \\
\text { increase) }\end{array}$ & $\begin{array}{c}\text { Serum } \\
\text { Amyloid A3 } \\
\text { mRNA (fold } \\
\text { increase) }\end{array}$ \\
\hline Control & $1.0 \pm 0.2$ & $1.0 \pm 0.3$ & $1.0 \pm 0.2$ & $1.0 \pm 0.2$ & $1.0 \pm 0.7$ \\
$7 d$ LPS & $3.5 \pm 0.5^{*}$ & $0.9 \pm 0.1$ & $4.7 \pm 0.8$ & $3.7 \pm 0.4$ & $29 \pm 10^{*}$ \\
$14 d$ LPS & $3.1 \pm 0.6$ & $1.1 \pm 0.2$ & $4.2 \pm 1.5$ & $3.8 \pm 0.9$ & $12 \pm 8.0$ \\
7d Beta & $1.2 \pm 0.3$ & $1.0 \pm 0.3$ & $1.0 \pm 0.4$ & $1.3 \pm 0.3$ & $1.2 \pm 0.5$ \\
14d Beta $+7 d$ LPS & $1.8 \pm 0.4$ & $0.8 \pm 0.1$ & $2.1 \pm 0.8$ & $1.7 \pm 0.5$ & $4.3 \pm 3.0$ \\
14d LPS $+7 d$ Beta & $3.2 \pm 1.5$ & $1.6 \pm 0.8$ & $4.3 \pm 2.3$ & $5.0 \pm 3.2$ & $31 \pm 26$
\end{tabular}

Data expressed as mean \pm SEM. * $p<0.05$ versus controls using a one-way ANOVA with Tukey's post hoc test. LPS- Lipopolysaccharide, Beta- Betamethasone.

mRNA levels of TLR2 (Figure 4A) and TLR4 (Figure 4B) more than doubled after 7 days of LPS exposure, but returned to control levels 14 days after exposure. Pre-treatment with betamethasone 7 days prior decreased the LPS induced increase in TLR4 but not TLR2 mRNA. Levels of TLR9 mRNA did not change in experimental groups compared to controls (Figure 4C). 
Fetal lung exposure to LPS and corticosteroids

A

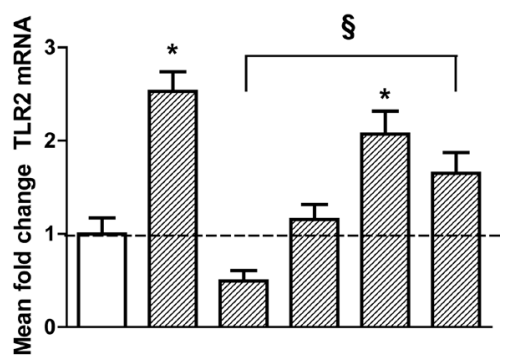

B

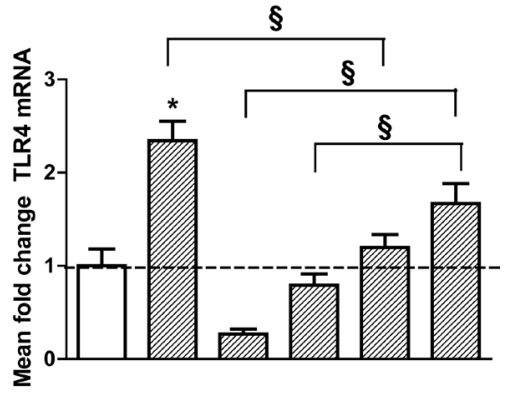

C

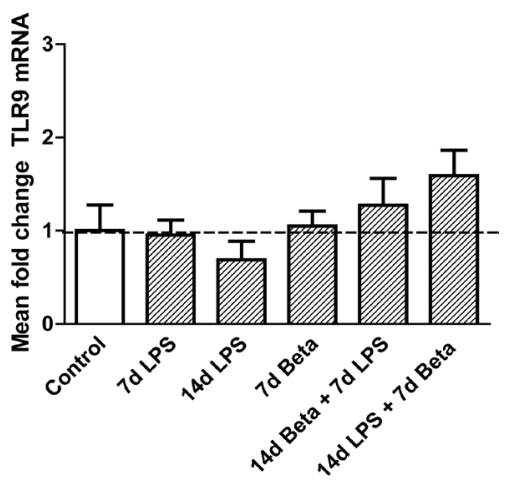

Figure 4: Expression of Toll-Like Receptors (TLR) 2, 4 and 9.

TLR2 (A) and TLR4 (B) mRNA expression were up-regulated 7 days after LPS exposure, but returned to baseline 14 days after exposure to LPS. Betamethasone treatment before LPS exposure prevented increased TLR4 expression, but not TLR2 expression. TLR2 and TLR4 mRNA levels increased in the lungs of lambs which received betamethasone after LPS exposure, although these levels were not higher than levels measured in controls. C: TLR9 was not differently expressed in experimental groups compared to controls. ${ }^{*} p<0.05$ versus controls; $\S$ $p<0.05$ between experimental groups using a oneway ANOVA with Tukey's post hoc test.

\section{Surfactant components}

Exposure to LPS alone modestly and variably increased SP-A and SP-B mRNA levels (nonsignificant) (Table 4). However, the combined exposure to LPS followed by betamethasone resulted in a more consistent and significant increase in SP-A and SP-B mRNAs. SP-C mRNA expression did not change with either the betamethasone or LPS exposure. SP-D mRNA expression increased 14 days after the exposure to LPS alone or with betamethasone $7 \mathrm{~d}$ after LPS (Figure 5A). Consistent with the mRNA data, combined exposure to 14d LPS followed by betamethasone $7 \mathrm{~d}$ exposure significantly increased SP-D protein in the BALF (Figure 5B).

To better assess the changes in the alveolar type II cells, we immunostained fetal lung sections using antibodies against TTF-1 and the precursor form of SP-C (Pro-SP-C) [31]. TTF-1, a transcription factor for alveolar type II cells [31], did not change in any of the treatment groups indicating no change in the alveolar type II cell numbers after exposure to either LPS or betamethasone (Table 4). 
Chapter 2

\begin{tabular}{l|ccccc}
\hline \multicolumn{2}{l}{ Table 4: Markers of lung maturation } & & & \\
Treatment group & $\begin{array}{c}\text { SP-A } \\
\text { mRNA } \\
\text { (fold } \\
\text { increase) }\end{array}$ & $\begin{array}{c}\text { SP-B } \\
\text { mRNA } \\
\text { (fold } \\
\text { increase) }\end{array}$ & $\begin{array}{c}\text { SP-C } \\
\text { mRNA } \\
\text { (fold } \\
\text { increase) }\end{array}$ & $\begin{array}{c}\text { Pro-SP-C+ } \\
\text { cells/HPF }\end{array}$ & $\begin{array}{c}\text { TTF-1+ } \\
\text { cells/HPF }\end{array}$ \\
\hline Control & $1.0 \pm 0.4$ & $1.0 \pm 0.3$ & $1.0 \pm 0.6$ & $38 \pm 17$ & $514 \pm 37$ \\
7d LPS & $4.6 \pm 0.6$ & $1.9 \pm 0.2$ & $1.7 \pm 0.7$ & $131 \pm 17^{*}$ & $501 \pm 25$ \\
14d LPS & $7.5 \pm 2.6$ & $2.4 \pm 0.4$ & $0.4 \pm 0.1$ & $83 \pm 11$ & $307 \pm 14$ \\
7d Beta & $1.4 \pm 0.2$ & $1.1 \pm 0.1$ & $0.2 \pm 0.1 *$ & $52 \pm 10$ & $400 \pm 17$ \\
14d Beta + 7d LPS & $5.6 \pm 3.3$ & $1.8 \pm 0.6$ & $1.0 \pm 0.3$ & $67 \pm 11$ & $269 \pm 19$ \\
14d LPS $+7 d$ Beta & $10.5 \pm 2.2^{*}$ & $2.7 \pm 0.3^{*}$ & $0.6 \pm 0.1$ & $51 \pm 9$ & $327 \pm 19$
\end{tabular}

Data expressed as mean \pm SEM. * $p<0.05$ versus controls using a one-way ANOVA with Tukey's post hoc test. LPS- Lipopolysaccharide, Beta- Betamethasone, HPF-High powerfield.

A

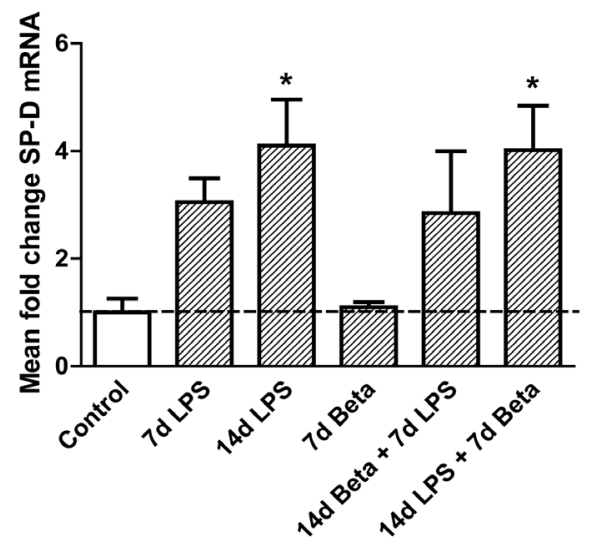

B

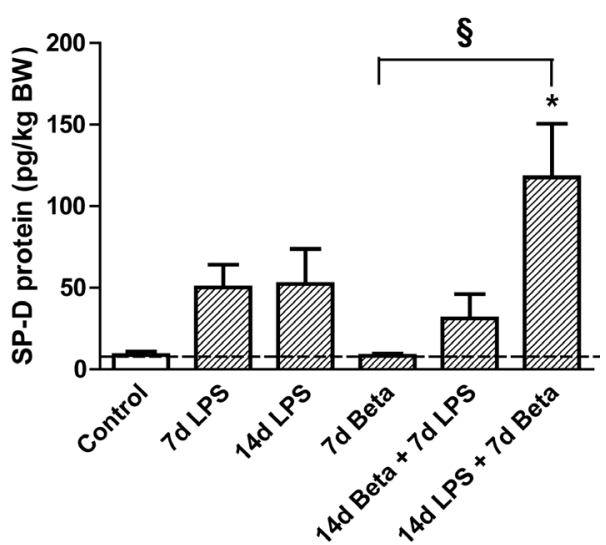

Figure 5: SP-D mRNA and protein expression.

A: SP-D mRNA levels increased 14 days after the exposure to LPS irrespectively of the betamethasone post-treatment. B: Only combined exposure to LPS for 14 days and betamethasone for 7 days increased SP-D protein expression in the bronchoalveolar lavage fluid. Exposure to LPS for 14 days did not increase SP-D protein expression. ${ }^{*} p<0.05$ versus controls $\S p<0.05$ between experimental groups using a one-way ANOVA with Tukey's post hoc test.

However, compared to controls, the number of Pro-SP-C-positive cells increased significantly 7, and 14 days after the exposure to LPS, and after 14d LPS+ 7d Beta, indicating maturation of alveolar type-II cells (Figure 6A-E). 
Fetal lung exposure to LPS and corticosteroids
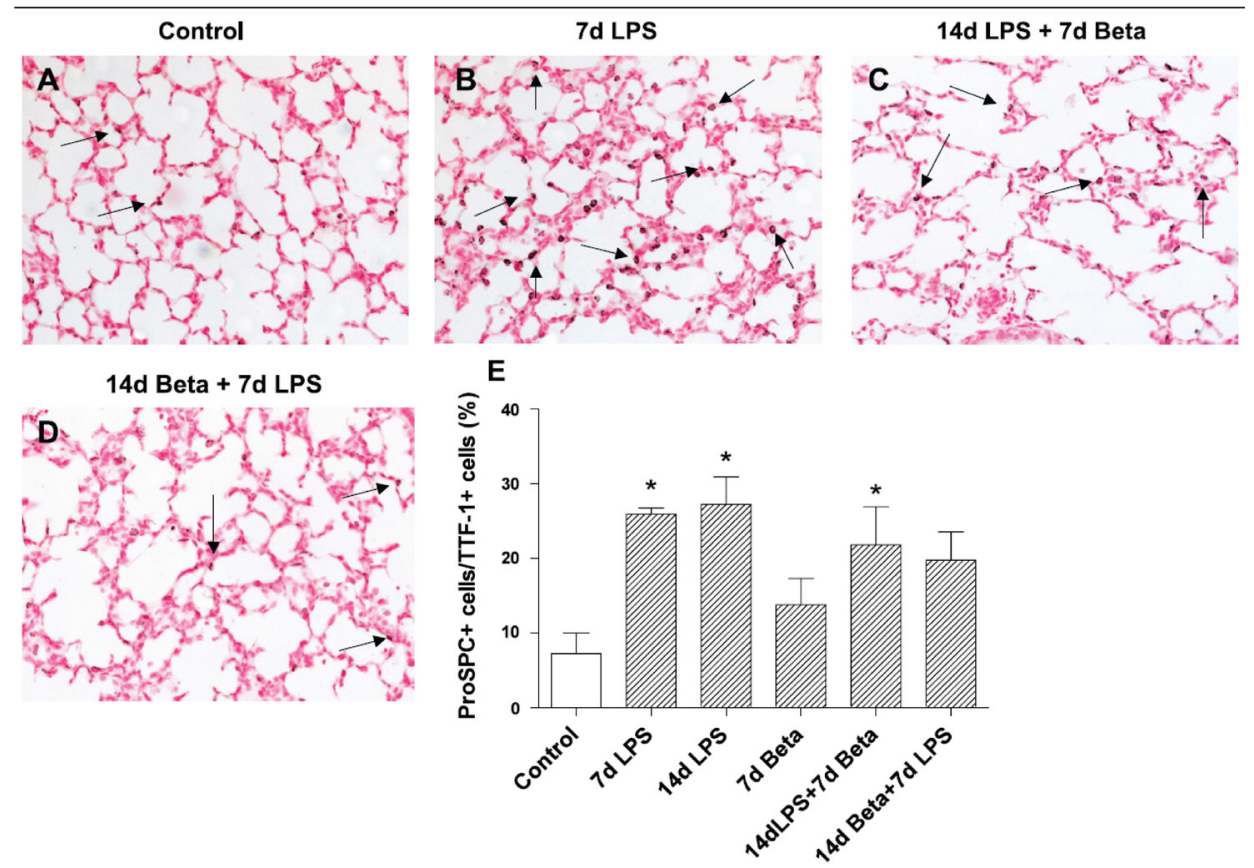

Figure 6: Pro-SP-C immunostaining in the lung.

The number of pro-SP-C+ cells was expressed as a percentage of TTF- 1 positive cells (data in table 4). Representative photomicrographs of immunostaining using lung sections from $\mathbf{A}$ : Controls $\mathbf{B}$ : 7d LPS C: 14d LPS + 7d Betamethasone D: 14d Bethamethasone + 7d LPS. E: Quantitation of ProSP-C expressing cells in lung sections per microscopic field using a 20X objective. LPS exposure increased Pro-SP-C expression in the alveolar 670 type II cells in the lung. $\left({ }^{*} p<0.05\right.$ vs. controls, scale bar is $50 \mu \mathrm{m}$ ).

Saturated phosphatidylcholine (Sat PC) is the major surfactant lipid [32]. Exposure to intra-amniotic LPS for 7 or 14 days increased Sat PC in the fetal airspaces (Figure 7A). Betamethasone alone did not significantly increase Sat PC expression. However, the 14 days LPS exposure followed by betamethasone 7d had the highest airway Sat PC levels (Figure 7A). Consistent with increases in surfactant Sat PC, lung volumes, a measure of compliance, increased in all the LPS groups regardless of betamethasone exposure, with the highest lung volumes recorded in the 14d LPS followed by $7 d$ betamethasone exposure group Figure 7B). 
A

Figure 7: Saturated phosphatidylcholine (Sat PC) and pressurevolume curves.

A: Sat PC levels in the bronchoalveolar lavage fluid were increased 7 and 14 days after exposure to intra-amniotic LPS. Betamethasone post-treatment 7 days after the exposure to LPS increased Sat PC levels further. B: The pressure-volume curve of animals after 14 days of LPS exposure was significantly higher compared to controls irrespectively of treatment with betamethasone. ${ }^{*} p<0.05$ versus controls; § $p<0.05$ between experimental groups using a oneway ANOVA with Tukey's post hoc test.
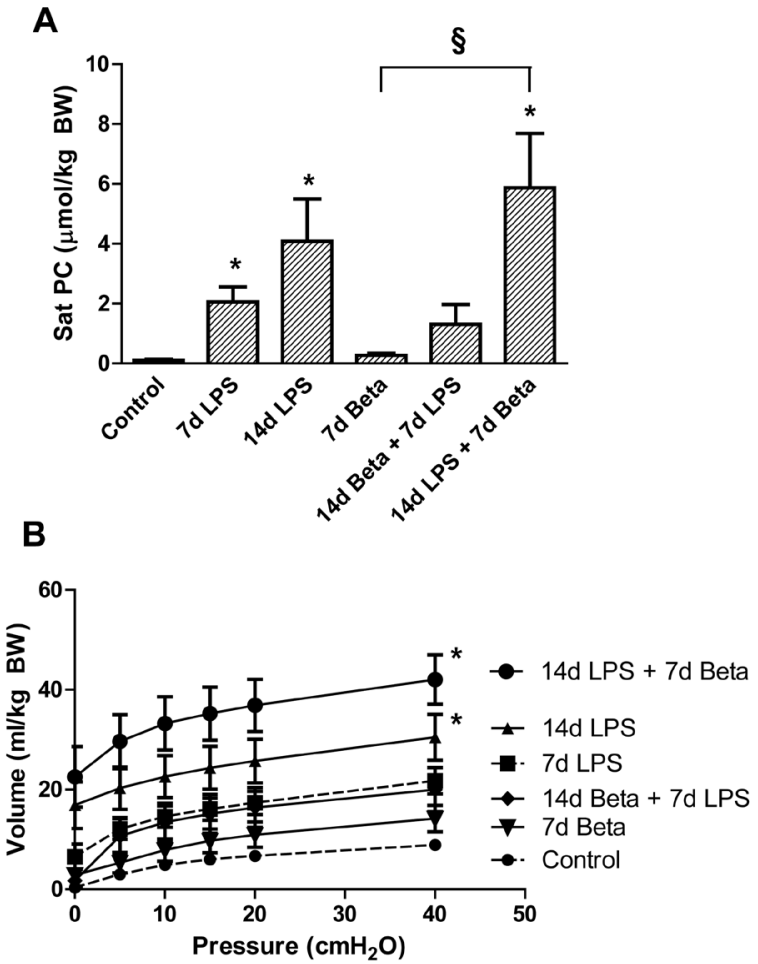

Discussion

Lung inflammation, increased airway surfactants and increased lung volumes consistent with clinical lung maturation are the major effects of experimental chorioamnionitis [28, 29]. In this study we evaluated if the exposure to the commonly used anti-inflammatory drug betamethasone altered the responses to LPS in the fetal lung. The major conclusion was that betamethasone when administered 7 days after intra-amniotic LPS did not inhibit lung inflammation but resulted in striking lung maturation. However, when betamethasone was given 7 days before intra-amniotic LPS, lung inflammation was suppressed and lung maturation was more modest.

Intra-amniotic LPS caused lung inflammation at 7 and 14 days after exposure. Both neutrophils and T-lymphocytes were recruited to the lung. Further, the neutrophils were activated as demonstrated by the MPO expression [33]. The influx of proinflammatory cells was also accompanied by an increase in Foxp3-positive cells, a prototypic marker of the anti-inflammatory T-regulatory cells [34]. The number of cells expressing PU.1 also increased which suggests maturation of lung monocytes, a 
Fetal lung exposure to LPS and corticosteroids

characteristic for LPS-mediated pulmonary inflammation [27]. Both the TLR2 and TLR4 mRNA levels increased in the lung tissue after LPS. Consistent with our previous results demonstrating an early rapid induction profile for cytokine expression [28], the mRNAs for pro-inflammatory cytokines were only modestly increased $7 \mathrm{~d}$ after exposure in the present study. Interestingly, betamethasone treatment 7d prior to LPS significantly decreased LPS induced lung inflammation. However, when LPS exposure preceded betamethasone treatment, lung inflammation was not altered. We previously reported that a concomitant administration of maternal betamethasone and LPS resulted in an early suppression but later amplification of lung inflammation $[16,17]$. Thus, the timing of exposure to betamethasone in relation to the pro-inflammatory stimulus is a major determinant of modulation of lung inflammation.

Maternal betamethasone and intra-amniotic LPS have different pharmaco-kinetic profiles in the fetus. In a human study, peak fetal serum betamethasone levels were measured 1-2h after maternal betamethasone treatment with a return to baseline within 2 days of treatment [35]. In fetal sheep, maternal betamethasone treatment resulted in peak fetal betamethasone levels $3 \mathrm{~h}$ after treatment with a decrease to 50 $\%$ of the peak levels at $6 \mathrm{~h}$ [36]. In contrast, the half-life of endotoxin was measured as approximately $30 \mathrm{~h}$ in the amniotic fluid of preterm lambs after an intra-amniotic administration and exhibited first order kinetics of elimination [14]. Neither antenatal betamethasone nor intra-amniotic LPS significantly change the levels of endogenous cortisol in the preterm fetus $[20,37]$. These results suggest that fetal betamethasone levels $7 \mathrm{~d}$ after maternal treatment must be negligible. Therefore, the inhibition of LPS induced fetal lung inflammation $7 \mathrm{~d}$ after maternal betamethasone suggests priming or conditioning of the inflammatory response cells rather than a straight forward drugdrug interaction. This interpretation is also consistent with our previous observation of an early suppression with a late amplification of lung inflammation with concomitant administration of maternal betamethasone and intra-amniotic LPS $[16,17]$. Our results also demonstrate that modulation of LPS induced fetal inflammation does not occur when betamethasone is administered after LPS.

Intra-amniotic exposure to LPS followed by betamethasone 7 days before delivery strikingly increased lung maturation as seen by increased Sat PC, SP-D and the increase in the pressure-volume curve. In contrast, betamethasone pre-treatment followed by exposure to LPS 7 days before delivery induced less lung maturation. The large effect of LPS on SP-D expression is consistent with recently reported up regulation of LPS-induced SP-D expression in fetal mice [38]. SP-D is an innate host-defense molecule protecting the host against a number of pulmonary pathogens [39]. Alveolar type II cell maturation was demonstrated by increased Pro-SP-C expression. The expression of surfactant protein 
mRNAs for SP-B increased but SP-C was unchanged after LPS. Betamethasone alone did not increase expression of any of the surfactant protein mRNAs. We previously reported a differential effect of LPS on SP-B and SP-C mRNA levels [40]. In vitro, these two mRNAs are differentially regulated by betamethasone [41]. The more pronounced effect of LPS compared to betamethasone in increasing mRNA levels of surfactant proteins in this study is consistent with previous reports showing a rapid but reversible effect of betamethasone, but a more lasting effect of intra-amniotic LPS on surfactant protein mRNA expression [40, 42]. Previous reports suggest that the effects of simultaneous exposure to explants of fetal rabbits to IL-1 $\alpha$ and glucocorticoids could be stimulate or inhibit surfactant protein mRNA depending on the gestational age [43]. Taken together, the combined effects of a pro-inflammatory exposure and glucocorticoids on the fetal lung are variable and context dependent including gestational age and the order of exposure.

We reported previously that intra-amniotic LPS but not maternal betamethasone improved lung compliance, ventilatory efficiency index and the alveolar wash saturated phosphatidyl choline pool sizes $15 \mathrm{~d}$ after treatment $[32,40]$. We did not study the effects of betamethasone alone $14 \mathrm{~d}$ after exposure, because of high rate of abortions in this group. Interestingly, the highest expression of surfactant components and the consequent increase in lung volumes was in the group exposed to LPS for $14 \mathrm{~d}$ along with betamethasone $7 \mathrm{~d}$ before delivery. This group of animals also had the most pronounced lung inflammation. These results are consistent with our previous studies demonstrating that lung inflammation was required for LPS induced lung maturation $[6,44]$.

Clinical studies indicate that maternal glucocorticoids can decrease fetal weight and head size [45]. We reported previously that simultaneous exposures of fetal sheep to maternal corticosteroid and intra-amniotic LPS protected the fetus from the growth restriction caused by the antenatal corticosteroids [13]. In this experiment, the maternal corticosteroid exposure did not decrease fetal weight, a result that probably represents animal variability. The new observation is that the combination of 14 day LPS +7 day Beta caused fetal growth restriction. Since exposure to intrauterine inflammation is the major cause for preterm labor and cervical dilation leading to preterm birth, pretreatment with betamethasone will rarely be an option to diminish or counteract inflammation in the clinical setting. An inference from the study is that prenatal betamethasone in conjunction with inflammation promotes the maturity of the surfactant system resulting in reduced RDS, but does not prevent BPD as noted in clinical studies [46, 47]. However, the interactions of LPS and Beta on fetal growth are complex and not fully understood, and this observation needs verification by replication.

Antenatal corticosteroids are routinely administered to mothers who are at risk of 
preterm birth to mature the fetal organs, suppress inflammation and thus reduce perinatal morbidity and mortality [48]. Antenatal steroids also reduce adverse neonatal outcome after preterm birth associated with chorioamnionitis [49]. Our experiments do not identify new concerns for the use of antenatal corticosteroids. It remains unknown if these antenatal corticosteroids also prevent or amplify the developmental and structural complications in the fetal lung, which are induced by infection/inflammation $[11,50]$. In summary, this study provides further molecular evidence into the protective effects of antenatal corticosteroids on the fetal lung and its interactions with pro-inflammatory stimuli in the setting of chorioamnionitis.

\section{References}

1. Goldenberg, R.L., Hauth, J.C., and Andrews, W.W., Intrauterine infection and preterm delivery. N Engl J Med, 2000. 342(20): p. 1500-7.

2. Gomez, R., Romero, R., Ghezzi, F., Yoon, B.H., Mazor, M., and Berry, S.M., The fetal inflammatory response syndrome. Am J Obstet Gynecol, 1998. 179(1): p. 194-202.

3. Romero, R., Gomez, R., Ghezzi, F., Yoon, B.H., Mazor, M., Edwin, S.S., and Berry, S.M., A fetal systemic inflammatory response is followed by the spontaneous onset of preterm parturition. American journal of obstetrics and gynecology, 1998. 179(1): p. 186-93.

4. Kallapur, S.G. and Ikegami, M., Physiological consequences of intrauterine insults. Paediatric respiratory reviews, 2006. 7(2): p. 110-6.

5. Andrews, W.W., Goldenberg, R.L., Faye-Petersen, O., Cliver, S., Goepfert, A.R., and Hauth, J.C., The Alabama Preterm Birth study: polymorphonuclear and mononuclear cell placental infiltrations, other markers of inflammation, and outcomes in 23- to 32-week preterm newborn infants. American journal of obstetrics and gynecology, 2006. 195(3): p. 803-8.

6. Kallapur, S.G., Moss, T.J., Ikegami, M., Jasman, R.L., Newnham, J.P., and Jobe, A.H., Recruited inflammatory cells mediate endotoxin-induced lung maturation in preterm fetal lambs. American journal of respiratory and critical care medicine, 2005. 172(10): p. 1315-21.

7. Lahra, M.M. and Jeffery, H.E., A fetal response to chorioamnionitis is associated with early survival after preterm birth. American journal of obstetrics and gynecology, 2004. 190(1): p. 147-51.

8. Roberts, D. and Dalziel, S., Antenatal corticosteroids for accelerating fetal lung maturation for women at risk of preterm birth. Cochrane Database Syst Rev, 2006. 3: p. CD004454.

9. Ikegami, M., Polk, D., and Jobe, A., Minimum interval from fetal betamethasone treatment to postnatal lung responses in preterm lambs. American journal of obstetrics and gynecology, 1996. 174(5): p. 1408-13.

10. Wade, K.C., Guttentag, S.H., Gonzales, L.W., Maschhoff, K.L., Gonzales, J., Kolla, V., Singhal, S., and Ballard, P.L., Gene induction during differentiation of human pulmonary type /I cells in vitro. American journal of respiratory cell and molecular biology, 2006. 34(6): p. 727-37.

11. Willet, K.E., Jobe, A.H., Ikegami, M., Newnham, J., Brennan, S., and Sly, P.D., Antenatal endotoxin and glucocorticoid effects on lung morphometry in preterm lambs. Pediatr Res, 2000. 48(6): p. 782-8.

12. Harding, J.E., Pang, J., Knight, D.B., and Liggins, G.C., Do antenatal corticosteroids help in the setting of preterm rupture of membranes? American journal of obstetrics and gynecology, 2001. 184(2): p. 131-9.

13. Newnham, J.P., Moss, T.J., Padbury, J.F., Willet, K.E., Ikegami, M., Ervin, M.G., Sly, P., and Jobe, A., The interactive effects of endotoxin with prenatal glucocorticoids on short-term 
lung function in sheep. Am J Obstet Gynecol, 2001. 185(1): p. 190-7.

14. Newnham, J.P., Kallapur, S.G., Kramer, B.W., Moss, T.J., Nitsos, I., Ikegami, M., and Jobe, A.H., Betamethasone effects on chorioamnionitis induced by intra-amniotic endotoxin in sheep. Am J Obstet Gynecol, 2003. 189(5): p. 1458-66.

15. Banks, B.A., Cnaan, A., Morgan, M.A., Parer, J.T., Merrill, J.D., Ballard, P.L., and Ballard, R.A., Multiple courses of antenatal corticosteroids and outcome of premature neonates. North American Thyrotropin-Releasing Hormone Study Group. American journal of obstetrics and gynecology, 1999. 181(3): p. 709-17.

16. Kallapur, S.G., Kramer, B.W., Moss, T.J., Newnham, J.P., Jobe, A.H., Ikegami, M., and Bachurski, C.J., Maternal glucocorticoids increase endotoxin-induced lung inflammation in preterm lambs. Am J Physiol Lung Cell Mol Physiol, 2003. 284(4): p. L633-42.

17. Kramer, B.W., Ikegami, M., Moss, T.J., Nitsos, I., Newnham, J.P., and Jobe, A.H., Antenatal betamethasone changes cord blood monocyte responses to endotoxin in preterm lambs. Pediatr Res, 2004. 55(5): p. 764-8.

18. Kallapur, S.G., Willet, K.E., Jobe, A.H., Ikegami, M., and Bachurski, C.J., Intra-amniotic endotoxin: chorioamnionitis precedes lung maturation in preterm lambs. Am J Physiol Lung Cell Mol Physiol, 2001. 280(3): p. L527-36.

19. Jobe, A.H., Newnham, J.P., Moss, T.J., and Ikegami, M., Differential effects of maternal betamethasone and cortisol on lung maturation and growth in fetal sheep. American journal of obstetrics and gynecology, 2003. 188(1): p. 22-8.

20. Jobe, A.H., Newnham, J.P., Willet, K.E., Moss, T.J., Gore Ervin, M., Padbury, J.F., Sly, P., and Ikegami, M., Endotoxin-induced lung maturation in preterm lambs is not mediated by cortisol. Am J Respir Crit Care Med, 2000. 162(5): p. 1656-61.

21. Kallapur, S.G., Kramer, B.W., Knox, C.L., Berry, C.A., Collins, J.J., Kemp, M.W., Nitsos, I., Polglase, G.R., Robinson, J., Hillman, N.H., Newnham, J.P., Chougnet, C., and Jobe, A.H., Chronic Fetal Exposure to Ureaplasma parvum Suppresses Innate Immune Responses in Sheep. J Immunol, 2011. 187(5): p. 2688-95.

22. Kallapur, S.G., Kramer, B.W., Nitsos, I., Pillow, J.J., Collins, J.J., Polglase, G.R., Newnham, J.P., and Jobe, A.H., Pulmonary and systemic inflammatory responses to intra-amniotic IL-1alpha in fetal sheep. Am J Physiol Lung Cell Mol Physiol, 2011. 301(3): p. L285-95.

23. Livak, K.J. and Schmittgen, T.D., Analysis of relative gene expression data using real-time quantitative PCR and the 2(-Delta Delta C(T)) Method. Methods, 2001. 25(4): p. 402-8.

24. Ikegami, M., Carter, K., Bishop, K., Yadav, A., Masterjohn, E., Brondyk, W., Scheule, R.K., and Whitsett, J.A., Intratracheal recombinant surfactant protein $d$ prevents endotoxin shock in the newborn preterm lamb. American journal of respiratory and critical care medicine, 2006. 173(12): p. 1342-7.

25. Ikegami, M., Grant, S., Korfhagen, T., Scheule, R.K., and Whitsett, J.A., Surfactant protein-D regulates the postnatal maturation of pulmonary surfactant lipid pool sizes. Journal of applied physiology, 2009. 106(5): p. 1545-52.

26. Bartlett, G.R., Phosphorus assay in column chromatography. The Journal of biological chemistry, 1959. 234(3): p. 466-8.

27. Kramer, B.W., Joshi, S.N., Moss, T.J., Newnham, J.P., Sindelar, R., Jobe, A.H., and Kallapur, S.G., Endotoxin-induced maturation of monocytes in preterm fetal sheep lung. Am J Physiol Lung Cell Mol Physiol, 2007. 293(2): p. L345-53.

28. Kallapur, S.G., Willet, K.E., Jobe, A.H., Ikegami, M., and Bachurski, C.J., Intra-amniotic endotoxin: chorioamnionitis precedes lung maturation in preterm lambs. American journal of physiology. Lung cellular and molecular physiology, 2001. 280(3): p. L527-36.

29. Kramer, B.W., Moss, T.J., Willet, K.E., Newnham, J.P., Sly, P.D., Kallapur, S.G., Ikegami, M., and Jobe, A.H., Dose and time response after intraamniotic endotoxin in preterm lambs. Am J Respir Crit Care Med, 2001. 164(6): p. 982-8. 
30. Wilson, T.C., Bachurski, C.J., Ikegami, M., Jobe, A.H., and Kallapur, S.G., Pulmonary and systemic induction of SAA3 after ventilation and endotoxin in preterm lambs. Pediatric research, 2005. 58(6): p. 1204-9.

31. Maeda, Y., Dave, V., and Whitsett, J.A., Transcriptional control of lung morphogenesis. Physiological reviews, 2007. 87(1): p. 219-44.

32. Ikegami, M., Jobe, A.H., Yamada, T., and Seidner, S., Relationship between alveolar saturated phosphatidylcholine pool sizes and compliance of preterm rabbit lungs. The effect of maternal corticosteroid treatment. The American review of respiratory disease, 1989. 139(2): p. 367-9.

33. Cheah, F.C., Pillow, J.J., Kramer, B.W., Polglase, G.R., Nitsos, I., Newnham, J.P., Jobe, A.H., and Kallapur, S.G., Airway inflammatory cell responses to intra-amniotic lipopolysaccharide in a sheep model of chorioamnionitis. Am J Physiol Lung Cell Mol Physiol, 2009. 296(3): p. L384-93.

34. Fontenot, J.D., Gavin, M.A., and Rudensky, A.Y., Foxp3 programs the development and function of CD4+CD25+ regulatory T cells. Nature immunology, 2003. 4(4): p. 330-6.

35. Ballard, P.L., Granberg, P., and Ballard, R.A., Glucocorticoid levels in maternal and cord serum after prenatal betamethasone therapy to prevent respiratory distress syndrome. The Journal of clinical investigation, 1975. 56(6): p. 1548-54.

36. Berry, L.M., Polk, D.H., Ikegami, M., Jobe, A.H., Padbury, J.F., and Ervin, M.G., Preterm newborn lamb renal and cardiovascular responses after fetal or maternal antenatal betamethasone. The American journal of physiology, 1997. 272(6 Pt 2): p. R1972-9.

37. Ikegami, M., Jobe, A.H., Newnham, J., Polk, D.H., Willet, K.E., and Sly, P., Repetitive prenatal glucocorticoids improve lung function and decrease growth in preterm lambs. American journal of respiratory and critical care medicine, 1997. 156(1): p. 178-84.

38. Schmiedl, A., Behrens, J., Zscheppang, K., Purevdorj, E., von Mayersbach, D., Liese, A., and Dammann, C.E., Lipopolysaccharide-induced injury is more pronounced in fetal transgenic ErbB4-deleted lungs. American journal of physiology. Lung cellular and molecular physiology, 2011. 301(4): p. L490-9.

39. Crouch, E., Persson, A., Chang, D., and Heuser, J., Molecular structure of pulmonary surfactant protein D (SP-D). The Journal of biological chemistry, 1994. 269(25): p. 17311-9.

40. Bachurski, C.J., Ross, G.F., Ikegami, M., Kramer, B.W., and Jobe, A.H., Intra-amniotic endotoxin increases pulmonary surfactant proteins and induces SP-B processing in fetal sheep. Am J Physiol Lung Cell Mol Physiol, 2001. 280(2): p. L279-85.

41. Ballard, P.L., Ertsey, R., Gonzales, L.W., and Gonzales, J., Transcriptional regulation of human pulmonary surfactant proteins SP-B and SP-C by glucocorticoids. American journal of respiratory cell and molecular biology, 1996. 14(6): p. 599-607.

42. Tan, R.C., Ikegami, M., Jobe, A.H., Yao, L.Y., Possmayer, F., and Ballard, P.L., Developmental and glucocorticoid regulation of surfactant protein mRNAs in preterm lambs. The American journal of physiology, 1999. 277(6 Pt 1): p. L1142-8.

43. Vayrynen, O., Glumoff, V., and Hallman, M., Regulation of surfactant proteins by LPS and proinflammatory cytokines in fetal and newborn lung. American journal of physiology. Lung cellular and molecular physiology, 2002. 282(4): p. L803-10.

44. Kallapur, S.G., Nitsos, I., Moss, T.J., Polglase, G.R., Pillow, J.J., Cheah, F.C., Kramer, B.W., Newnham, J.P., Ikegami, M., and Jobe, A.H., IL-1 mediates pulmonary and systemic inflammatory responses to chorioamnionitis induced by lipopolysaccharide. Am J Respir Crit Care Med, 2009. 179(10): p. 955-61.

45. French, N.P., Hagan, R., Evans, S.F., Godfrey, M., and Newnham, J.P., Repeated antenatal corticosteroids: size at birth and subsequent development. American journal of obstetrics and gynecology, 1999. 180(1 Pt 1): p. 114-21.

46. Been, J., Degraeuwe, P., Kramer, B., and Zimmermann, L., Antenatal steroids and neonatal 
outcome after chorioamnionitis: a meta-analysis. BJOG, 2011. 118(2): p. 113-22.

47. Wapner, R. and Jobe, A.H., Controversy: antenatal steroids. Clinics in perinatology, 2011. 38(3): p. 529-45.

48. Effect of corticosteroids for fetal maturation on perinatal outcomes. NIH Consensus Development Panel on the Effect of Corticosteroids for Fetal Maturation on Perinatal Outcomes. JAMA : the journal of the American Medical Association, 1995. 273(5): p. 413-8.

49. Goldenberg, R.L., Andrews, W.W., Faye-Petersen, O.M., Cliver, S.P., Goepfert, A.R., and Hauth, J.C., The Alabama preterm birth study: corticosteroids and neonatal outcomes in 23to 32-week newborns with various markers of intrauterine infection. Am J Obstet Gynecol, 2006. 195(4): p. 1020-4.

50. Collins, J.J., Kallapur, S.G., Knox, C.L., Nitsos, I., Polglase, G.R., Pillow, J.J., Kuypers, E., Newnham, J.P., Jobe, A.H., and Kramer, B.W., Inflammation in fetal sheep from intraamniotic injection of Ureaplasma parvum. Am J Physiol Lung Cell Mol Physiol, 2010. 299(6): p. L852-60. 


\section{Inflammation in fetal sheep from}

intra-amniotic injection of Ureaplasma parvum

Collins JJP, Kallapur SG, Knox CL, Nitsos I, Polglase GR, Pillow JJ, Kuypers E, Newnham JP, Jobe AH, Kramer BW Am J Physiol Lung Cell Mol Physiol. 2010 Dec;299(6):L852-60. 
Abstract

Rationale: Bronchopulmonary dysplasia is associated with chorioamnionitis and fetal lung inflammation. Ureaplasma species are the bacteria most frequently isolated from chorioamnionitis. Very chronic ureaplasma colonization of amniotic fluid causes low grade lung inflammation and functional lung maturation in fetal sheep. Less is known about shorter exposures of the fetal lung. Therefore, we hypothesized that ureaplasmas would cause an acute inflammatory response tha would alter lung development.

Methods: Singleton ovine fetuses received intra-amniotic U. parvum serovar 3 or control media at 110, 117, or 121 days, and were delivered at 124 days gestational age (term=150 days). Inflammation was assessed by cell counts in bronchoalveolar lavage fluid (BALF) and by cytokine mRNA measurements, immunohistochemistry and flow cytometry for inflammatory cells, and elastin and alpha smooth muscle actin ( $\alpha$-SMA) staining in lung tissue.

Results: Neutrophils were increased in BALF 3 days after exposure to ureaplasmas $(p=0.01)$. Myeloperoxidase positive cells increased after 3 days $(p=0.03)$ and MHC class II positive cells increased after 14 days ureaplasma exposure $(p=0.001)$. PU.1 (macrophage marker) or CD3 (T-lymphocyte marker) positive cells were not induced by ureaplasmas. CD3 positive cells in the posterior mediastinal lymph node increased in ureaplasma exposed animals at 3,7 and 14 days $(p=0.002)$. Focal elastin depositions decreased in alveolar septa at 14 days ( $p=0.002$ ), whereas $\alpha$-SMA increased in arteries and bronchioli.

Conclusions: $U$. parvum induced a mild acute inflammatory response and changed elastin and $\alpha$-SMA deposition in the lung, which may affect lung structure and subsequent development.

\section{Introduction}

Chorioamnionitis that is often clinically asymptomatic is associated with the majority of early gestational preterm births [1, 2]. The fetus is born with inflamed lungs and often a systemic inflammatory response [3, 4]. This fetal lung inflammation is associated with the development of bronchopulmonary dysplasia (BPD) $[5,6]$. In experimental models, lipopolysaccharide (LPS) and intra-amniotic and/or maternal interleukin-1 (IL-1) can modulate lung development/maturation [7-12], but the major organisms associated with chorioamnionitis are Ureaplasma species, which are very small bacteria without a cell wall $[13,14]$. Ureaplasmas are chronically tolerated in the urogenital tracts of men and women and can be present in amniotic fluid without inducing preterm labor [15, 16]. Chronic fetal exposure to Ureaplasma parvum induced functional lung maturation 
in fetal lambs [17-19], but did not change lung function or modulate the lung injury and inflammation caused by high tidal volume ventilation [20]. Very short term intra-uterine exposures to ureaplasmas caused pulmonary inflammatory responses in fetal mice [21], baboons [22, 23] and rhesus macaque monkeys [24]. Short interval fetal exposures to ureaplasmas with subsequent ventilation for 14 days after preterm birth initiated fibrosis and altered developmental signaling in the lungs of preterm baboons [23], indicating that chronic postnatal ventilation aggravated the lung injury. It is however not clear when these structural changes occurred, or if ureaplasma exposure in utero alone was sufficient to induce developmental changes in the short term.

Given the chronic nature of ureaplasma infections, we hypothesized that $U$. parvum would induce an initial acute fetal lung inflammatory response that would lead to changes in lung development. Pregnant ewes were given $U$. parvum serovar 3 by intraamniotic injection 3, 7 or 14 days prior to preterm delivery at 124 days gestational age (GA). We evaluated inflammation in the lung and its draining lymph node, the posterior mediastinal lymph node (PMLN). Inflammatory cells were identified by histological and immunohistochemical analysis, using CD3 for T-cells [25], myeloperoxidase (MPO) for neutrophils and PU.1, a transcription factor which is highly expressed in differentiated alveolar macrophages $[25,26]$. To evaluate whether changes in lung development had occurred as a result of exposure to $U$. parvum we measured markers of lung damage and assessed changes in the structural proteins elastin and $\alpha$-SMA that are involved in alveolar septation [27-29].

\section{Materials and methods}

\section{Intra-amniotic injections}

All studies were approved by the Animal Ethics Committees at The University of Western Australia, the Queensland University of Technology and at the Cincinnati Children's Hospital Medical Center. Ureaplasmas were grown and prepared for the ultrasound guided injections as reported previously [17]. Time-mated ewes with singleton fetuses were randomized to receive either an intra-amniotic injection of Ureaplasma parvum serovar 3 ( $2 \times 10^{7}$ colony forming units) or media control at 110,117 or 121 days gestational age (GA) (Figure 1). Preterm lambs were delivered by Cesarean section at 124 days $\mathrm{GA}$ (term=150 days GA). Just prior to delivery each pregnant ewe was sedated and given spinal anesthesia with lidocaine. 


\section{Ureaplasma and media exposed animals}

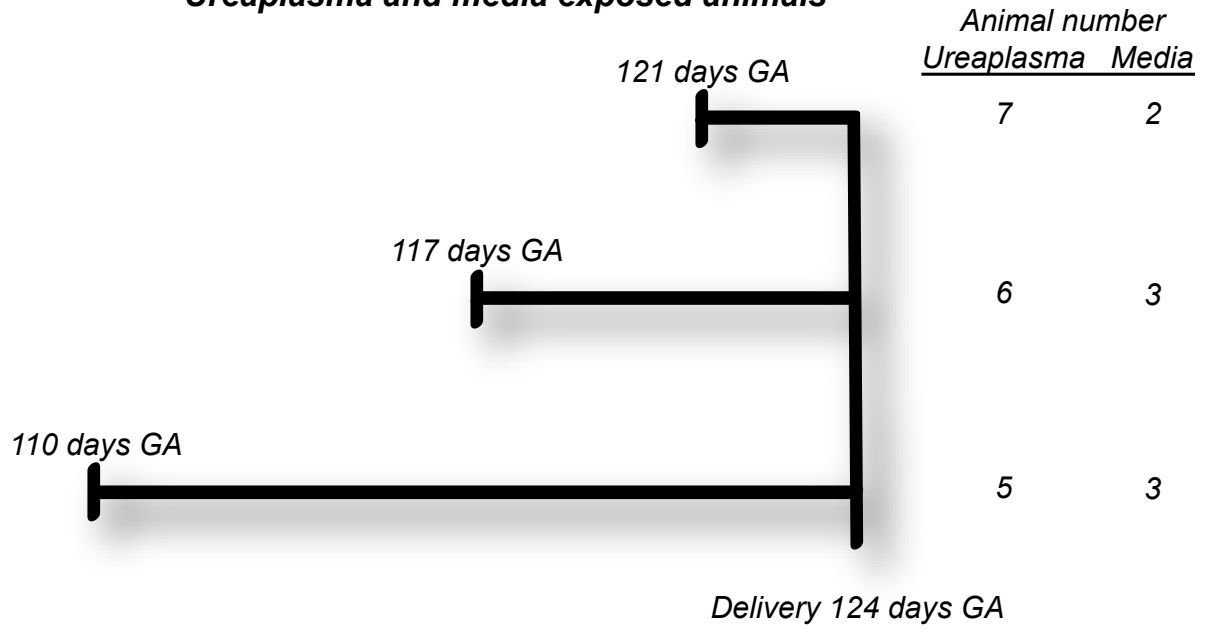

Figure 1: Study design.

Pregnant ewes received an intra-amniotic injection of $U$. parvum serovar 3 (UP) or media controls at 14 days, 7 days or 3 days before surgical delivery at 124 days gestational age (GA). One stillbirth in the $121 \mathrm{~d}$ media group and one malformed and growth restricted fetus in the $110 \mathrm{~d}$ ureaplasma exposed group were excluded. The media exposed animals were combined into a single group for analysis to create a group of sufficient sample size.

\section{Sample collection}

Ureaplasma titers were measured in amniotic fluid (AF) samples. Umbilical arterial blood was collected for blood gas and pH analysis (Rapidlab 865, Bayer Diagnostics, Pymble, NSW) and total and differential white blood cell counts. A maximal lung volume was measured ( $40 \mathrm{~cm} \mathrm{H}_{2} \mathrm{O}$ airway pressure) and the left lung was lavaged 3 times with $0.9 \%$ $\mathrm{NaCl}[30]$. The resultant bronchoalveolar lavage fluid (BALF) from the left lung was used for total and differential cell counts and protein measurements. The posterior mediastinal lymph node (PMLN) was fixed in $10 \%$ buffered formalin. The right upper lobe of the lung (RULL) was inflation fixed with $10 \%$ buffered formalin at $30 \mathrm{~cm} \mathrm{H}_{2} \mathrm{O}$ pressure $[31,32]$.

\section{Ureaplasma titers}

Ureaplasma colonization of the AF and lung tissue was measured as described previously [19].

\section{FACS analysis}

Single cell suspensions of inflammatory cells were recovered from tissue of the right lung [33] using the MACS cell separation system (Miltenyi Biotec GmbH, Germany). CD45 positive cells were isolated from the cell suspension with anti-CD45-biotin antibodies 
(AbD Serotec, MCA2220B). After a washing step to remove unbound antibody, MACS anti-biotin magnetic microbeads were added and the suspension was passed through MACS columns for separation of CD45 positive cells by magnetism. CD45 positive cells were counted and incubated with monoclonal anti major histocompatibility class II (MHC class II) antibody (VMRD, H42A). An IgG2a isotype antibody (Santa Cruz Biotechnology, sc-3878) was used as a negative control. MHC class II positive cells labeled with an anti-IgG2a-RPE secondary antibody (Southern Biotechnology Associates Inc., 1080-09) were counted by flow cytometry (BD FACSCantoll and BD FACSDiva software, Becton Dickinson, USA).

\section{Immunohistochemistry}

Paraffin embedded RULL sections ( $4 \mu \mathrm{m}$, transverse) were stained for CD3 (DAKO, A0452), myeloperoxidase (MPO) (DAKO, A0398), transcription factor PU.1 (Santa Cruz Biotechnology, sc-352) and alpha smooth muscle actin ( $\alpha$-SMA) (Sigma-Aldrich, A5228) [34]. Sections of the PMLN (4 $\mu$ m, transverse) were stained for CD3 only. Briefly, the sections were deparaffinized with xylol, $100 \%$ ethanol, $96 \%$ ethanol and $70 \%$ ethanol. Subsequently, endogenous peroxidase-activity was blocked by incubation with $0.3 \%$ or $0.5 \%$ hydrogen peroxide. Antigen retrieval was performed by incubating the slides in heated citrate buffer (DAKO Real Target Retrieval Solution 10x, S2031) for 30 minutes. In order to block nonspecific binding, the tissue sections were incubated with either $20 \%$ normal goat serum (NGS) or $5 \%$ bovine serum albumin (BSA) / phosphate buffered saline (PBS) in a humidified box for 30 minutes (this step was omitted for $\alpha$-SMA). After adding the primary antibody, the sections were incubated overnight at $4^{\circ} \mathrm{C}$. A negative control was included by incubating with $0.1 \%$ BSA/PBS (for CD3, MPO and PU.1) or $2 \%$ NGS/PBS (for $\alpha$-SMA) instead of the primary antibody. After incubation with polyclonal swine antirabbit biotin labeled secondary antibody (DAKO, E0353), the sections were incubated with StrepABComplex/HRP (DAKO, K0377). The sections were then washed with 0.1 $M$ acetate buffer and incubated for 4 minutes with nickel sulfate-diaminobenzidine (NiDAB) solution in a closed, dark box. Subsequently the tissue sections were rinsed with tris/saline and incubated with tris/cobalt. After counterstaining with $0.1 \%$ nuclear fast red, the sections were washed and finally dehydrated in a series of $70 \%, 96 \%$ and $100 \%$ ethanol, followed by xylol. Evaluation was performed by light microscopy (Axioskop 40, Zeiss, Germany) with LeicaQWin Pro v.3.4.0 software Leica Microsystems, Germany). Sections were scored for positive CD3, MPO and PU.1 staining with a semi-quantitative scoring system: 1 - little staining, 2 -some staining or 3 - heavy staining. The intensity of $\alpha$-SMA staining in arteries and bronchioli was quantified using Image J software (Rasband, W.S., ImageJ, U.S. National Institutes of Health, Bethesda, Maryland, USA) and presented as a percentage of arterial wall surface area and entire bronchus surface area 
Chapter 3

staining, respectively.

\section{Immunofluorescence}

U. parvum serovar 3 staining was performed on paraffin embedded RULL sections $(4 \mu \mathrm{m}$, transverse) using a protocol modified from Moss et al [17]. Aspecific binding was blocked using $20 \%$ NGS/PBS, prior to overnight incubation at $4^{\circ} \mathrm{C}$ with polyclonal rabbit-anti-U. parvum serovar 3 antibody. After incubation with polyclonal swine anti-rabbit biotin labeled secondary antibody (DAKO, E0353) for 1 hour, the sections were incubated with fluorescent quantum dots (Qdot 585, streptavidin conjugate, Invitrogen, Q10111MP) for 30 minutes at room temperature in a closed, dark box. Subsequently sections were washed in PBS and mounted in glycerol/DABCO anti-fade/DAPI. Imaging was performed with two photon microscopy (Leica TCS SP5 system, Leica, Germany), using a Compact Ultrafast Ti:Sapphire Laser (Chameleon, Coherent, California, USA) for excitation at a wavelength of $840 \mathrm{~nm}$ and Leica Application Suite Advanced Fluorescence imaging software (Leica Microsystems, Mannheim, Germany).

\section{Elastin staining}

Elastin staining was performed on RULL sections (4 $\mu \mathrm{m}$, transverse) [29]. Briefly, the sections were deparaffinized in an ethanol series and incubated for 20 minutes in Weigerts Resorcine-Fuchsine (Chroma, $2 \mathrm{E} 030$ ) at $60-70^{\circ} \mathrm{C}$. After rinsing with water, the sections were incubated for 3 minutes in a tartrazin solution at room temperature. Subsequently the sections were washed and dehydrated in ethanol and xylol. Elastin foci were counted using Image J software (Rasband, W.S., ImageJ, U.S. National Institutes of Health, Bethesda, Maryland, USA).

\section{Surfactant protein and cytokine mRNA}

Surfactant protein A, B and C mRNA levels and pro-inflammatory cytokine mRNAs for interleukin (IL) IL-16 and IL-6 were measured by RNAse protection analysis [35], using RNA from the right lower lobe. Briefly, solution hybridization was performed for $16 \mathrm{~h}$ using a molar excess of ( $\alpha$-P32) UTP labeled riboprobes. Un-hybridized single-strand RNA was digested with RNase A/T1 (Pharmingen, San Diego, CA). RNase was then inactivated and protected RNA was precipitated using the RPA IIITM inactivation buffer (Ambion, Austin TX). The ribosomal protein mRNA L32 was used as an internal control (E4). The protected fragments were resolved on $6 \%$ polyacrylamide $8 \mathrm{~mol} / \mathrm{L}$ urea gels, visualized by autoradiography, and quantified on a Phosphorlmager using ImageQuant v1.2 software (Molecular Dynamics, Sunnyvale, CA). Results from the control group were standardized to 1 and results from ureaplasma exposed groups were expressed as fold changes. 


\section{Measurement of total protein}

Total protein in the BAL fluid was measured using the Lowry assay [36].

\section{Data Analysis}

Results are given as means \pm standard error of means (SEM). The groups were compared using one-way ANOVA with Dunnett's test for post-hoc analysis or a non-parametric Kruskal-Wallis ANOVA with Dunn's test for post-hoc analysis as appropriate. Two group comparisons were done by Mann-Whitney test. Statistical analysis was performed by GraphPad Prism v5.0. Significance was accepted at $p<0.05$.

\section{Results}

\section{Fetuses exposed to $U$. parvum serovar 3 and media control}

Of the 28 animals randomized, there was one stillbirth in the control group and one malformed and growth restricted fetus in the 14 day ureaplasma exposure group: both animals were excluded from the analysis. Body weight and cord blood $\mathrm{pH}$ values were not altered in fetuses exposed to ureaplasmas compared to controls (Table 1). The lung gas volume (V40), measured at a pressure of $40 \mathrm{~cm} \mathrm{H}_{2} \mathrm{O}$, showed a trend for decrease in fetuses delivered 3 days after exposure to ureaplasmas compared to controls, but this was not significant.

\section{Culture and fluorescent immunohistochemistry for Ureaplasma parvum}

Cultures of amniotic fluid (AF) and lung tissue of animals exposed to ureaplasmas were all positive, with $>1.0 \times 10^{10} \mathrm{CFU} / \mathrm{mL}$ in $\mathrm{AF}$. The lung tissues contained ureaplasmas at average titers of $2.3 \times 10^{6} \mathrm{CFU} / \mathrm{g}$ at 3 days, $5.3 \times 10^{5} \mathrm{CFU} / \mathrm{g}$ at 7 days and $1.7 \times 10^{6} \mathrm{CFU} / \mathrm{g}$ at 14 days of exposure. No ureaplasmas were detected in the AF or lungs of fetuses exposed to media. Immunohistochemistry for $U$. parvum in the fetal lung demonstrated organisms in the alveoli of the ureaplasma-exposed animals (Figure 2A). No ureaplasmas were found in lung sections of media exposed animals (Figure 2B).

Table 1: Observations of fetal lambs (GA 124 days) exposed to U. parvum.

\begin{tabular}{|c|c|c|c|c|}
\hline & $\begin{array}{l}\text { Control } \\
(n=8)\end{array}$ & $\begin{array}{l}\text { UP 3d } \\
(n=7)\end{array}$ & $\begin{array}{l}\text { UP 7d } \\
(n=6)\end{array}$ & $\begin{array}{l}\text { UP 14d } \\
(n=5)\end{array}$ \\
\hline \multicolumn{5}{|c|}{ Assessments at delivery } \\
\hline Body weight (kg) & $2.7 \pm 0.1$ & $2.7 \pm 0.1$ & $2.8 \pm 0.1$ & $2.9 \pm 0.1$ \\
\hline Cord blood $\mathrm{pH}$ & $7.1 \pm 0.03$ & $7.2 \pm 0.03$ & $7.2 \pm 0.03$ & $7.2 \pm 0.03$ \\
\hline \multicolumn{5}{|c|}{ White blood cell counts in cord blood ( $\times 10^{9}$ cells/L) } \\
\hline
\end{tabular}


Chapter 3

\begin{tabular}{l|llll}
\hline \multicolumn{1}{l}{$\begin{array}{l}\text { Control } \\
(\mathbf{n}=8)\end{array}$} & $\begin{array}{l}\text { UP 3d } \\
(\mathbf{n}=7)\end{array}$ & $\begin{array}{l}\text { UP 7d } \\
(\mathbf{n}=6)\end{array}$ & $\begin{array}{l}\text { UP 14d } \\
(\mathbf{n}=5)\end{array}$ \\
\hline Lymphocytes & $2.3 \pm 0.2$ & $2.6 \pm 1.0$ & $2.9 \pm 0.2$ & $2.9 \pm 0.4$ \\
Neutrophils & $0.6 \pm 0.1$ & $0.4 \pm 0.1$ & $0.5 \pm 0.02$ & $0.7 \pm 0.1$ \\
Monocytes & $0.2 \pm 0.03$ & $0.2 \pm 0.1$ & $0.2 \pm 0.1$ & $0.1 \pm 0.02$ \\
\hline Cytokine and surfactant protein mRNA levels in the lung & \\
\hline IL-16 & $1.0 \pm 0.1$ & $6.7 \pm 3.8$ & $0.8 \pm 0.3$ & $2.0 \pm 0.5$ \\
IL-6 & $1.0 \pm 0.1$ & $5.5 \pm 3.3$ & $0.8 \pm 0.1$ & $1.2 \pm 0.1$ \\
SP-A & $1.0 \pm 0.2$ & $1.9 \pm 1.0$ & $3.2 \pm 2.2$ & $1.4 \pm 0.6$ \\
SP-B & $1.0 \pm 0.1$ & $1.3 \pm 0.3$ & $1.9 \pm 0.9$ & $1.5 \pm 0.4$ \\
SP-C & $1.0 \pm 0.1$ & $0.8 \pm 0.1$ & $1.6 \pm 0.5$ & $1.2 \pm 0.2$ \\
Total protein ( $\mu$ g / mL & $245 \pm 26$ & $319 \pm 57$ & $332 \pm 87$ & $246 \pm 64$ \\
BALF) & & & & \\
V4O (mL/ kg bodyweight) & $12.2 \pm 2.0$ & $6.2 \pm 0.6$ & $19.3 \pm 4.0$ & $14.5 \pm 4.3$
\end{tabular}

UP - Ureaplasma parvum. IL - interleukin. SP - surfactant protein. BALF - bronchoalveolar lavage fluid. V40 - lung volume at $40 \mathrm{~cm} \mathrm{H}_{2} \mathrm{O}$. Data expressed as mean $\pm \mathrm{SEM} .{ }^{*} p<0.05$ versus controls using a one-way ANOVA with Dunnett's post hoc test or a non-parametric Kruskal-Wallis ANOVA with Dunn's test for post-hoc analysis as appropriate.
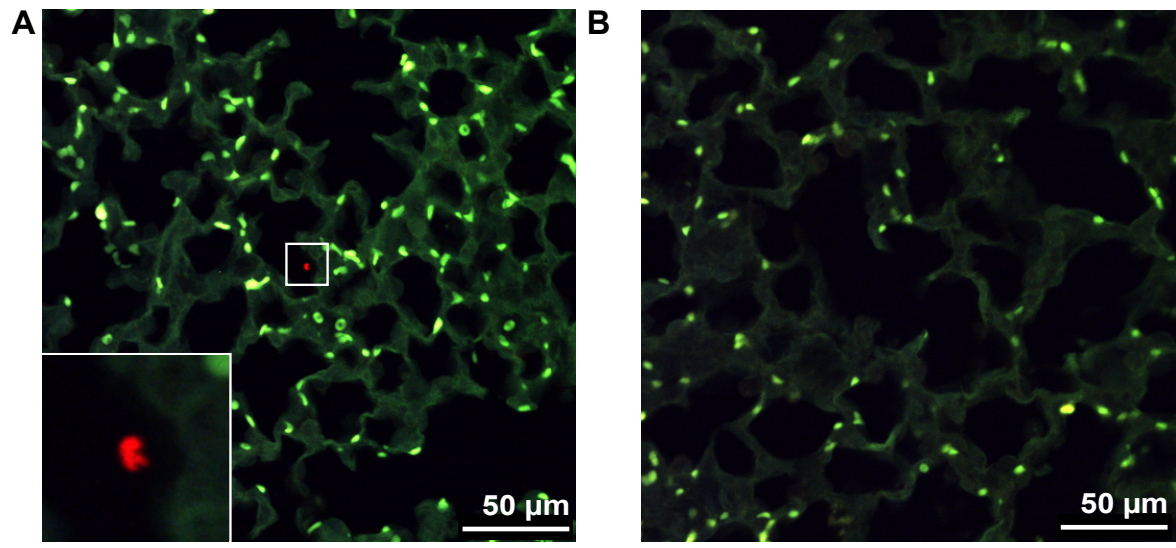

Figure 2: U. parvum serovar 3 in the lung.

Fluorescent immunohistochemistry performed on lung tissue from fetal lambs exposed to ureaplasmas (UP) for 3 days (A) and media (B). Ureaplasmas were detected by culture in all ureaplasma exposed lungs and not in media exposed lungs. Lung tissue is depicted in green, UP in red.

\section{Systemic and local inflammatory mediators}

Fetal systemic inflammation was assessed by the number of lymphocytes, neutrophils 
and monocytes in the cord blood. There were no changes in the levels of systemic inflammatory cells in ureaplasma exposed fetuses compared to controls (Table 1).

Inflammation in the lung was assessed by the number of neutrophils, monocytes and lymphocytes in the bronchoalveolar lavage fluid (BALF). The absolute BALF neutrophil count increased after 3 days of exposure (Figure $3 A$ ). The number of monocytes did not change significantly in the BALF of ureaplasma exposed fetuses (Figure 3B). In most BALF samples no lymphocytes were counted, in either control or experimental groups (data not shown). Therefore, ureaplasmas induced a modest neutrophil response. Markers for inflammatory cells were used to assess the inflammatory cells in lung tissue. MPOpositive cells were increased in the UP-3 day fetuses, but this increase was not consistent in the lung tissue of UP-7 day and UP-14 day fetuses (Figure 3C). Cells expressing PU.1, a macrophage specific transcription factor, did not increase in the lung tissue (Figure 3D). The percentage of MHC class II positive cells in the CD45 cell population increased after 14 days of ureaplasma exposure, as measured by flow cytometry (Figure $3 \mathrm{E})$. This analysis was not performed for UP-3 or UP-7 day animals.

A

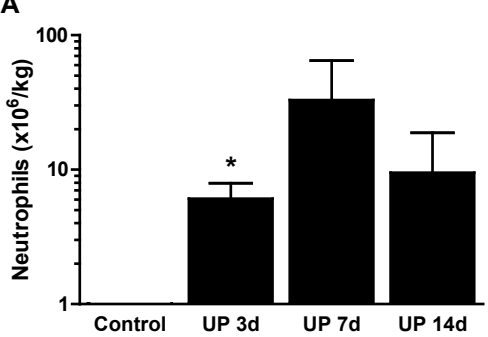

C

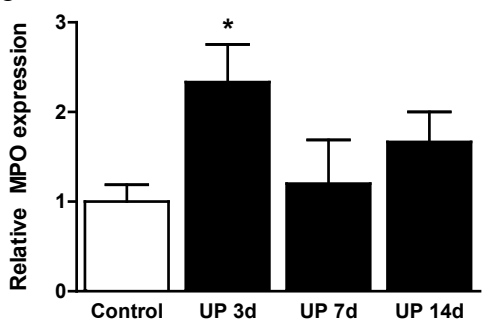

B

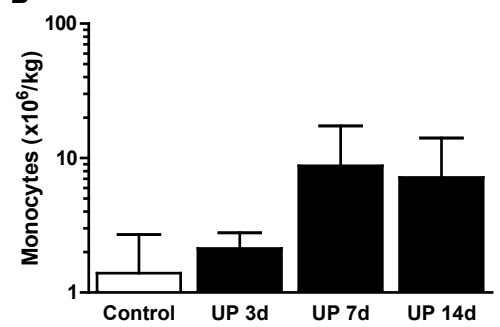

D

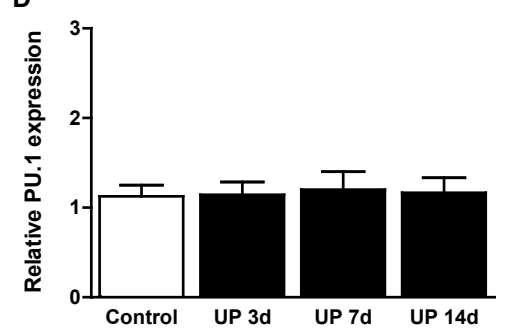

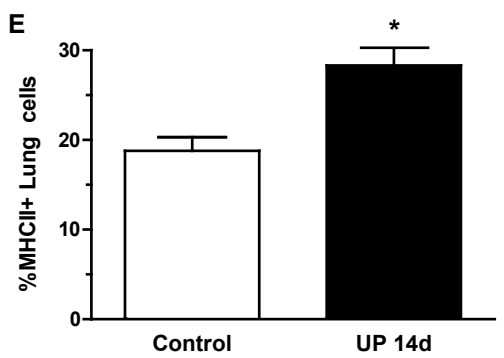


Figure 3: Inflammatory cell numbers in bronchoalveolar lavage fluid (BALF) and myeloperoxidase (MPO), transcription factor PU.1 and major histocompatibility complex (MHC) class II positive cells in the lung.

A The number of neutrophils was increased in the BALF of UP-3 day fetuses compared to controls. * $p<0.05$ versus controls using a Kruskal-Wallis ANOVA B The number of monocytes did not change significantly in the BALF of ureaplasma exposed fetuses. C MPO positive cells increased in lung tissue after 3 days of ureaplasma exposure compared to controls. ${ }^{*} p<0.05$ versus controls using a one-way ANOVA with Dunnett's post hoc test. D The PU.1 positive cells in lung tissue exposed to ureaplasmas did not differ significantly from controls. E MHC class II positive cells increased in the lungs of UP-14 day animals. ${ }^{*} p<0.05$ versus controls using a Mann-Whitney test.

Ureaplasma exposure did not change mRNA levels of the pro-inflammatory cytokines IL16 and IL-6 in the lung, nor did it increase the mRNA levels of surfactant proteins A, B and $C$ (Table 1). Furthermore there was no increase of total protein levels in the BALF (Table 1).
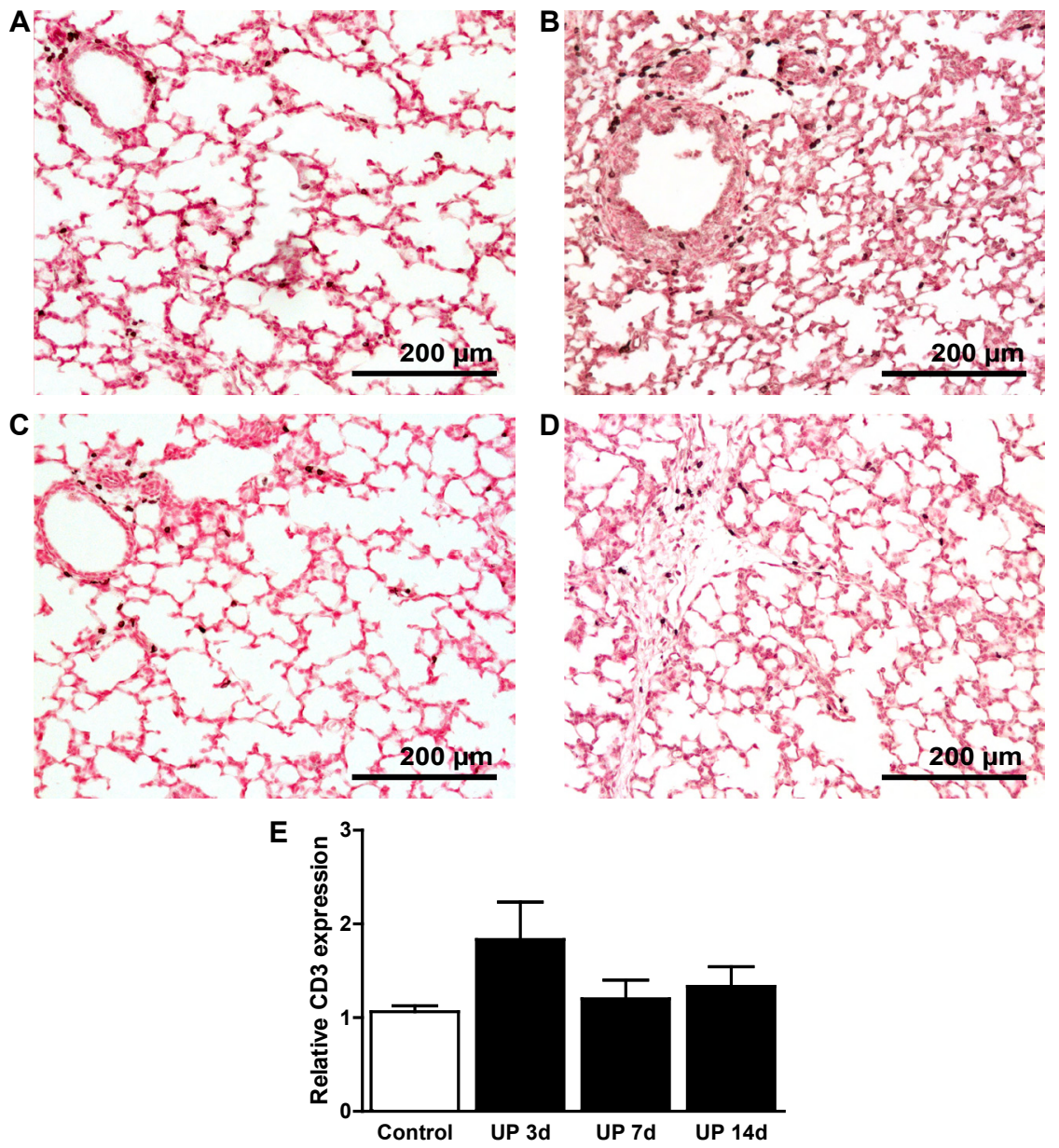
Figure 4: CD3 positive cells in the fetal ovine lung after exposure to U. parvum serovar 3. Expression of CD3 in the lung was evaluated in controls (A), and after exposure to ureaplasmas (UP) for 3 days (B), 7 days (C) or 14 days (D) before delivery at 124 days GA. E There were no changes in CD3 positive cells as a result of exposure to ureaplasmas. ${ }^{*} p<0.05$ versus controls using a one-way ANOVA with Dunnett's post hoc test.

CD3 positive cells were not increased in the lungs of animals exposed to ureaplasmas (Figure 4). However, compared to media exposed fetuses (Figure 5A) CD3 positive cells increased in the posterior mediastinal lymph node (PMLN) of the fetuses that had been exposed to ureaplasmas for 3 days (Figure 5B), 7 days (Figure 5C) or 14 days (Figure 5D). Figure $5 \mathrm{E}$ shows the increases between the different experimental groups. There was a tendency for increased PMLN weight after exposure to ureaplasmas, but this was not significant (Figure 5F).
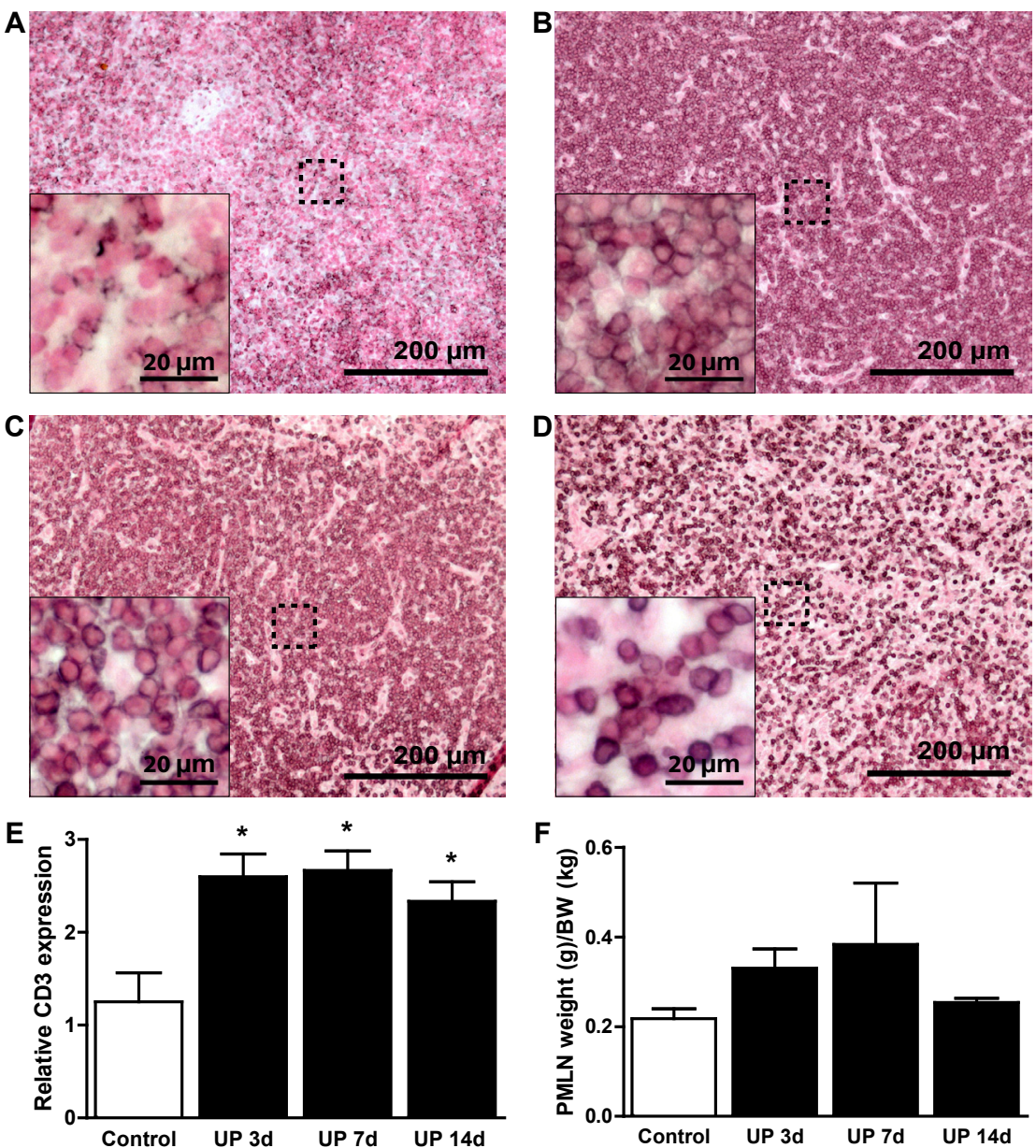

Figure 5: CD3 expression in the posterior mediastinal lymph node (PMLN). 
Expression of $C D 3$ in the PMLN was evaluated in controls (A), and after exposure to ureaplasmas (UP) at 3 days (B), 7 days (C) or 14 days (D) before delivery at 124 days GA. E Levels of CD3 positive cells were increased 3,7 and 14 days after exposure to ureaplasmas compared to controls. F PMLN weight, relative to body weight. * $p<0.05$ versus controls using a one-way ANOVA with Dunnett's post hoc test.

\section{Structural protein expression in the lung}

The elastin foci on alveolar septa were counted on the lung sections (Figure 6A-D). In the UP-14 day fetal lungs decreased numbers of elastin foci were observed. The elastin was localized more diffusely compared to lungs after no exposure or shorter ureaplasma exposure times. A small increase of elastin foci was seen in UP-3 day fetal lungs (Figure $6 E$ ). The lungs of UP-3 day animals inflated less well, leading to a higher density of the lung and the apparent increase in elastin foci.
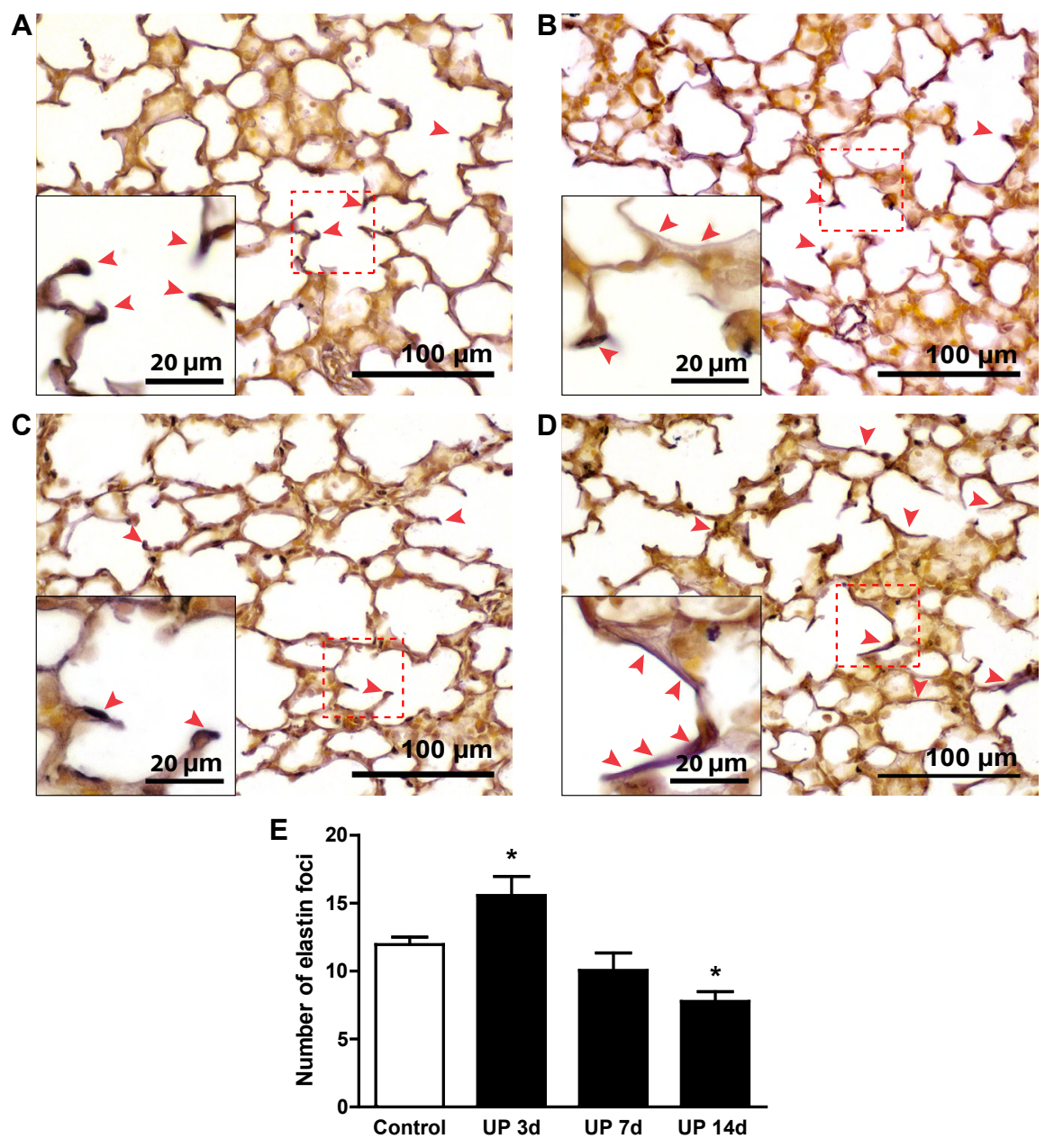
Figure 6: Expression of elastin in the lungs

of controls (A), and after an exposure to ureaplasmas (UP) for 3 days (B), 7 days (C) and 14 days (D) before delivery at 124 days GA. Red arrows indicate locations of focal expression of elastin. E The number of elastin foci was increased in lungs 3 days after ureaplasma exposure. At 14 days the number of elastin foci decreased. * $p<0.05$ versus controls using a one-way ANOVA with Dunnett's post hoc test.

The intensity of $\alpha$-SMA staining was measured for arteries and bronchioli in the lung sections (Figure 7A-D). $\alpha$-SMA staining was increased in arteries of UP-14 day fetuses (Figure 7E). In bronchioli $\alpha$-SMA expression was increased in UP-3 day fetuses and remained high in UP-7 day and UP-14 day fetuses (Figure 7F).
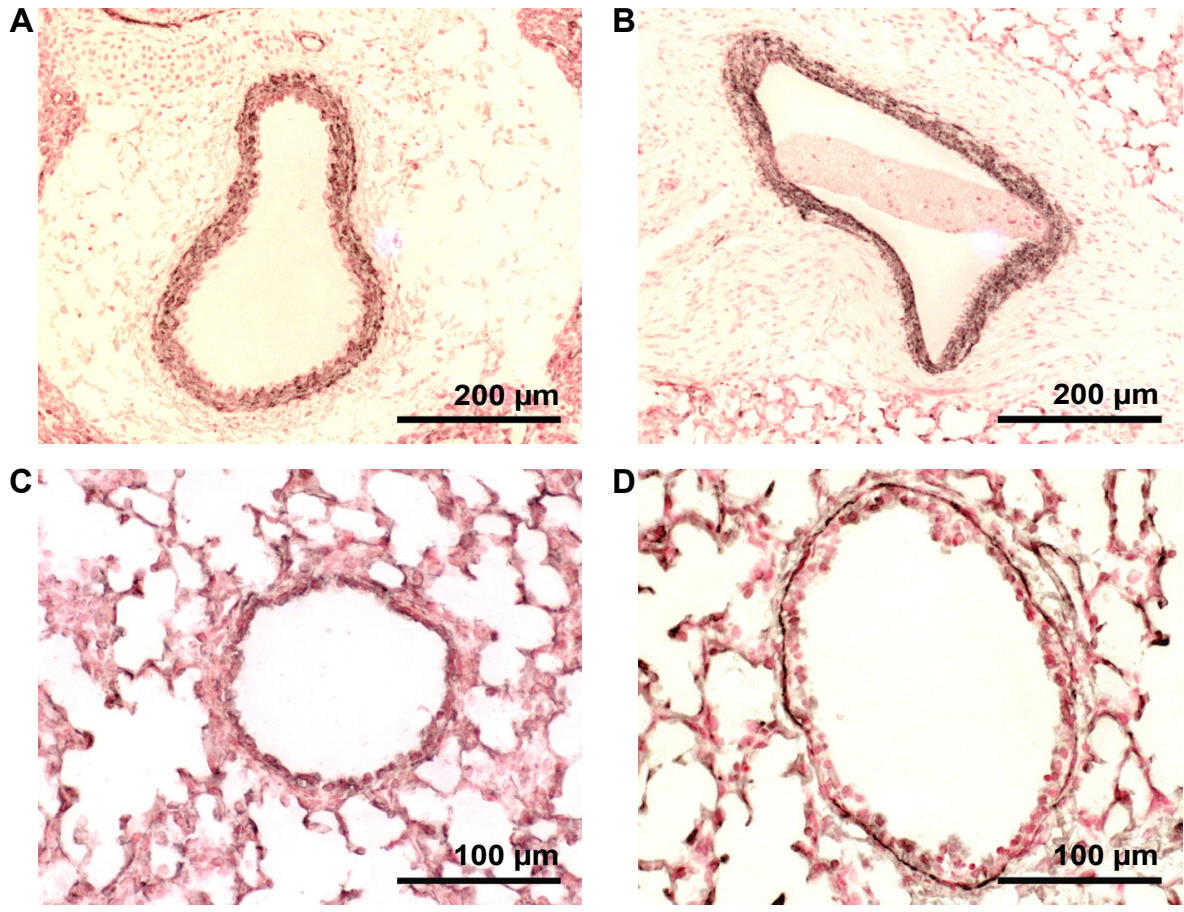

E

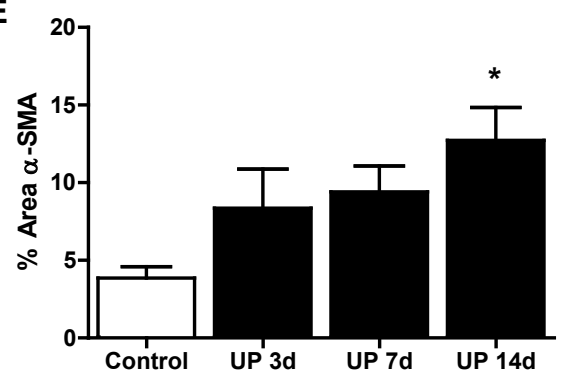

$\mathbf{F}$

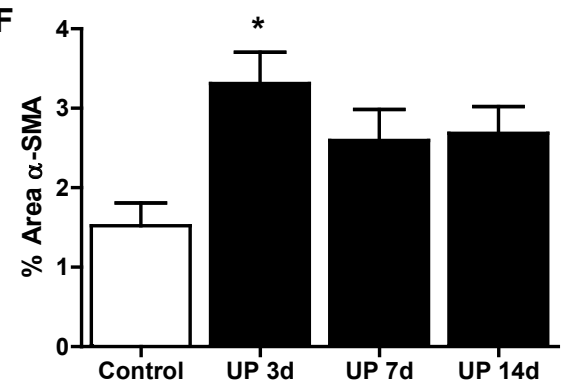

Figure 7: Expression of $\alpha$-SMA in the lungs.

Expression of $\alpha$-SMA in the arteries of controls (A) and after exposure to ureaplasmas (UP) for 14 
days (B), and in the bronchioli of controls (C) and after 3 days of ureaplasma exposure (D) before delivery at 124 days GA. E The intensity of $\alpha$-SMA staining in the pulmonary vascular wall was increased 14 days after ureaplasma exposure. $\mathbf{F}$ The intensity of $\alpha$-SMA staining in bronchioli was increased 3 days after ureaplasma exposure. ${ }^{*} p<0.05$ versus controls using a one-way ANOVA with Dunnett's post hoc test.

\section{Discussion}

The effect of short term intra-uterine ureaplasma exposure on lung development has previously only been studied after postnatal ventilation treatment in preterm baboons [23]. In this study we show that short term exposure of fetal lambs to $U$. parvum serovar 3 in utero induced an inflammatory response and structural changes in the lung at 124 days GA. Neutrophils were recruited into the alveolar compartment of the lungs within 3 days of intra-amniotic ureaplasma injection. After 7 days of exposure to ureaplasmas the neutrophils in the lung decreased and after 14 days the MHC class II positive cells increased, although macrophage levels were not elevated. Simultaneously, T-lymphocytes were increased in the posterior mediastinal lymph node, which was reflected in a tendency for increased weight of the PMLN. This pulmonary inflammation was not associated with increased inflammatory cell counts in cord blood, which is consistent with previous reports of intra-amniotic ureaplasma exposure in other animal models [17-19, 24]. Long term exposure to $U$. parvum serovar 3 or 6 (21-70 days of exposure, surgical delivery at 125 days GA) did not elicit an increase in inflammatory cells in cord blood of fetal lambs, despite a marked increase in the inflammatory cell count in bronchoalveolar lavage fluid [17-19]. In fetal rhesus macaques inoculated with U. parvum serovar 1 at 4-9 days before delivery at 145 days GA (term = 167 days GA), leukocytes were strongly increased in the amniotic fluid and the fetal lungs [24].

Interestingly, macrophages were not involved in the pulmonary inflammatory response to ureaplasmas in our study. The lack of a macrophage response to this pulmonary inflammation is quite different from the inflammatory response that is induced by intraamniotic lipopolysaccharide (LPS) in fetal lambs [26, 37]. With LPS as the agonist immature monocytes express PU.1 and mature to macrophages within days of exposure to LPS. The differences between an LPS and ureaplasma induced inflammatory response are further illustrated by the observation that the cytokines IL- $1 \beta$ and IL- 6 and surfactant proteins A, $B$ and $C$ were not significantly increased and that there was an absence of lymphocytes in the lungs after exposure to ureaplasma, whereas these factors did increase after LPS exposure $[10,35,38]$. This is supported by a study performed by Menon and colleagues [39], who reported that in cultured human fetal membranes ureaplasmas caused a much milder cytokine response than LPS. In this model ureaplasmas only triggered an increase in levels of tumor necrosis factor $\alpha$ (TNF $\alpha)$ and IL-10. Fetal sheep neither make 
much TNF $\alpha$ nor respond to TNF $\alpha[40,41]$. Perhaps the different responses of the innate immune system result from how and when the immune system makes first contact with the microbe [25]. LPS is a substance found on the cell wall of Gram-negative bacteria and is recognized by a different array of pattern recognition receptors than bacteria like ureaplasma, which do not have cell walls. LPS triggers the immune response by binding to the CD14 receptor on antigen presenting cells, leading to activation of Toll-like receptor (TLR) 4 and the MyD88 dependent and independent pathways. This subsequently leads to early and late nuclear factor kappa B (NF-KB) activation, inducing pro-inflammatory gene expression repetitively [25]. Conversely, ureaplasmas activate NF-KB via TLR 1, 2 and 6 signaling with lipoproteins, predominantly the multiple banded antigen, on its cell membrane [42]. It also binds to mannose-binding lectin through terminal mannose residues [43], activating the lectin pathway of complement activation. These differences in the way the immune response is activated may very well lead to the different inflammatory phenotypes in the fetus.

In the developing fetal lung alveolar septation is orchestrated by a number of structural proteins, among which elastin and alpha smooth muscle actin ( $\alpha$-SMA) play important roles [27-29, 44, 45]. Clustering of elastin and $\alpha-S M A$ at the tips of alveolar septa identifies the sites of budding for new alveoli [27, 44]. If immature lungs are exposed to mechanical ventilation or chorioamnionitis at this point during development, focal elastin expression is diminished and a more diffuse elastin expression develops along the alveolar cell wall $[28,29]$. As a result a simplification of lung structure is observed, with fewer but larger alveoli. This phenomenon has been reported in mechanically ventilated infants and in patients with BPD [27, 28, 46-50]. Infants with bronchopulmonary dysplasia (BPD) also have increased numbers of $\alpha$-SMA positive cells, or myofibroblasts, in their lungs, in relation to the severity of the disease [51]. Furthermore ureaplasma respiratory tract colonization in premature infants was associated with an increased incidence of BPD $[6,52,53]$. Therefore we tested if changes in elastin organization and $\alpha$-SMA expression occurred in premature lungs that were exposed to ureaplasmas. A decrease in foci of concentrated elastin on alveolar septa was noted 14 days after exposure to ureaplasmas, along with a more diffuse, dysmorphic expression of elastin elsewhere in the alveolar walls. $\alpha$-SMA expression increased in pulmonary arteries and bronchioli after exposure to ureaplasmas. This decrease in elastin foci and elevated $\alpha$-SMA expression in arteries and bronchioli may disrupt the further development of the lung. These findings are consistent with observations in preterm ventilated, ureaplasma infected baboons by Viscardi and colleagues [23]. In contrast, it was recently reported that long term exposure to $U$. parvum serovar 3 or 6 (70 days of exposure, delivery at 125 days GA) did lead to a functional maturation in the lungs but without causing sustained effects on airspace and vascular development in fetal lambs [54]. The effects 


\section{Chapter 3}

of resuscitation, mechanical ventilation and oxygen therapy need to be further studied to determine the effects on the long term pulmonary outcome [55].

This study raises the question as to whether other sites of first contact, like the developing fetal skin and gastrointestinal tract, respond to ureaplasmas similarly. The developing gut in sheep is affected by exposure to LPS [56], however it is unclear if this is also true for ureaplasma exposure.

Our results support the hypothesis that ureaplasmas induce an acute inflammatory response in the fetal lung, as a site in direct contact with the contaminated amniotic fluid. Our findings suggest that a short term exposure to ureaplasmas is sufficient to induce structural changes in elastin deposition antenatally, which may affect further alveolarization of the lung. This would explain why postnatal administration of antibiotics to counteract the ureaplasma infection has not been found to improve lung function [5759].

\section{References}

1. Preterm birth: Causes, consequences and prevention, ed. R.E. Behrman and A. Stith Butler 2007, Washington: National Academies Press.

2. Goldenberg, R.L., Hauth, J.C., and Andrews, W.W., Intrauterine infection and preterm delivery. N Engl J Med, 2000. 342(20): p. 1500-7.

3. Chaiworapongsa, T., Romero, R., Kim, J.C., Kim, Y.M., Blackwell, S.C., Yoon, B.H., and Gomez, R., Evidence for fetal involvement in the pathologic process of clinical chorioamnionitis. Am J Obstet Gynecol, 2002. 186(6): p. 1178-82.

4. Watterberg, K.L., Demers, L.M., Scott, S.M., and Murphy, S., Chorioamnionitis and early lung inflammation in infants in whom bronchopulmonary dysplasia develops. Pediatrics, 1996. 97(2): p. 210-5.

5. Speer, C.P., Chorioamnionitis, postnatal factors and proinflammatory response in the pathogenetic sequence of bronchopulmonary dysplasia. Neonatology, 2009. 95(4): p. 35361.

6. Schelonka, R.L., Katz, B., Waites, K.B., and Benjamin, D.K., Jr., Critical appraisal of the role of Ureaplasma in the development of bronchopulmonary dysplasia with metaanalytic techniques. Pediatr Infect Dis J, 2005. 24(12): p. 1033-9.

7. Willet, K.E., Jobe, A.H., Ikegami, M., Newnham, J., Brennan, S., and Sly, P.D., Antenatal endotoxin and glucocorticoid effects on lung morphometry in preterm lambs. Pediatr Res, 2000. 48(6): p. 782-8.

8. Kallapur, S.G., Nitsos, I., Moss, T.J., Polglase, G.R., Pillow, J.J., Cheah, F.C., Kramer, B.W., Newnham, J.P., Ikegami, M., and Jobe, A.H., IL-1 mediates pulmonary and systemic inflammatory responses to chorioamnionitis induced by lipopolysaccharide. Am J Respir Crit Care Med, 2009. 179(10): p. 955-61.

9. Bry, K., Lappalainen, U., and Hallman, M., Intraamniotic interleukin-1 accelerates surfactant protein synthesis in fetal rabbits and improves lung stability after premature birth. J Clin Invest, 1997. 99(12): p. 2992-9.

10. Kramer, B.W., Moss, T.J., Willet, K.E., Newnham, J.P., Sly, P.D., Kallapur, S.G., Ikegami, M., and Jobe, A.H., Dose and time response after intraamniotic endotoxin in preterm lambs. Am J 
Respir Crit Care Med, 2001. 164(6): p. 982-8.

11. Ye, X., Acharya, R., Herbert, J.B., Hamilton, S.E., and Folkesson, H.G., IL-1beta stimulates alveolar fluid absorption in fetal guinea pig lungs via the hypothalamus-pituitary-adrenal gland axis. Am J Physiol Lung Cell Mol Physiol, 2004. 286(4): p. L756-66.

12. Norlin, A. and Folkesson, H.G., Alveolar fluid clearance in late-gestational guinea pigs after labor induction: mechanisms and regulation. Am J Physiol Lung Cell Mol Physiol, 2001. 280(4): p. L606-16.

13. Yoon, B.H., Chang, J.W., and Romero, R., Isolation of Ureaplasma urealyticum from the amniotic cavity and adverse outcome in preterm labor. Obstet Gynecol, 1998. 92(1): p. 7782.

14. Schelonka, R.L. and Waites, K.B., Ureaplasma infection and neonatal lung disease. Semin Perinatol, 2007. 31(1): p. 2-9.

15. Perni, S.C., Vardhana, S., Korneeva, I., Tuttle, S.L., Paraskevas, L.R., Chasen, S.T., Kalish, R.B., and Witkin, S.S., Mycoplasma hominis and Ureaplasma urealyticum in midtrimester amniotic fluid: association with amniotic fluid cytokine levels and pregnancy outcome. Am J Obstet Gynecol, 2004. 191(4): p. 1382-6.

16. Iwasaka, T., Wada, T., Kidera, Y., and Sugimori, H., Hormonal status and mycoplasma colonization in the female genital tract. Obstet Gynecol, 1986. 68(2): p. 263-6.

17. Moss, T.J., Knox, C.L., Kallapur, S.G., Nitsos, I., Theodoropoulos, C., Newnham, J.P., Ikegami, M., and Jobe, A.H., Experimental amniotic fluid infection in sheep: effects of Ureaplasma parvum serovars 3 and 6 on preterm or term fetal sheep. Am J Obstet Gynecol, 2008. 198(1): p. 122 e1-8.

18. Moss, T.J., Nitsos, I., Ikegami, M., Jobe, A.H., and Newnham, J.P., Experimental intrauterine Ureaplasma infection in sheep. Am J Obstet Gynecol, 2005. 192(4): p. 1179-86.

19. Moss, T.J., Nitsos, I., Knox, C.L., Polglase, G.R., Kallapur, S.G., Ikegami, M., Jobe, A.H., and Newnham, J.P., Ureaplasma colonization of amniotic fluid and efficacy of antenatal corticosteroids for preterm lung maturation in sheep. Am J Obstet Gynecol, 2009. 200(1): p. 96 e1-6.

20. Polglase, G.R., Hillman, N.H., Pillow, J.J., Nitsos, I., Newnham, J.P., Knox, C.L., Kallapur, S.G., and Jobe, A.H., Ventilation mediated injury following preterm delivery of Ureaplasma parvum colonized fetal lambs. Pediatr Res.

21. Normann, E., Lacaze-Masmonteil, T., Eaton, F., Schwendimann, L., Gressens, P., and Thebaud, B., A novel mouse model of Ureaplasma-induced perinatal inflammation: effects on lung and brain injury. Pediatr Res, 2009. 65(4): p. 430-6.

22. Yoder, B.A., Coalson, J.J., Winter, V.T., Siler-Khodr, T., Duffy, L.B., and Cassell, G.H., Effects of antenatal colonization with ureaplasma urealyticum on pulmonary disease in the immature baboon. Pediatr Res, 2003. 54(6): p. 797-807.

23. Viscardi, R.M., Atamas, S.P., Luzina, I.G., Hasday, J.D., He, J.R., Sime, P.J., Coalson, J.J., and Yoder, B.A., Antenatal Ureaplasma urealyticum respiratory tract infection stimulates proinflammatory, profibrotic responses in the preterm baboon lung. Pediatr Res, 2006. 60(2): p. 141-6.

24. Novy, M.J., Duffy, L., Axthelm, M.K., Sadowsky, D.W., Witkin, S.S., Gravett, M.G., Cassell, G.H., and Waites, K.B., Ureaplasma parvum or Mycoplasma hominis as sole pathogens cause chorioamnionitis, preterm delivery, and fetal pneumonia in rhesus macaques. Reprod Sci, 2009. 16(1): p. 56-70.

25. Elgert, K.D., Immunology: understanding the immune system. 2nd ed. Vol. 1. 2009, Hoboken, New Jersey: Wiley-Blackwell. 726.

26. Kramer, B.W., Joshi, S.N., Moss, T.J., Newnham, J.P., Sindelar, R., Jobe, A.H., and Kallapur, S.G., Endotoxin-induced maturation of monocytes in preterm fetal sheep lung. Am J Physiol Lung Cell Mol Physiol, 2007. 293(2): p. L345-53. 
27. Burri, P.H., Structural aspects of postnatal lung development - alveolar formation and growth. Biol Neonate, 2006. 89(4): p. 313-322.

28. Bland, R.D., Ertsey, R., Mokres, L.M., Xu, L., Jacobson, B.E., Jiang, S., Alvira, C.M., Rabinovitch, M., Shinwell, E.S., and Dixit, A., Mechanical ventilation uncouples synthesis and assembly of elastin and increases apoptosis in lungs of newborn mice. Prelude to defective alveolar septation during lung development? Am J Physiol Lung Cell Mol Physiol, 2008. 294(1): p. L3-L14.

29. Kramer, B.W., Albertine, K.H., Moss, T.J., Nitsos, I., Ladenburger, A., Speer, C.P., Newnham, J.P., and Jobe, A.H., All-trans retinoic acid and intra-amniotic endotoxin-mediated effects on fetal sheep lung. Anat Rec (Hoboken), 2008. 291(10): p. 1271-7.

30. Jobe, A.H., Newnham, J.P., Willet, K.E., Moss, T.J., Gore Ervin, M., Padbury, J.F., Sly, P., and Ikegami, M., Endotoxin-induced lung maturation in preterm lambs is not mediated by cortisol. Am J Respir Crit Care Med, 2000. 162(5): p. 1656-61.

31. Kramer, B.W., Kramer, S., Ikegami, M., and Jobe, A.H., Injury, inflammation, and remodeling in fetal sheep lung after intra-amniotic endotoxin. Am J Physiol Lung Cell Mol Physiol, 2002. 283(2): p. L452-9.

32. Hsia, C.C., Hyde, D.M., Ochs, M., and Weibel, E.R., An official research policy statement of the American Thoracic Society/European Respiratory Society: standards for quantitative assessment of lung structure. Am J Respir Crit Care Med. 181(4): p. 394-418.

33. Kallapur, S.G., Moss, T.J., Auten, R.L., Jr., Nitsos, I., Pillow, J.J., Kramer, B.W., Maeda, D.Y., Newnham, J.P., Ikegami, M., and Jobe, A.H., IL-8 signaling does not mediate intra-amniotic LPS-induced inflammation and maturation in preterm fetal lamb lung. Am J Physiol Lung Cell Mol Physiol, 2009. 297(3): p. L512-9.

34. Kallapur, S.G., Bachurski, C.J., Le Cras, T.D., Joshi, S.N., Ikegami, M., and Jobe, A.H., Vascular changes after intra-amniotic endotoxin in preterm lamb lungs. Am J Physiol Lung Cell Mol Physiol, 2004. 287(6): p. L1178-85.

35. Kallapur, S.G., Willet, K.E., Jobe, A.H., Ikegami, M., and Bachurski, C.J., Intra-amniotic endotoxin: chorioamnionitis precedes lung maturation in preterm lambs. Am J Physiol Lung Cell Mol Physiol, 2001. 280(3): p. L527-36.

36. Lowry, O.H., Rosebrough, N.J., Farr, A.L., and Randall, R.J., Protein measurement with the Folin phenol reagent. J Biol Chem, 1951. 193(1): p. 265-75.

37. Kramer, B.W., Ikegami, M., Moss, T.J., Nitsos, I., Newnham, J.P., and Jobe, A.H., Endotoxininduced chorioamnionitis modulates innate immunity of monocytes in preterm sheep. Am J Respir Crit Care Med, 2005. 171(1): p. 73-7.

38. Bachurski, C.J., Ross, G.F., lkegami, M., Kramer, B.W., and Jobe, A.H., Intra-amniotic endotoxin increases pulmonary surfactant proteins and induces SP-B processing in fetal sheep. Am J Physiol Lung Cell Mol Physiol, 2001. 280(2): p. L279-85.

39. Menon, R., Peltier, M.R., Eckardt, J., and Fortunato, S.J., Diversity in cytokine response to bacteria associated with preterm birth by fetal membranes. Am J Obstet Gynecol, 2009. 201(3): p. 306 e1-6.

40. Ikegami, M., Moss, T.J., Kallapur, S.G., Mulrooney, N., Kramer, B.W., Nitsos, I., Bachurski, C.J., Newnham, J.P., and Jobe, A.H., Minimal lung and systemic responses to TNF-alpha in preterm sheep. Am J Physiol Lung Cell Mol Physiol, 2003. 285(1): p. L121-9.

41. Kallapur, S.G., Jobe, A.H., Ball, M.K., Nitsos, I., Moss, T.J., Hillman, N.H., Newnham, J.P., and Kramer, B.W., Pulmonary and systemic endotoxin tolerance in preterm fetal sheep exposed to chorioamnionitis. J Immunol, 2007. 179(12): p. 8491-9.

42. Shimizu, T., Kida, Y., and Kuwano, K., Ureaplasma parvum lipoproteins, including MB antigen, activate NF-\{kappa\}B through TLR1, TLR2 and TLR6. Microbiology, 2008. 154(Pt 5): p. 131825.

43. Benstein, B.D., Ourth, D.D., Crouse, D.T., and Shanklin, D.R., Ureaplasma urealyticum binds 
mannose-binding lectin. Exp Mol Pathol, 2004. 77(2): p. 138-44.

44. Yamada, M., Kurihara, H., Kinoshita, K., and Sakai, T., Temporal expression of alpha-smooth muscle actin and drebrin in septal interstitial cells during alveolar maturation. J Histochem Cytochem, 2005. 53(6): p. 735-44.

45. Leslie, K.O., Mitchell, J.J., Woodcock-Mitchell, J.L., and Low, R.B., Alpha smooth muscle actin expression in developing and adult human lung. Differentiation, 1990. 44(2): p. 143-9.

46. Bland, R.D., Xu, L., Ertsey, R., Rabinovitch, M., Albertine, K.H., Wynn, K.A., Kumar, V.H., Ryan, R.M., Swartz, D.D., Csiszar, K., and Fong, K.S.K., Dysregulation of pulmonary elastin synthesis and assembly in preterm lambs with chronic lung disease. Am J Physiol Lung Cell Mol Physiol, 2007. 292(6).

47. Bland, R.D., Mokres, L.M., Ertsey, R., Jacobson, B.E., Jiang, S., Rabinovitch, M., Xu, L., Shinwell, E.S., Zhang, F., and Beasley, M.A., Mechanical ventilation with $40 \%$ oxygen reduces pulmonary expression of genes that regulate lung development and impairs alveolar septation in newborn mice. Am J Physiol Lung Cell Mol Physiol, 2007. 293(5): p. L1099-L1110.

48. Thibeault, D.W., Mabry, S.M., Ekekezie, II, and Truog, W.E., Lung elastic tissue maturation and perturbations during the evolution of chronic lung disease. Pediatrics, 2000. 106(6): p. 1452-9.

49. Starcher, B., Mechanical ventilation and elastic fiber assembly. Am J Physiol Lung Cell Mol Physiol, 2008. 294(1): p. L1-2.

50. Bruce, M.C., Schuyler, M., Martin, R.J., Starcher, B.C., Tomashefski, J.F., Jr., and Wedig, K.E., Risk factors for the degradation of lung elastic fibers in the ventilated neonate. Implications for impaired lung development in bronchopulmonary dysplasia. Am Rev Respir Dis, 1992. 146(1): p. 204-12.

51. Toti, P., Buonocore, G., Tanganelli, P., Catella, A.M., Palmeri, M.L., Vatti, R., and Seemayer, T.A., Bronchopulmonary dysplasia of the premature baby: an immunohistochemical study. Pediatr Pulmonol, 1997. 24(1): p. 22-8.

52. Hannaford, K., Todd, D.A., Jeffery, H., John, E., Blyth, K., and Gilbert, G.L., Role of ureaplasma urealyticum in lung disease of prematurity. Arch Dis Child Fetal Neonatal Ed, 1999. 81(3): p. F162-7.

53. Waites, K.B., Schelonka, R.L., Xiao, L., Grigsby, P.L., and Novy, M.J., Congenital and opportunistic infections: Ureaplasma species and Mycoplasma hominis. Semin Fetal Neonatal Med, 2009. 14(4): p. 190-9.

54. Polglase, G.R., Dalton, R.G., Nitsos, I., Knox, C.L., Pillow, J.J., Jobe, A.H., Moss, T.J., Newnham, J.P., and Kallapur, S.G., Pulmonary Vascular and Alveolar Development in Preterm Lambs Chronically Colonized with Ureaplasma Parvum. Am J Physiol Lung Cell Mol Physiol, 2010. 299(2): p. L232-41.

55. Jobe, A.H., Hillman, N., Polglase, G., Kramer, B.W., Kallapur, S., and Pillow, J., Injury and inflammation from resuscitation of the preterm infant. Neonatology, 2008. 94(3): p. 190-6.

56. Wolfs, T.G., Buurman, W.A., Zoer, B., Moonen, R.M., Derikx, J.P., Thuijls, G., Villamor, E., Gantert, M., Garnier, Y., Zimmermann, L.J., and Kramer, B.W., Endotoxin induced chorioamnionitis prevents intestinal development during gestation in fetal sheep. PLoS One, 2009. 4(6): p. e5837.

57. Mabanta, C.G., Pryhuber, G.S., Weinberg, G.A., and Phelps, D.L., Erythromycin for the prevention of chronic lung disease in intubated preterm infants at risk for, or colonized or infected with Ureaplasma urealyticum. Cochrane Database Syst Rev, 2003(4): p. CD003744.

58. Lyon, A.J., McColm, J., Middlemist, L., Fergusson, S., McIntosh, N., and Ross, P.W., Randomised trial of erythromycin on the development of chronic lung disease in preterm infants. Arch Dis Child Fetal Neonatal Ed, 1998. 78(1): p. F10-4.

59. Jonsson, B., Karell, A.C., Ringertz, S., Rylander, M., and Faxelius, G., Neonatal Ureaplasma urealyticum colonization and chronic lung disease. Acta Paediatr, 1994. 83(9): p. 927-30. 



\section{4}

Antenatal inflammation reduces Cav-1 expression and influences multiple signaling pathways in

\section{preterm fetal lungs}

Kunzmann S, Collins JJP, Yang Y, Uhlig S, Kallapur SG, Speer CP, Jobe $\mathrm{AH}$, Kramer BW

Am J Respir Cell Mol Biol. 2011 Nov;45(5):969-76. 
Abstract

Bronchopulmonary dysplasia (BPD), associated with chorioamnionitis, results from the simultaneous effects of disrupted lung development, lung injury and repair superimposed on the developing lung. Caveolins (Cav) are implicated as major modulator of lung injury and remodeling by multiple signaling pathways, although Cav have been minimally studied in the injured developing lung. We hypothesized that chorioamnionitis-associated antenatal lung inflammation would decrease Cav-1 expression in preterm fetal lungs. We tested if there were changes in transcription factors Smad2/3, Smad1/5, Stat3, Stat1, activation of a-SMase with ceramide generation, and changes in expression of HO-1 as indicators of possible Cav-1 mediated effects. Fetal sheep were exposed to $10 \mathrm{mg}$ of intra-amniotic endotoxin or saline for 2, 7 or 2+7 days before preterm delivery at 124 days gestation. Cav-1 and HO-1 expression and Smad- and Stat-phosphorylation were evaluated by real-time PCR, western-blotting and/or immunohistochemistry. A-SMase activity and ceramide levels were measured. Intra-amniotic endotoxin decreased Cav-1 mRNA and protein expression in the lungs, with a maximum reduction of Cav-1 mRNA to $50 \% \pm 7 \%$ of the control value $(p<0.05)$ and of Cav-1 protein expression to $20 \% \pm 5 \%$ of the control value $(p<0.05)$. Decreased Cav-1 levels were associated with elevated phosphorylation of Smad2/3, Stat3 and Stat1, but not Smad1/5. Expression of HO-1, a-SMase activity and ceramide increased. Antenatal inflammation decreased pulmonary Cav-1 expression in the preterm fetal lung. Decreased Cav-1 was associated with activation of the Smad2/3-, Stat- and a-SMase/ceramide pathways, and increased HO-1 expression. The decreased Cav-1 and changes in multiple other signaling pathways may contribute to BPD.

\section{Introduction}

Chorioamnionitis that is often clinically asymptomatic is associated with the majority of Lung inflammation is a major contributor to the impaired development of alveoli and the microvasculature that results in BPD [1]. However, the mechanisms that link inflammation to alveolar and microvascular simplification are unclear [2]. For many very preterm infants the pulmonary inflammation begins in utero with chorioamnionitis. Chorioamnionitis is defined as microbial infection of the amnion and chorion, and is an important risk factor for preterm delivery in about $60 \%$ of very preterm deliveries [3]. Chorioamnionitis increases pro-inflammatory cytokines in human amniotic fluid and fetal cord blood, presumably by fetal responses to bacterial products and injury [4]. These pro-inflammatory cytokines may be important mediators which recruit activated inflammatory cells to the fetal lung [2]. Fetal sheep develop chorioamnionitis following injections of LPS into amniotic fluid, which initiates a sequence of lung injury 
Regulation of Caveolin-1 by antenatal inflammation in preterm fetal lungs

(inflammation, apoptosis, remodeling) that results both lung maturation and decreased alveolar septation with microvascular injury [5]. These changes in the fetal lung may initiate progress to BPD [6].

Caveolin-1 (Cav-1) could be central in this pathophysiological sequence as a component of caveolae, the 50-100-nm wide omega-shaped plasma membrane invaginations [7]. Caveolae and caveolins are present in high levels in the airway epithelium, smooth muscle, fibroblasts and inflammatory cells and also in the pulmonary vasculature [8]. Caveolae function in protein trafficking, signal transduction and sphingolipid biology [9]. Down-regulation of Cav-1 occurs in diverse lung diseases such as asthma, chronic obstructive pulmonary disease (COPD) and idiopathic pulmonary fibrosis (IPF)[10]. Cav-1 is also a major modulator of LPS induced lung injury in animal models [10].

At the molecular level Cav-1 is fundamental to organizing multiple signaling pathways, including the TGF- $\beta$ induced Smad-[11], Stat- [12-14] and a-SMase/ceramide pathways $[15,16]$. These signaling pathways participate in airway inflammation and remodeling [17-21]. Cav-1 also regulates inducible heme oxygenase (HO)-1 [22] which modulates oxidative and inflammatory defences in the lung[23]. Changes in Cav-1 or associated changes in these signaling pathways have not been evaluated in the preterm fetal lung exposed to inflammation.

We previously reported increased TGF- $\beta 1$ activity in fetal lungs after antenatal exposure to inflammation [24]. TGF- $\beta 1$ was identified in lung fibroblasts and endothelial cells as a negative regulator for Cav-1 [25-27]. We therefore hypothesized that antenatal inflammation would decrease the expression and function of Cav-1 in preterm lungs and thereby affect the Smad, Stat and a-SMase/ceramide-pathways as well as the expression of HO-1. We used a well characterized sheep model of LPS induced chorioamnionitis to cause inflammation in the fetal lung [28]. A better understanding of signal transduction pathways in fetal lung inflammation may provide new therapeutic approaches to the treatment of postnatal lung injury.

\section{Materials and methods}

\section{Animals}

All animal experiments were performed in Western Australia with the approval of the ethical committees of the Department of Agriculture, Western Australia, Australia, and the Children's Hospital Research Foundation, Cincinnati, OH, USA. Time-mated ewes with singletons were assigned to groups of 6 or 7 animals for ultrasound-guided intraamniotic injections of LPS (10 mg, E. coli O55:B5; Sigma Chemicals, St Louis, MO, USA) in 


\section{Chapter 4}

$2 \mathrm{ml}$ saline 2, 7 or 2 and 7 days before delivery (Fig. 1). Control animals received a $2 \mathrm{ml}$ intra-amniotic saline injection. There were no differences between the control animals that received saline injections at the different time points before delivery. Therefore the control animals have been combined into one group. All animals were operatively Interval from treatment to delivery

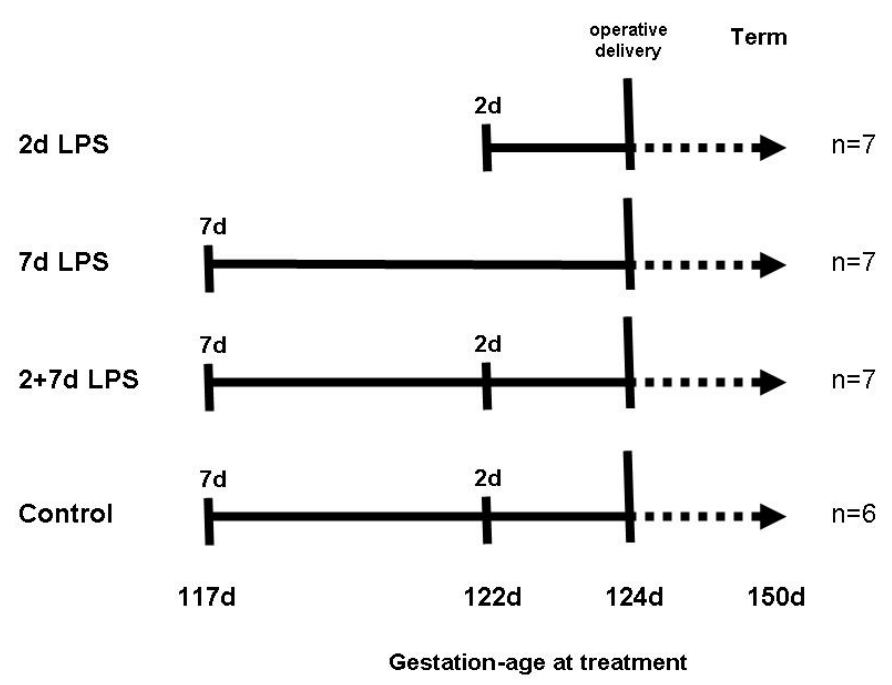

Figure 1: Study design.

Six to seven animals per group received ultrasound-guided intra-amniotic injections with $10 \mathrm{mg}$ LPS or $\mathrm{NaCl} 0.9 \%$ (control) $2 \mathrm{~d}, 7 \mathrm{~d}$ or $2+7 \mathrm{~d}$ before delivery at the same gestational age of 124 days.

delivered at the same gestational age of 124 days (term 150 days). Lung tissue was used for multiple assessments. Results for lung inflammation and maturation were previously reported for these animals [29].

\section{Immunohistochemistry and histological analysis}

The immunostaining methods were performed as previously described [30]. Please see online data supplement.

\section{Acid-sphingomyelinase (a-SMase) and ceramide measurements}

Acid sphingomyelinase (ASM) activity was determined with 14C-labelled Sphingomyelin[31]. Lung powder was mixed with ASM-buffer (250 mM Na-Acetate, $1 \mathrm{mM}$ EDTA, 0.1\% Triton X-100, pH 5.0) and homogenized. Samples were centrifuged at $4^{\circ} \mathrm{C}, 20,000 \mathrm{~g}$ for $20 \mathrm{~min}$, and the protein content of the supernatant was determined. Samples were incubated at $37^{\circ} \mathrm{C}$ for $2 \mathrm{~h}$ with $14 \mathrm{C}$-labelled sphingomyelin substrate. Samples were separated by chloroform/methanol extraction, scintillation liquid was 
added and radioactivity measured. Ceramide levels in lung tissue and serum were determined as described[32]. In brief, lung powder mixed in methanol/chloroform water emulsion, sonificated and centrifuged $4^{\circ} \mathrm{C}, 4000 \mathrm{~g}$ for $10 \mathrm{~min}$ to extract the lipids. The lipids were separated from other membrane components by chloroform/methanol extraction and dried with N2. Subsequently lipids were dissolved in chloroform/methanol (9:1) and spotted on high-performance thin layer chromatography (HPTLC) plates (silica gel 60 precoated plate; Merck, Darmstadt, Germany). Ceramide was resolved with dichlormethane/methanol/acetate (100:2:5). Thin-layer chromathography plates were dried at $180^{\circ} \mathrm{C}$, cooled and put into $10 \%$ cupric sulfate, $8 \%$ phosphoric acid solution. After heating for $2 \mathrm{~min}$ at $110^{\circ} \mathrm{C}$, lipid bands were visible and measured with a Fujix-1000 Bioimager (Raytest, Straubenhardt, Germany).

For RNA extraction and PCR-, Western-Blot- and Statistical Analysis please see online data supplement.

\section{Results}

\section{Pulmonary Cav-1 expression is reduced by LPS-induced chorioamnionitis}

PCR results expressed as Cav-1 mRNA transcripts by PCR normalized to ovRPS15 showed LPS reduced Cav- 1 mRNA by $50 \%$ in the $2 d, 7 d$ and $2+7 d$ LPS groups relative to the control group $(p<0.05)$ (Fig. $2 A)$. To confirm that decreased Cav-1 mRNA expression corresponded with reduced protein levels, Cav-1 was quantified by Western blot (Fig. $2 \mathrm{~B}+\mathrm{C}$ ) and immunohistochemistry (Fig. 2D-F) analysis. Cav-1 decreased similarly at $2 \mathrm{~d}$ and $7 d$ with these measurements, and a second exposure to LPS had no further effect on Cav-1 protein expression.
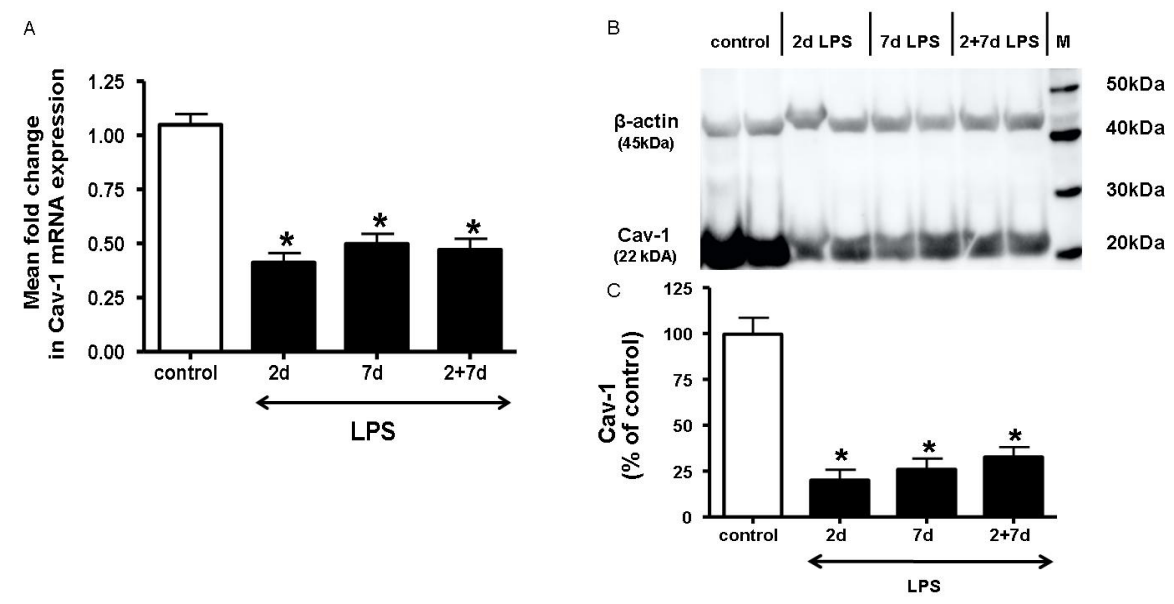

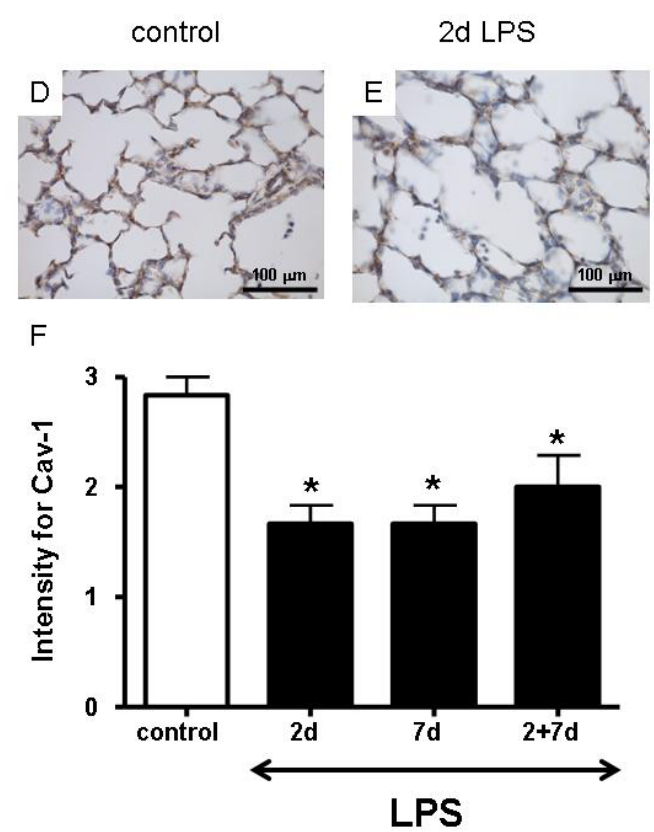

Figure 2: Intra-amniotic LPS exposure decreases Cav-1 expression.

A. Real-time PCR measurements of Cav-1 mRNA expression in whole lung homogenates. Mean fold change in lung mRNA expression of Cav-1 normalized for ovRPS15 by the $\triangle \Delta \mathrm{Ct}$-method. B. Westernblot measurements of Cav-1 protein expression with an anti-Cav1 antibody. The same membrane was analyzed with anti- $\beta$-actin antibody. C. Cav- 1 and $\beta$-actin protein levels were semi-quantified by densitometry. Optical density of Cav- 1 protein band was corrected to $\beta$-actin, and results are expressed as ratio (\%) of endotoxin-exposed to control animals. D-F. Immunohistochemical evaluation of Cav-1 expression in preterm lung tissue. Representative sections from a control animal (D) and an animal exposed to LPS-induced chorioamnionitis for 2 days (E) stained for Cav1. Magnification $\times 50$. F. Immunostaining for Cav-1 was graded on a scale from 0 to 3 . Values are means \pm SEM; $* p<0.05$ vs control.

\section{Smad2/3 but not Smad1/5 phosphorylation increase with LPS-induced chorioamnionitis}

Cytoplasmic staining for phosphorylated Smad2/3 was weak in bronchial epithelial cells in control lungs (Fig. 3A). In contrast, LPS resulted in intense phosphorylated Smad2/3 staining (Fig. 3B). The Smad2/3-P staining increased 2 days after LPS exposure and increased further about 3-fold 7 days after LPS exposure (Fig. $3 \mathrm{C}$ ). The majority of the cells had nuclear staining (Fig. 3B insert and arrow), consistent with TGF- $\beta 1$ signaling and nuclear translocation of phosphorylated Smad2/3. Only weak staining could be detected for phosphorylated Smad1/5 in LPS treated and control animals (Fig. 3D). 


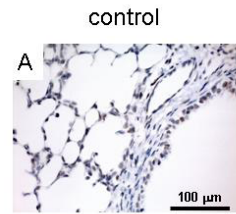

C

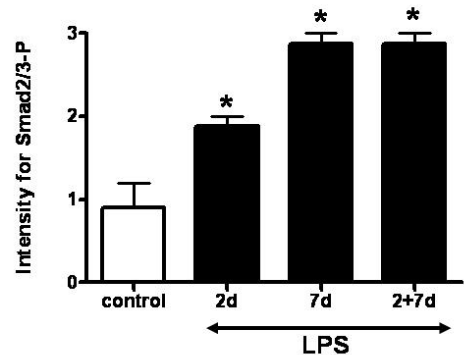

$7 d$ LPS

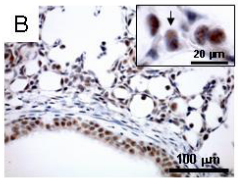

D

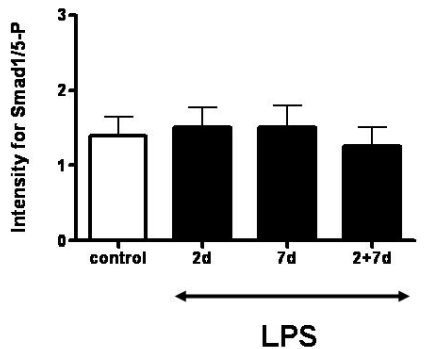

Figure 3: Effect of intra-amniotic LPS exposure on Smad signaling.

Smad2/3 (A-C) and Smad1/5 (D) phosphorylation were evaluated in lung tissue by immunohistochemistry. Representative sections from a control animal (A) and an animal exposed to LPS-induced chorioamnionitis for 7d (B) stained for phosphorylated Smad2/3. Magnification x50; insert shows higher magnification and arrows identify nuclear staining for phosphorylated Smad2/3 C: Immunohistochemical semi-quantification of phosphorylated $\mathrm{Smad} 2 / 3$ in lung sections. D: Immunohistochemical semi-quantification of phosphorylated Smad1/5 in lung sections. Immunostaining for phosphorylated Smad2/3 or Smad1/5 were graded on a scale from 0 to 3 . Values are means $\pm \mathrm{SEM} ;{ }^{*} \mathrm{P}<0.05$ vs. control.

\section{Phosphorylation of Stat-3 and Stat-1 by LPS-induced chorioamnionitis}
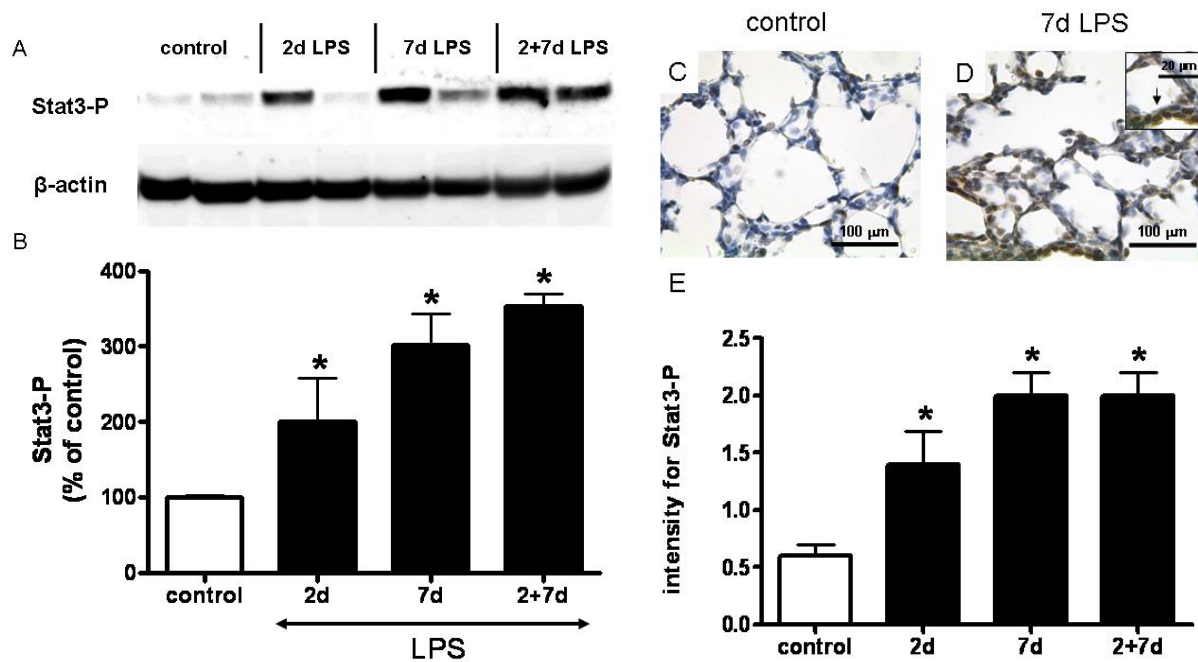

Figure 4: Effect of intra-amniotic LPS exposure on Stat3. 
A+B: Western blot measurements of Stat-3 phosphorylation with an anti-Stat3-P antibody (A). The same membrane was analyzed with anti- $\beta$-actin antibody. Stat3-P and $\beta$-actin protein levels were semi-quantified by densitometry. Optical density of Stat3P protein bands were corrected to $\beta$-actin, and results are expressed as ratio (\%) of LPS-exposed to control animals (B). C-E: Evaluation of Stat3 phosphorylation in lung tissue by immunohistochemistry. Representative sections from a control animal (C) and an animal exposed to LPS-induced chorioamnionitis for 7d (D) stained for phosphorylated Stat3. Magnification $\times 50$; insert shows higher magnification and arrows identity nuclear staining for phosphorylated Stat3. Immunohistochemical semi-quantification of phosphorylated Stat-3 in lung sections (E). Values are means \pm SEM; ${ }^{*} \mathrm{P}<0.05$ vs. control.

Stat3-P levels increased in the $2 d, 7 d$ and $2+7 d$ LPS-exposed animals by westernblot analysis compared with controls (Fig. 4A). A semi-quantitative analysis of the immunoblots demonstrated that Stat3-P was induced 355\% $(p<0.05)$ in the $2+7 d$ LPS exposed group compared with the controls (Fig. 4B). Stat3 phosphorylation also was detected by immunohistochemistry with anti-phosphorylated Stat3-specific antibodies (Fig. 4C-E). Staining for Stat3-P was weak in the control lungs (Fig. 4C). In contrast, LPS exposure resulted in intense staining of Stat3-P (Fig. 4D). A semi-quantitative analysis of the immunohistochemistry demonstrated that Stat3-P increased about 4-fold $(p<0.05)$ in the $7 d$ and $2+7 d$ LPS exposed group compared with controls (Fig. 4E).

Stat1 phosphorylation increased to $210 \%$ of the control value by western blot analysis with $2 \mathrm{~d}$ of LPS exposure (Fig. 5A+B). By immunohistochemical analysis a 4.8-fold increase (Fig. 5C-E) also was measured after $2 d$ of LPS exposure relative to control $(p<0.05)$. For Stat-3 and Stat- 1 the majority of the bronchial epithelial cells had nuclear staining, consistent with translocation to the nucleus (Fig. 4D and 5D inserts and arrow).
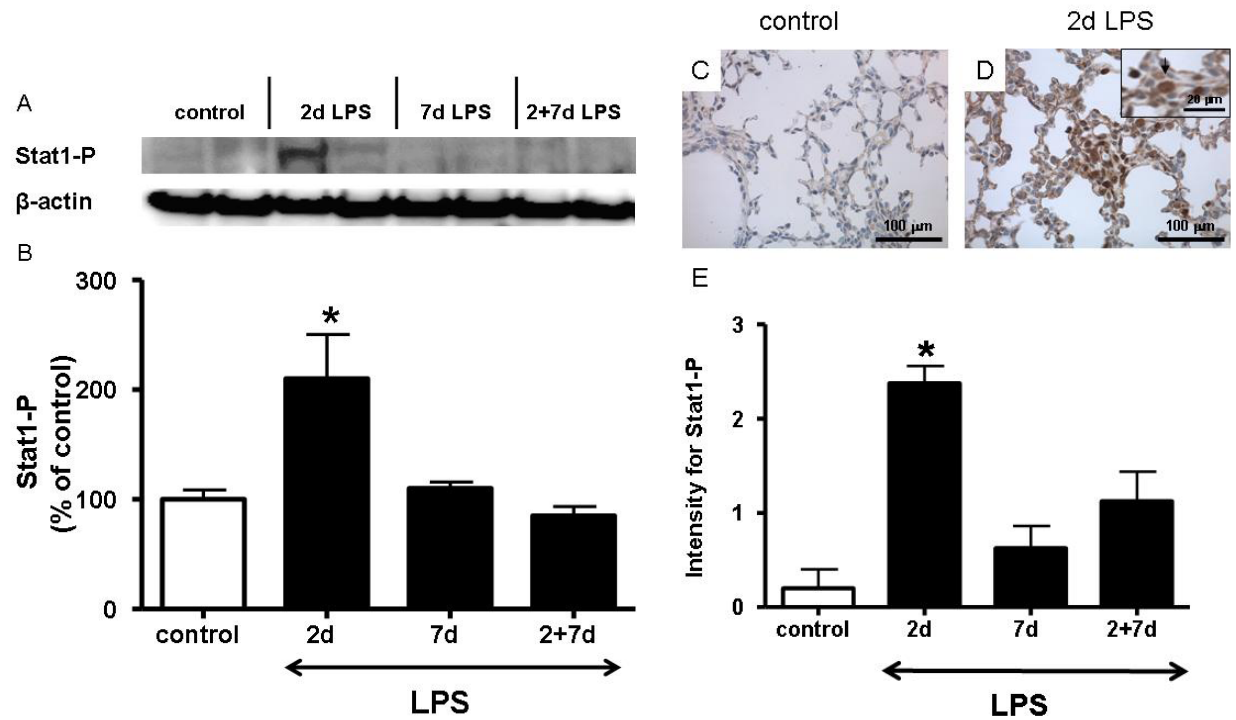
Figure 5: Effect of intra-amniotic LPS exposure on Stat1 signaling.

A+B: Western-blot measurements of Stat1 phosphorylation with an anti-Stat1-P antibody (A). The same membrane was analyzed with anti- $\beta$-actin antibody. Stat1-P and $\beta$-actin protein levels were semi-quantified by densitometry. Optical density of Stat1-P protein band was corrected for $\beta$-actin, and results are expressed as ratio (\%) of LPS-exposed to control animals (B). Values are means \pm SEM; ${ }^{*} \mathrm{P}<0.05$ vs. control. C-E: Evaluation of Stat1 phosphorylation in lung tissue by immunohistochemistry. Representative sections from a control animal (C) and an animal exposed to LPS-induced chorioamnionitis for 2d (D) stained for phosphorylated Stat1. Magnification x50; insert shows higher magnification and arrows indicate nuclear staining for phosphorylated Stat1. Immunohistochemical semi-quantification of phosphorylated Stat1 in lung sections (E). Values are means $\pm \mathrm{SEM} ;{ }^{*} \mathrm{P}<0.05$ vs. control.

\section{a-SMase activity and ceramide increase with LPS-induced chorioamnionitis}

In the LPS exposed groups, both a-SMase activity and ceramide levels were elevated compared with the control (Fig. 6). The a-SMase activity increased 18-fold in the 7d LPS exposed group (Fig. $6 \mathrm{~A} ; \mathrm{p}<0.05$ ) and the ceramide level increased 38 -fold increase in the 7d LPS exposed group (Fig. 6B; $p<0.05$ ).

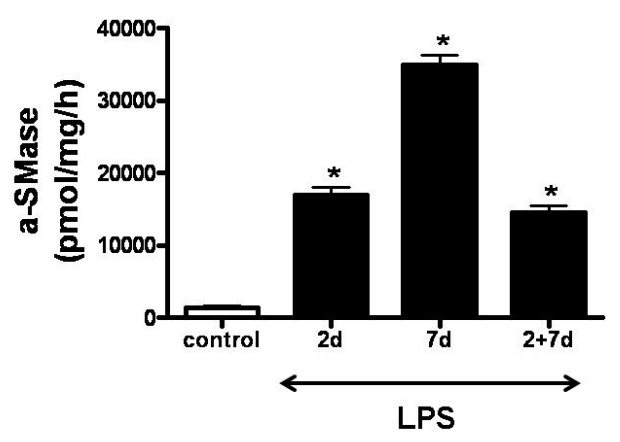

B

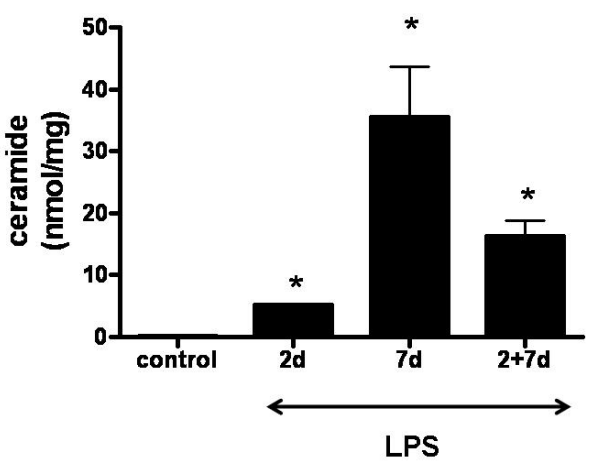

Figure 6: Effect of intra-amniotic LPS exposure on a-SMase activity and ceramide.

A: Measurements of a-SMase activity in lung tissue by a modified micellar in vitro assay. B: Measurements of ceramide level by two-dimensional charring densitometry. Values are means \pm SEM; ${ }^{*} \mathrm{P}<0.05$ vs. control.

\section{Induction of HO-1 expression by LPS-induced chorioamnionitis}

By western-blot analysis the ratio of $\mathrm{HO}-1$ protein to $\beta$-actin protein increased 4.5 -fold in the 7d LPS exposed group compared with the control group $(p<0.05) \quad($ Fig. 7A+B). $\mathrm{HO}-1$ protein was increased in all three experimental groups by immunohistochemical analysis, with a maximum increase of 12 -fold in the $7 d$ LPS exposed group compared with controls ( $p<0.05)$ (Fig. 7C-E). 


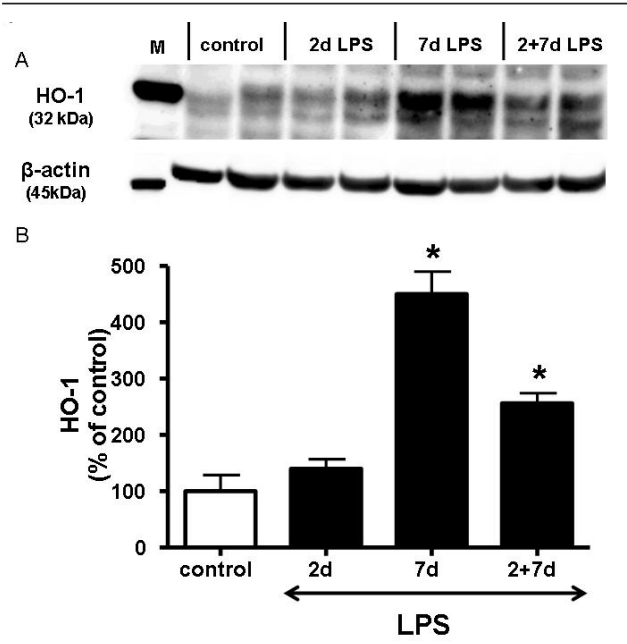

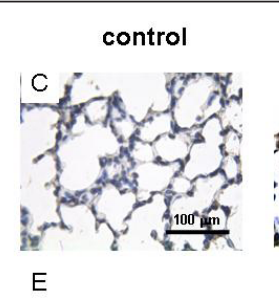
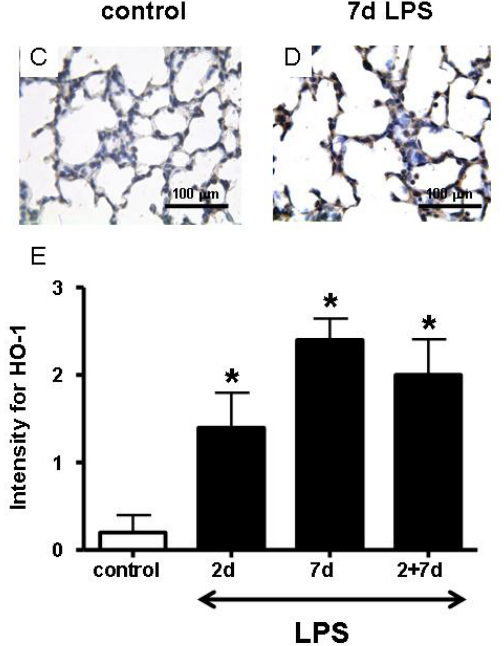

Figure 7: Intra-amniotic LPS exposure induces HO-1 expression.

A+B: Western-blot measurements of HO-1 protein expression with an anti-HO-1 antibody (A). The same membrane was analyzed with anti- $\beta$-actin antibody. $\mathrm{HO}-1$ and $\beta$-actin protein levels were semi-quantified by densitometry. Optical density of HO-1 protein bands were corrected for $\beta$-actin, and results are expressed as ratio (\%) of endotoxin-exposed to control animals (B). C-E: Evaluation of HO-1 expression in lung tissue by immunohistochemistry. Representative sections from a control animal (C) and an animal exposed to endotoxin-induced chorioamnionitis for 7 days (D) stained for HO-1. Magnification x50. Immunohistochemical semi-quantification of HO-1 in lung sections on a scale from 0 to $3(E)$. Values are means \pm SEM; $* p<0.05$ vs control.

\section{Discussion}

Chorioamnionitis caused LPS induced lung inflammation and airway remodeling [33, 34]. This fetal inflammatory response also down-regulated Cav-1, activated Stat, Smad and a-SMase, and up-regulated ceramide and HO-1 expression in the fetal lung. These findings support the hypothesis that decreased pulmonary Cav-1 expression and effects on downstream signaling pathways may contribute to remodeling and functional impairment of the developing lung.

Animal models of LPS induced chorioamnionitis have been extensively used to evaluate inflammation effects on lung and other organs [35-37] and potential mediators [3840]. Intra-amniotic LPS can reliably reproduce the fetal inflammatory response in chorioamnionitis, however one limitation is that chorioamnionitis is induced with only one pro-inflammatory Toll-like receptor ligand and not with living bacterial infections, which are often polymicrobial in chorioamnionitis [41].

TGF- $\beta 1$ can be a negative regulator of Cav-1 expression in lung, because in human 
Regulation of Caveolin-1 by antenatal inflammation in preterm fetal lungs

pulmonary fibroblasts TGF- $\beta 1$ can markedly decrease Cav-1 expression $[25,27]$. Furthermore, treatment of cultured bovine aortic endothelial cells with TGF- $\beta 1$ decreased Cav-1 expression [26]. We also found down-regulation of Cav-1 mRNA expression by TGF- $\beta 1$ in HPMEC-ST1.6R cells (a human lung endothelial cell line), in A549 cells (a Figure 7. Intra-amniotic LPS exposure induces HO-1 expression. A+B: Western-blot measurements of HO-1 protein expression with an anti-HO-1 antibody (A). The same membrane was analyzed with anti- $\beta$-actin antibody. $\mathrm{HO}-1$ and $\beta$-actin protein levels were semi-quantified by densitometry. Optical density of HO-1 protein bands were corrected for $\beta$-actin, and results are expressed as ratio (\%) of endotoxinexposed to control animals (B). C-E: Evaluation of HO-1 expression in lung tissue by immunohistochemistry. Representative sections from a control animal (C) and an animal exposed to endotoxin-induced chorioamnionitis for 7 days (D) stained for HO-1. Magnificationx50. Immunohistochemical semi-quantification of HO-1 in lung sections on a scale from 0 to $3(E)$. Values are means \pm SEM; * $p<0.05$ vs control. cell line) and in H441 cells (a human lung adenocarcinoma cell line with characteristics of bronchiolar Clara epithelial cells) (data not shown). Antenatal inflammation induced TGF- $\beta 1$ expression in the lung of fetal lambs[24], and TGF- $\beta 1$ levels were increased in airway samples from preterm infants developing BPD $[42,43]$. Therefore, the reduction of Cav-1 expression by chorioamnionitis induced inflammation could be mediated by increased TGF- $\beta 1$ concentrations in the lung [24]. While down-regulation of Cav-1 was described previously in other lung diseases [10], reduced Cav-1 expression in preterm lung disease is a new observation.

In this translational model in fetal sheep, we cannot directly demonstrate that TGF- $\beta 1$ was regulating Cav-1. Cav-1 also contributes to the regulation of TGF- $\beta$ signaling by its participation in T $\beta R$ (TGF- $\beta$ receptor) internalization [44]. T $\beta$ Rs can be internalized by two different mechanisms: firstly by Cav-1 associated lipid rafts and secondly by early endosome antigen 1 (EEA-1) non-lipid raft pathways. While non-lipid raft associated internalization increases TGF- $\beta$ signaling, the caveolin-associated internalization increases T $\beta R$ degradation and decreases TGF- $\beta$ signaling [45]. Absence of one compartment or imbalance in the densities of the two compartments may affect the level of TGF- $\beta$ pathway activity given the same amount of ligand binding. Because this process occurs at the level of internalization of the $T \beta R$ immediately following ligand engagement, it likely represents an important mechanism of regulation of TGF- $\beta$ signaling. In human fetal pulmonary fibroblasts, both gain and loss of function experiments identified the regulatory role of Cav-1 in this process [25]. Down-regulation of Cav-1 by siRNA transfection increased Smad-2 phosphorylation and Smad2/3 nuclear translocation, while overexpression of Cav-1 suppressed Smad2 phosphorylation and nuclear translocation [25]. Additionally, enhanced TGF- $\beta$ signaling was measured in Cav- 
1-deficient mice [46] and OVA-allergen challenged Cav-1-deficient mice in a model for asthma [47]. Furthermore, Razani et al. described an interaction between Cav-1 and the Typ I TGF- $\beta$ receptor, where Cav-1 suppressed TGF- $\beta 1$ mediated phosphorylation of Smad-2[48]. We analyzed phosphorylation of Smad2/3 and Smad1/5 in preterm lung. Smads are downstream effectors of TGF- $\beta$ and provide an indication of the extent to which TGF- $\beta$ signaling is activated. In concordance with other studies the decreased Cav1 expression in our model is associated with a substantial increase in Smad2/3-P in the lungs of LPS exposed animals. The increase of Smad2/3 phosphorylation is in agreement with an earlier similar study with different LPS exposure intervals [24].

In addition to the Smad signaling pathway, Cav-1 can also regulate the Stat signaling pathway. Like Smad, Stat proteins exist in a latent form in the cytoplasm and upon receptor activation by cytokines Stat are phosphorylated on tyrosine residues by members of the Janus kinase (JAK) family (JAK1, JAK2, JAK3) or Tyrosine kinase 2 (Tyk2) [49]. An activated Stat pathway is commonly observed in acute lung injury, e.g. in endotoxin-induced lung injury [18]. Caveolins associate with Stat proteins, Stat3 was hyperphosphorylated in lung from Cav-1 ${ }^{-1}$-deficient mice [12]. In addition, the Jak/Stat signaling cascade is hyperactivated in mammary glands of Cav-1\% mice [50]. Thus, down-regulation of Cav-1 expression should hyperactivate Stat-3 phosphorylation. In our model of LPS-induced lung injury reduced expression of Cav-1 was associated with increased phosphorylation of Stat-3 and Stat-1.

The a-SMase/ceramide pathway is critical in a variety of lung diseases [20], including acute neonatal inflammatory lung injury [21]. Sphingolipids are structure-bearing elements of biological membranes which regulate key physiological processes such as apoptosis, innate and acquired immunity, vascular permeability and smooth muscle tone [20]. Ceramide is a structure bearing lipid and probably also a second messenger that is generated by hydrolysis of sphingomyelin by a-SMase during inflammation. Consistent with interaction between a-SMase and Cav-1 [15, 16, 51], we observed that decreased pulmonary Cav-1 induced by antenatal inflammation was associated with increased pulmonary a-SMase activity and ceramide production which has been observed in many models of acute lung injury [20]. The decreased expression of a-SMase/ceramide after repetitive endotoxin injection into the amniotic fluid may be part of the endotoxin tolerance that we previously reported in this model [29].

We further investigated the role of HO-1 in LPS induced lung injury, because of the known association between decreased Cav-1 and increased HO-1 expression in the lung $[22,52]$. Like the Smad and Stat signaling pathways, HO-1 can influence pulmonary remodeling [23]. HO-1 is a mediator of cyto- and tissue protection against a wide variety of injurious insults [23]. Increased HO-1 expression was described in premature infants 
Regulation of Caveolin-1 by antenatal inflammation in preterm fetal lungs

with respiratory distress syndrome (RDS) [53]. In addition, Maroti et al. suggest that HO-1 plays a role in the early adaption process with increased expression of HO-1 for 2-3 days after birth [54]. A direct link between Cav-1 and HO-1 was characterized by Jin et al. [22], when they examined the underlying mechanisms by which Cav-1/- mice had prolonged survival and reduced lung injury after hyperoxia. The apparent resistance to hyperoxia in Cav-1 $1^{-1-}$ pulmonary cells and tissues resulted from increased expression of the stress protein HO-1 [22]. Furthermore, Kim et al. demonstrated that HO-1 activity dramatically increased in endothelial cells expressing Cav-1 antisense transcripts, suggesting a negative regulatory role for Cav-1 [52].

In parallel with these observations, the connections between Cav-1 and these signaling pathways are consistent with the associations between Cav-1 and the signaling pathways in LPS-induced chorioamnionitis. A limitation of this study is that a direct mechanistic linkage between Cav-1 and these signaling pathways was not shown because of the nature of this translational research model in a large animal. However, our results support the involvement of Cav-1 down-regulation and associated signaling pathways in the lung remodeling induced by LPS-induced chorioamnionitis. A next step is to test therapies that increase Cav-1 bioavailability in the lung of sheep. Razani et al. demonstrated that the interaction between Cav- 1 and the TGF- $\beta$ receptor was mediated by a small region within the Cav-1 protein identified as the caveolin scaffolding domain (CSD) which specifically recognizes and binds to a short amino acid sequence, termed the caveolin binding motif, present in TGF- $\beta$ receptor [55]. Cav-1 function could be mimicked by delivery of a penetrating-CSD fusion peptide leading to inhibition of TGF$\beta$-induced Smad2/3 activation and collagen expression [56]. This peptide might restore Cav-1 function in setting of lung injury induced by LPS-induced chorioamnionitis.

Taken together, our study supports a role for Cav-1 in lung remodeling induced by antenatal inflammation (Fig. S1). Cav-1 mRNA and protein expression were low in lung tissues after antenatal inflammation. In contrast, TGF- $\beta 1$ increased considerably with antenatal inflammation induced lung remodeling [24], which is the basis for the hypothesis that TGF- $\beta 1$ may be one of the negative regulators of lung Cav-1 expression [25-27]. In addition, Cav-1 expression is associated with the activation of other signaling pathways and enzymes in lung. The Stat- and a-SMase/ceramide pathways and HO-1 expression may contribute to inflammation and remodeling in the preterm injured lung. We do not know whether these events are cause or effects of the loss of pulmonary Cav-1. It is also unknown whether Cav-1 has positive or negative effects on airway remodeling [8]. 


\section{Online data supplement}

\section{Materials and Methods}

\section{Immunohistochemistry and histological analysis}

Lung tissue was fixed in formalin for $24 \mathrm{~h}$, embedded in paraffin, and cut into $5-\mu \mathrm{m}$ sections. Endogenous peroxidase activity was removed by incubation with hydrogen peroxide. Nonspecific binding sites were blocked with serum. Sections were incubated at $4^{\circ} \mathrm{C}$ overnight with a polyclonal rabbit antibody for Caveolin-1 (sc-894, Santa Cruz Biotechnology, Santa Cruz, CA, USA), a monoclonal rabbit Smad2/3-P (Ser465/467) (\#3108, Cell Signaling Technology, Boston, USA), a monoclonal rabbit Smad1/5-P (Ser463/465) (\#9516, Cell Signaling Technology, Boston, USA), a monoclonal rabbit Stat3-P (Tyr705) (\#9145, Cell Signaling Technology, Boston, USA), a polyclonal rabbit Stat1-P (Tyr701) (\#9171, Cell Signaling Technology, Boston, USA) or a polyclonal goat HO-1 (\#sc-1796, Santa Cruz Biotechnology, Santa Cruz, CA, USA). Unbound antibody was removed with $\mathrm{PBS}$, and the slides were incubated with the secondary biotinylated antibody against rabbit IgG (Vector Laboratories, Burlingame, CA) for $1 \mathrm{~h}$ at room temperature. Immunostaining was visualized by the Vectastain $A B C$ peroxidase Elite kit for detection of the antigen-antibody complexes (Vector Laboratories). Omission of the primary antibody was the negative control. An average for each sample was calculated from five fields that were chosen at random. The intensity of staining was measured using a semi-quantitative scale as no staining $(0)$, weak $(+1)$, moderate $(+2)$, or strong $(+3)$ by a blinded examiner and results are expressed as percentages of all cells counted. Four to five tissue sections from different regions of each lung were analyzed. The average counts of all results were calculated for each lung.

\section{RNA extraction and PCR Analysis}

Total RNA was isolated from tissue from the right lower lung lobe by guanidinium thiocyanate-phenol-chloroform extraction [57]. Purity and yield of the RNA were photometrically determined and $1 \mu \mathrm{g}$ of total RNA was reverse transcribed with Omniscript Reverse Transcriptase in a final volume of $20 \mu$ l (chemicals were obtained from QIAGEN, Germany). PCR primers were constructed on the basis of published nucleotide sequences of the ovine Cav-1 and ovRPS15 cDNA. Ovine ribosomal protein S15 (ovRPS15) was used as house-keeping gene. Primer sequences: Fwd Cav1: 5'-TGATCAGCCGTGTCTATTCC-3', Rev Cav-1: 5'-GCGTGTTGATGCGgATATTGC-3', Probe Cav-1: 5'-GFAM-CGTCCACACCTTCTGTGACCCGCT-TAM-3', Fwd ovRPS15: 5 '-CGAGATGGTGGGCAGCAT-3', Rev ovRPS15: 5 'GCTTGATT TCCACCTGGTTGA-3' and Probe ovRPS15: 5 '-VIC-CCGGCGTCTACAACGG CAAGACC-TAMRA -3'. Cav-1 and ovRPS15 
Regulation of Caveolin-1 by antenatal inflammation in preterm fetal lungs

primers and probes were purchased from Sigma-Aldrich Chemie $\mathrm{GmbH}$ (Munich, Germany). All PCRs were performed with $1 \mu \mathrm{g} / \mu \mathrm{l}$ cDNA per reaction in duplicates of $30 \mu \mathrm{l}$ volume on an ABI Prism 7300 Sequence Detection System (TaqMan) using a 2-step PCR protocol with $40 \mathrm{cycles}$ of $95^{\circ} \mathrm{C}$ for $15 \mathrm{~s}$ and $60^{\circ} \mathrm{C}$ for $1 \mathrm{~min}$. Universal master mix from Applied Biosystems contained all reagents including Taq-polymerase apart from specific primers and probes. The amplification batches did not include template controls. Neither negative controls nor mRNA resulted in elevated fluorescence signals after PCR. Dilution experiments were performed to ensure similar efficiency of the PCRs, and standard curves were calculated based on the threshold cycle to the log of each cDNA dilution step. Results of Cav-1 were normalized to ovRPS15 and mean fold changes in mRNA expression were calculated by the $\Delta \Delta \mathrm{Ct}$-method [58].

\section{Western-Blot analysis}

Frozen lung tissue was homogenized in ice-cold buffer containing $50 \mathrm{mM}$ Tris- $\mathrm{HCl}, \mathrm{pH}$ 7.5, $1 \mathrm{mM}$ EGTA, $1 \mathrm{mM}$ EDTA, and protease inhibitor cocktail (complete minitablets; Roche, Mannheim, Germany) supplemented with $1 \mathrm{mM}$ phenylmethylsulfonyl fluoride (Sigma Chemical, Munich, Germany). The samples were sonicated and then centrifuged at $500 \mathrm{~g}$ for $20 \mathrm{~min}$ at $4^{\circ} \mathrm{C}$ to remove cellular debris. Protein content in the supernatant was determined by the bicinchoninic acid method, with BSA as the standard. Protein samples (50 $\mathrm{\mu g} /$ lane) were boiled and loaded with a molecular weight marker (Invitrogen, Karlsruhe, Germany) on NuPAGE 4-12\% Bis•Tris gel (Invitrogen, Darmstadt, Germany) under reducing conditions. The proteins were electroblotted onto a Hybond-P polyvinylidene difluoride membrane (Amersham Life Science, Freiburg, Germany), and the blots were blocked for $1 \mathrm{~h}$ in $5 \%$ nonfat dry milk in TBS with $0.1 \%$ Tween 20. Western Blots were probed with primary antibodies to Cav-1 (sc-894, Santa Cruz Biotechnology, Santa Cruz, CA, USA), Stat3-P (\#9145, Cell Signaling Technology, Boston, USA), Stat1-P (\#9171, Cell Signaling Technology, Boston, USA) and HO-1 (\#sC1796, Santa Cruz Biotechnology, Santa Cruz, CA, USA), followed by the corresponding horseradish peroxidase-conjugated secondary antibody (Pierce, Bonn, Germany) for $1 \mathrm{~h}$ at room temperature. The reaction was visualized on X-ray medical film (Konica Minolta, Unterföhring, Germany) after incubation of membranes with luminolbased chemiluminescence reagent (Pierce Biotechnology, Rockford, IL) for $1 \mathrm{~min}$. For normalization of the experiments, membranes were stripped, as recommended by the manufacturer (Pierce Biotechnology), and reprobed with an antibody against $\beta$-actin (Santa Cruz Biotechnology). Specific protein bands were visualized using enhanced chemiluminescence (SuperSignal West Dura, Pierce Inc., Bonn, Germany) and detected using the LAS 3000 computer-based luminescent image analyzer (FujiFilm, Tokyo, Japan). Accumulated signals were analyzed using AIDA software (Raytest, Germany). 


\section{Statistical Analysis}

Results are given as means \pm standard error of mean. Comparisons between the groups were performed by analysis of variance (ANOVA) with Student-Newman tests for post hoc analysis. Significance was accepted at $p<0.05$. All statistical analyses were performed using the statistical software GraphPad Prism 5.0 (GraphPad Software, San Diego, CA, USA).

\section{Figure $\mathbf{S 1}$}

initial triggering event (e.g. antenatal inflammation)
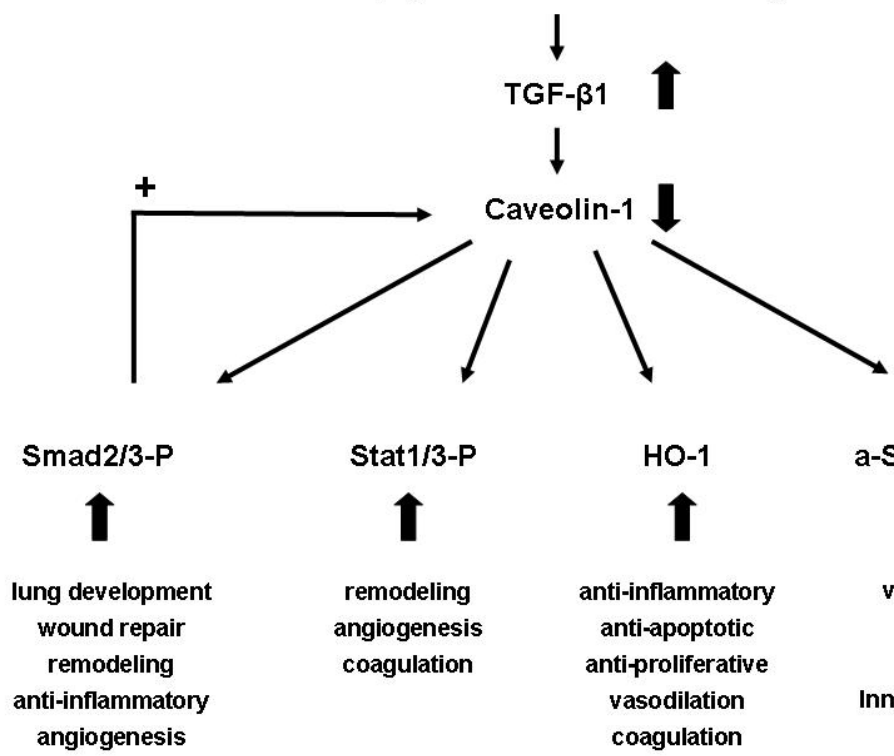

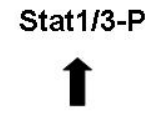

remodeling angiogenesis coagulation
HO-1

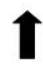

anti-inflammatory anti-apoptotic anti-proliferative vasodilation coagulation
a-SMase/Ceramide

1

vascular permeability vasoconstriction apoptotic Innate/acquired immunity

\section{Figures:}

Figure S1: Model of the possible role of TGF- $\beta 1$, Cav- 1 and downstream mechanisms in remodeling in preterm lungs.

An initial triggering event such as antenatal inflammation results in an increase of TGF- $\beta 1$ mediating a decrease in Cav-1 gene expression. This Cav-1 decrease then shifts TGF- $\beta$ internalization to the EEA-1 pathway, leading to accentuation and perpetuation of the TGF- $\beta 1$ effects and simultaneously causing further down-regulation of Cav- 1 gene expression. One unique feature of this regulatory pathway would be that it provides a plausible mechanism for the perpetuation of TGF- $\beta 1$ effects during airway remodeling following an initial triggering event. In addition, Cav-1 seems to influence other signaling pathways and enzymes in lung, as shown for the Stat- and a-SMase/ ceramide pathways and HO-1 expression, contributing to inflammation and remodeling processes in the preterm injured lung. 
References

1. Thomas, W. and Speer, C.P., Chorioamnionitis: Important Risk Factor or Innocent Bystander for Neonatal Outcome? Neonatology. 99(3): p. 177-187.

2. Kramer, B.W., Kallapur, S., Newnham, J., and Jobe, A.H., Prenatal inflammation and lung development. Semin Fetal Neonatal Med, 2009. 14(1): p. 2-7.

3. Lahra, M.M. and Jeffery, H.E., A fetal response to chorioamnionitis is associated with early survival after preterm birth. Am J Obstet Gynecol, 2004. 190(1): p. 147-51.

4. Yoon, B.H., Jun, J.K., Romero, R., Park, K.H., Gomez, R., Choi, J.H., and Kim, I.O., Amniotic fluid inflammatory cytokines (interleukin-6, interleukin-1beta, and tumor necrosis factoralpha), neonatal brain white matter lesions, and cerebral palsy. Am J Obstet Gynecol, 1997. 177(1): p. 19-26.

5. Gantert, M., Been, J.V., Gavilanes, A.W., Garnier, Y., Zimmermann, L.J., and Kramer, B.W., Chorioamnionitis: a multiorgan disease of the fetus? J Perinatol. 30 Suppl: p. S21-30.

6. Jobe, A.J., The new BPD: an arrest of lung development. Pediatr Res, 1999. 46(6): p. 641-3.

7. Razani, B., Engelman, J.A., Wang, X.B., Schubert, W., Zhang, X.L., Marks, C.B., Macaluso, F., Russell, R.G., Li, M., Pestell, R.G., Di Vizio, D., Hou, H., Jr., Kneitz, B., Lagaud, G., Christ, G.J., Edelmann, W., and Lisanti, M.P., Caveolin-1 null mice are viable but show evidence of hyperproliferative and vascular abnormalities. J Biol Chem, 2001. 276(41): p. 38121-38.

8. Jin, Y., Lee, S.J., Minshall, R.D., and Choi, A.M., Caveolin-1: a critical regulator of lung injury. Am J Physiol Lung Cell Mol Physiol.

9. Williams, T.M. and Lisanti, M.P., The Caveolin genes: from cell biology to medicine. Ann Med, 2004. 36(8): p. 584-95.

10. Gosens, R., Mutawe, M., Martin, S., Basu, S., Bos, S.T., Tran, T., and Halayko, A.J., Caveolae and caveolins in the respiratory system. Curr Mol Med, 2008. 8(8): p. 741-53.

11. Santibanez, J.F., Blanco, F.J., Garrido-Martin, E.M., Sanz-Rodriguez, F., del Pozo, M.A., and Bernabeu, C., Caveolin-1 interacts and cooperates with the transforming growth factor-beta type I receptor ALK1 in endothelial caveolae. Cardiovasc Res, 2008. 77(4): p. 791-9.

12. Jasmin, J.F., Mercier, I., Hnasko, R., Cheung, M.W., Tanowitz, H.B., Dupuis, J., and Lisanti, M.P., Lung remodeling and pulmonary hypertension after myocardial infarction: pathogenic role of reduced caveolin expression. Cardiovasc Res, 2004. 63(4): p. 747-55.

13. Sehgal, P.B., Guo, G.G., Shah, M., Kumar, V., and Patel, K., Cytokine signaling: STATS in plasma membrane rafts. J Biol Chem, 2002. 277(14): p. 12067-74.

14. Bennett, D. and Alphey, L., PP1 binds Sara and negatively regulates Dpp signaling in Drosophila melanogaster. Nat Genet, 2002. 31(4): p. 419-23.

15. Veldman, R.J., Maestre, N., Aduib, O.M., Medin, J.A., Salvayre, R., and Levade, T., A neutral sphingomyelinase resides in sphingolipid-enriched microdomains and is inhibited by the caveolin-scaffolding domain: potential implications in tumour necrosis factor signalling. Biochem J, 2001. 355(Pt 3): p. 859-68.

16. Yang, Y., Yin, J., Baumgartner, W., Samapati, R., Solymosi, E.A., Reppien, E., Kuebler, W.M., and Uhlig, S., Platelet-activating factor reduces endothelial nitric oxide production: role of acid sphingomyelinase. Eur Respir J. 36(2): p. 417-27.

17. Gao, H. and Ward, P.A., STAT3 and suppressor of cytokine signaling 3: potential targets in lung inflammatory responses. Expert Opin Ther Targets, 2007. 11(7): p. 869-80.

18. Severgnini, M., Takahashi, S., Rozo, L.M., Homer, R.J., Kuhn, C., Jhung, J.W., Perides, G., Steer, M., Hassoun, P.M., Fanburg, B.L., Cochran, B.H., and Simon, A.R., Activation of the STAT pathway in acute lung injury. Am J Physiol Lung Cell Mol Physiol, 2004. 286(6): p. L1282-92.

19. Severgnini, M., Takahashi, S., Tu, P., Perides, G., Homer, R.J., Jhung, J.W., Bhavsar, D., Cochran, B.H., and Simon, A.R., Inhibition of the Src and Jak kinases protects against lipopolysaccharide-induced acute lung injury. Am J Respir Crit Care Med, 2005. 171(8): p. 
858-67.

20. Uhlig, S. and Gulbins, E., Sphingolipids in the lungs. Am J Respir Crit Care Med, 2008. 178(11): p. 1100-14.

21. von Bismarck, P., Wistadt, C.F., Klemm, K., Winoto-Morbach, S., Uhlig, U., Schutze, S., Adam, D., Lachmann, B., Uhlig, S., and Krause, M.F., Improved pulmonary function by acid sphingomyelinase inhibition in a newborn piglet lavage model. Am J Respir Crit Care Med, 2008. 177(11): p. 1233-41.

22. Jin, Y., Kim, H.P., Chi, M., Ifedigbo, E., Ryter, S.W., and Choi, A.M., Deletion of caveolin-1 protects against oxidative lung injury via up-regulation of heme oxygenase-1. Am J Respir Cell Mol Biol, 2008. 39(2): p. 171-9.

23. Fredenburgh, L.E., Perrella, M.A., and Mitsialis, S.A., The role of heme oxygenase-1 in pulmonary disease. Am J Respir Cell Mol Biol, 2007. 36(2): p. 158-65.

24. Kunzmann, S., Speer, C.P., Jobe, A.H., and Kramer, B.W., Antenatal inflammation induced TGF-beta1 but suppressed CTGF in preterm lungs. Am J Physiol Lung Cell Mol Physiol, 2007. 292(1): p. L223-31.

25. Wang, X.M., Zhang, Y., Kim, H.P., Zhou, Z., Feghali-Bostwick, C.A., Liu, F., Ifedigbo, E., Xu, X., Oury, T.D., Kaminski, N., and Choi, A.M., Caveolin-1: a critical regulator of lung fibrosis in idiopathic pulmonary fibrosis. J Exp Med, 2006. 203(13): p. 2895-906.

26. Igarashi, J., Shoji, K., Hashimoto, T., Moriue, T., Yoneda, K., Takamura, T., Yamashita, T., Kubota, Y., and Kosaka, H., Transforming growth factor-beta1 downregulates caveolin-1 expression and enhances sphingosine 1-phosphate signaling in cultured vascular endothelial cells. Am J Physiol Cell Physiol, 2009. 297(5): p. C1263-74.

27. Ding, H., Zhou, F.Q., Cai, H.R., Zhou, Y.H., and Meng, F.Q., [Expression of caveolin-1 and extracellular matrix induced by transforming growth factor beta1 in human fetal lung fibroblasts]. Zhonghua Jie He He Hu Xi Za Zhi. 33(4): p. 280-3.

28. Kramer, B.W., Moss, T.J., Willet, K.E., Newnham, J.P., Sly, P.D., Kallapur, S.G., Ikegami, M., and Jobe, A.H., Dose and time response after intraamniotic endotoxin in preterm lambs. Am J Respir Crit Care Med, 2001. 164(6): p. 982-8.

29. Kramer, B.W., Kallapur, S.G., Moss, T.J., Nitsos, I., Newnham, J.P., and Jobe, A.H., Intraamniotic LPS modulation of TLR signaling in lung and blood monocytes of fetal sheep. Innate Immun, 2009. 15(2): p. 101-7.

30. Kramer, B.W., Kramer, S., Ikegami, M., and Jobe, A.H., Injury, inflammation, and remodeling in fetal sheep lung after intra-amniotic endotoxin. Am J Physiol Lung Cell Mol Physiol, 2002. 283(2): p. L452-9.

31. Wiegmann, K., Schutze, S., Machleidt, T., Witte, D., and Kronke, M., Functional dichotomy of neutral and acidic sphingomyelinases in tumor necrosis factor signaling. Cell, 1994. 78(6): p. 1005-15.

32. Jensen, J.M., Schutze, S., Forl, M., Kronke, M., and Proksch, E., Roles for tumor necrosis factor receptor $p 55$ and sphingomyelinase in repairing the cutaneous permeability barrier. J Clin Invest, 1999. 104(12): p. 1761-70.

33. Benjamin, J.T., Carver, B.J., Plosa, E.J., Yamamoto, Y., Miller, J.D., Liu, J.H., van der Meer, R., Blackwell, T.S., and Prince, L.S., NF-kappaB activation limits airway branching through inhibition of Sp1-mediated fibroblast growth factor-10 expression. J Immunol. 185(8): p. 4896-903.

34. Benjamin, J.T., Gaston, D.C., Halloran, B.A., Schnapp, L.M., Zent, R., and Prince, L.S., The role of integrin alpha8beta1 in fetal lung morphogenesis and injury. Dev Biol, 2009. 335(2): p. 407-17.

35. Kunzmann, S., Glogger, K., Been, J.V., Kallapur, S.G., Nitsos, I., Moss, T.J., Speer, C.P., Newnham, J.P., Jobe, A.H., and Kramer, B.W., Thymic changes after chorioamnionitis induced by intraamniotic lipopolysaccharide in fetal sheep. Am J Obstet Gynecol. 202(5): p. 476 e1-9. 
36. Moss, T.J., Newnham, J.P., Willett, K.E., Kramer, B.W., Jobe, A.H., and Ikegami, M., Early gestational intra-amniotic endotoxin: lung function, surfactant, and morphometry. Am J Respir Crit Care Med, 2002. 165(6): p. 805-11.

37. Wolfs, T.G., Buurman, W.A., Zoer, B., Moonen, R.M., Derikx, J.P., Thuijls, G., Villamor, E., Gantert, M., Garnier, Y., Zimmermann, L.J., and Kramer, B.W., Endotoxin induced chorioamnionitis prevents intestinal development during gestation in fetal sheep. PLoS One, 2009. 4(6): p. e5837.

38. Jobe, A.H., Newnham, J.P., Willet, K.E., Moss, T.J., Gore Ervin, M., Padbury, J.F., Sly, P., and Ikegami, M., Endotoxin-induced lung maturation in preterm lambs is not mediated by cortisol. Am J Respir Crit Care Med, 2000. 162(5): p. 1656-61.

39. Kallapur, S.G., Moss, T.J., Auten, R.L., J., Nitsos, I., Pillow, J.J., Kramer, B.W., Maeda, D.Y., Newnham, J.P., Ikegami, M., and Jobe, A.H., IL-8 signaling does not mediate intra-amniotic LPS-induced inflammation and maturation in preterm fetal lamb lung. Am J Physiol Lung Cell Mol Physiol, 2009. 297(3): p. L512-9.

40. Kallapur, S.G., Nitsos, I., Moss, T.J., Polglase, G.R., Pillow, J.J., Cheah, F.C., Kramer, B.W., Newnham, J.P., Ikegami, M., and Jobe, A.H., IL-1 mediates pulmonary and systemic inflammatory responses to chorioamnionitis induced by lipopolysaccharide. Am J Respir Crit Care Med, 2009. 179(10): p. 955-61.

41. DiGiulio, D.B., Romero, R., Amogan, H.P., Kusanovic, J.P., Bik, E.M., Gotsch, F., Kim, C.J., Erez, O., Edwin, S., and Relman, D.A., Microbial prevalence, diversity and abundance in amniotic fluid during preterm labor: a molecular and culture-based investigation. PLoS One, 2008. 3(8): p. e3056.

42. Kotecha, S., Wangoo, A., Silverman, M., and Shaw, R.J., Increase in the concentration of transforming growth factor beta-1 in bronchoalveolar lavage fluid before development of chronic lung disease of prematurity. J Pediatr, 1996. 128(4): p. 464-9.

43. Lecart, C., Cayabyab, R., Buckley, S., Morrison, J., Kwong, K.Y., Warburton, D., Ramanathan, R., Jones, C.A., and Minoo, P., Bioactive transforming growth factor-beta in the lungs of extremely low birthweight neonates predicts the need for home oxygen supplementation. Biol Neonate, 2000. 77(4): p. 217-23.

44. Del Galdo, F., Lisanti, M.P., and Jimenez, S.A., Caveolin-1, transforming growth factor-beta receptor internalization, and the pathogenesis of systemic sclerosis. Curr Opin Rheumatol, 2008. 20(6): p. 713-9.

45. Di Guglielmo, G.M., Le Roy, C., Goodfellow, A.F., and Wrana, J.L., Distinct endocytic pathways regulate TGF-beta receptor signalling and turnover. Nat Cell Biol, 2003. 5(5): p. 410-21.

46. Le Saux, O., Teeters, K., Miyasato, S., Choi, J., Nakamatsu, G., Richardson, J.A., Starcher, B., Davis, E.C., Tam, E.K., and Jourdan-Le Saux, C., The role of caveolin-1 in pulmonary matrix remodeling and mechanical properties. Am J Physiol Lung Cell Mol Physiol, 2008. 295(6): p. L1007-17.

47. Le Saux, C.J., Teeters, K., Miyasato, S.K., Hoffmann, P.R., Bollt, O., Douet, V., Shohet, R.V., Broide, D.H., and Tam, E.K., Down-regulation of caveolin-1, an inhibitor of transforming growth factor-beta signaling, in acute allergen-induced airway remodeling. J Biol Chem, 2008. 283(9): p. 5760-8.

48. Razani, B., Zhang, X.L., Bitzer, M., von Gersdorff, G., Bottinger, E.P., and Lisanti, M.P., Caveolin-1 regulates transforming growth factor (TGF)-beta/SMAD signaling through an interaction with the TGF-beta type I receptor. J Biol Chem, 2001. 276(9): p. 6727-38.

49. Darnell, J.E., Jr., STATs and gene regulation. Science, 1997. 277(5332): p. 1630-5.

50. Park, D.S., Lee, H., Frank, P.G., Razani, B., Nguyen, A.V., Parlow, A.F., Russell, R.G., Hulit, J., Pestell, R.G., and Lisanti, M.P., Caveolin-1-deficient mice show accelerated mammary gland development during pregnancy, premature lactation, and hyperactivation of the Jak-2/ STAT5a signaling cascade. Mol Biol Cell, 2002. 13(10): p. 3416-30. 


\section{Chapter 4}

51. Marchesini, N. and Hannun, Y.A., Acid and neutral sphingomyelinases: roles and mechanisms of regulation. Biochem Cell Biol, 2004. 82(1): p. 27-44.

52. Kim, H.P., Wang, X., Galbiati, F., Ryter, S.W., and Choi, A.M., Caveolae compartmentalization of heme oxygenase-1 in endothelial cells. Faseb J, 2004. 18(10): p. 1080-9.

53. Farkas, I., Maroti, Z., Katona, M., Endreffy, E., Monostori, P., Mader, K., and Turi, S., Increased heme oxygenase-1 expression in premature infants with respiratory distress syndrome. Eur J Pediatr, 2008. 167(12): p. 1379-83.

54. Maroti, Z., Katona, M., Orvos, H., Nemeth, I., Farkas, I., and Turi, S., Heme oxygenase-1 expression in premature and mature neonates during the first week of life. Eur J Pediatr, 2007. 166(10): p. 1033-8.

55. Razani, B. and Lisanti, M.P., Caveolin-deficient mice: insights into caveolar function human disease. J Clin Invest, 2001. 108(11): p. 1553-61.

56. Tourkina, E., Richard, M., Gooz, P., Bonner, M., Pannu, J., Harley, R., Bernatchez, P.N., Sessa, W.C., Silver, R.M., and Hoffman, S., Antifibrotic properties of caveolin-1 scaffolding domain in vitro and in vivo. Am J Physiol Lung Cell Mol Physiol, 2008. 294(5): p. L843-61.

57. Kallapur, S.G., Willet, K.E., Jobe, A.H., Ikegami, M., and Bachurski, C.J., Intra-amniotic endotoxin: chorioamnionitis precedes lung maturation in preterm lambs. Am J Physiol Lung Cell Mol Physiol, 2001. 280(3): p. L527-36.

58. Livak, K.J. and Schmittgen, T.D., Analysis of relative gene expression data using real-time quantitative PCR and the 2(-Delta Delta C(T)) Method. Methods, 2001. 25(4): p. 402-8. 


\section{Antenatal glucocorticoids}

counteract LPS changes in TGF $\beta$ pathway and Caveolin-1 in ovine fetal lung

Collins JJP*, Kunzmann S*, Kuypers E, Kemp MW, Speer CP, Newnham JP, Kallapur SG, Jobe AH, Kramer BW

Submitted 
Abstract

Inflammation and antenatal glucocorticoids, the latter given to mothers at risk for preterm birth, affect lung development and may contribute to the development of bronchopulmonary dysplasia (BPD). The effects of the combined exposures on inflammation and antenatal glucocorticoids on transforming growth factor (TGF) $\beta$ signaling are unknown. TGF $\beta$ and its downstream mediators are implicated in the etiology of BPD. Therefore we asked whether glucocorticoids altered intra-amniotic lipopolysaccharide (LPS) effects on TGF $\beta$ expression, its signaling molecule pSmad2, and the downstream mediators connective tissue growth factor (CTGF) and Caveolin-1 (Cav1). Ovine singleton fetuses were randomized to receive either an intra-amniotic injection of LPS and/or maternal betamethasone (Beta) intra-muscularly with delivery at 120 days $\mathrm{GA}$ (term=150 days GA). Saline was used for controls. Protein levels of TGF $\beta 1$ and 2 were measured by ELISA. pSmad2 expression was assessed by immunohistochemistry. CTGF and Cav-1 mRNA and protein levels were determined by RT-PCR and Western blot. Free TGF $\beta 1$ and 2 and total TGF $\beta 1$ levels were unchanged after LPS and/or Beta exposure, although total TGF $\beta 2$ increased in animals exposed to Beta 7 days before LPS. Smad2 phosphorylation increased 7 days after LPS exposure. Similarly, CTGF mRNA and protein levels increased 7 days after LPS exposure as Cav-1 mRNA and protein levels decreased. Beta exposure prior to LPS prevented Smad2 phosphorylation, CTGF induction and Cav-1 down-regulation. This study demonstrated that the intra-uterine inflammation induced TGF $\beta$ signaling can be inhibited by antenatal glucocorticoids in fetal lungs.

\section{Introduction}

A high percentage of preterm infants is exposed to antenatal inflammation [1, 2], including chorioamnionitis [3], sepsis [4, 5], inflammation resulting from oxidative stress [6] and volutrauma [7], or a combination of these pre- and postnatal causes of inflammation. Exposure to inflammation is associated with the development of bronchopulmonary dysplasia (BPD) [7-9]. BPD is characterized by a decrease in alveolarization and vascularization and by the need for supplemental oxygen [10]. The etiology of BPD is multifactorial and very complex. For example, in clinical practice, antenatal glucocorticoids are given to women at risk for preterm birth. However, glucocorticoids also inhibit alveolarization [11, 12].

Transforming growth factor $\beta$ (TGF $\beta$ ), as a mediator of inflammation, has been linked to the etiology of BPD $[13,14]$. The relevance of TGF $\beta$ in BPD is supported by findings in several animal models [15-18]. Interestingly, glucocorticoids decrease TGF $\beta$ production in experimental models with pulmonary cells $[19,20]$. TGF $\beta$ is expressed in three isoforms, TGF $\beta 1, T G F \beta 2$ and TGF $\beta 3$, each of which have distinct roles in the developing lung as 
regulators of cell proliferation, remodeling, repair [21,22] and as an anti-inflammatory cytokine [21]. With activation by cleavage from the latent TGF $\beta$ binding protein (LTBP), TGF $\beta$ binds TGF $\beta$ receptor II (TGF $\beta$ RII), which then forms a complex with TGF $\beta$ receptor I (TGF $\beta R I)[21,22]$. TGF $\beta R I$ then can phosphorylate Smad2 and -3, which in turn complex with Smad4, leading to TGF $\beta$ activated gene transcription [21, 22]. TGF $\beta$ also has effects through several downstream mediators, including connective tissue growth factor (CTGF) and Caveolin-1 (Cav-1). CTGF contributes to tissue remodeling and fibrosis [23] and may contribute to the pathogenesis of BPD through both ventilation mediated injury and inflammation $[17,24,25]$. Cav-1 is a component of caveolae, omega-shaped invaginations of the plasma membrane which facilitate protein trafficking and signal transduction [26, 27]. Cav-1 regulates the contractile phenotype of maturing airway smooth muscle cells under influence of TGF $\beta 1$ [28]. Altered expression of Cav-1 has been implicated in the pathogenesis of several lung diseases [29]. Cav ${ }^{-/}$mice have thickened alveolar walls and irregular alveolar spaces with increased deposition of extracellular matrix and TGF $\beta$ activity, whereas overexpression of Cav-1 aggravates LPS-induced inflammation and subsequent lung injury $[26,30]$.

Previously, we reported that TGF $\beta 1$ and pSmad2 were up-regulated in fetal lambs exposed to intra-uterine LPS and brief postnatal ventilation [17, 31]. These increases were associated with down regulation of CTGF and Cav-1 [17, 31]. It is however unknown how a combined exposure to antenatal inflammation and glucocorticoids, common for many preterm fetuses $[32,33]$, might affect TGF $\beta$ signaling and its downstream mediators. Therefore we asked whether glucocorticoids alter the effect of LPS on TGF $\beta$ expression, the phosphorylation of its transcription factor $\operatorname{Smad2}$, and the expression of its regulated genes CTGF and Cav-1. We hypothesized that maternal betamethasone would modulate LPS induced activation of the TGF $\beta$ signaling pathway and the expression of CTGF and Cav-1.

\section{Materials and methods}

\section{Animal model and sampling protocol}

All studies were approved by the Animal Ethics Committees at The University of Western Australia (animal ethics protocol RA/3/100/830) and Cincinnati Children's Hospital Medical Center. The experimental design and lung maturation outcome of this study was published previously [34]. Time-mated ewes with singleton fetuses were randomly assigned to one of six treatment groups to receive an intra-amniotic (IA) injection of lipopolysaccharide (LPS) (10 mg Escherichia Coli 055:B5, Sigma Aldrich, St. Louis, MO, USA) and/or an intra-muscular injection of betamethasone (Beta) (Celestone Soluspan, 
Schering-Plough, North Ryde, New South Wales (NSW), Australia, $0.5 \mathrm{mg} / \mathrm{kg}$ maternal weight) and/or an equivalent injection of saline for control animals at 107 days and/ or 114 days GA. An overview of the number of animals included in each group is presented in table 1 . Due to fetal losses, the animals that had been assigned to a 14 day

Table 1: Group names and animal numbers

\begin{tabular}{cc} 
Group & Number of animals ( $\mathbf{n})$ \\
\hline Control & 5 \\
7d LPS & 8 \\
14d LPS & 8 \\
7d Beta & 7 \\
14d Beta + 7d LPS & 6 \\
14d LPS + 7d Beta & 8
\end{tabular}

LPS - lipopolysaccharide; Beta - betamethasone; d - day

betamethasone group were reassigned to other groups as combined exposures were given a higher priority [34]. All ewes in this study received a single intra-muscular injection of $150 \mathrm{mg}$ medroxyprogesterone acetate (Depo-Provera, Kenral, NSW, Australia) at 100 days $G A$ to reduce the risk of preterm birth induced by betamethasone treatment. Lambs were surgically delivered at 120 days GA (term $=150$ days GA) and euthanized directly after birth. Lung tissue from the right lower lobe was snap frozen and the right upper lobe was inflation-fixed in $10 \%$ buffered formalin for 24 hours.

\section{Analysis of TGF $\beta 1$ and TGF $\beta 2$}

Frozen lung tissue was homogenized (PRO Quick Connect Generators part no. 02-07095; PRO Scientific Inc., Oxford, CT) in ice-cold RIPA buffer (Sigma Aldrich) containing 0.1\% protease inhibitors (Sigma Aldrich) and subsequently centrifuged at 12 rcf for 5 minutes at $4^{\circ} \mathrm{C}$. Free, bound and total TGF $\beta 1$ and TGF $\beta 2$ (referred to by R\&D Systems as active, latent and total TGF $\beta$ ) were measured with R\&D DuoSet ELISA development kits (human TGFß1: DY240, human TGF 32 : DY302, R\&D Systems, Minneapolis, MN, USA) according to manufacturer's instructions. Protein concentrations of TGF $\beta 1$ and TGF $\beta 2$ were calculated per kilogram bodyweight.

\section{Immunohistochemistry}

Paraffin embedded lung sections ( $4 \mu \mathrm{m}$, transverse) were stained for phosphorylated mothers against decapentaplegic homolog 2 (pSmad2, Ser465/467) (\#3101, Cell Signaling Technology, Boston, USA) and connective tissue growth factor (CTGF) (sc14939, Santa Cruz Biotechnology, Santa Cruz, USA). CTGF staining was performed as 
Effects of betamethasone and LPS on TGF $\beta$ signaling

described previously [35]. For pSmad2, the sections were deparaffinized in an ethanol series and endogenous peroxidase-activity was blocked by incubation with $3 \% \mathrm{H}_{2} \mathrm{O}_{2}$ in milli-Q. Antigen retrieval was performed by incubating the sections in heated citrate buffer (10 mM, pH 6.0) for 30 minutes. In order to block aspecific binding, the slides were incubated with $5 \%$ NGS in $1 x$ tris-buffered saline (TBS, pH 7.6) with $0.1 \%$ Tween. Sections were incubated overnight at $4^{\circ} \mathrm{C}$ with the diluted primary antibody (pSmad2: 1/2000, CTGF: $1 / 75)$. After incubation with the appropriate secondary antibody, immunostaining was enhanced with Vectastain ABC peroxidase Elite kit (PK-6200, Vector Laboratories, Burlingame, USA) and stained with nickel sulfate-diaminobenzidine (NiDAB). Subsequently, the sections were rinsed in Tris/saline and incubated with Tris/ cobalt. After counterstaining with $0.1 \%$ Nuclear Fast Red, the sections were washed and dehydrated. Evaluation was performed by light microscopy (Axioskop 40, Zeiss, Germany) with LeicaQWin Pro v.3.4.0 software (Leica Microsystems, Germany). Sections were scored for positive $\mathrm{pSmad} 2$ or CTGF with a semi-quantitative scoring system by a blinded observer: 1 - little staining, 2 - some staining, 3 - strong staining, 4 - very strong staining.

\section{RNA extraction and real-time PCR}

Total RNA was extracted from frozen lung tissue using the SV Total RNA Isolation system (Z3100, Promega, Madison, USA) according to the manufacturer's instructions. Genomic DNA contamination was removed by treatment with RQ1 DNase (M610A, Promega) and the RNA was tested for the presence of genomic GAPDH as described previously. Total RNA was reverse transcribed with the First Strand cDNA synthesis kit (4379012001, Roche-Applied, Mannheim, Germany) according to manufacturer's instructions using anchored oligo-primers. RT-PCR reactions were performed in duplicate with the LightCycler 480 SYBR Green I Master mix (4707516001, Roche-Applied) on a LightCycler 480 Instrument according to the manufacturer's instructions. RT-PCR results were normalized to ovRSP15 [31], a housekeeping gene, and mean fold changes in mRNA expression were calculated by the $\Delta \Delta \mathrm{Ct}$-method [36]. CTGF primers were based on the published CTGF cDNA sequence of Ovis aries (NM_001164714.1). CTGF primer sequences: FW: 5'- TATAGCTCCAGCGACAGCTC-3', RV: 5' - ACGAACTTGACTCAGCCTCA-3', amplicon size $=64 \mathrm{bp}, \mathrm{Tm}=62^{\circ} \mathrm{C}$. Cav-1 primers have been reported previously [31].

\section{Western blot}

The western blot for caveolin-1 was performed as described previously [31]. Briefly, frozen lung tissue was homogenized in ice-cold buffer containing $50 \mathrm{mM}$ Tris $\bullet \mathrm{HCl}, \mathrm{pH}$ 7.5, 1 mM EGTA, 1 mM EDTA, and protease inhibitor cocktail (complete minitablets; 11836153, Roche-Applied) supplemented with $1 \mathrm{mM}$ phenylmethylsulfonyl fluoride 
(Sigma Aldrich). The samples were sonicated and then centrifuged at $500 \mathrm{~g}$ for $20 \mathrm{~min}$ at $4^{\circ} \mathrm{C}$ to remove cellular debris. Protein content in the supernatant was determined by the bicinchoninic acid method, with BSA as the standard. Protein samples (50 $\mathrm{\mu g} /$ lane) were boiled ( 5 minutes, $95^{\circ} \mathrm{C}$ ) and loaded with a molecular weight marker (LC5602, Invitrogen-Life Technologies Ltd, Paisley, UK) on NuPAGE 4-12\% Bis•Tris gel (NP0321PK2, Invitrogen) under reducing conditions. The proteins were electroblotted onto a Hybond-P polyvinylidene difluoride membrane (RPN1416F, Amersham Life Science, Freiburg, Germany), and the blots were blocked for $1 \mathrm{~h}$ in $5 \%$ nonfat dry milk in $1 x$ TBS with $0.1 \%$ Tween 20 . Western Blots were probed with primary antibodies to Cav-1 (sc-894, Santa Cruz Biotechnology), followed by the corresponding horseradish peroxidase-conjugated secondary antibody (32430/32460, Pierce, Bonn, Germany) for $1 \mathrm{~h}$ at room temperature. The reaction was visualized on X-ray medical film (Konica Minolta, Unterföhring, Germany) after incubation of membranes with luminol-based chemiluminescence reagent (32106, Pierce Biotechnology, Rockford, IL) for $1 \mathrm{~min}$. For normalization of the experiments, membranes were stripped, as recommended by the manufacturer (Pierce Biotechnology), and reprobed with an antibody against $\beta$-actin (sc-130301, Santa Cruz Biotechnology). Specific protein bands were visualized using enhanced chemiluminescence (SuperSignal West Dura, Pierce Biotechnology) and detected using the LAS 3000 computer-based luminescent image analyzer (FujiFilm, Tokyo, Japan). Accumulated signals were analyzed using AIDA software (Raytest, Germany).

\section{Data analysis}

Results are given as means \pm standard error of mean (SEM). The groups were compared using one-way ANOVA with Tukey's test for post-hoc analysis. Statistical analysis was performed by GraphPad Prism v5.0. Significance was accepted at $p<0.05$.

\section{Results}

\section{LPS and betamethasone induced expression of TGF $\beta$ pathway members}

Exposure to LPS and/or betamethasone did not change the amount of free (Figure 1A) and total (Figure 1B) TGF $\beta 1$ in the fetal lung tissue compared to controls. The amount of free TGF $\beta 2$ (Figure 1C) also remained unchanged. Total TGF $\beta 2$ levels increased in the animals that were exposed to betamethasone 7 days before exposure to LPS (Figure 1D). There was a non-significant trend towards increased TGF $\beta 1$ and 2 expressions in the fetal lung 7 days after the LPS exposure.

Expression of pSmad2 was mainly detected in the nucleus of epithelial cells. The relative 
expression of pSmad2 increased 7 days after the exposure to LPS compared to controls (Figure 2E). Treatment with betamethasone 7 days before the exposure to LPS prevented the increase in pSmad2. Representative images are shown for controls (Figure 2A), 7 day betamethasone exposed lungs (Figure 2B), 7 day LPS exposed lungs (Figure 2C) and 14 day betamethasone followed by LPS exposed lungs (Figure 2D).

CTGF mRNA levels increased 7 days after the exposure to LPS, and this increase was prevented by betamethasone treatment 7 days before LPS exposure (Figure $3 \mathrm{~A}$ ). Relative CTGF protein expression showed similar changes with increased expression after LPS exposure (Figure 3B). Treatment with betamethasone before the exposure to LPS prevented the increase in CTGF protein expression.

A

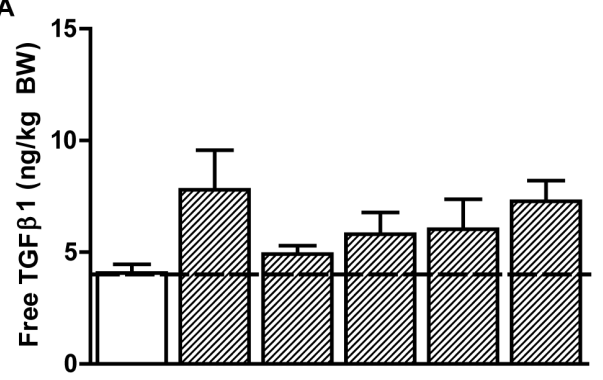

C

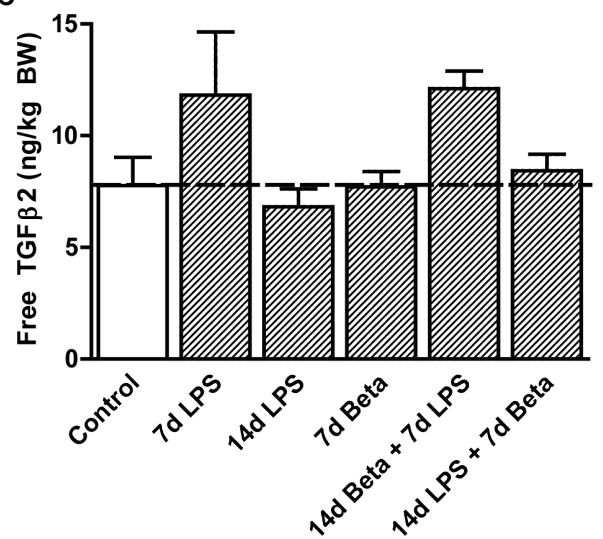

B

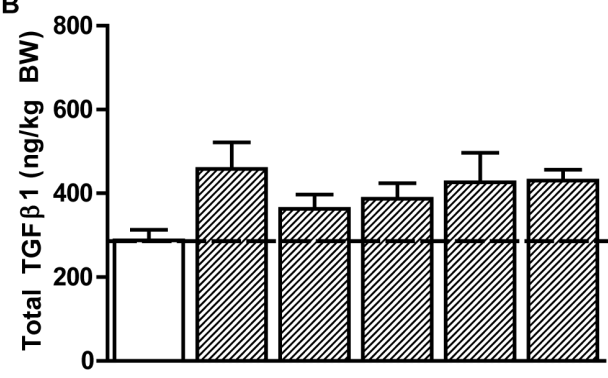

D

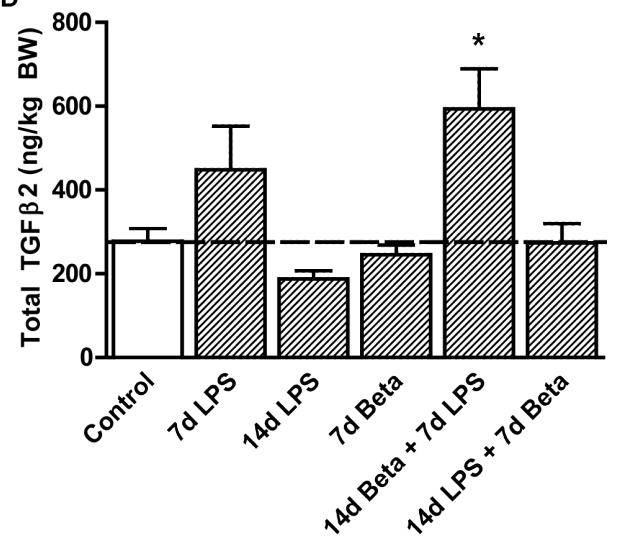

Figure 1: Expression of TGF $\beta 1$ and 2 in the fetal lung.

A: Protein expression of free TGF $\beta 1$ in the fetal lung tissue did not change by exposure to intraamniotic LPS and/or maternal betamethasone. B: Total TGF $\beta 1$ was unchanged by LPS and/or betamethasone exposure. C: LPS and/or betamethasone exposure did not change the protein expression of free TGF $\beta 2$. D: Total TGF $\beta 2$ levels increased in the animals that were exposed to betamethasone 7 days before exposure to LPS.BW - bodyweight. ${ }^{*} p<0.05$ versus controls using a one-way ANOVA with Tukey's post hoc test. 

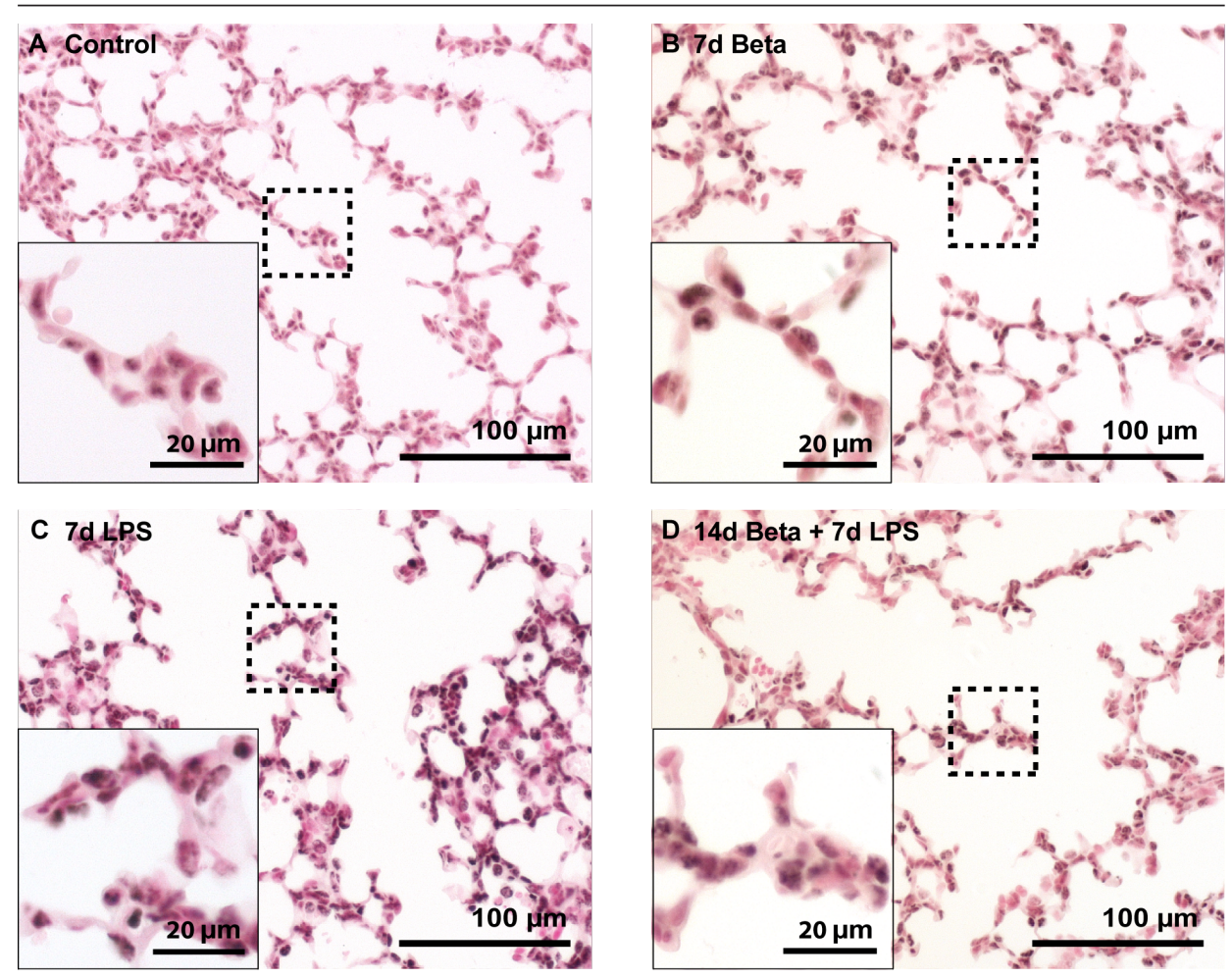

E pSMAD2 expression

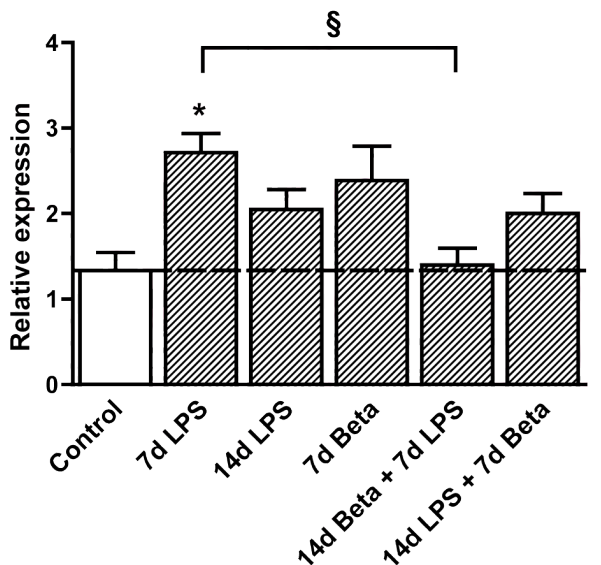

Figure 2: Betamethasone prevented LPS-mediated induction of pSmad2.

Phosphorylated-Smad2 (pSmad2) expression in alveolar tissue as seen in controls (A), 7 days after betamethasone (Beta) treatment (B) 7 days after LPS exposure (C) and after a combination of pretreatment with Beta followed by 7 days LPS (D). E: The relative expression of pSmad2 increased 7 days after the exposure to LPS compared to controls and was prevented by betamethasone pretreatment. * $p<0.05$ versus controls and $\S p<0.05$ between experimental groups using a one-way ANOVA with Tukey's post hoc test. 
Effects of betamethasone and LPS on TGF $\beta$ signaling

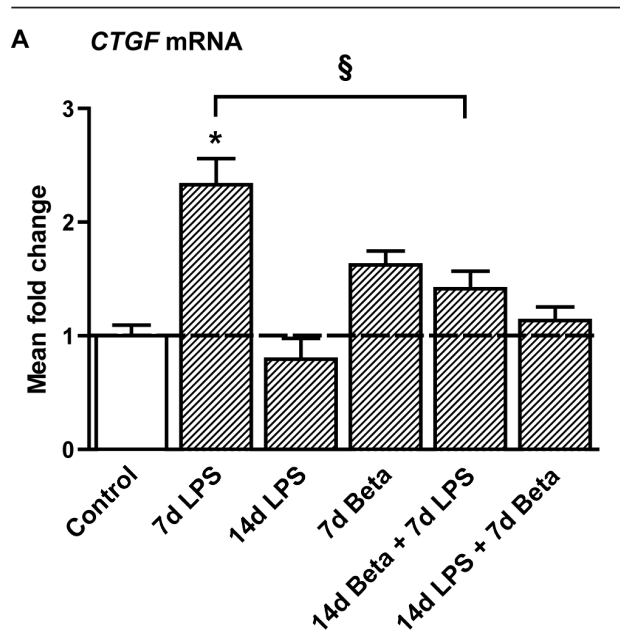

B CTGF expression

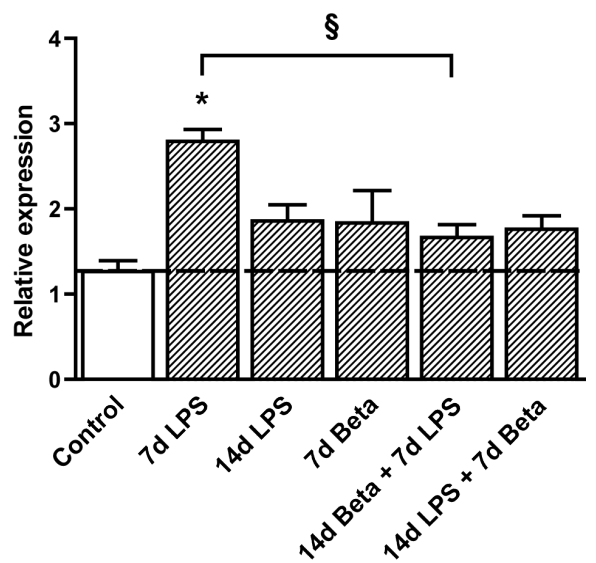

Figure 3: Betamethasone prevented LPS-mediated induction of CTGF expression.

A: CTGF mRNA levels increased 7 days after the exposure to LPS in the fetal lung which was prevented by betamethasone pre-treatment. B: 7 days after the exposure to LPS CTGF protein expression increased. Pre-treatment with betamethasone before the exposure to LPS prevented the increase in CTGF protein expression. * $p<0.05$ versus controls and $\S p<0.05$ between experimental groups using a one-way ANOVA with Tukey's post hoc test.

\section{Betamethasone prevented decreased Caveolin-1 expression after LPS exposure}

Intra-amniotic LPS decreased Caveolin-1 mRNA levels (Figure 4A) and protein expression (Figure 4B) 7 days after the exposure by $50 \%$ compared to controls. Treatment with betamethasone prior to the LPS exposure prevented this decrease. Betamethasone treatment 7 days after the exposure to LPS increased Caveolin-1 mRNA compared to a single 14 day LPS exposure.

\section{Discussion}

Antenatal exposure to either inflammation or glucocorticoids causes maturational responses in the developing lung, but also contributes to the development of BPD [10, 37]. A combination of these exposures in preterm neonates is frequent $[33,38]$, yet it is unclear whether these stimuli create additive or antagonistic effects on signaling pathways that direct lung development.

Recently, we demonstrated in preterm sheep that exposure to intra-amniotic LPS 14 days and maternal betamethasone 7 days before preterm delivery caused a larger maturational response than either agent alone, as measured by surfactant production and lung compliance [34]. A recent meta-analysis by Been and colleagues also concluded 
Figure 4: LPS exposure decreased Caveolin-1 expression in the fetal lung.

A: Intra-amniotic LPS decreased caveolin-1 mRNA levels 7 days after the exposure by $50 \%$ compared to controls. Pre-treatment with betamethasone prior to the LPS exposure prevented this decrease. Betamethasone treatment 7 days after the exposure to LPS also increased caveolin-1 mRNA compared to animals only exposed to LPS for 14 days. B: Caveolin-1 protein expression decreased 7 days after LPS exposure which was prevented by betamethasone pre-treatment. $* \mathrm{p}<0.05$ versus controls and $\S p<0.05$ between experimental groups using a one-way ANOVA with Tukey's post hoc test.

that antenatal steroids improved neonatal outcomes after preterm birth associated with chorioamnionitis [39]. Surprisingly the antagonistic combination of inflammation and anti-inflammatory glucocorticoids caused more lung maturation than either stimulus alone. The changes in the fetal lungs have been described as "maturation" because of the improved physiology for gas exchange, but multiple aspects of lung development may be abnormal. It is unknown whether antenatal glucocorticoids and inflammation share common modulatory mechanisms or work in parallel [40].

Lung development is orchestrated by multiple pathways, one of which is the TGF $\beta$ pathway. A balanced and timed expression of TGF $\beta$ is crucial for both embryonic and fetal lung development, as TGF $\beta$ signaling is essential for lung bud formation [41], whereas overexpression of TGF $\beta$ later in lung development inhibits branching morphogenesis [42] and alveolarization [43]. We asked how TGF $\beta$, the phosphorylation of its transcription factor Smad2, and its regulated genes CTGF and Cav-1, would be affected by sequential exposure to both LPS-induced inflammation and antenatal glucocorticoids in a large mammalian model relevant to the preterm infant. Exposure of fetal lambs to only 
LPS increased TGF 1 and 2 levels in the lung after 7 days, although not significantly. The moderate increase in TGF $\beta$ levels can potentially explain the increased alveolar pSmad2 7 days after LPS exposure. Downstream of TGF $\beta$ signaling CTGF increased, which is consistent with the general understanding of this pathway [17, 44]. In another study however, in which lambs received an IA injection of LPS plus subsequent short time mechanical ventilation at a later time point in gestation, a decrease in CTGF was reported despite increased TGF $\beta 1$ and pSmad2 levels [17]. TGF $\beta$ signaling also is supported by decreased caveolin-1, a structural component of caveolae which facilitates the degradation of TGF $\beta$ receptors $[45,46]$. This is consistent with our previous study, in which intra-uterine LPS exposure was also associated with decreased Cav-1 and increased pSmad2 levels in the fetal sheep lung after 2 and 7 days of LPS exposure [31].

The anti-inflammatory effects of maternal glucocorticoids include inhibition of TGF $\beta$ transcription and production [19]. In BPD patients, prenatal corticosteroid exposure decreased TGF $\beta$ levels in endotracheal aspirate fluid [14]. In contrast to LPS exposed lambs, the levels of both pSmad2 and CTGF were at control levels in the lungs of fetal lambs that had been exposed to antenatal betamethasone in addition to LPS. The same was true for Cav-1 expression, as a negative regulator of TGF $\beta$ signaling. While we found no direct inhibitory effect of prenatal glucocorticoids on TGF $\beta$, maternal glucocorticoids counteracted LPS-induced TGF $\beta$ pathway activation. The anti-inflammatory capabilities of glucocorticoids are often attributed to the antagonistic interactions of the glucocorticoid receptor (GR) with several subunits of NF-KB, a transcriptional activator of pro-inflammatory genes $[47,48]$. However, glucocorticoids can maintain or even increase LPS-induced inflammation, implying that activation of NF-KB is not the only inducer of pro-inflammatory gene transcription. Activation of both NF-kB and the GR can have very different effects on signaling pathways, and can lead to either up-regulation or silencing of different clusters of genes [49]. TGF $\beta$ signaling has been implicated in inflammation-induced maturation $[13,17,43]$. Our results in fetal sheep do not support a role for TGF $\beta$ signaling in corticosteroid-induced maturation. GR activation by synthetic glucocorticoids like betamethasone can stimulate caveolin-1 expression and caveolae formation selectively in alveolar epithelial cells [50], supporting our observation of the counteractive effect of betamethasone exposure for LPS-induced TGF $\beta$-signaling. It is unclear why TGF $\beta 2$ is specifically up-regulated after a sequential exposure to LPS and betamethasone, but not to a single exposure to either stimulus. Perhaps this could be a side effect of co-activation of NF-KB and the GR as described by Rao and colleagues [49].

Our results support the involvement of TGF $\beta$, CTGF and Cav-1 in the pulmonary response to LPS-induced inflammation, which in turn may be involved in the maturational response seen in the same animals [34]. TGF $\beta$ pathway components, such as CTGF, have promise 
as therapeutic targets for the treatment of BPD, particularly after ventilation induced injury [24]. Although our study has identified interactions of LPS, glucocorticoids and TGF $\beta$ in a time-dependent manner, a detailed exploration using this large animal model with multiple time points of assessment is impractical. We have, however, demonstrated interferences between LPS and corticosteroid mediated molecular effects in the developing lung. These interactions will pose a challenge for the future development of treatment strategies, as perinatal inflammation and ante- or postnatal administration of glucocorticoids are very common.

\section{References}

1. Viscardi, R.M., Perinatal inflammation and lung injury. Seminars in fetal \& neonatal medicine, 2012. 17(1): p. 30-5.

2. Knox, I.C., Jr. and Hoerner, J.K., The role of infection in premature rupture of the membranes. American journal of obstetrics and gynecology, 1950. 59(1): p. 190-4, illust.

3. Watterberg, K.L., Demers, L.M., Scott, S.M., and Murphy, S., Chorioamnionitis and early lung inflammation in infants in whom bronchopulmonary dysplasia develops. Pediatrics, 1996. 97(2): p. 210-5.

4. Stoll, B.J., Hansen, N., Fanaroff, A.A., Wright, L.L., Carlo, W.A., Ehrenkranz, R.A., Lemons, J.A., Donovan, E.F., Stark, A.R., Tyson, J.E., Oh, W., Bauer, C.R., Korones, S.B., Shankaran, S., Laptook, A.R., Stevenson, D.K., Papile, L.A., and Poole, W.K., Late-onset sepsis in very low birth weight neonates: the experience of the NICHD Neonatal Research Network. Pediatrics, 2002. 110(2 Pt 1): p. 285-91.

5. Ronnestad, A., Abrahamsen, T.G., Medbo, S., Reigstad, H., Lossius, K., Kaaresen, P.I., Engelund, I.E., Irgens, L.M., and Markestad, T., Septicemia in the first week of life in a Norwegian national cohort of extremely premature infants. Pediatrics, 2005. 115(3): p. e262-8.

6. Syrkina, O., Jafari, B., Hales, C.A., and Quinn, D.A., Oxidant stress mediates inflammation and apoptosis in ventilator-induced lung injury. Respirology, 2008. 13(3): p. 333-40.

7. Van Marter, L.J., Dammann, O., Allred, E.N., Leviton, A., Pagano, M., Moore, M., and Martin, C., Chorioamnionitis, mechanical ventilation, and postnatal sepsis as modulators of chronic lung disease in preterm infants. The Journal of pediatrics, 2002. 140(2): p. 171-6.

8. Gantert, M., Been, J.V., Gavilanes, A.W., Garnier, Y., Zimmermann, L.J., and Kramer, B.W., Chorioamnionitis: a multiorgan disease of the fetus? J Perinatol, 2010. 30 Suppl: p. S21-30.

9. Beeton, M.L., Maxwell, N.C., Davies, P.L., Nuttall, D., McGreal, E., Chakraborty, M., Spiller, O.B., and Kotecha, S., Role of pulmonary infection in the development of chronic lung disease of prematurity. The European respiratory journal : official journal of the European Society for Clinical Respiratory Physiology, 2011. 37(6): p. 1424-30.

10. Jobe, A.H. and Bancalari, E., Bronchopulmonary dysplasia. Am J Respir Crit Care Med, 2001. 163(7): p. 1723-9.

11. Massaro, G.D. and Massaro, D., Formation of alveoli in rats: postnatal effect of prenatal dexamethasone. The American journal of physiology, 1992. 263(1 Pt 1): p. L37-41.

12. Willet, K.E., Jobe, A.H., Ikegami, M., Kovar, J., and Sly, P.D., Lung morphometry after repetitive antenatal glucocorticoid treatment in preterm sheep. American journal of respiratory and critical care medicine, 2001. 163(6): p. 1437-43.

13. Kotecha, S., Wangoo, A., Silverman, M., and Shaw, R.J., Increase in the concentration of transforming growth factor beta-1 in bronchoalveolar lavage fluid before development of chronic lung disease of prematurity. The Journal of pediatrics, 1996. 128(4): p. 464-9. 
14. Lecart, C., Cayabyab, R., Buckley, S., Morrison, J., Kwong, K.Y., Warburton, D., Ramanathan, R., Jones, C.A., and Minoo, P., Bioactive transforming growth factor-beta in the lungs of extremely low birthweight neonates predicts the need for home oxygen supplementation. Biology of the neonate, 2000. 77(4): p. 217-23.

15. Gauldie, J., Galt, T., Bonniaud, P., Robbins, C., Kelly, M., and Warburton, D., Transfer of the active form of transforming growth factor-beta 1 gene to newborn rat lung induces changes consistent with bronchopulmonary dysplasia. The American journal of pathology, 2003. 163(6): p. 2575-84.

16. Vicencio, A.G., Lee, C.G., Cho, S.J., Eickelberg, O., Chuu, Y., Haddad, G.G., and Elias, J.A., Conditional overexpression of bioactive transforming growth factor-beta1 in neonatal mouse lung: a new model for bronchopulmonary dysplasia? American journal of respiratory cell and molecular biology, 2004. 31(6): p. 650-6.

17. Kunzmann, S., Speer, C.P., Jobe, A.H., and Kramer, B.W., Antenatal inflammation induced TGF-b1 but suppressed CTGF in preterm lungs. Am J Physiol Lung Cell Mol Physiol, 2006. 292: p. 223-231.

18. Viscardi, R.M., Atamas, S.P., Luzina, I.G., Hasday, J.D., He, J.R., Sime, P.J., Coalson, J.J., and Yoder, B.A., Antenatal Ureaplasma urealyticum respiratory tract infection stimulates proinflammatory, profibrotic responses in the preterm baboon lung. Pediatr Res, 2006. 60(2): p. 141-6.

19. Wen, F.Q., Kohyama, T., Skold, C.M., Zhu, Y.K., Liu, X., Romberger, D.J., Stoner, J., and Rennard, S.I., Glucocorticoids modulate TGF-beta production. Inflammation, 2002. 26(6): p. 279-90.

20. McDevitt, T.M., Gonzales, L.W., Savani, R.C., and Ballard, P.L., Role of endogenous TGF-beta in glucocorticoid-induced lung type I/ cell differentiation. Am J Physiol Lung Cell Mol Physiol, 2007. 292(1): p. L249-L257.

21. Bartram, U. and Speer, C.P., The role of transforming growth factor beta in lung development and disease. Chest, 2003. 125(2): p. 754-765.

22. Massague, J., TGF-beta signal transduction. Annu Rev Biochem, 1998. 67: p. 753-91.

23. Leask, A. and Abraham, D.J., All in the CCN family: essential matricellular signaling modulators emerge from the bunker. Journal of cell science, 2006. 119(Pt 23): p. 4803-10.

24. Alapati, D., Rong, M., Chen, S., Hehre, D., Rodriguez, M.M., Lipson, K.E., and Wu, S., Connective tissue growth factor antibody therapy attenuates hyperoxia-induced lung injury in neonatal rats. American journal of respiratory cell and molecular biology, 2011. 45(6): p. 1169-77.

25. Chen, S., Rong, M., Platteau, A., Hehre, D., Smith, H., Ruiz, P., Whitsett, J., Bancalari, E., and Wu, S., CTGF disrupts alveolarization and induces pulmonary hypertension in neonatal mice: implication in the pathogenesis of severe bronchopulmonary dysplasia. American journal of physiology. Lung cellular and molecular physiology, 2011. 300(3): p. L330-40.

26. Jin, Y., Lee, S.J., Minshall, R.D., and Choi, A.M., Caveolin-1: a critical regulator of lung injury. American journal of physiology. Lung cellular and molecular physiology, 2011. 300(2): p. L151-60.

27. Williams, T.M. and Lisanti, M.P., The Caveolin genes: from cell biology to medicine. Annals of medicine, 2004. 36(8): p. 584-95.

28. Gosens, R., Stelmack, G.L., Bos, S.T., Dueck, G., Mutawe, M.M., Schaafsma, D., Unruh, H., Gerthoffer, W.T., Zaagsma, J., Meurs, H., and Halayko, A.J., Caveolin-1 is required for contractile phenotype expression by airway smooth muscle cells. Journal of cellular and molecular medicine, 2011. 15(11): p. 2430-42.

29. Gosens, R., Mutawe, M., Martin, S., Basu, S., Bos, S.T., Tran, T., and Halayko, A.J., Caveolae and caveolins in the respiratory system. Current molecular medicine, 2008. 8(8): p. 741-53.

30. Lv, X.J., Li, Y.Y., Zhang, Y.J., Mao, M., and Qian, G.S., Over-expression of caveolin-1 aggravate LPS-induced inflammatory response in AT-1 cells via up-regulation of CPLA2/p38 MAPK. 
Inflammation research : official journal of the European Histamine Research Society ... [et al.], 2010. 59(7): p. 531-41.

31. Kunzmann, S., Collins, J.J., Yang, Y., Uhlig, S., Kallapur, S.G., Speer, C.P., Jobe, A.H., and Kramer, B.W., Antenatal inflammation reduces expression of caveolin-1 and influences multiple signaling pathways in preterm fetal lungs. Am J Respir Cell Mol Biol, 2011. 45(5): p. 969-76.

32. Goldenberg, R.L., Andrews, W.W., Faye-Petersen, O.M., Cliver, S.P., Goepfert, A.R., and Hauth, J.C., The Alabama preterm birth study: corticosteroids and neonatal outcomes in 23to 32-week newborns with various markers of intrauterine infection. Am J Obstet Gynecol, 2006. 195(4): p. 1020-4.

33. Carlo, W.A., McDonald, S.A., Fanaroff, A.A., Vohr, B.R., Stoll, B.J., Ehrenkranz, R.A., Andrews, W.W., Wallace, D., Das, A., Bell, E.F., Walsh, M.C., Laptook, A.R., Shankaran, S., Poindexter, B.B., Hale, E.C., Newman, N.S., Davis, A.S., Schibler, K., Kennedy, K.A., Sanchez, P.J., Van Meurs, K.P., Goldberg, R.N., Watterberg, K.L., Faix, R.G., Frantz, I.D., 3rd, and Higgins, R.D., Association of antenatal corticosteroids with mortality and neurodevelopmental outcomes among infants born at 22 to 25 weeks' gestation. JAMA : the journal of the American Medical Association, 2011. 306(21): p. 2348-58.

34. Kuypers, E., Collins, J.J., Kramer, B.W., Ofman, G., Nitsos, I., Pillow, J.J., Polglase, G.R., Kemp, M.W., Newnham, J.P., Gavilanes, A.W., Nowacki, R., Ikegami, M., Jobe, A.H., and Kallapur, S.G., Intra-amniotic LPS and antenatal betamethasone: inflammation and maturation in preterm lamb lungs. Am J Physiol Lung Cell Mol Physiol, 2012. 302(4): p. L380-9.

35. Kunzmann, S., Speer, C.P., Jobe, A.H., and Kramer, B.W., Antenatal inflammation induced TGF-beta1 but suppressed CTGF in preterm lungs. Am J Physiol Lung Cell Mol Physiol, 2007. 292(1): p. L223-31.

36. Livak, K.J. and Schmittgen, T.D., Analysis of relative gene expression data using real-time quantitative PCR and the 2(-Delta Delta C(T)) Method. Methods, 2001. 25(4): p. 402-8.

37. Jobe, A.H., Glucocorticoids, inflammation and the perinatal lung. Semin Neonatol, 2001. 6(4): p. 331-42.

38. Goldenberg, R.L., Andrews, W.W., Faye-Petersen, O.M., Cliver, S.P., Goepfert, A.R., and Hauth, J.C., The Alabama preterm birth study: corticosteroids and neonatal outcomes in 23to 32-week newborns with various markers of intrauterine infection. American journal of obstetrics and gynecology, 2006. 195(4): p. 1020-4.

39. Been, J., Degraeuwe, P., Kramer, B., and Zimmermann, L., Antenatal steroids and neonatal outcome after chorioamnionitis: a meta-analysis. BJOG, 2011. 118(2): p. 113-22.

40. Sweet, D.G., Huggett, M.T., Warner, J.A., Moss, T.J., Kloosterboer, N., Halliday, H.L., Newnham, J.P., Kallapur, S.G., Jobe, A.H., and Kramer, B.W., Maternal betamethasone and chorioamnionitis induce different collagenases during lung maturation in fetal sheep. Neonatology, 2008. 94(2): p. 79-86.

41. Chen, F., Desai, T.J., Qian, J., Niederreither, K., Lu, J., and Cardoso, W.V., Inhibition of Tgf beta signaling by endogenous retinoic acid is essential for primary lung bud induction. Development, 2007. 134(16): p. 2969-79.

42. Serra, R., Pelton, R.W., and Moses, H.L., TGF beta 1 inhibits branching morphogenesis and $N$-myc expression in lung bud organ cultures. Development, 1994. 120(8): p. 2153-61.

43. Gauldie, J., Galt, T., Bonniaud, P., Robbins, C., Kelly, M., and Warburton, D., Transfer of the active form of transforming growth factor-beta 1 gene to newborn rat lung induces changes consistent with bronchopulmonary dysplasia. Am J Pathol, 2003. 163(6): p. 2575-84.

44. Nishioka, M., Ogawa, E., Kinose, D., Haruna, A., Ohara, T., Ito, I., Hoshino, Y., Ito, Y., Matsumoto, H., Niimi, A., Mio, T., Chin, K., Hirai, T., Muro, S., and Mishima, M., Lipopolysaccharide induced connective tissue growth factor gene expression in human bronchial epithelial cells. Respirology, 2010. 15(4): p. 669-76.

45. Razani, B., Zhang, X.L., Bitzer, M., von Gersdorff, G., Bottinger, E.P., and Lisanti, M.P., 
Caveolin-1 regulates transforming growth factor (TGF)-beta/SMAD signaling through an interaction with the TGF-beta type I receptor. The Journal of biological chemistry, 2001. 276(9): p. 6727-38.

46. Di Guglielmo, G.M., Le Roy, C., Goodfellow, A.F., and Wrana, J.L., Distinct endocytic pathways regulate TGF-beta receptor signalling and turnover. Nature cell biology, 2003. 5(5): p. 41021.

47. Smoak, K.A. and Cidlowski, J.A., Mechanisms of glucocorticoid receptor signaling during inflammation. Mechanisms of ageing and development, 2004. 125(10-11): p. 697-706.

48. Murphy, S.H., Suzuki, K., Downes, M., Welch, G.L., De Jesus, P., Miraglia, L.J., Orth, A.P., Chanda, S.K., Evans, R.M., and Verma, I.M., Tumor suppressor protein (p)53, is a regulator of NF-kappaB repression by the glucocorticoid receptor. Proceedings of the National Academy of Sciences of the United States of America, 2011. 108(41): p. 17117-22.

49. Rao, N.A., McCalman, M.T., Moulos, P., Francoijs, K.J., Chatziioannou, A., Kolisis, F.N., Alexis, M.N., Mitsiou, D.J., and Stunnenberg, H.G., Coactivation of GR and NFKB alters the repertoire of their binding sites and target genes. Genome research, 2011. 21(9): p. 1404-16.

50. Barar, J., Campbell, L., Hollins, A.J., Thomas, N.P., Smith, M.W., Morris, C.J., and Gumbleton, M., Cell selective glucocorticoid induction of caveolin-1 and caveolae in differentiating pulmonary alveolar epithelial cell cultures. Biochemical and biophysical research communications, 2007. 359(2): p. 360-6. 



\section{6}

Repetitive intra-uterine exposures

to inflammatory stimuli attenuated

\section{transforming growth factor $\beta$ \\ signaling in the ovine fetal lung}

Collins JJP, Kallapur SG, Knox CL, Kemp MW, Kuypers E, Zimmermann LJI, Newnham JP, Jobe AH, Kramer BW

Submitted 
Abstract

Background: Bronchopulmonary dysplasia (BPD) is one of the most common complications of preterm birth and is associated with intra-uterine exposure to bacteria, which is diagnosed as chorioamnionitis. The resultant pulmonary inflammation can arrest lung development. Transforming growth factor (TGF) $\beta$ participates in changes after prenatal inflammatory lung injury that progresses to BPD. We asked whether activation of the immune system by single or double fetal exposures to different bacterial agents would affect TGF $\beta$ signaling in fetal lungs similarly.

Methods: Time-mated pregnant ewes received an intra-amniotic injection of $10 \mathrm{mg}$ Escherichia coli 055:B5 lipopolysaccharide (LPS) and/or $2 \times 10^{7}$ colony forming units Ureaplasma parvum serovar 3 (UP) and/or an equivalent injection of saline or media for control animals at 117 days (d) and/or 121-122d gestation (GA). Lambs were euthanized at 124d GA (with term being 150d GA). TGF $\beta 1$, TGF 32 , TGF $\beta 3$, TGF $\beta R 1$ and TGF $\beta R 2$ protein levels, Smad2 phosphorylation and elastin deposition were evaluated in lung tissue.

Results: Total TGF $\beta 2$ concentrations decreased by $50 \% 2$ days after single LPS and after UP+LPS exposure. TGF $\beta 1$ and 2 concentrations were unaffected in UP only and double LPS exposed lungs. Alveolar expression of TGF $\beta$ R2 increased $75 \%$ after $2 \mathrm{~d}$ LPS and decreased $75 \%$ after $3 d$ UP, but remained unaltered after double exposures. Neither TGFßR1 expression nor Smad2 phosphorylation changed after LPS or UP exposure. Decreased focal elastin deposition after LPS exposure(s) was prevented by UP exposure.

Conclusions: TGF $\beta$ signaling components responded differently to intra-uterine LPS and UP exposure, but were not altered after exposure to both LPS and UP. Contrary to observations after single exposures, focal elastin deposition was unchanged after exposure to the two inflammatory mediators. These results suggest that multiple bacterial exposures attenuated TGF $\beta$ signaling and normalized elastin deposition.

\section{Background}

Bronchopulmonary dysplasia (BPD), the most common adverse outcome after preterm birth [1], is characterized by arrested alveolar development resulting in fewer but larger alveoli $[2,3]$. The development of BPD is associated with pulmonary inflammation, which may result from antenatal exposure to pathogens associated with chorioamnionitis [4-6]. Although many different microbes have been identified in amniotic fluid [7], the most common bacteria found in the placenta and membranes of preterm infants are Ureaplasma spp [8-10]. Culture-positive placental tissue of 41 percent of preterm 
neonates delivered before 27 weeks was however polymicrobial [11]. It is unclear how this exposure to multiple bacteria affects the fetal immune response. A single inflammatory and immunologic trigger will elicit variable fetal inflammatory responses in several animal models, including fetal baboons, rhesus macaques and sheep [1220]. Interestingly, repeated exposure to lipopolysaccharide (LPS) in fetal sheep induced tolerance to a second challenge with LPS in monocytes isolated from the blood and lungs [16, 21, 22]. Repeated LPS exposure suppressed Toll-like Receptor (TLR) 2, 4, 5 and 9 signaling in monocytes from the fetal lung and blood [22]. Recently, we reported that the fetal immune response to LPS was not changed by a short term intra-amniotic exposure to ureaplasmas in fetal sheep [17]. However a long fetal exposure to ureaplasmas suppressed the fetal immune system to intra-amniotic LPS [17]. The interactions of the immune system with both ureaplasmas and LPS may be complex, as each is recognized by different TLRs. LPS, a cell wall component of Gram-negative bacteria, activates TLR4 by binding to the CD14 receptor, which in turn triggers myeloid differentiation factor- 88 (MyD88)-dependent and -independent pathways [23, 24]. In contrast, Ureaplasma spp. activate TLR1, 2 and 6 with cell membrane associated lipoproteins, as they lack a cell wall [25].

The links between inflammation and the arrest in alveolar development are a focus of ongoing experimental and clinical studies. Transforming growth factor (TGF) $\beta$, an antiinflammatory cytokine, has an ambiguous role in the pathogenesis of BPD [26, 27], as it is also a growth factor for lung development and repair [28]. TGF $\beta$ is produced in a latent form which is cleaved to be activated [28]. Inflammation-mediated changes in the biological activity of TGF $\beta$ may contribute to the arrest in alveolar development leading to $\operatorname{BPD}[5,29,30]$. Because chorioamnionitis is frequently polymicrobial, we hypothesized that different and/or multiple bacterial signals could elicit divergent TGF $\beta$ signaling responses in the developing lung. We used models of chorioamnionitis $[12,16$, 17] in which fetal sheep received short term intra-amniotic exposures of LPS or U. parvum serovar 3, or both. Expression and activation of TGF $\beta 1,2$ and 3 and TGF $\beta$ receptors 1 and 2 were measured in fetal lungs. In addition, intracellular activation of the TGF $\beta$ signaling pathway was assessed by phosphorylation of mothers against decapentaplegic homolog 2 (Smad2), which acts as a signal transducer upon coupling and activation of TGF $\beta$ receptors 1 and 2 [31]. Focal elastin deposition, thought to play a crucial role in the outgrowth of secondary septa [32, 33], was quantified as a measure for arrested alveolar development. We found that TGF $\beta$ signaling components responded differently to intra-uterine LPS and Ureaplasma exposure, but were not altered after exposure to both LPS and Ureaplasmas. Contrary to observations after single exposures, focal elastin deposition was unchanged after exposure to the two inflammatory mediators. 
Methods

\section{Animal model and sampling protocol}

All studies were approved by the Animal Ethics Committees at The University of Western Australia, the Queensland University of Technology and at the Cincinnati Children's Hospital Medical Center. The description of the animals has previously been published $[12,16,17]$. Briefly, Ureaplasmas were cultured and prepared for the intra-amniotic injections as reported previously $[12,18]$. Time-mated ewes with singleton fetuses were randomized to receive an ultrasound guided intra-amniotic (IA) injection of either Ureaplasma parvum serovar 3 ( $2 \times 10^{7}$ colony forming units) (UP) at 117 or 121 days gestational age (GA) and/or an IA injection of lipopolysaccharide (LPS) (10 mg Escherichia coli 055:B5, Sigma Chemical, St. Louis, MO, USA) at 117 and/or 122 days GA. Controls were injected concurrently for each intervention with either of saline or $10 \mathrm{~B}$ media inoculum [18]. This resulted in 9 experimental groups: $2 d$ LPS (6 lambs), $7 d$ LPS (7 lambs), $2+7 d$ LPS (6 lambs), saline injected controls (6 lambs), 3d UP (7 lambs), 7d UP (4 lambs), media injected controls (8 lambs), 2d LPS $+7 \mathrm{~d}$ UP (7 lambs) and saline and media injected controls (5 lambs). Preterm lambs were delivered and euthanized at 124 days $\mathrm{GA}$ (term=150 days GA). The lungs were pressure inflated to measure a maximal lung gas volume at $40 \mathrm{~cm} \mathrm{H}_{2} \mathrm{O}$ airway pressure [34]. Tissue from the right lower lobe (RLL) of the lung was snap frozen and the right upper lobe (RUL) was inflation-fixed at $30 \mathrm{cmH} 2 \mathrm{O}$ in $10 \%$ buffered formalin for 24 hours.

Protein extraction and enzyme-linked immunosorbent assay (ELISA) of TGF $\beta 1$, TGF $\beta 2$ and TGF $\beta 3$

Frozen lung tissue from the RLL was homogenized (PRO Quick Connect Generators part no. 02-07095; PRO Scientific Inc., Oxford, CT) in ice-cold RIPA buffer (Sigma Aldrich) containing $0.1 \%$ protease inhibitors (Sigma Aldrich) and subsequently centrifuged at 12 rcf for 5 minutes at $4^{\circ} \mathrm{C}$ [35]. Free, bound and total TGF $\beta 1$, TGF $\beta 2$ and TGF $\beta 3$ (referred to by R\&D Systems as active, latent and total TGF $\beta$ ) were measured with R\&D DuoSet ELISA development kits (human TGF $\beta 1$ : DY240, human TGF 32 : DY302, human TGF 33 : DY243, R\&D Systems, Minneapolis, MN, USA) according to manufacturer's instructions [35, 36]. TGF $\beta 1$ and TGF $\beta 2$ protein concentrations were calculated per kilogram bodyweight and reported as a mean fold change compared to controls.

\section{Immunohistochemistry}

Paraffin-embedded RUL lung sections ( $4 \mu \mathrm{m}$, transverse) were stained for transforming growth factor $\beta$ receptor 1 (TGF $\beta$ R1) (ab31013, Abcam, Cambridge, UK), transforming 
growth factor $\beta$ receptor 2 (TGF $\beta R 2$ ) (ab28382, Abcam, Cambridge, UK) and phosphorylated mothers against decapentaplegic homolog 2 (pSmad2, Ser465/467) (\#3101, Cell Signaling Technology, Boston, USA). Briefly, sections were deparaffinized in an ethanol series and endogenous peroxidase-activity was blocked by incubation with $0.3 \% \mathrm{H}_{2} \mathrm{O}_{2}$ in $1 x$ phosphate buffered saline (PBS, $\mathrm{pH}$ 7.4) (for TGF $\beta R 1$ and 2) or $3 \% \mathrm{H}_{2} \mathrm{O}_{2}$ in milli-Q (for pSmad2). Antigen retrieval was performed by incubating the slides in heated citrate buffer ( $10 \mathrm{mM}, \mathrm{pH}$ 6.0) for 30 minutes. To prevent non-specific binding, sections were incubated with $20 \%$ normal goat serum (NGS) in PBS (for TGFßR1 and 2) or $5 \%$ NGS in $1 x$ tris-buffered saline (TBS, pH 7.6) with $0.1 \%$ Tween (for pSmad2). Sections were incubated overnight at $4^{\circ} \mathrm{C}$ with the diluted primary antibody (TGF $\beta R 1: 1 / 100$, TGFBR2: $1 / 500$, pSmad2: 1/2000). After incubation with the secondary antibody (swineanti-rabbit Ig*biotin, E0353, DAKO), immunostaining was enhanced with Vectastain ABC peroxidase Elite kit (PK-6200, Vector Laboratories, Burlingame, USA) and visualized with nickel sulfate-diaminobenzidine (NiDAB). Subsequently, the sections were rinsed in Tris/ saline and incubated with Tris/cobalt. After counterstaining with 0.1\% Nuclear Fast Red, the sections were washed, dehydrated and coverslipped.

Evaluation was performed by light microscopy (Axioskop 40, Zeiss, Germany) with LeicaQWin Pro v.3.4.0 software (Leica Microsystems, Germany). For each animal three random locations of the section were photographed at 200x and 400x magnification. Sections were scored by a blinded observer for positive TGF $\beta R 1$, TGF $\beta 22$ and pSmad 2 by ranking all sections by ascending staining intensity by a blinded observer. After ranking, the scores of each experimental group were normalized to the average score of the control group, and statistical analysis was performed as described below.

\section{Elastin staining}

Elastin staining was performed on paraffin-embedded RUL lung sections ( $4 \mu \mathrm{m}$, transverse) [37]. Briefly, the sections were deparaffinized in an ethanol series and incubated for 20 minutes in Weigerts Resorcine-Fuchsine (Chroma, $2 \mathrm{E} \mathrm{030)}$ ) at $60-70^{\circ} \mathrm{C}$. After rinsing with water, the sections were incubated for 3 minutes in a tartrazin solution at room temperature. Subsequently the sections were washed and dehydrated in ethanol and xylol. Evaluation was performed by light microscopy (Zeiss, Axioskop 40) with LeicaQWin Pro v.3.4.0 software. Elastin foci were counted using Image J software (Rasband, W.S., ImageJ, U.S. National Institutes of Health, Bethesda, Maryland, USA) [12], corrected for photomicrograph surface area, and expressed as elastin foci $/ \mathrm{mm}^{2}$. The values of each experimental group were normalized to the average value of the control group. Results for 3 and 7 day ureaplasma exposure were reported previously [12]. 


\section{Chapter 6}

\section{Data analysis}

Results are given as means \pm standard error of mean (SEM). The groups were compared using one-way ANOVA with Dunnett's test for post-hoc analysis. Two group comparisons were done by Mann-Whitney test. Statistical analysis was performed by GraphPad Prism v5.0. Significance was accepted at $p<0.05$.

\section{Results}

\section{Modulated expression of TGF $\beta$ signaling components in response to a single} intra-amniotic LPS injection

After LPS exposure the levels of TGF 32 slightly decreased at 2 days, a result which did not reach statistical significance ( $p=0.054$ for total TGF $\beta 2$ ) (Table 1$)$. This was accompanied by a significant increase by $76 \%$ in alveolar TGF $\beta R 2$. The focal expression of elastin on secondary septa also decreased (Table 1).

Table 1: Effect of single LPS exposures on TGF $\beta$ pathway components and elastin deposition

\begin{tabular}{|c|c|c|c|c|}
\hline & & Control & 2d LPS & 7d LPS \\
\hline \multicolumn{5}{|c|}{ TGFB protein levels } \\
\hline \multirow[t]{2}{*}{ TGFB1 } & free & $1.00 \pm 0.32$ & $0.70 \pm 0.09$ & $1.30 \pm 0.26$ \\
\hline & total & $1.00 \pm 0.06$ & $0.95 \pm 0.02$ & $1.31 \pm 0.05^{*}$ \\
\hline \multirow[t]{2}{*}{ TGFB2 } & free & $1.00 \pm 0.14$ & $0.62 \pm 0.05$ & $1.42 \pm 0.24$ \\
\hline & total & $1.00 \pm 0.06$ & $0.56 \pm 0.05$ & $1.10 \pm 0.23$ \\
\hline \multicolumn{5}{|c|}{ TGF8 signaling components } \\
\hline \multicolumn{2}{|c|}{ TGFBR1 } & $1.00 \pm 0.24$ & $0.98 \pm 0.22$ & $0.91 \pm 0.21$ \\
\hline \multicolumn{2}{|c|}{ TGFBR2 } & $1.00 \pm 0.16$ & $1.76 \pm 0.08^{*}$ & $0.72 \pm 0.27$ \\
\hline \multicolumn{2}{|c|}{ pSmad2 } & $1.00 \pm 0.27$ & $1.53 \pm 0.42$ & $1.89 \pm 0.41$ \\
\hline \multicolumn{2}{|c|}{ Elastin foci/mm $\mathrm{mm}^{2}$} & $1.00 \pm 0.07$ & $0.65 \pm 0.08 *$ & $0.89 \pm 0.05$ \\
\hline
\end{tabular}

All values are presented as mean fold change compared to control. Data expressed as mean \pm SEM. LPS-lipopolysaccharide; $d$-day; TGF $\beta$-transforming growth factor $\beta$. * $p<0.05$ versus controls using a one-way ANOVA with Dunnett's post hoc test.

7 days after LPS exposure there were increases in free and total TGF $\beta 1$ and 2 levels, which was statistically significant for total TGF $\beta 1$ only. In contrast, the alveolar expression of both TGF $\beta$ receptors, $\mathrm{pSmad} 2$ and elastin foci were similar to controls. No measurable levels of TGF $\beta 3$ could be detected by ELISA in protein extracts of the lungs of any lambs (data not shown). 


\section{Repeated LPS exposure at 2 \& 7 days normalizes TGF $\beta$ expression but} increases TGF $\beta$ signaling

Free and total TGF $\beta 1$ (Figure $1 A-B$ ) and free TGFB2 levels (Figure $2 A$ ) in the lungs of fetal lambs exposed to LPS twice, at 2 and 7 days before sacrifice, were similar to those in controls. Total TGF $\beta 2$ levels however were decreased, similar to a single 2 day LPS exposure, reaching a $p$-value of 0.06 (Figure 2B). Although the expression of both TGF $\beta$ receptors was similar to controls (Figure $3 A-B$ ), pSmad2 intensity nearly doubled at a p-value of 0.07 (Figure 4A). Focal elastin deposition was diminished after double LPS exposure (Figure $5 \mathrm{~A}$ ), as seen after single LPS exposures.
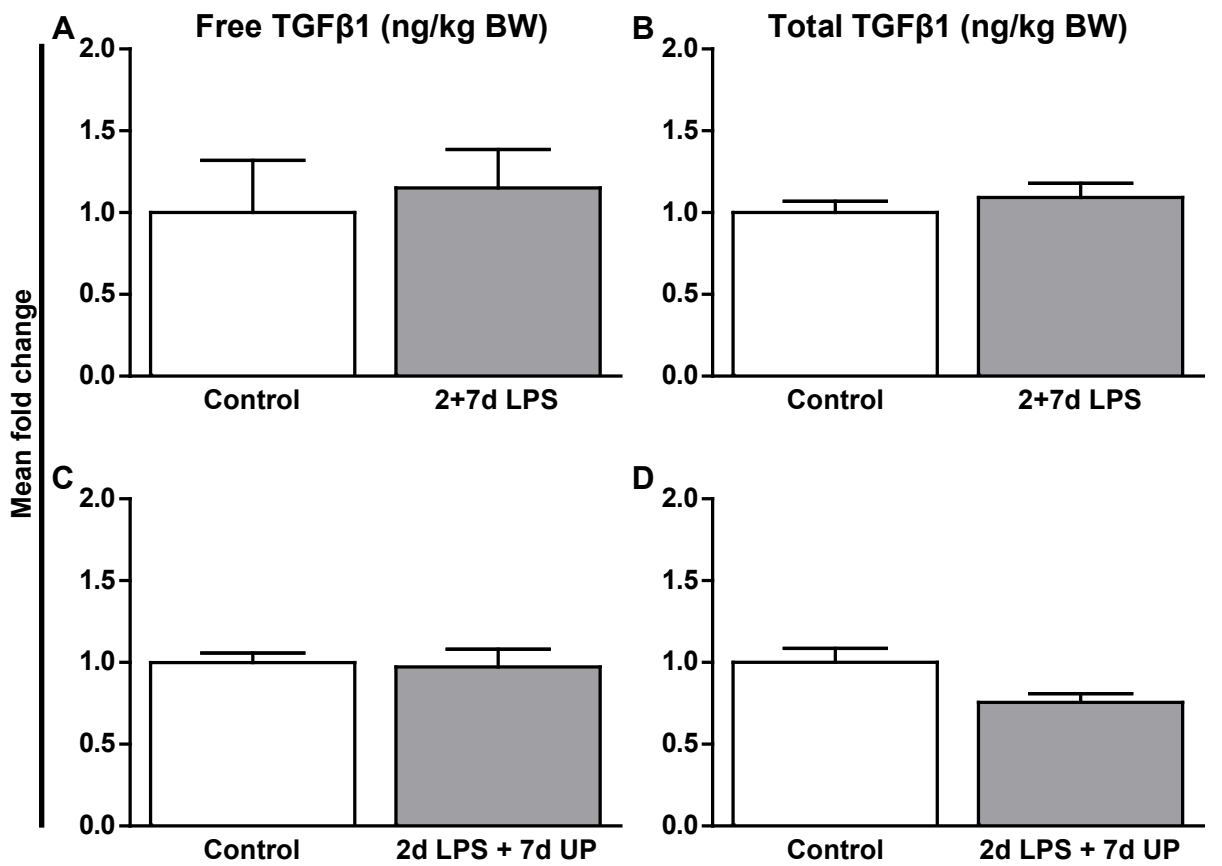

Figure 1: Expression and activation of Transforming Growth Factor (TGF) B1.

Repeated LPS exposure 2 and 7 days before birth $(\mathbf{A}+\mathbf{B})$ did not influence free or total TGF $\beta 1$ levels. Exposure to $U$. parvum at 7 days combined with LPS exposure at 2 days before birth did not alter free TGF $\beta 1$ levels (C), but decreased levels of total TGF $\beta 1$ ( $p=0.07)$ (D). ${ }^{*} p<0.05$ versus controls using a Mann-Whitney test. UP: U. parvum

\section{Fetal colonization with $U$. parvum did not consistently affect expression of TGF $\beta$ pathway members}

3 days after IA $U$. parvum injection, levels of both free and total TGF $\beta 1$ and 2 remained unaffected, with no sign of pathway activity as indicated by the presence of pSmad2 (Table 2). Contrasting with a single LPS injection after a similar exposure time, there was 


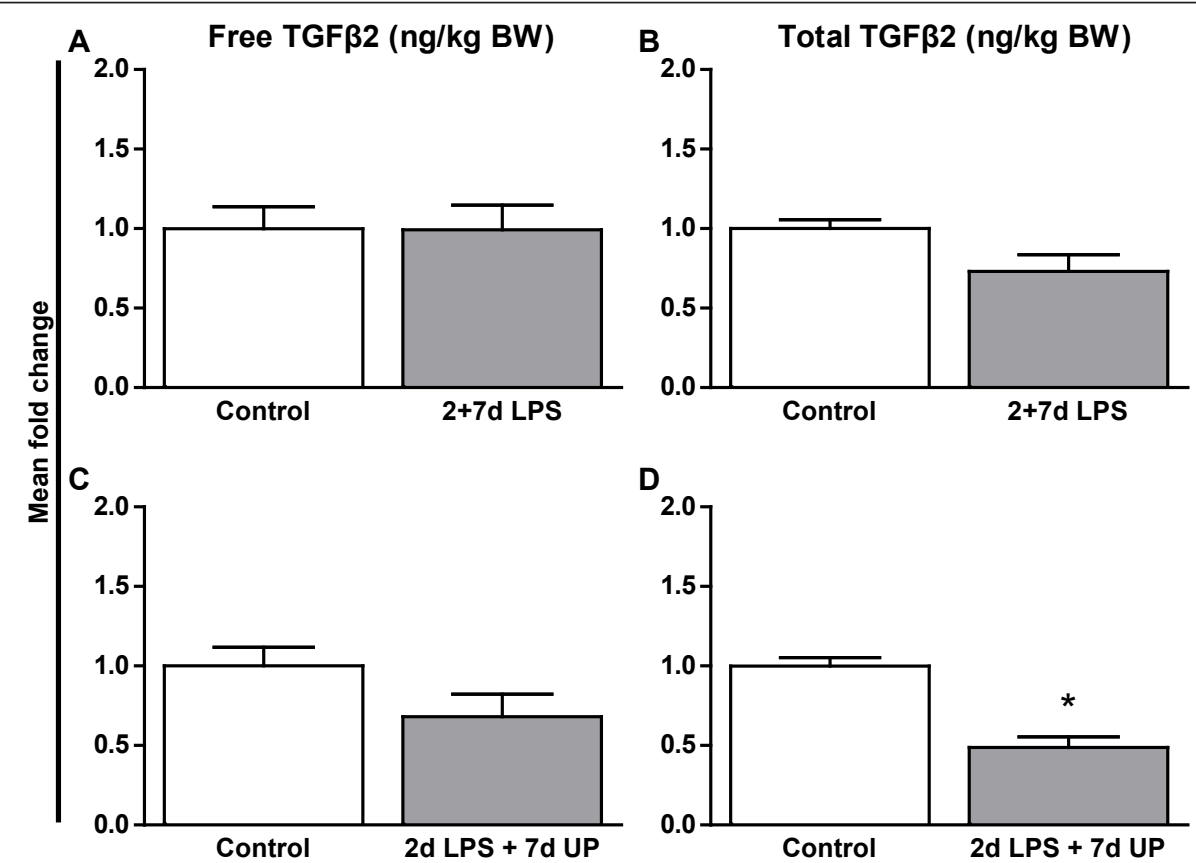

Figure 2: Expression and activation of Transforming Growth Factor (TGF) $\beta 2$.

Repeated LPS exposure 2 and 7 days before birth did not influence free TGF $\beta$ levels (A), but decreased total TGF $\beta$ levels $(p=0.06$ ) (B). Likewise, exposure to $U$. parvum at 7 days combined with LPS exposure at 2 days before birth decreased total TGF 32 content 2-fold without affecting free TGF $\beta 2$ content $(C+D)$. ${ }^{*} p<0.05$ versus controls using a Mann-Whitney test. UP: U. parvum

Table 2: Effect of single U. parvum exposures on TGF $\beta$ pathway components and elastin deposition

\begin{tabular}{|c|c|c|c|c|}
\hline & & Control & 3d UP & 7d UP \\
\hline \multicolumn{5}{|c|}{ TGFB protein levels } \\
\hline \multirow[t]{2}{*}{ TGFß1 } & free & $1.00 \pm 0.18$ & $1.48 \pm 0.24$ & $1.75 \pm 0.36$ \\
\hline & total & $1.00 \pm 0.07$ & $1.04 \pm 0.09$ & $0.80 \pm 0.06$ \\
\hline \multirow[t]{2}{*}{ TGF $\beta 2$} & free & $1.00 \pm 0.08$ & $1.14 \pm 0.27$ & $0.87 \pm 0.15$ \\
\hline & total & $1.00 \pm 0.08$ & $0.88 \pm 0.11$ & $0.74 \pm 0.07$ \\
\hline \multicolumn{5}{|c|}{ TGFB signaling components } \\
\hline \multicolumn{2}{|c|}{ TGFBR1 } & $1.00 \pm 0.24$ & $1.25 \pm 0.25$ & $1.00 \pm 0.32$ \\
\hline \multicolumn{2}{|c|}{ TGFBR2 } & $1.00 \pm 0.13$ & $0.26 \pm 0.06 *$ & $1.14 \pm 0.19$ \\
\hline \multicolumn{2}{|c|}{ pSmad2 } & $1.00 \pm 0.18$ & $0.90 \pm 0.23$ & $1.35 \pm 0.37$ \\
\hline \multicolumn{2}{|c|}{ Elastin foci/mm $\mathrm{mm}^{2}$} & $1.00 \pm 0.05$ & $1.32 \pm 0.12 *$ & $0.85 \pm 0.11$ \\
\hline
\end{tabular}

All values are presented as mean fold change compared to control. Data expressed as mean \pm SEM. UP-U. parvum; d-day; TGF $\beta$-transforming growth factor $\beta$. * $p<0.05$ versus controls using a oneway ANOVA with Dunnett's post hoc test. 
a decline of TGF $\beta$ R2 by $74 \%$, whereas TGF $\beta$ R1 remained at control levels. Interestingly, focal elastin deposition was increased after 3 days.

After an incubation of 7 days, none of the tested pathway members differed significantly from levels in the lungs of media exposed lambs.

A

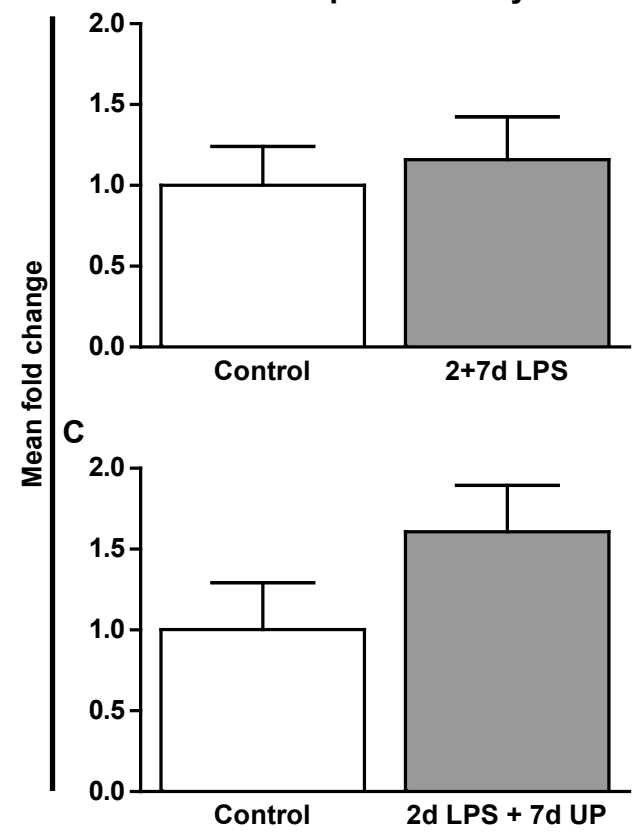

B

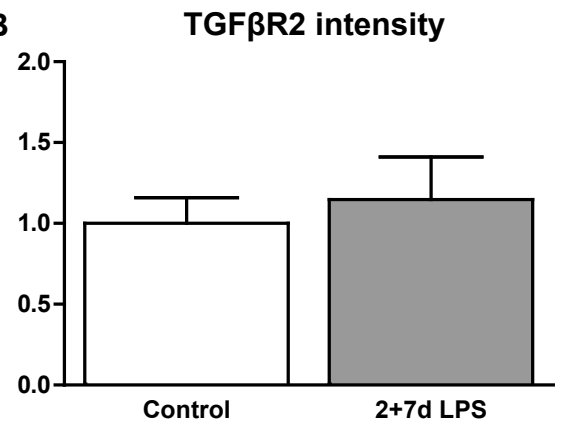

D

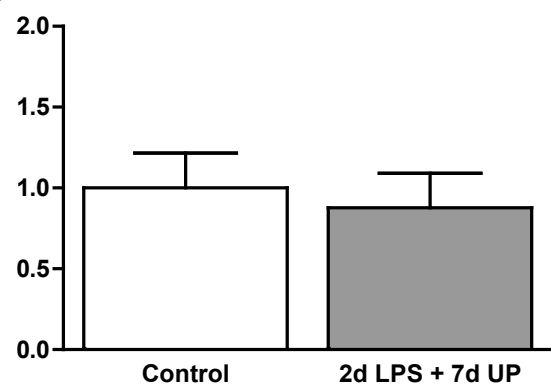

Figure 3: Expression of Transforming Growth Factor $\beta$ Receptor (TGFBR) 1 and 2.

Repeated LPS exposure 2 and 7 days before birth $(\mathbf{A}+\mathbf{B})$ or exposure to ureaplasma at 7 days combined with LPS exposure at 2 days before birth $(\mathbf{C}+\mathbf{D})$ did not influence either TGFBR1 or TGFBR2 levels. ${ }^{*} p<0.05$ versus controls using a Mann-Whitney test.

\section{Simultaneous exposure to LPS and U. parvum lowered expression of TGF $\beta$ pathway components}

Levels of free TGF $\beta 1$ (Figure 1C) and TGFB2 (Figure 2C) were unchanged compared to controls after sequential exposure to $U$. parvum and LPS, despite a marked decrease in levels of total TGF $\beta 1$ (Figure 1D, $p=0.07$ ) and TGF $\beta 2$ (Figure 2D, $p=0.006$ ). Downstream of TGF $\beta$, expression of TGF $\beta R 1$ and 2 (Figure 3C-D) and levels of pSmad2 (Figure 4B) were similar to controls. Likewise, the density of elastin foci on secondary septa was comparable to controls. 


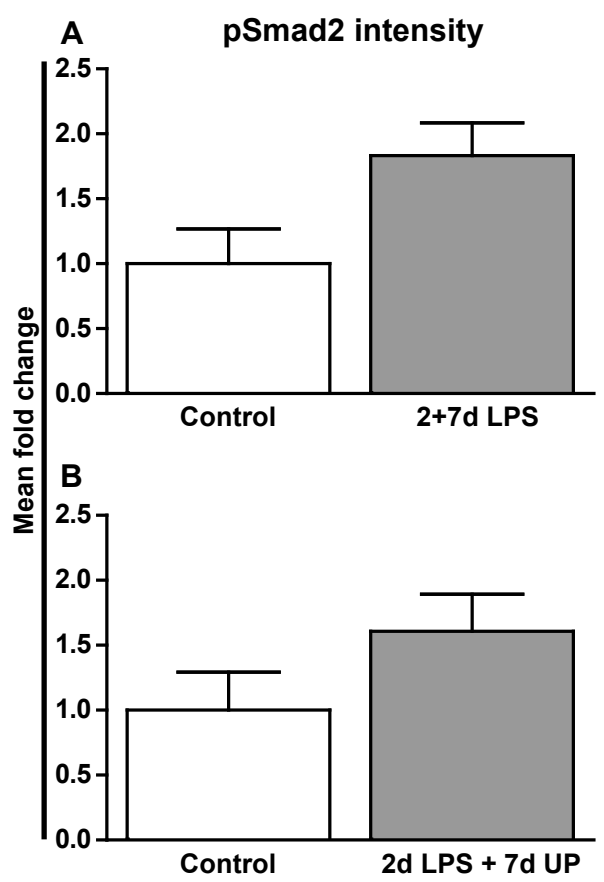

Figure 4: Phosphorylation of mothers against decapentaplegic homolog 2 (pSmad2).

Activation of TGF $\beta$ signaling by phosphorylation of Smad2 was elevated in fetal lungs exposed to LPS repetitively ( $p=0.07$ ) (A). pSmad2 levels did not alter in the lungs of fetal lambs exposed to $U$. parvum followed by LPS injections (B). * $\mathrm{p}<0.05$ versus controls using a Mann-Whitney test. UP: U. parvum

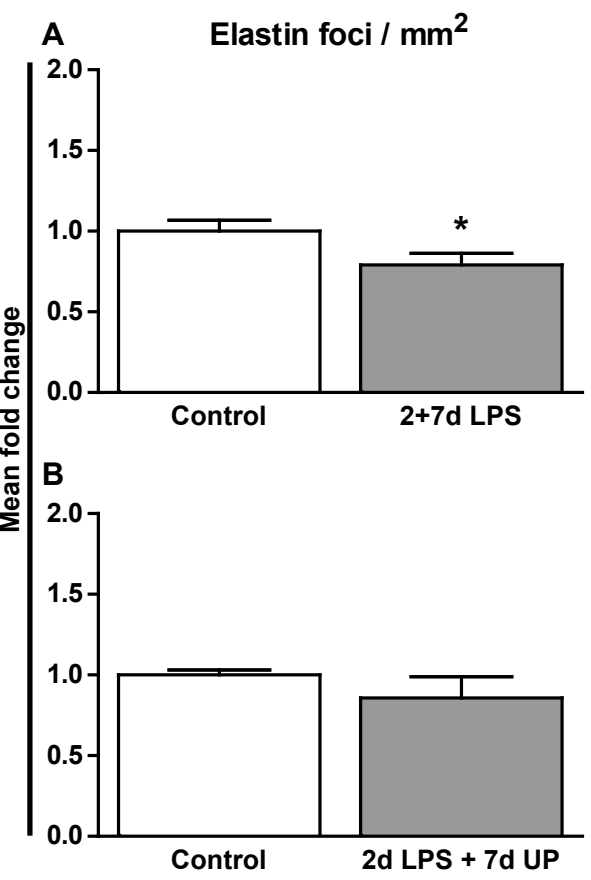

Figure 5: Elastin foci.

The number of elastin foci on secondary septa was decreased in the lungs of fetuses that were exposed to LPS 2 and 7 days before birth (A). Interestingly, the lungs of lambs that underwent a 7 day ureaplasma exposure followed by a 2 day LPS exposure showed similar numbers of elastin foci compared to controls (B). ${ }^{*} \mathrm{p}<0.05$ versus controls using a Mann-Whitney test. UP: U. parvum

\section{Discussion}

By the time infants are diagnosed with BPD at 28 days or at 36 weeks gestational age [2], their lungs have been exposed to a variety of potentially damaging situations [10]. Epidemiological studies suggest however that infants exposed to intra-uterine inflammation are more likely to develop BPD, but do not provide information as to why their lungs are more prone to this condition [38]. In the bronchoalveolar lavage of newborn preterm babies increased TGF $\beta 1$-levels were identified as a marker for the development of BPD [27]. Whether chorioamnionitis caused this increase in TGF $\beta 1$-levels associated with BPD remains unclear, as clinical findings on this matter are inconsistent $[26,39,40]$. Because a variety of bacteria can induce chorioamnionitis, the nature of the intra-uterine inflammation may vary. We therefore injected LPS, ureaplasmas or both 
to determine their effects on the TGF $\beta$ expression profile in the fetal ovine lung. There were very different outcomes for TGF $\beta$ signaling after LPS exposure when compared to ureaplasmas. Ureaplasma exposure, which caused a modest inflammatory response in fetal sheep lungs [12], hardly changed expression levels of TGF $\beta$ pathway components. Only the expression of TGF $\beta$ receptor 2 decreased. In contrast, the balance between TGF $\beta 1$ and 2 did change after LPS exposure, a stimulus which caused induction of the immune system [16]. Remarkably, these effects were not apparent in lungs that were exposed to LPS twice. The same was seen in lungs in which a polymicrobial infection was simulated by sequential exposures to ureaplasmas and LPS. In the lungs of fetal lambs which had undergone ureaplasma exposure 5 days before the LPS exposure, there was no decrease of elastin foci.

The clinical implication of this finding remains to be shown. A recent paper analyzing a large clinical cohort suggested a decreased risk for late-onset sepsis in babies that had been exposed to chorioamnionitis [41]. Similarly, preterm neonates exposed in utero to chorioamnionitis [38] and/or Ureaplasma spp. [42] had lower rates of chronic lung disease and sepsis respectively. It is unclear by which mechanisms this protection is mediated but the responsiveness of immune cells may play a role as suggested in our experimental work. For example, a preterm lung is deficient in alveolar macrophages since alveolar macrophages differentiate late in gestation from blood-derived monocytes which become residential in the fetal lung $[43,44]$. We showed that fetal lung exposure to chorioamnionitis matured monocytes to alveolar macrophages that had functional properties of adult alveolar macrophages [45]. The role and function of this cell population remains to be determined. "Mature" alveolar macrophages can provide a better protection against infectious agents but also can initiate an inflammatory response after mechanical ventilation by activating for example TGF $\beta[28,46-48]$. The outcome reported here is highly reminiscent of the immune tolerance seen in fetal lung and blood monocytes after repeated LPS exposure, in which subsequent exposure to different bacterial agents failed to elicit a second inflammatory response [22, 49]. It is therefore possible that the lack of involvement of TGF $\beta$ pathway components is a direct result of such an effect on the immune system by the repeated exposures.

TGF $\beta$ is implicated in the pathogenesis of BPD, but these data underline the multifactorial character of this process. Intra-uterine inflammation by itself may not lead to the high levels of TGF $\beta$ as seen in BPD, but it could very well prime the fetal lung for future responses. It should therefore be taken into account that clinical data are based on samples obtained from ventilated infants. A frequent second hit like mechanical ventilation could trigger an exaggerated TGF $\beta$ response leading to BPD [50]. In a previous study this scenario caused a very high TGF $\beta$ expression in the lung tissue of lambs, with 
the same LPS exposure as reported here, and who were briefly ventilated after preterm birth [36]. An additional factor that might influence the extent of TGF $\beta$ induction in fetal lungs before birth is the duration of bacterial exposure. We only evaluated the effects of short term exposure in lung tissue. The bronchoalveolar lavage fluid of preterm lambs exposed to ureaplasmas for 70 days, with or without additional acute LPS exposure, contained over 10-fold higher total TGF $\beta 1$ levels [17]. This suggests that a long term colonization with Ureaplasma spp. of the intra-amniotic pulmonary environment could well cause the elevated TGF $\beta$ levels at birth in children that go on to develop BPD [51]. Whether other gram negative or positive bacteria associated with chorioamnionitis would elicit a similar increase in TGF $\beta$ expression remains to be elucidated. Future research will have to focus on the responsiveness of the fetal immune system after multiple hits like chorioamnionitis and ventilation induced injury, and how these contribute to the lung developmental delay seen in BPD.

In conclusion, this study shows that TGF $\beta$ signaling components and elastin deposition in the fetal lung were affected differently by single intra-uterine exposure to LPS or ureaplasmas. More importantly, these responses were strongly attenuated or not seen at all after sequential exposure to LPS and ureaplasmas. This outcome may be the result of a fetal immune tolerance after multiple bacterial exposures.

\section{References}

1. Section IV Chapter 10: Mortality and acute complications in preterm infants, in Preterm birth: causes, consequences and prevention, R.E. Behrman and A. Stith Butler, Editors. 2007, National Academies Press: Washington. p. 313-345.

2. Jobe, A.H. and Bancalari, E., Bronchopulmonary dysplasia. Am J Respir Crit Care Med, 2001. 163(7): p. 1723-9.

3. Husain, A.N., Siddiqui, N.H., and Stocker, J.T., Pathology of arrested acinar development in postsurfactant bronchopulmonary dysplasia. Human pathology, 1998. 29(7): p. 710-7.

4. Yoon, B.H., Romero, R., Kim, K.S., Park, J.S., Ki, S.H., Kim, B.I., and Jun, J.K., A systemic fetal inflammatory response and the development of bronchopulmonary dysplasia. Am J Obstet Gynecol, 1999. 181(4): p. 773-9.

5. Speer, C.P., Inflammation and bronchopulmonary dysplasia. Semin Neonatol, 2003. 8(1): p. 29-38.

6. Schelonka, R.L., Katz, B., Waites, K.B., and Benjamin, D.K., Jr., Critical appraisal of the role of Ureaplasma in the development of bronchopulmonary dysplasia with metaanalytic techniques. Pediatr Infect Dis J, 2005. 24(12): p. 1033-9.

7. DiGiulio, D.B., Romero, R., Kusanovic, J.P., Gomez, R., Kim, C.J., Seok, K.S., Gotsch, F., MazakiTovi, S., Vaisbuch, E., Sanders, K., Bik, E.M., Chaiworapongsa, T., Oyarzun, E., and Relman, D.A., Prevalence and diversity of microbes in the amniotic fluid, the fetal inflammatory response, and pregnancy outcome in women with preterm pre-labor rupture of membranes. Am J Reprod Immunol, 2010. 64(1): p. 38-57.

8. Yoon, B.H., Chang, J.W., and Romero, R., Isolation of Ureaplasma urealyticum from the amniotic cavity and adverse outcome in preterm labor. Obstet Gynecol, 1998. 92(1): p. 77- 
82.

9. Viscardi, R.M., Ureaplasma species: role in diseases of prematurity. Clin Perinatol, 2010. 37(2): p. 393-409.

10. Gantert, M., Been, J.V., Gavilanes, A.W., Garnier, Y., Zimmermann, L.J., and Kramer, B.W., Chorioamnionitis: a multiorgan disease of the fetus? J Perinatol, 2010. 30 Suppl: p. S21-30.

11. Onderdonk, A.B., Delaney, M.L., DuBois, A.M., Allred, E.N., and Leviton, A., Detection of bacteria in placental tissues obtained from extremely low gestational age neonates. Am J Obstet Gynecol, 2008. 198(1): p. 110 e1-7.

12. Collins, J.J., Kallapur, S.G., Knox, C.L., Nitsos, I., Polglase, G.R., Pillow, J.J., Kuypers, E., Newnham, J.P., Jobe, A.H., and Kramer, B.W., Inflammation in fetal sheep from intraamniotic injection of Ureaplasma parvum. Am J Physiol Lung Cell Mol Physiol, 2010. 299(6): p. L852-60.

13. Novy, M.J., Duffy, L., Axthelm, M.K., Sadowsky, D.W., Witkin, S.S., Gravett, M.G., Cassell, G.H., and Waites, K.B., Ureaplasma parvum or Mycoplasma hominis as sole pathogens cause chorioamnionitis, preterm delivery, and fetal pneumonia in rhesus macaques. Reprod Sci, 2009. 16(1): p. 56-70.

14. Viscardi, R.M., Atamas, S.P., Luzina, I.G., Hasday, J.D., He, J.R., Sime, P.J., Coalson, J.J., and Yoder, B.A., Antenatal Ureaplasma urealyticum respiratory tract infection stimulates proinflammatory, profibrotic responses in the preterm baboon lung. Pediatr Res, 2006. 60(2): p. 141-6.

15. Kramer, B.W., Moss, T.J., Willet, K.E., Newnham, J.P., Sly, P.D., Kallapur, S.G., Ikegami, M., and Jobe, A.H., Dose and time response after intraamniotic endotoxin in preterm lambs. Am J Respir Crit Care Med, 2001. 164(6): p. 982-8.

16. Kallapur, S.G., Jobe, A.H., Ball, M.K., Nitsos, I., Moss, T.J., Hillman, N.H., Newnham, J.P., and Kramer, B.W., Pulmonary and systemic endotoxin tolerance in preterm fetal sheep exposed to chorioamnionitis. J Immunol, 2007. 179(12): p. 8491-9.

17. Kallapur, S.G., Kramer, B.W., Knox, C.L., Berry, C.A., Collins, J.J., Kemp, M.W., Nitsos, I., Polglase, G.R., Robinson, J., Hillman, N.H., Newnham, J.P., Chougnet, C., and Jobe, A.H., Chronic Fetal Exposure to Ureaplasma parvum Suppresses Innate Immune Responses in Sheep. J Immunol, 2011. 187(5): p. 2688-95.

18. Moss, T.J., Knox, C.L., Kallapur, S.G., Nitsos, I., Theodoropoulos, C., Newnham, J.P., Ikegami, M., and Jobe, A.H., Experimental amniotic fluid infection in sheep: effects of Ureaplasma parvum serovars 3 and 6 on preterm or term fetal sheep. Am J Obstet Gynecol, 2008. 198(1): p. 122 e1-8.

19. Knox, C.L., Dando, S.J., Nitsos, I., Kallapur, S.G., Jobe, A.H., Payton, D., Moss, T.J., and Newnham, J.P., The severity of chorioamnionitis in pregnant sheep is associated with in vivo variation of the surface-exposed multiple-banded antigen/gene of Ureaplasma parvum. Biology of reproduction, 2010. 83(3): p. 415-26.

20. Dando, S.J., Nitsos, I., Kallapur, S.G., Newnham, J.P., Polglase, G.R., Pillow, J.J., Jobe, A.H., Timms, P., and Knox, C.L., The role of the multiple banded antigen of Ureaplasma parvum in intra-amniotic infection: major virulence factor or decoy? PLoS One, 2012. 7(1): p. e29856.

21. Kramer, B.W., Ikegami, M., Moss, T.J., Nitsos, I., Newnham, J.P., and Jobe, A.H., Endotoxininduced chorioamnionitis modulates innate immunity of monocytes in preterm sheep. Am J Respir Crit Care Med, 2005. 171(1): p. 73-7.

22. Kramer, B.W., Kallapur, S.G., Moss, T.J., Nitsos, I., Newnham, J.P., and Jobe, A.H., Intraamniotic LPS modulation of TLR signaling in lung and blood monocytes of fetal sheep. Innate Immun, 2009. 15(2): p. 101-7.

23. Elgert, K.D., Immunology: understanding the immune system. 2nd ed. Vol. 1. 2009, Hoboken, New Jersey: Wiley-Blackwell. 726.

24. Akira, S. and Takeda, K., Toll-like receptor signalling. Nature reviews. Immunology, 2004. 
4(7): p. 499-511.

25. Shimizu, T., Kida, Y., and Kuwano, K., Ureaplasma parvum lipoproteins, including MB antigen, activate NF-\{kappa\}B through TLR1, TLR2 and TLR6. Microbiology, 2008. 154(Pt 5): p. 131825.

26. Ichiba, H., Saito, M., and Yamano, T., Amniotic fluid transforming growth factor-beta1 and the risk for the development of neonatal bronchopulmonary dysplasia. Neonatology, 2009. 96(3): p. 156-61.

27. Kotecha, S., Wangoo, A., Silverman, M., and Shaw, R.J., Increase in the concentration of transforming growth factor beta-1 in bronchoalveolar lavage fluid before development of chronic lung disease of prematurity. J Pediatr, 1996. 128(4): p. 464-9.

28. Bartram, U. and Speer, C.P., The role of transforming growth factor beta in lung development and disease. Chest, 2003. 125(2): p. 754-765.

29. Willems, C.H., Kloosterboer, N., Kunzmann, S., Kramer, B.W., Zimmermann, L.J., and van Iwaarden, J.F., Dissociation of transforming growth factors beta1 and beta 2 from surfactant protein A (SP-A) by deglycosylation or deoxycholate treatment. J Immunol Methods, 2012. 375(1-2): p. 111-7.

30. Kunzmann, S., Wright, J.R., Steinhilber, W., Kramer, B.W., Blaser, K., Speer, C.P., and SchmidtWeber, C., TGF-beta1 in SP-A preparations influence immune suppressive properties of SP-A on human CD4+ Tlymphocytes. Am J Physiol Lung Cell Mol Physiol, 2006. 291(4): p. L747-56.

31. Massague, J., TGF-beta signal transduction. Annu Rev Biochem, 1998. 67: p. 753-91.

32. Bland, R.D., Xu, L., Ertsey, R., Rabinovitch, M., Albertine, K.H., Wynn, K.A., Kumar, V.H., Ryan, R.M., Swartz, D.D., Csiszar, K., and Fong, K.S.K., Dysregulation of pulmonary elastin synthesis and assembly in preterm lambs with chronic lung disease. Am J Physiol Lung Cell Mol Physiol, 2007. 292(6).

33. Burri, P.H., Structural aspects of postnatal lung development - alveolar formation and growth. Biol Neonate, 2006. 89(4): p. 313-322.

34. Jobe, A.H., Newnham, J.P., Willet, K.E., Moss, T.J., Gore Ervin, M., Padbury, J.F., Sly, P., and Ikegami, M., Endotoxin-induced lung maturation in preterm lambs is not mediated by cortisol. Am J Respir Crit Care Med, 2000. 162(5): p. 1656-61.

35. Lee, A.J., Lambermont, V.A., Pillow, J.J., Polglase, G.R., Nitsos, I., Newnham, J.P., Beilharz, M.W., Kallapur, S.G., Jobe, A.H., and Kramer, B.W., Fetal responses to lipopolysaccharideinduced chorioamnionitis alter immune and airway responses in 7-week-old sheep. Am J Obstet Gynecol, 2011. 204(4): p. 364 e17-24.

36. Kunzmann, S., Speer, C.P., Jobe, A.H., and Kramer, B.W., Antenatal inflammation induced TGF-b1 but suppressed CTGF in preterm lungs. Am J Physiol Lung Cell Mol Physiol, 2006. 292: p. 223-231.

37. Kramer, B.W., Albertine, K.H., Moss, T.J., Nitsos, I., Ladenburger, A., Speer, C.P., Newnham, J.P., and Jobe, A.H., All-trans retinoic acid and intra-amniotic endotoxin-mediated effects on fetal sheep lung. Anat Rec (Hoboken), 2008. 291(10): p. 1271-7.

38. Lahra, M.M., Beeby, P.J., and Jeffery, H.E., Intrauterine inflammation, neonatal sepsis, and chronic lung disease: a 13-year hospital cohort study. Pediatrics, 2009. 123(5): p. 1314-9.

39. Been, J.V., Debeer, A., van Iwaarden, J.F., Kloosterboer, N., Passos, V.L., Naulaers, G., and Zimmermann, L.J., Early alterations of growth factor patterns in bronchoalveolar lavage fluid from preterm infants developing bronchopulmonary dysplasia. Pediatr Res, 2010. 67(1): p. 83-9.

40. Choi, C.W., Kim, B.I., Joung, K.E., Lee, J.A., Lee, Y.K., Kim, E.K., Kim, H.S., Park, J.D., and Choi, J.H., Decreased expression of transforming growth factor-beta1 in bronchoalveolar lavage cells of preterm infants with maternal chorioamnionitis. Journal of Korean medical science, 2008. 23(4): p. 609-15.

41. Strunk, T., Doherty, D., Jacques, A., Simmer, K., Richmond, P., Kohan, R., Charles, A., and 
Burgner, D., Histologic chorioamnionitis is associated with reduced risk of late-onset sepsis in preterm infants. Pediatrics, 2012. 129(1): p. e134-41.

42. Berger, A., Witt, A., Haiden, N., Kretzer, V., Heinze, G., and Pollak, A., Amniotic cavity cultures, blood cultures, and surface swabs in preterm infants--useful tools for the management of early-onset sepsis? Journal of perinatal medicine, 2004. 32(5): p. 446-52.

43. Sherman, M. and Truog, W., The role of pulmonary macrophages in chronic lung disease of early infancy, in Chronic Lung Disease in Early Infancy, R. Bland and J. Coalson, Editors. 1999, Marcel Dekker: New York. p. 813-839.

44. Kramer, B.W., Jobe, A.H., and Ikegami, M., Monocyte function in preterm, term, and adult sheep. Pediatr Res, 2003. 54(1): p. 52-7.

45. Kramer, B.W., Joshi, S.N., Moss, T.J., Newnham, J.P., Sindelar, R., Jobe, A.H., and Kallapur, S.G., Endotoxin-induced maturation of monocytes in preterm fetal sheep lung. Am J Physiol Lung Cell Mol Physiol, 2007. 293(2): p. L345-53.

46. Deguchi, Y., Spontaneous increase of transforming growth factor beta production by bronchoalveolar mononuclear cells of patients with systemic autoimmune diseases affecting the lung. Annals of the rheumatic diseases, 1992. 51(3): p. 362-5.

47. de Boer, W.I., van Schadewijk, A., Sont, J.K., Sharma, H.S., Stolk, J., Hiemstra, P.S., and van Krieken, J.H., Transforming growth factor beta1 and recruitment of macrophages and mast cells in airways in chronic obstructive pulmonary disease. American journal of respiratory and critical care medicine, 1998. 158(6): p. 1951-7.

48. Fadok, V.A., Bratton, D.L., Konowal, A., Freed, P.W., Westcott, J.Y., and Henson, P.M., Macrophages that have ingested apoptotic cells in vitro inhibit proinflammatory cytokine production through autocrine/paracrine mechanisms involving TGF-beta, PGE2, and PAF. The Journal of clinical investigation, 1998. 101(4): p. 890-8.

49. Azizia, M., Lloyd, J., Allen, M., Klein, N., and Peebles, D., Immune status in very preterm neonates. Pediatrics, 2012. 129(4): p. e967-74.

50. Van Marter, L.J., Dammann, O., Allred, E.N., Leviton, A., Pagano, M., Moore, M., and Martin, C., Chorioamnionitis, mechanical ventilation, and postnatal sepsis as modulators of chronic lung disease in preterm infants. The Journal of pediatrics, 2002. 140(2): p. 171-6.

51. Kotecha, S., Wangoo, A., Silverman, M., and Shaw, R.J., Increase in the concentration of transforming growth factor beta-1 in bronchoalveolar lavage fluid before development of chronic lung disease of prematurity. The Journal of pediatrics, 1996. 128(4): p. 464-9. 



\section{LPS-induced chorioamnionitis and}

\section{antenatal corticosteroids modulate}

\section{Wnt and Shh signaling in the ovine}

\section{fetal lung}

Collins JJP*, Kuypers E*, Nitsos I, Pillow JJ, Polglase GR, Kemp MW, Newnham JP, Cleutjens JP, Frints SGM, Kallapur SG, Jobe AH, Kramer BW

Published in part:

Am J Physiol Lung Cell Mol Physiol. 2012 Sep 7 Epub 
Abstract

Rationale Chorioamnionitis and antenatal corticosteroids mature the fetal lung functionally but disrupt late gestation lung development. Because Wingless-Int (Wnt) and Sonic Hedgehog (Shh) signaling are major pathways directing lung development, we hypothesized that chorioamnionitis and antenatal corticosteroids modulated these pathways resulting in an altered fetal lung structure.

Methods Time-mated ewes with singleton ovine fetuses received an intra-amniotic injection of lipopolysaccharide (LPS) and/or maternal intra-muscular betamethasone 7 and/or 14 days before delivery at 120 days gestational age (GA) (term=150 days GA).

Results LPS-induced chorioamnionitis modulated both Wnt and Shh signaling. Wnt1, Wnt4 and Wnt5a mRNA levels and $\beta$-catenin protein expression decreased 7 days after LPS exposure whereas Wnt7b mRNA levels increased 4-fold 14 days after LPS exposure. Sh mRNA levels and Gli1 protein expression decreased both 7 and 14 days after LPS exposure which was counteracted by betamethasone. mRNA and protein levels of fibroblast growth factor 10 and bone morphogenetic protein 4, which are important mediators of lung development, increased 2-fold and 3.5-fold respectively, 14 days after LPS exposure. Changes in Wnt and Shh signaling were accompanied by structural changes including fewer elastin foci, decreased $\alpha$-smooth muscle actin and collagen type I expression in the alveolar septa.

Conclusion Fetal lung exposure to LPS was accompanied by changes in key modulators of lung development resulting in abnormal lung structure. Betamethasone treatment partially prevented the changes in developmental processes and lung structure. This study provides new insights into clinically relevant prenatal exposures and fetal lung development.

\section{Introduction}

Bronchopulmonary dysplasia (BPD), a disease of impaired lung development, is the most common adverse lung outcome of preterm birth [1,2]. BPD is associated with fetal lung inflammation which can be initiated by chorioamnionitis, an intra-uterine bacterial infection of the placental membranes and amniotic fluid that is often clinically silent [3]. Chorioamnionitis can induce a potentially harmful inflammatory response in the immature fetal lungs which disrupts lung septation and vascular development leading to a decreased lung surface area [4].

Antenatal corticosteroids are given to mothers at risk of imminent preterm birth to induce lung maturation in the fetus which increases neonatal survival, but do not decrease BPD 
Chorioamnionitis and fetal lung development

$[5,6]$. Because the incidence of chorioamnionitis is about $60 \%$ for very preterm babies, the administration of maternal antenatal corticosteroids in the presence of chorioamnionitis is common and standard of care [7]. Although antenatal corticosteroids cause functional lung maturation, they also can inhibit lung development [8]. As a result, a large number of premature infants are exposed in utero to both pro- and anti-inflammatory stimuli which each alter normal fetal lung development and might predispose the infants to the development of BPD [9]. The molecular mechanisms by which chorioamnionitis and antenatal corticosteroids influence these lung developmental processes are largely unknown.

The Wnt signaling cascade is a key regulator of cell proliferation, polarity and differentiation and is essential for lung morphogenesis [10]. During early lung development, the Wnt pathway regulates branching and epithelial-mesenchymal interactions [11]. The canonical Wnt members, Wnt1, Wnt4 and Wnt7b, play pivotal roles in lung development, disease and remodeling [12-14]. Deletion of Wnt7b during embryonic lung development in mice resulted in hypoplastic lungs from defects in mesenchymal proliferation, and severe smooth muscle hypertrophy around the arteries [15]. Although the role of non-canonical Wnt signaling in the developing lung is less clear, several studies showed that altered Wnt5a expression interferes with normal pulmonary and vascular development $[16,17]$. Additionally, Wnt signaling modulates remodeling and repair in lung inflammation and fibrosis $[13,18]$.

Sonic Hedgehog (Shh) signaling is equally important in lung development as Shh-null mice have hypoplastic lungs and die due to respiratory failure [19]. During lung development, Shh expression is localized to the epithelium and activates Gli transcriptional activators Gli1, Gli2 and Gli3 [20]. The Shh pathway regulates the expression of lung growth factors such as fibroblast growth factor 10 (FGF10) and bone morphogenetic protein 4 (BMP4) which both mediate branching and myofibroblast differentiation [21].

We hypothesized that chorioamnionitis and/or antenatal corticosteroids modulate Wnt and Shh signaling to alter fetal lung structural development. We evaluated these signaling pathways after LPS-induced chorioamnionitis in a $120 \mathrm{~d}$ gestational age (GA) preterm lamb model during a stage of early alveolar septation. Fetal sheep were exposed in utero to intra-amniotic lipopolysaccharide (LPS) from gram negative bacteria and/or antenatal betamethasone, a corticosteroid used clinically to induce lung maturation [22, 23]. We correlated Wnt and Shh signaling components with markers for lung damage (heat shock protein (HSP)70, cell proliferation (Ki67) and changes in the lung structural proteins elastin, alpha- smooth muscle actin ( $\alpha$-SMA) and collagen, which are crucial for alveolar septation [24-27]. 
Materials and methods

\section{Animal model and sampling protocol}

All studies were approved by the Animal Ethics Committees at The University of Western Australia and Cincinnati Children's Hospital Medical Center (animal ethics protocol $\mathrm{RA} / 3 / 100 / 830$ ). The experimental design of this study was published previously [28]. Time-mated ewes with singleton fetuses were randomly assigned to one of six treatment groups to receive an intra-amniotic (IA) injection of lipopolysaccharide (LPS) (10 mg Escherichia Coli 055:B5, Sigma Chemical, St. Louis, MO, USA) and/or an intra-muscular injection of betamethasone (Beta) (Celestone Soluspan, Schering-Plough, North Ryde, New South Wales (NSW), Australia, $0.5 \mathrm{mg} / \mathrm{kg}$ maternal weight) and/or an equivalent injection of saline for control animals at 107 days and/or 114 days GA. All ewes in this study received a single intra-muscular injection of $150 \mathrm{mg}$ medroxyprogesterone acetate (Depo-Provera, Kenral, NSW, Australia) at 100 days GA to prevent preterm birth induced by betamethasone treatment. Lambs were surgically delivered at 120 days GA (term = 150 days $G A$ ) and euthanized after birth. Lung tissue from the right lower lobe (RLL) was snap frozen and the right upper lobe (RUL) was inflation-fixed in $10 \%$ buffered formalin for 24 hours.

\section{RNA extraction and real-time PCR}

Total RNA was extracted from frozen lung tissue of the RLL using the SV Total RNA Isolation system (Z3100, Promega, Madison, USA) according to the manufacturer's instructions. Genomic DNA contamination was removed by treatment with RQ1 DNase (M610A, Promega) and the RNA was tested for the presence of genomic GAPDH. Briefly, PCR amplification for the detection of genomic DNA was performed with DNA Taq Polymerase (M124B, Promega) at $95^{\circ} \mathrm{C}$ for 5 minutes followed by 40 cycles at $95^{\circ} \mathrm{C}$ for 30 seconds, $55^{\circ} \mathrm{C}$ for 45 seconds and $72^{\circ} \mathrm{C}$ for 30 seconds. Total RNA was used as a template. PCR products were analyzed on a $1.5 \%$ agarose gel. Total RNA was reverse transcribed with the First Strand cDNA synthesis kit (4379012001, Roche-Applied, Mannheim, Germany) according to manufacturer's instructions using anchored oligoprimers. Primers for real-time PCR (RT-PCR) were constructed based on published ovine or bovine cDNA sequences (Table 1). Dilution experiments were performed to ensure similar PCR amplification efficiency of the primers. RT-PCR reactions were performed in duplicate with the LightCycler 480 SYBR Green I Master mix (4707516001, RocheApplied) on a LightCycler 480 Instrument according to the manufacturer's instructions. RT-PCR results were normalized to cyclophilin A, a housekeeping gene, and mean fold changes in mRNA expression were calculated by the $\Delta \Delta \mathrm{Ct}$-method [29]. 
Table 1: Primers used for RT-PCR

\begin{tabular}{|c|c|c|c|c|}
\hline Gene & Sequence (5'-3') & $\begin{array}{l}\text { Amplicon } \\
\text { size }\end{array}$ & $T^{m}$ & $\begin{array}{l}\text { Accession code } \\
\text { (RefSeq) }\end{array}$ \\
\hline \multirow[t]{2}{*}{ Wnt1 } & Fw: ATTTATCTTCGCCATCACCTC & $123 b p$ & $64^{\circ} \mathrm{C}$ & NM_001114191.1 \\
\hline & Rv: ATTCGATGGAGCCCTCTG & & & \\
\hline \multirow[t]{2}{*}{ Wnt4 } & Fw: GCTGGGCTCCAAGTACACC & $241 b p$ & $60^{\circ} \mathrm{C}$ & NM_001170828.1 \\
\hline & Rv: GGCTATCCTGACACACATGC & & & \\
\hline \multirow[t]{2}{*}{ Wnt5a } & Fw: AGCTAATTCTTGGTGGTCGCTAGG & $124 b p$ & $66^{\circ} \mathrm{C}$ & NM_001205971.1 \\
\hline & Rv: CAAGTGGCAGAGTTTCTTCTGTCC & & & \\
\hline \multirow[t]{2}{*}{ Wnt7b } & Fw: TGCACTCCAGCTTCATGCGC & $60 b p$ & $58^{\circ} \mathrm{C}$ & XM_603482.5 \\
\hline & Rv: ACCTGCACAACAACGAGGCG & & & \\
\hline \multirow[t]{2}{*}{ Axin2 } & $\begin{array}{l}\text { Fw: } \\
\text { CTCAGCAAAAAGGGAAATTACAGGTAT }\end{array}$ & 97bp & $60^{\circ} \mathrm{C}$ & NM_004655.3 \\
\hline & Rv: ACTGTCTCGTCGTCCCAGATCTC & & & \\
\hline \multirow[t]{2}{*}{ Shh } & Fw: ACTGGAGCGGACCGGCTGAT & $82 b p$ & $68^{\circ} \mathrm{C}$ & XM_614193.3 \\
\hline & Rv: CCGGCCACTGGCTCATCAC & & & \\
\hline \multirow[t]{2}{*}{ Gli1 } & Fw: AATCTGAAGACGCACCTG & $137 b p$ & $60^{\circ} \mathrm{C}$ & NM_001099000.1 \\
\hline & Rv: GTAGGGCTTCTCATTGGA & & & \\
\hline \multirow[t]{2}{*}{ Gli2 } & Fw: CCTGGAGAACCTGAAGAC & $147 \mathrm{bp}$ & $60^{\circ} \mathrm{C}$ & NM_001192250.1 \\
\hline & Rv: GATGTAGGGTTTCTCGTTGG & & & \\
\hline \multirow[t]{2}{*}{ Gli3 } & Fw: AGAAGCCTCACAAATGCAC & 197bp & $60^{\circ} \mathrm{C}$ & XM_002686896.1 \\
\hline & Rv: ACACATATGGTTTCTCGTTGG & & & \\
\hline \multirow[t]{2}{*}{ FGF10 } & Fw: TGCCCGTACAGTATCCTG & $220 b p$ & $60^{\circ} \mathrm{C}$ & NM_001009230.1 \\
\hline & Rv: GCCACATACATTTGCCTC & & & \\
\hline \multirow[t]{2}{*}{ BMP4 } & Fw: ACCACGAAGAACATCTGGAG & $173 b p$ & $61^{\circ} \mathrm{C}$ & NM_001110277.1 \\
\hline & Rv: TTATACGATGAAAGCCCTGC & & & \\
\hline \multirow{3}{*}{$\begin{array}{l}\text { Cyclo } \\
\text { philinA }\end{array}$} & Fw: & $93 b p$ & $60^{\circ} \mathrm{C}$ & NM_178320.2 \\
\hline & TTATAAAGGTTCCTGCTTTCACAGAA & & & \\
\hline & Rv: ATGGACTTGCCACCAGTACCA & & & \\
\hline
\end{tabular}

Protein extraction and enzyme-linked immunosorbent assay (ELISA) of HSP70 Frozen RLL lung tissue was homogenized (PRO Quick Connect Generators part no. 0207095; PRO Scientific Inc., Oxford, CT) in ice-cold RIPA buffer (R0278, Sigma Aldrich) containing $0.1 \%$ protease inhibitors (p9599, Sigma Aldrich) and subsequently centrifuged 
at $12 x$ RCF for 5 minutes at $4^{\circ} \mathrm{C}$ [30]. HSP70 was measured with an R\&D DuoSet ELISA development kit (human/mouse/rat total HSP70: DYC1663, R\&D Systems, Minneapolis, MN, USA) according to manufacturer's instructions. HSP70 protein concentrations were calculated per kilogram bodyweight.

\section{Western blot}

Protein concentrations, of lung extracts as obtained above, were determined with the Micro BCA Protein assay kit (\#23235, Thermo Fisher Scientific Inc., Rockford, IL USA), according to manufacturer's instructions with BSA as the standard. To confirm equal protein loading, immunoblotting was performed with a $\beta$-actin antibody (A5441, Sigma Aldrich). Proteins were denatured by heating at $100^{\circ} \mathrm{C}$ for 5 minutes in SDS sample buffer ( $5 x$ reduced: $1 \mathrm{~g}$ glycerol, $1 \mathrm{~g}$ SDS, $2.13 \mathrm{~mL} 0.5 \mathrm{M}$ Tris- $\mathrm{HCl}$ pH $6.8+0.4 \%$ SDS, small amount of bromophenol blue, $385 \mathrm{mg}$ dithiothreitol $+2.56 \mathrm{~mL}$ MilliQ), separated on $15 \%$ SDS-polyacrylamide gels and transferred to Protran BA83 nitrocellulose membranes (10402495, Whatman GmbH, Dassel, Germany). After blocking with a 1:1 mixture of TBS (Tris/HCl 2.5mM, pH 7.5) and ODYSSEY infrared Imaging System Blocking buffer (92740000 , LI-COR, Lincoln, NE), the membranes were incubated with the primary antibodies overnight at $4^{\circ} \mathrm{C}$. The following dilutions were used: 1:1000 for monoclonal rabbit-anti $\beta$-catenin (9582S, Cell Signaling Technology, Danvers MA) and 1:1000 for monoclonal mouse anti- $\beta$-actin (A5441, Sigma Aldrich). As secondary antibodies, IRDye800-goat anti-rabbit and IRDye680 goat anti-mouse were used in a dilution of 1:6000 (LI-COR). Protein bands were analyzed using a LI-COR Odyssey Infrared Imaging System.

\section{Immunohistochemistry}

Paraffin embedded RUL lung sections ( $4 \mu \mathrm{m}$, transverse) were stained for Ki67 (M7240, DAKO, Denmark), c-myc (sc-40, Santa Cruz Biotechnology), Gli1 (ab49314, Abcam, Cambridge, UK), bone morphogenetic protein 4 (BMP4) (sc-6896, Santa Cruz Biotechnology) and alpha smooth muscle actin ( $\alpha$-SMA) (A5228, Sigma-Aldrich). Briefly, the sections were deparaffinized in an ethanol series and endogenous peroxidaseactivity was blocked by incubation with $0.5 \% \mathrm{H}_{2} \mathrm{O}_{2}$ in 1 x phosphate buffered saline (PBS, $\mathrm{pH}$ 7.4). Antigen retrieval was performed by incubating the sections in heated citrate buffer (10 mM, pH 6.0) for 30 minutes. In order to block aspecific binding, the slides were incubated with $20 \%$ normal goat serum (NGS) in PBS (this step was omitted for $\alpha$-SMA). Sections were incubated overnight at $4^{\circ} \mathrm{C}$ with the diluted primary antibody (Ki67 1:50, c-myc: 1:50, Gli1 1:500, BMP4 1:500, $\alpha$-SMA 1:1000). After incubation with the appropriate secondary antibody, immunostaining was enhanced with Vectastain ABC peroxidase Elite kit (PK-6200, Vector Laboratories, Burlingame, USA) and stained with nickel sulfate-diaminobenzidine (NiDAB). Subsequently, the sections were rinsed in 
Chorioamnionitis and fetal lung development

Tris/saline and incubated with Tris/cobalt. After counterstaining with $0.1 \%$ Nuclear Fast Red, the sections were washed, dehydrated and coverslipped. All slides were stained at the same time under the same conditions.

Evaluation was performed by light microscopy (Axioskop 40, Zeiss, Germany) with LeicaQWin Pro v.3.4.0 software (Leica Microsystems, Germany). Alveolar Ki67 and Gli1 staining was scored by blinded observers with a semi-quantitative scoring system: 1 , little staining; 2, some staining; and 3, heavy staining. BMP4 and c-myc staining was semi-quantitatively scored in three representative bronchioli using Image J software (Rasband, W.S., Image J US National Institutes of Health, Bethesda, Maryland, USA) and represented as a percentage of the entire bronchiole surface area. The intensity of $\alpha$-SMA staining in bronchioli and bronchi was quantified using Image J software and represented as a percentage of entire bronchiole or bronchus surface area staining [4]. The number of $\alpha$-SMA concentrated foci was counted in the alveoli by a blinded observer using Image J software.

\section{Elastin and collagen staining}

Elastin and collagen stainings were performed on paraffin sections of the RUL of the lung ( $4 \mu \mathrm{m}$, transverse). For the visualization of elastin, the sections were deparaffinized in an ethanol series and incubated in Weigerts Resorcine-Fuchsine (2E 030, Chroma, Münster, Germany) at $60-70^{\circ} \mathrm{C}$ for 20 minutes. After rinsing with water, the sections were incubated for 3 minutes in a tartrazine solution at room temperature. Subsequently the sections were washed and dehydrated [4]. For the detection of collagen fibers, the sections were deparaffinized and incubated in Sirius Red solution for 60 minutes in the dark. After rinsing with $0.01 \mathrm{M} \mathrm{HCl}$ for 3 minutes, the sections were washed, dehydrated and coverslipped. Evaluation was performed by light microscopy (Zeiss, Axioskop 40) with LeicaQWin Pro v.3.4.0 software. Elastin and collagen foci were measured in three representative sections across septa at 200x magnification by a blinded observer using Image J software.

\section{Data Analysis}

Results are given as means \pm standard error of mean (SEM). The groups were compared using one-way ANOVA with Dunnett's or Tukey's test for post-hoc analysis as appropriate. Statistical analysis was performed by GraphPad Prism v5.0. Significance was accepted at $p<0.05$. 
Results

\section{Lung damage and cell proliferation}

Characteristics of the animals and the pulmonary inflammatory and maturation response to LPS-induced chorioamnionitis and/or antenatal corticosteroids were reported previously [28]. Lung injury due to the exposure to LPS was assessed by measurement of heat shock protein 70 (HSP70) in the lung tissue. HSP70 protein expression was not increased in any of the experimental groups compared to control (Figure 1A). To assess cell proliferation, lung tissue was stained for Ki67, a marker of mitotic cells. There were increased proliferating cells 7 and 14 days after the exposure to LPS (Figure 1B).

A

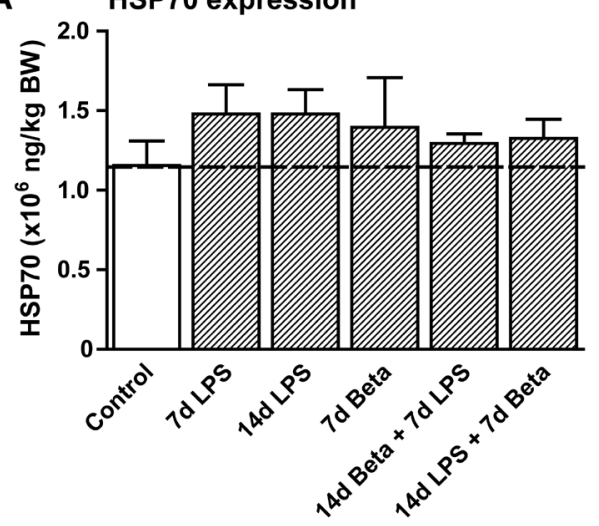

B

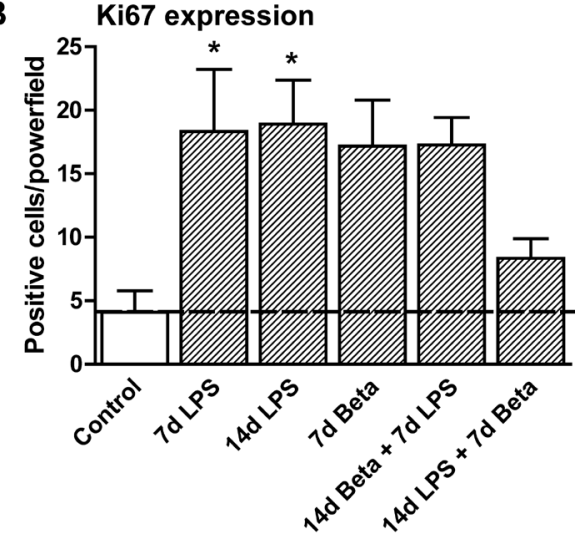

Figure 1: Lung injury and cell proliferation.

A: Protein levels of Heat Shock Protein (HSP)70 did not change in homogenates of LPS and/or betamethasone (Beta) exposed fetal lungs. B: The number of Ki67-positive cells in the alveoli increased after LPS exposure. Pre- and particularly post-treatment with Beta partially prevented this increase. BW - bodyweight. * $p<0.05$ versus controls using a one-way ANOVA with Tukey's post hoc test.

\section{Pathways regulating lung development}

We measured lung mRNA levels of Wnt1, Wnt4, Wnt5a and Wnt7b to evaluate if exposure to LPS and/or betamethasone affected Wnt signaling. Wnt1 levels decreased $90 \% 7$ days after the LPS exposure compared to controls (Figure 2A). Wnt4 mRNA expression was decreased in all groups that received LPS independently of the betamethasone treatment (Figure 2B). Wnt5a mRNA decreased 50\% in all experimental groups except for the animals that received betamethasone 7 days before the exposure to LPS (Figure 2C). In this group, there was a $40 \%$ increase in Wnt5a mRNA levels compared to controls. Wnt7b levels were increased 4-fold after LPS exposure compared to controls (Figure 2D). Treatment with betamethasone 7 days after the LPS exposure prevented this increase. 
Chorioamnionitis and fetal lung development

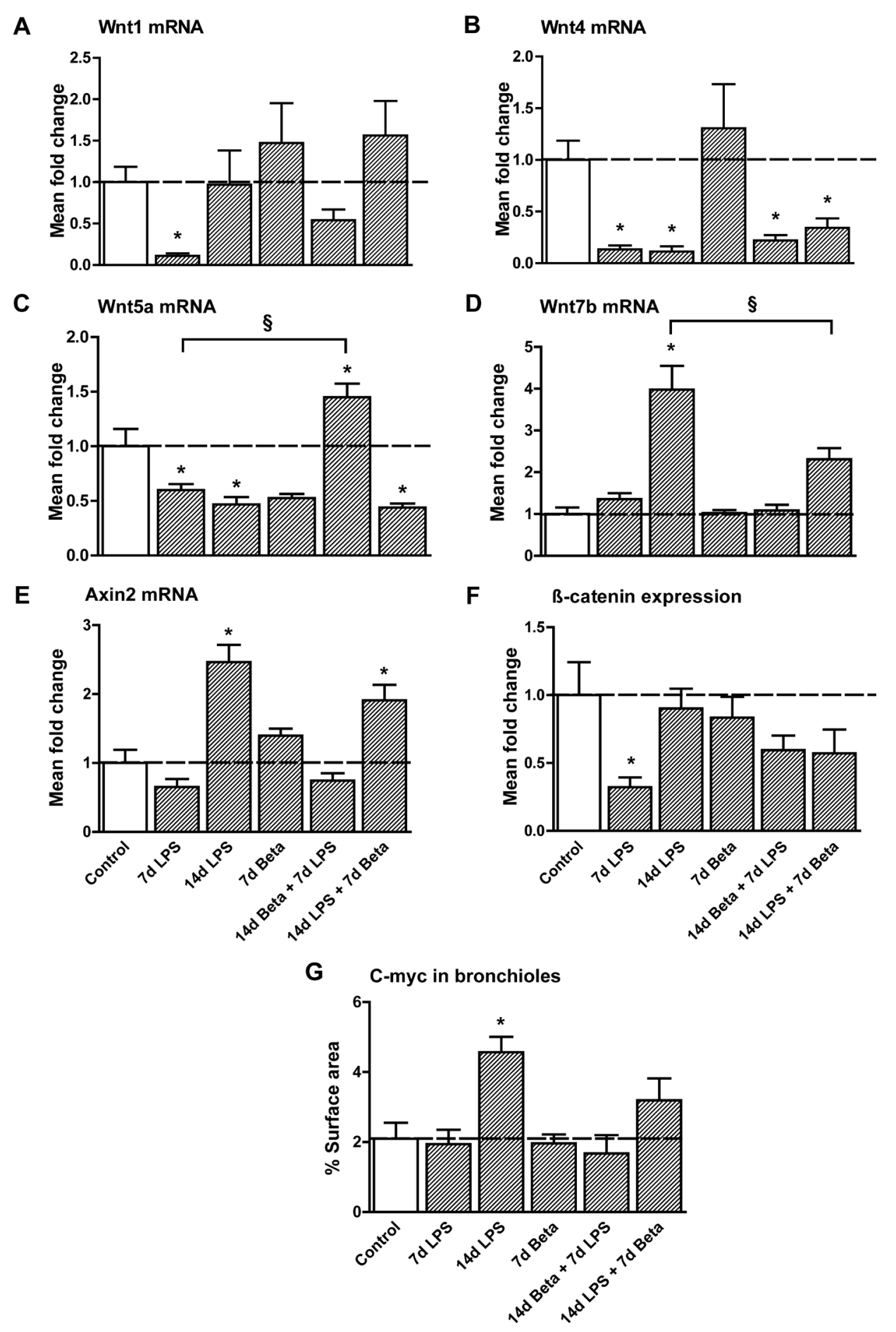


Figure 2: Changes in the Wingless-Int (Wnt) pathway.

A: Expression of Wnt1 decreased 9-fold 7 days after LPS exposure compared to controls. Antenatal exposure to Beta prior to 7 day LPS exposure could attenuate this decrease. B: Expression of Wnt4 decreased 7 and 14 days after LPS exposure compared to controls. This drop in Wnt4 expression after LPS exposure was not affected by treatment with Beta. C: Wnt5a mRNA levels decreased to $50 \%$ in all experimental groups except in the group that received betamethasone 7 days before the LPS exposure. This group showed a $40 \%$ increase in Wnt5a mRNA compared to controls.D: Expression of Wnt $7 b$ increased nearly 4 -fold 14 days after LPS exposure compared to controls. This increase was prevented if betametasone (Beta) was administered 7 days after LPS exposure. E: mRNA levels of Axin2 increased 14 days after LPS exposure. Post-treatment with Beta lowered, but did not completely prevent an increase in Axin2 expression. $\mathrm{F}$ : $\beta$-catenin protein levels decreased by two-thirds in fetal lungs exposed to LPS for 7 days. Pre-treatment of fetal lambs with Beta could partially prevent this decrease G: C-myc expression increased in lungs 14 days after LPS exposure. C-myc expression returned to control levels in lambs that received post-treatment with Beta. * $p<0.05$ versus controls and $\S p<0.05$ between experimental groups using a one-way ANOVA with Tukey's post hoc test.

However, in this group there was still a trend towards increased Wnt7b expression. Expression of Axin2 mRNA, which is regulated by Wnt7b [31], had a pattern similar to $W n t 7 b$ mRNA expression (Figure 2E). $\beta$-catenin protein expression, which is the major downstream effector of the canonical Wnt pathway, decreased 7 days after the exposure to LPS similar to Wnt1 and Wnt4 (Figure 2F). C-myc expression, which is regulated by Wnt7b [32, 33], increased 14 days after LPS exposure in the bronchioles (Figure 2G).

The Shh pathway interacts with Wnt signaling during lung development [34]. Because the Wnt pathway was affected by LPS exposure, Shh mRNA expression was measured in the lungs. Shh mRNA levels decreased to less than $25 \%$ of control value after 7 and 14 days of LPS exposure (Figure $3 \mathrm{E}$ ). Betamethasone pre- or post-treatment prevented the decrease in Shh mRNA. In addition, we analyzed the expression of Gli1 and Gli2, which are components of the Shh pathway. Gli1 mRNA expression had a similar decreased expression at 7 and 14 days following LPS exposure (Figure 3F). Gli1 protein expression was mainly detected in the bronchiolar and alveolar epithelium in controls (Figure 3A). Exposure to LPS for 7 or 14 days selectively decreased Gli1 protein expression in the alveolar epithelium (Figure 3B). Betamethasone pre- or post-treatment again prevented this decline (Figure 3G). Representative images are shown for controls (Figure 3A), 14 day LPS exposed lungs (Figure 3B), 7 day betamethasone exposed lungs (Figure 3C) and 14 day LPS and 7 day betamethasone exposed lungs (Figure 3D). Gli2 mRNA expression had similar trends towards declines after LPS exposure (Figure $3 \mathrm{H}$ ).

Levels of FGF10 and BMP4, two important Wnt and Shh regulated mediators of lung development, were also assessed. Both FGF10 and BMP4 mRNA increased 14 days after LPS exposure, by 2 -fold and 3.5 fold respectively (Figure $4 A$ and $4 B$ ). Exposure to betamethasone after LPS exposure lowered FGF10 and BMP4 mRNA. BMP4 protein 
Chorioamnionitis and fetal lung development
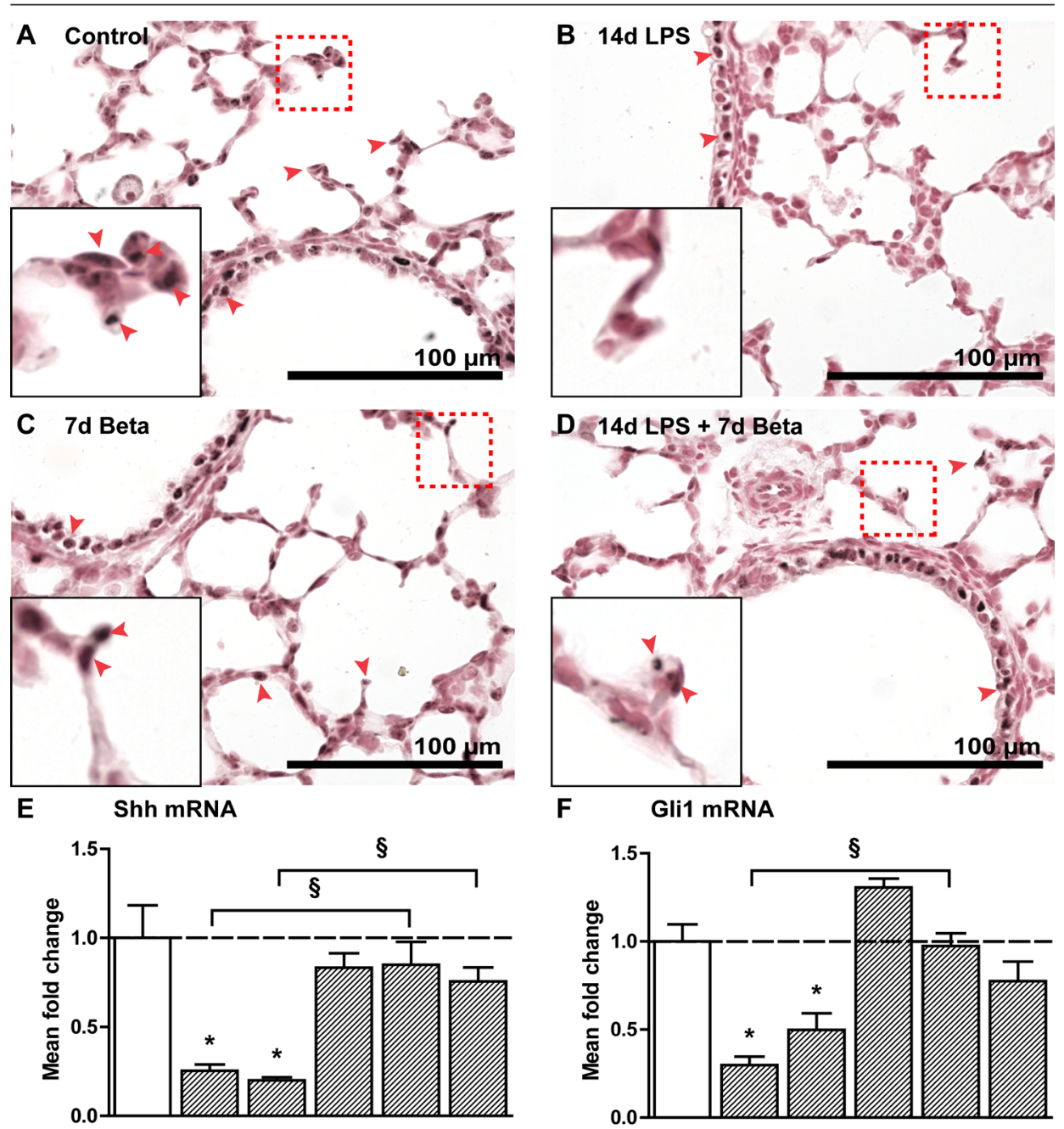

G Gli1 expression
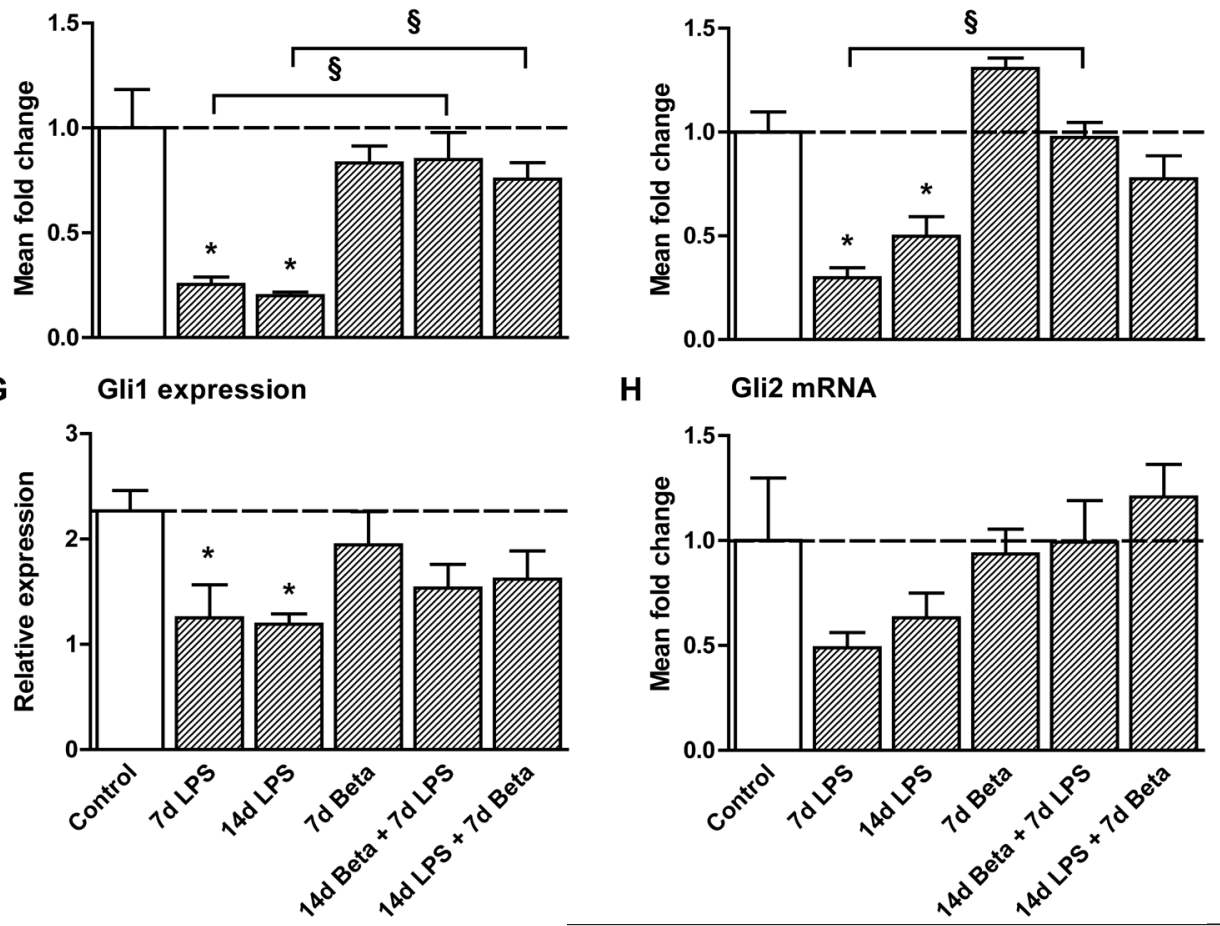
Figure 3: Inhibition of the Sonic Hedgehog (Shh) pathway.

Gli1 expression in alveolar and bronchial tissue as seen in controls (A), 14 days after LPS exposure (B), 7 days after betamethasone (Beta) treatment (C) and after a combination of 14 days LPS followed by post-treatment with Beta (D). E: Expression of Shh was decreased after 7 and 14 days LPS exposure. Both pre- and post-treatment with betamethasone (Beta) normalized Shh mRNA levels compared to controls. F: Gli1 mRNA levels were decreased in LPS exposed lungs. Both preand post-treatment with Beta normalized Gli1 mRNA levels compared to controls. G: Gli1 protein expression as scored in the alveoli in lung sections decreased after 7 and 14 day LPS exposure. Preor post-treatment could partially attenuate this decrease.H: Levels of Gli2 mRNA in experimental groups did not differ significantly from controls. ${ }^{*} p<0.05$ versus controls and $\S p<0.05$ between experimental groups using a one-way ANOVA with Tukey's post hoc test.

\section{A FGF10 mRNA}

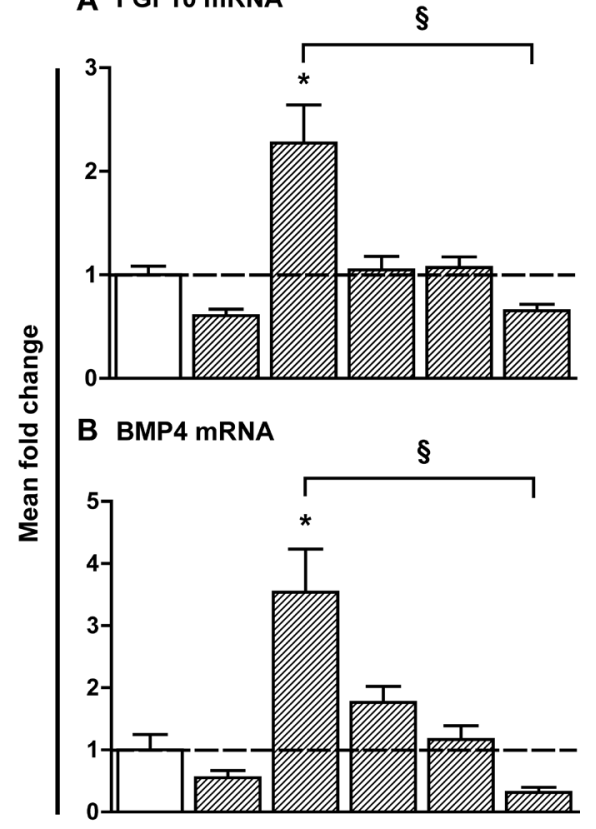

C BMP4 expression

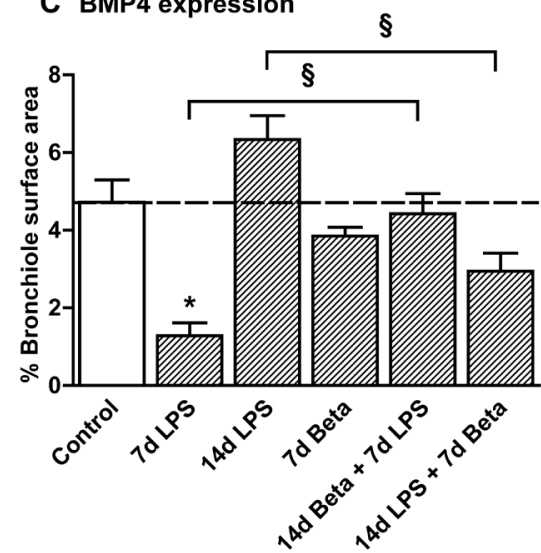

expression was mainly localized in the bronchial epithelial cells, which corresponds with recent data obtained in adult lung tissue [35, 36]. Immunohistochemical analysis of BMP4 expression in bronchioli revealed that BMP4 was decreased 7 days after LPS exposure, and showed a trend towards increased expression at 14 days after LPS exposure (Figure 4C). Treatment with betamethasone before LPS exposure prevented the decrease in BMP4 levels seen after 7 day LPS exposure only. Treatment with betamethasone 7 days after the LPS exposure decreased BMP4 levels.

\section{Figure 4: Expression of Fibroblast Growth Factor (FGF)10 and Bone Morphogenetic Protein (BMP)4.}

A: mRNA levels of FGF10 were increased two-fold 14 days after LPS exposure. Post-treatment with betamethasone (Beta) normalized FGF10 levels compared to controls. B: mRNA levels of BMP4 were increased 3.5-fold 14 days after LPS exposure. Post-treatment with Beta normalized BMP4 levels compared to controls. C: Immunohistochemical analysis of BMP4 expression in bronchioli decreased after 7 days of LPS exposure, but a recovery of BMP4 14 days after LPS exposure. Pre-treatment with Beta before LPS exposure prevented a drop in BMP4 levels. ${ }^{*} p<0.05$ versus controls and $\S p<0.05$ between experimental groups using a one-way ANOVA with Tukey's post hoc test. 


\section{Expression of lung structural proteins}

Elastin foci were measured in lung sections as an assessment of secondary septation. Representative images are shown for controls (Figure 5A) and 14 day LPS and 7 day betamethasone exposed lungs (Figure 5B). The number of elastin foci was decreased in the lungs of LPS exposed groups lambs (Figure 5C). Pre-treatment, but not posttreatment, with betamethasone minimized the decrease in elastin foci. Collagen I deposition was similar to elastin deposition. Representative images are shown for controls (Figure 5D) and 14 day LPS and 7 day betamethasone exposed lungs (Figure 5E). 14 day LPS exposure combined with betamethasone post-treatment after 7 days decreased the number of collagen I foci. There was a trend towards decreased collagen foci in lungs exposed to LPS.

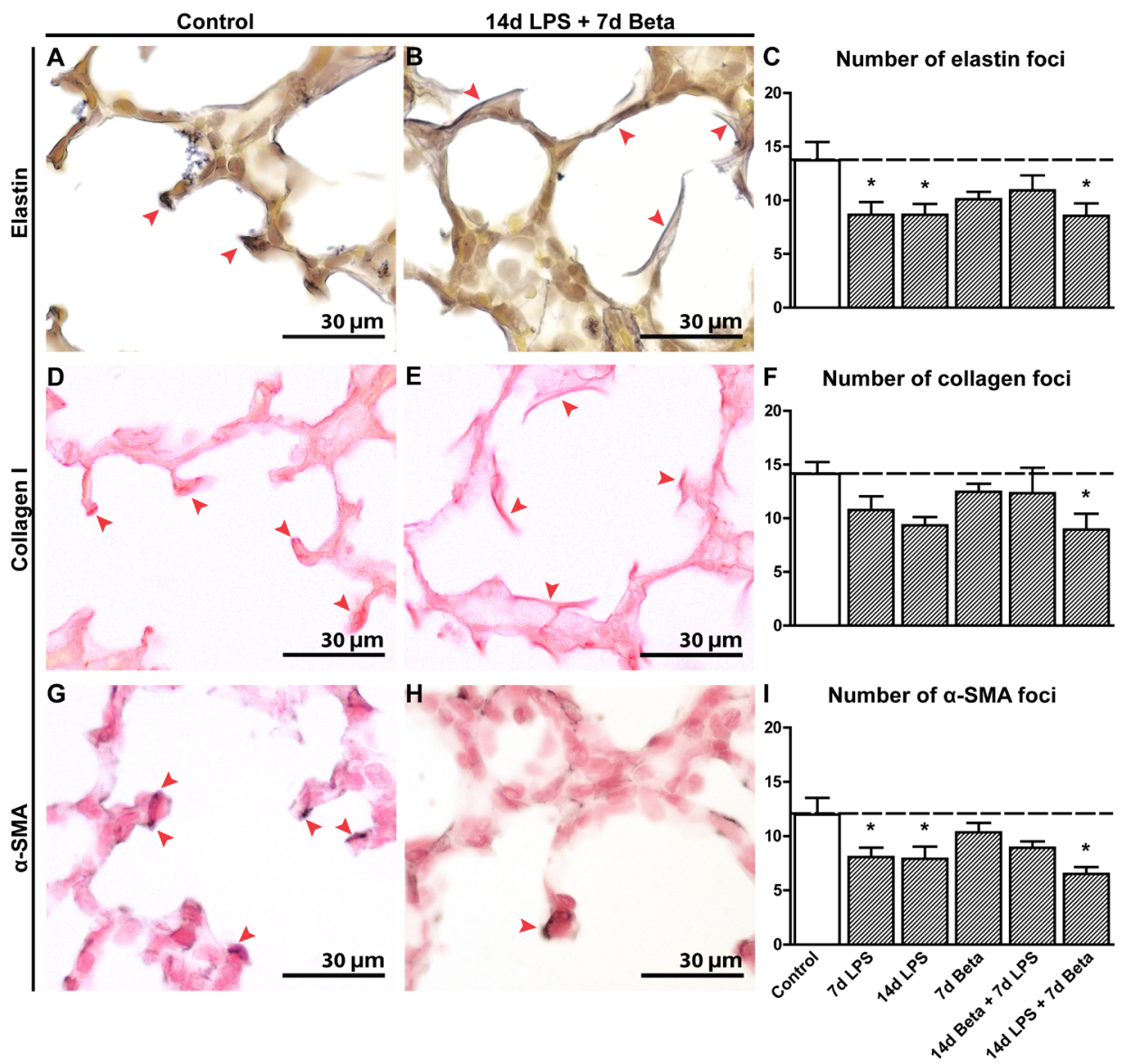

Figure 5: Altered expression of structural components of the lung.

Elastin deposition in the alveoli of control (A) and 14d LPS $+7 \mathrm{~d}$ betamethasone (Beta) (B) lambs. C: The number of elastin foci was decreased in LPS exposed lambs. Pre-treatment, but not posttreatment, with Beta could prevent a significant decrease in elastin foci. Collagen I deposition in 
the alveoli of control (D) and 14d LPS $+7 d$ Beta (E) lambs. F: 14 day LPS exposure and 7 day Beta exposure decreased the number of collagen I foci. $\alpha$ - Smooth muscle actin ( $\alpha$-SMA) expression in the alveoli of control (G) and 14d LPS $+7 d$ Beta $(\mathbf{H})$ lambs. I: The number of $\alpha$-SMA foci was decreased in LPS exposed lambs.. ${ }^{*} p<0.05$ versus controls and $\S p<0.05$ between experimental groups using a one-way ANOVA with Dunnett's post hoc test.

Additionally, lung sections were stained for $\alpha$-SMA and the tips of alveolar septa with $\alpha$-SMA were counted. Representative images are shown for controls (Figure 5G) and 14 day LPS and 7 betamethasone exposed lungs (Figure $5 \mathrm{H}$ ). Figure $5 \mathrm{I}$ shows a similar expression pattern for these $\alpha$-SMA positive septa, or foci, as for elastin foci. The number
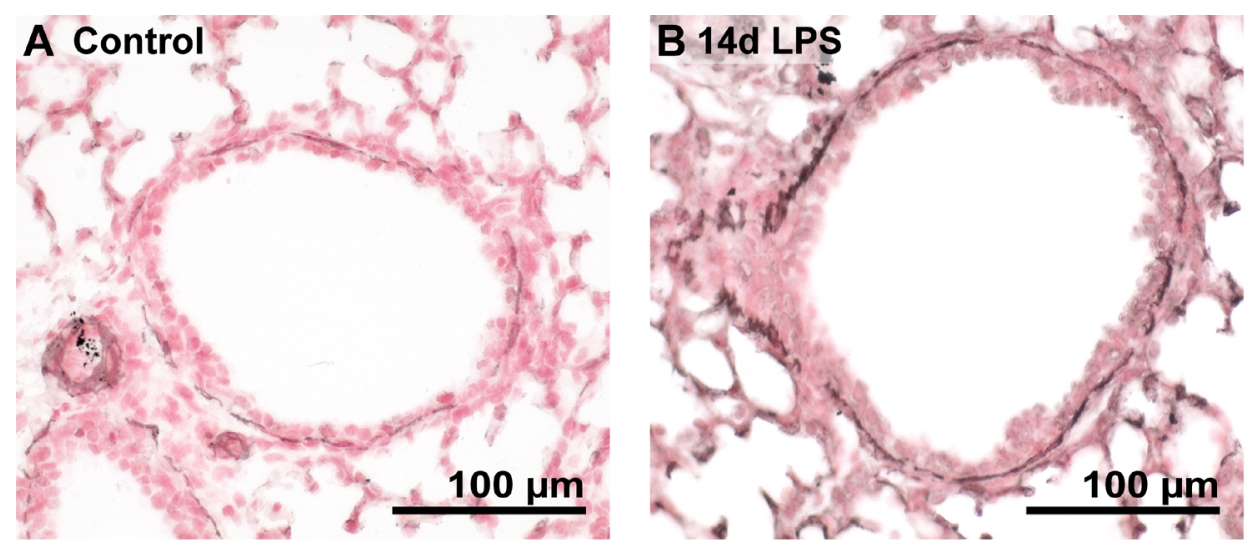

\section{C $\alpha$-SMA bronchioli}

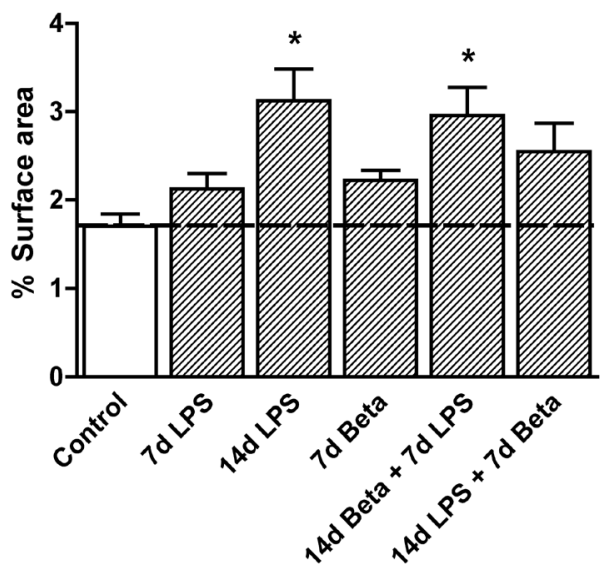

\section{D a-SMA bronchi}

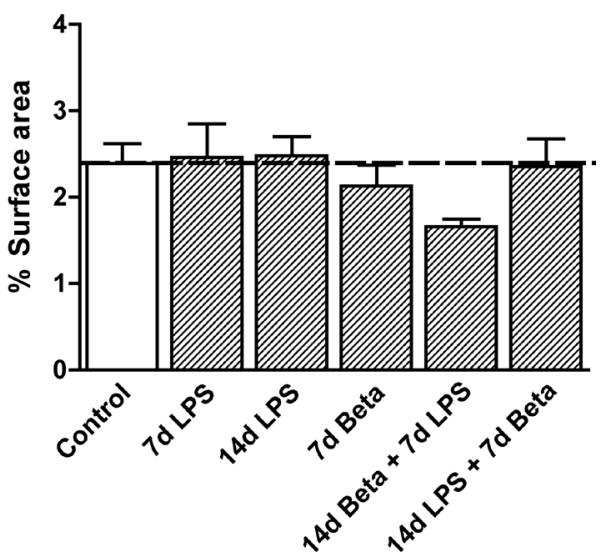

Figure 6: Airway $\alpha$-Smooth muscle actin ( $\alpha$-SMA) expression.

$\alpha$-SMA expression in the bronchioli of control (A) and 14d LPS (B) lambs. C: $\alpha$-SMA expression increased around bronchioli 14 days after LPS exposure. Post-treatment with Beta could prevent this increase. Interestingly, pre-treatment with Beta before LPS exposure also increased $\alpha$-SMA expression. 7d LPS exposure only did not change $\alpha$-SMA expression. D: $\alpha$-SMA expression around the bronchi remained unaffected by either LPS or Beta exposure. ${ }^{*} p<0.05$ versus controls and $\S$ $p<0.05$ between experimental groups using a one-way ANOVA with Tukey's post hoc test. 
Chorioamnionitis and fetal lung development

of $\alpha$-SMA foci decreased with LPS exposure. Pre-treatment, but not post-treatment, with betamethasone prevented this decrease in $\alpha$-SMA foci. The intensity of $\alpha$-SMA expression also was measured in the bronchioli and bronchi. Representative images of the changes in the bronchioli are shown for controls (Figure 6A) and 14 day LPS exposed lungs (Figure 6B). $\alpha$-SMA expression increased around bronchioli 14 days after LPS exposure (Figure 6C). Post-treatment with betamethasone prevented this increase. Interestingly, pre-treatment with betamethasone before LPS exposure also increased $\alpha$-SMA expression. 7 days of exposure to LPS only did not change $\alpha$-SMA expression. No changes in $\alpha$-SMA expression around the bronchi were noticed in any of the treatment groups (Figure 6D). Further computerized morphometric analysis is reported elsewhere and did not show differences [28].

\section{Discussion}

\section{LPS exposure leads to changes in both Wnt and Shh signaling in the fetal lung}

In the context of developmental biology research, less is known about later fetal lung development than early organogenesis. Later lung development is, however, an area of human biology where clinical care interfaces with development since survival after very preterm birth at $60 \%$ of gestation is now frequent. We used an animal model with similarities to late gestation human lung development to test two very common clinical exposures, chorioamnionitis and antenatal steroids. We used 7 and 14 day intra-uterine periods of exposure based on our previous findings of a delay in alveolar development after 7 and 14 days of LPS-induced inflammation $[8,25]$. Here we show that fetal lung exposure to LPS-induced inflammation [37] is accompanied by changes in the Wnt and Shh pathways, which are crucial for early lung development. In addition, we demonstrated that a maternal intra-muscular injection of betamethasone attenuated the effects of LPS on these developmental pathways. We therefore provide some molecular insights into the observational data from clinical practice that maternal corticosteroids are beneficial despite the inflammation of chorioamnionitis [38].

There is increasing evidence that the Wnt and Shh pathways are involved during aberrant lung development and disease $[13,39,40]$. We found a decrease in Wnt1, Wnt4 and Wnt5a mRNA levels and decreased $\beta$-catenin protein expression 7 days after LPS exposure. Several reports demonstrated that inhibition of Wnt signaling leads to impaired branching and defects in vascular development in the embryonic lung $[15,17$, 41,42 ] suggesting that down regulation of the Wnt pathway may disrupt branching lung morphogenesis. Our study is one of the first to show aberrant Wnt signaling following intra-uterine lung inflammation in a late lung development model. 14 Days after the 
exposure to LPS, Wnt7b mRNA expression was up regulated. In addition, we found a 2.5-fold increase in Axin2 mRNA and c-myc protein levels upon Wnt-activation. Because Wnt signaling is involved in the repair phases of several lung diseases [13,43, 44], these relatively late effects are very likely to represent a compensation of the developing lung for the damage inflicted by LPS-induced chorioamnionitis [45]. Although we did not measure an increased expression of HSP70, an indicator of oxidant-stress mediated lung damage in this study, previous work from our group showed that LPS-induced chorioamnionitis causes fetal lung injury as early as $5 \mathrm{~h}$ after the exposure [45]. Tissue remodeling was further characterized by increased proliferation and maturation of alveolar type II cells after the exposure to LPS $[28,45]$.

Recently, LPS was shown to down-regulate Shh in vitro in pulmonary microvascular endothelial cells [46]. In our study, LPS strongly down-regulated mRNA expression of Shh and its signaling components Gli1 and Gli2 in the ovine fetal lung. LPS exposure also selectively decreased Gli1 protein expression in the distal epithelial tips where Shh signaling in the lung is mainly localized [47]. Shh expression can be induced by retinoic acid [48], which is decreased in babies who develop BPD [49]. The down-regulation of Shh is in line with a previous study from our group, in which LPS-induced chorioamnionitis decreased retinoic acid in fetal sheep lungs [25]. Therefore, the LPS-induced decrease of retinoic acid may have decreased Shh mRNA.

These decreases in mRNA and protein expression of Shh signaling pathway components were accompanied by 2 - to 3-fold increases in FGF10 and BMP4 expression 14 days after LPS exposure, following a slight decrease 7 days after LPS exposure. The initial decrease in FGF10 expression, which has also been measured in the lung tissue of infants with BPD [50], might be due to the activation of TLR2 and 4 by LPS, which can suppress FGF10 through binding of NF-KB to the FGF10 promotor [51]. As FGF10 induces BMP4 expression in the developing lung [21], the inhibition of FGF10 may indirectly decrease BMP4 expression. The continuous suppression of Shh measured at 7 and 14 days after LPS exposure, which normally down-regulates FGF10 [52], may have caused FGF10 and BMP4 levels to rise.

The changes in these pivotal developmental pathways were accompanied by changes in the deposition of structural proteins which are known to direct alveolar septation [24-27]. In a normally developing lung, focal expression of elastin and $\alpha$-SMA identify sites for alveolar budding [53]. In the lungs of the LPS exposed lambs, the numbers of elastin, collagen and $\alpha$-SMA foci on the alveolar septa were decreased, along with a more diffuse expression of these proteins along the alveolar walls. In addition, $\alpha$-SMA deposition around bronchioli increased 14 days after LPS exposure, which could be a response to increased FGF10 and BMP4 expression [54, 55]. 
Chorioamnionitis and fetal lung development

\section{Betamethasone and lung development}

Antenatal corticosteroids are routinely administered to mothers who are at risk of preterm birth to mature the fetal organs [5]. A secondary benefit may be suppression of inflammation [5]. Antenatal steroids also reduce adverse neonatal outcome after preterm birth associated with chorioamnionitis [38], which constitute the majority of early gestational preterm births [5]. The effect of these combined pro- and antiinflammatory stimuli on pathways that are crucial for the developing lung are however unknown. In our study, we found that betamethasone administration before the LPS exposure partially attenuated the decrease in Wnt1 and Wnt5a mRNA levels and $\beta$-catenin protein expression thereby preventing down regulation of the Wnt pathway. Recently, we showed that betamethasone treatment before the LPS exposure suppressed fetal lung inflammation by an unknown priming or conditioning mechanism of the fetal immune system [28]. As such, little pulmonary damage was inflicted by the exposure to LPS explaining the modest changes in the developmental pathways we have studied here. Interestingly, betamethasone treatment alone selectively lowered Wnt5a mRNA levels in the fetal lung. These findings are in line with micro-array data showing down regulation of Wnt5a in fetal rat lung fibroblasts after dexamethasone treatment [56]. Betamethasone treatment after LPS exposure lowered Wnt7b and Axin2 mRNA levels and c-myc protein expression. Others have reported interactions that are consistent with these results. The interactions of the glucocorticoid receptor (GR) with PI3K result in a potent complex which not only leads to increased TNF $\alpha$ production, but also activates glycogen synthase kinase $3 \beta$ (GSK3 $\beta$ ) by decreasing the phosphorylation of Akt [57]. Activation of GSK3 $\beta$ increases $\beta$-catenin breakdown and thus inhibits the Wnt pathway. In addition, the GR can directly inhibit Wnt signaling by binding to the transcription factor (tcf)- $\beta$-catenin complex [58].

Very little is known about the effect of maternal corticosteroids on Shh, FGF10 and BMP4. Corticosteroids can to inhibit Shh-mediated neural development and as such can have a detrimental effect on the neonatal developing brain [59]. We found that maternal corticosteroids alone did not change the expression of these factors in comparison with controls. However, the effects of LPS on these factors were neutralized by maternal betamethasone, irrespective if betamethasone was given 7 days before or after LPS. At the lung structural level, only treatment with betamethasone before LPS exposure could mitigate the decrease of elastin, collagen and $\alpha$-SMA foci. Betamethasone treatment after LPS exposure did attenuate an increase in $\alpha$-SMA expression around bronchioli, where pre-treatment could not.

In this study, we modeled common clinical exposure to provide new insights into the effects of exposures on fetal lung development $[8,60]$. However, there are limitations, as 
exposures at different time points, for different intervals and to a single dose or repeated doses of corticosteroids during fetal development may have different outcomes. The effects of pro- and anti-inflammatory stimuli on the developing lung are clearly complex. As we recognized the need for in-depth analysis of the signaling pathways in this model, we attempted to further characterize changes in the canonical Wnt pathway by evaluating Sox9 and c-myc protein expression by Western blot, and in non-canonical Wnt signaling. However, due to the low expression of c-myc and BMP4 and a lack of specific reagents for ovine tissue, we were not able to measure these components. It remains to be determined whether the observed changes are the result of direct or indirect effects of LPS and betamethasone with these developmental pathways. Based on these results, intervention studies using inhibitors of the Wnt and Shh pathways (e.g. cyclopamine [61]) would be helpful. The developing lung is plastic in that it is continually changing over gestation. Because chorioamnionitis is often clinically silent, the duration of exposure of the lung to chorioamnionitis and the subsequent inflammatory response are unknown. It is generally unknown whether antenatal maternal corticosteroids are administered before or after the onset of chorioamnionitis [5]. This report provides some insights into the complicated interactions that can alter lung structure during the maturation phase of lung development.

\section{References}

1. Bancalari, E., Claure, N., and Sosenko, I.R., Bronchopulmonary dysplasia: changes in pathogenesis, epidemiology and definition. Semin Neonatol, 2003. 8(1): p. 63-71.

2. Laughon, M., Bose, C., Allred, E.N., O'Shea, T.M., Ehrenkranz, R.A., Van Marter, L.J., and Leviton, A., Antecedents of chronic lung disease following three patterns of early respiratory disease in preterm infants. Arch Dis Child Fetal Neonatal Ed. 96(2): p. F114-20.

3. Goldenberg, R.L., Culhane, J.F., lams, J.D., and Romero, R., Epidemiology and causes of preterm birth. Lancet, 2008. 371(9606): p. 75-84.

4. Collins, J.J., Kallapur, S.G., Knox, C.L., Nitsos, I., Polglase, G.R., Pillow, J.J., Kuypers, E., Newnham, J.P., Jobe, A.H., and Kramer, B.W., Inflammation in fetal sheep from intraamniotic injection of Ureaplasma parvum. Am J Physiol Lung Cell Mol Physiol, 2010. 299(6): p. L852-60.

5. Preterm birth: Causes, consequences and prevention, ed. R.E. Behrman and A. Stith Butler2007, Washington: National Academies Press.

6. Carlo, W.A., McDonald, S.A., Fanaroff, A.A., Vohr, B.R., Stoll, B.J., Ehrenkranz, R.A., Andrews, W.W., Wallace, D., Das, A., Bell, E.F., Walsh, M.C., Laptook, A.R., Shankaran, S., Poindexter, B.B., Hale, E.C., Newman, N.S., Davis, A.S., Schibler, K., Kennedy, K.A., Sanchez, P.J., Van Meurs, K.P., Goldberg, R.N., Watterberg, K.L., Faix, R.G., Frantz, I.D., 3rd, and Higgins, R.D., Association of antenatal corticosteroids with mortality and neurodevelopmental outcomes among infants born at 22 to 25 weeks' gestation. JAMA. 306(21): p. 2348-58.

7. Been, J., Degraeuwe, P., Kramer, B., and Zimmermann, L., Antenatal steroids and neonatal outcome after chorioamnionitis: a meta-analysis. BJOG, 2011. 118(2): p. 113-22.

8. Willet, K.E., Jobe, A.H., Ikegami, M., Newnham, J., Brennan, S., and Sly, P.D., Antenatal endotoxin and glucocorticoid effects on lung morphometry in preterm lambs. Pediatr Res, 
2000. 48(6): p. 782-8.

9. Bourbon, J., Boucherat, O., Chailley-Heu, B., and Delacourt, C., Control mechanisms of lung alveolar development and their disorders in bronchopulmonary dysplasia. Pediatr Res, 2005. 57(5 Pt 2): p. 38R-46R.

10. Mucenski, M.L., Wert, S.E., Nation, J.M., Loudy, D.E., Huelsken, J., Birchmeier, W., Morrisey, E.E., and Whitsett, J.A., beta-Catenin is required for specification of proximal/distal cell fate during lung morphogenesis. J Biol Chem, 2003. 278(41): p. 40231-8.

11. Rajagopal, J., Carroll, T.J., Guseh, J.S., Bores, S.A., Blank, L.J., Anderson, W.J., Yu, J., Zhou, Q., McMahon, A.P., and Melton, D.A., Wnt7b stimulates embryonic lung growth by coordinately increasing the replication of epithelium and mesenchyme. Development, 2008. 135(9): p. 1625-34.

12. Bernardi, H., Gay, S., Fedon, Y., Vernus, B., Bonnieu, A., and Bacou, F., Wnt4 activates the canonical beta-catenin pathway and regulates negatively myostatin: functional implication in myogenesis. Am J Physiol Cell Physiol. 300(5): p. C1122-38.

13. Konigshoff, M., Balsara, N., Pfaff, E.M., Kramer, M., Chrobak, I., Seeger, W., and Eickelberg, O., Functional Wht signaling is increased in idiopathic pulmonary fibrosis. PLoS One, 2008. 3(5): p. e2142.

14. Sharma, S., Tantisira, K., Carey, V., Murphy, A.J., Lasky-Su, J., Celedon, J.C., Lazarus, R., Klanderman, B., Rogers, A., Soto-Quiros, M., Avila, L., Mariani, T., Gaedigk, R., Leeder, S., Torday, J., Warburton, D., Raby, B., and Weiss, S.T., A role for Wnt signaling genes in the pathogenesis of impaired lung function in asthma. Am J Respir Crit Care Med. 181(4): p. 328-36.

15. Shu, W., Jiang, Y.Q., Lu, M.M., and Morrisey, E.E., Wnt7b regulates mesenchymal proliferation and vascular development in the lung. Development, 2002. 129(20): p. 4831-42.

16. Li, C., Hu, L., Xiao, J., Chen, H., Li, J.T., Bellusci, S., Delanghe, S., and Minoo, P., Wnt5a regulates Shh and Fgf10 signaling during lung development. Dev Biol, 2005. 287(1): p. 86-97.

17. Li, C., Xiao, J., Hormi, K., Borok, Z., and Minoo, P., Wnt5a participates in distal lung morphogenesis. Dev Biol, 2002. 248(1): p. 68-81.

18. Dasgupta, C., Sakurai, R., Wang, Y., Guo, P., Ambalavanan, N., Torday, J.S., and Rehan, V.K., Hyperoxia-induced neonatal rat lung injury involves activation of TGF-\{beta\} and Wht signaling and is protected by rosiglitazone. Am J Physiol Lung Cell Mol Physiol, 2009. 296(6): p. L1031-41.

19. Litingtung, Y., Lei, L., Westphal, H., and Chiang, C., Sonic hedgehog is essential to foregut development. Nat Genet, 1998. 20(1): p. 58-61.

20. Bellusci, S., Furuta, Y., Rush, M.G., Henderson, R., Winnier, G., and Hogan, B.L., Involvement of Sonic hedgehog (Shh) in mouse embryonic lung growth and morphogenesis. Development, 1997. 124(1): p. 53-63.

21. Weaver, M., Dunn, N.R., and Hogan, B.L., Bmp4 and Fgf10 play opposing roles during lung bud morphogenesis. Development, 2000. 127(12): p. 2695-704.

22. Kramer, B.W., Moss, T.J., Willet, K.E., Newnham, J.P., Sly, P.D., Kallapur, S.G., Ikegami, M., and Jobe, A.H., Dose and time response after intraamniotic endotoxin in preterm lambs. Am J Respir Crit Care Med, 2001. 164(6): p. 982-8.

23. Roberts, D. and Dalziel, S., Antenatal corticosteroids for accelerating fetal lung maturation for women at risk of preterm birth. Cochrane Database Syst Rev, 2006. 3: p. CD004454.

24. Bland, R.D., Xu, L., Ertsey, R., Rabinovitch, M., Albertine, K.H., Wynn, K.A., Kumar, V.H., Ryan, R.M., Swartz, D.D., Csiszar, K., and Fong, K.S.K., Dysregulation of pulmonary elastin synthesis and assembly in preterm lambs with chronic lung disease. Am J Physiol Lung Cell Mol Physiol, 2007. 292(6).

25. Kramer, B.W., Albertine, K.H., Moss, T.J., Nitsos, I., Ladenburger, A., Speer, C.P., Newnham, J.P., and Jobe, A.H., All-trans retinoic acid and intra-amniotic endotoxin-mediated effects on 
fetal sheep lung. Anat Rec (Hoboken), 2008. 291(10): p. 1271-7.

26. Leslie, K.O., Mitchell, J.J., Woodcock-Mitchell, J.L., and Low, R.B., Alpha smooth muscle actin expression in developing and adult human lung. Differentiation, 1990. 44(2): p. 143-9.

27. Thibeault, D.W., Mabry, S.M., Ekekezie, II, Zhang, X., and Truog, W.E., Collagen scaffolding during development and its deformation with chronic lung disease. Pediatrics, 2003. 111(4 Pt 1): p. 766-76.

28. Kuypers, E., Collins, J.J., Kramer, B.W., Ofman, G., Nitsos, I., Pillow, J.J., Polglase, G.R., Kemp, M.W., Newnham, J.P., Gavilanes, A.W., Nowacki, R., Ikegami, M., Jobe, A.H., and Kallapur, S.G., Intra-amniotic LPS and antenatal betamethasone: inflammation and maturation in preterm lamb lungs. Am J Physiol Lung Cell Mol Physiol.

29. Livak, K.J. and Schmittgen, T.D., Analysis of relative gene expression data using real-time quantitative PCR and the 2(-Delta Delta C(T)) Method. Methods, 2001. 25(4): p. 402-8.

30. Lee, A.J., Lambermont, V.A., Pillow, J.J., Polglase, G.R., Nitsos, I., Newnham, J.P., Beilharz, M.W., Kallapur, S.G., Jobe, A.H., and Kramer, B.W., Fetal responses to lipopolysaccharideinduced chorioamnionitis alter immune and airway responses in 7-week-old sheep. Am J Obstet Gynecol. 204(4): p. 364 e17-24.

31. Jho, E.H., Zhang, T., Domon, C., Joo, C.K., Freund, J.N., and Costantini, F., Wnt/beta-catenin/ Tcf signaling induces the transcription of Axin2, a negative regulator of the signaling pathway. Mol Cell Biol, 2002. 22(4): p. 1172-83.

32. He, T.C., Sparks, A.B., Rago, C., Hermeking, H., Zawel, L., da Costa, L.T., Morin, P.J., Vogelstein, B., and Kinzler, K.W., Identification of c-MYC as a target of the APC pathway. Science, 1998. 281(5382): p. 1509-12.

33. Ziegler, S., Rohrs, S., Tickenbrock, L., Moroy, T., Klein-Hitpass, L., Vetter, I.R., and Muller, O., Novel target genes of the Wnt pathway and statistical insights into Wnt target promoter regulation. FEBS J, 2005. 272(7): p. 1600-15.

34. Watt, F.M., Unexpected Hedgehog-Wnt interactions in epithelial differentiation. Trends Mol Med, 2004. 10(12): p. 577-80.

35. Masterson, J.C., Molloy, E.L., Gilbert, J.L., McCormack, N., Adams, A., and O'Dea, S., Bone morphogenetic protein signalling in airway epithelial cells during regeneration. Cellular signalling, 2011. 23(2): p. 398-406.

36. Rosendahl, A., Pardali, E., Speletas, M., Ten Dijke, P., Heldin, C.H., and Sideras, P., Activation of bone morphogenetic protein/Smad signaling in bronchial epithelial cells during airway inflammation. American journal of respiratory cell and molecular biology, 2002. 27(2): p. 160-9.

37. Kuypers, E., Collins, J.J., Kramer, B.W., Ofman, G., Nitsos, I., Pillow, J.J., Polglase, G.R., Kemp, M.W., Newnham, J.P., Gavilanes, A.W., Nowacki, R., Ikegami, M., Jobe, A.H., and Kallapur, S.G., Intra-amniotic LPS and antenatal betamethasone: inflammation and maturation in preterm lamb lungs. Am J Physiol Lung Cell Mol Physiol, 2012. 302(4): p. L380-9.

38. Goldenberg, R.L., Andrews, W.W., Faye-Petersen, O.M., Cliver, S.P., Goepfert, A.R., and Hauth, J.C., The Alabama preterm birth study: corticosteroids and neonatal outcomes in 23to 32-week newborns with various markers of intrauterine infection. Am J Obstet Gynecol, 2006. 195(4): p. 1020-4.

39. Shi, W., Chen, F., and Cardoso, W.V., Mechanisms of lung development: contribution to adult lung disease and relevance to chronic obstructive pulmonary disease. Proc Am Thorac Soc, 2009. 6(7): p. 558-63.

40. Katoh, Y. and Katoh, M., Hedgehog target genes: mechanisms of carcinogenesis induced by aberrant hedgehog signaling activation. Curr Mol Med, 2009. 9(7): p. 873-86.

41. De Langhe, S.P., Sala, F.G., Del Moral, P.M., Fairbanks, T.J., Yamada, K.M., Warburton, D., Burns, R.C., and Bellusci, S., Dickkopf-1 (DKK1) reveals that fibronectin is a major target of Wnt signaling in branching morphogenesis of the mouse embryonic lung. Dev Biol, 2005. 
Chorioamnionitis and fetal lung development

277(2): p. 316-31.

42. Takayasu, H., Nakazawa, N., Montedonico, S., and Puri, P., Down-regulation of Wnt signal pathway in nitrofen-induced hypoplastic lung. J Pediatr Surg, 2007. 42(2): p. 426-30.

43. Kneidinger, N., Yildirim, A.O., Callegari, J., Takenaka, S., Stein, M.M., Dumitrascu, R., Bohla, A., Bracke, K.R., Morty, R.E., Brusselle, G.G., Schermuly, R.T., Eickelberg, O., and Konigshoff, M., Activation of the WNT/beta-catenin pathway attenuates experimental emphysema. Am J Respir Crit Care Med, 2011. 183(6): p. 723-33.

44. Al Alam, D., Green, M., Tabatabai Irani, R., Parsa, S., Danopoulos, S., Sala, F.G., Branch, J., El Agha, E., Tiozzo, C., Voswinckel, R., Jesudason, E.C., Warburton, D., and Bellusci, S., Contrasting Expression of Canonical Wht Signaling Reporters TOPGAL, BATGAL and Axin2 during Murine Lung Development and Repair. PLoS One. 6(8): p. e23139.

45. Kramer, B.W., Kramer, S., Ikegami, M., and Jobe, A.H., Injury, inflammation, and remodeling in fetal sheep lung after intra-amniotic endotoxin. Am J Physiol Lung Cell Mol Physiol, 2002. 283(2): p. L452-9.

46. Yang, Y., Li, Q., Deng, Z., Zhang, Z., Xu, J., Qian, G., and Wang, G., Protection from lipopolysaccharide-induced pulmonary microvascular endothelial cell injury by activation of hedgehog signaling pathway. Mol Biol Rep, 2010.

47. Zhang, M., Wang, H., Teng, H., Shi, J., and Zhang, Y., Expression of SHH signaling pathway components in the developing human lung. Histochem Cell Biol. 134(4): p. 327-35.

48. Riddle, R.D., Johnson, R.L., Laufer, E., and Tabin, C., Sonic hedgehog mediates the polarizing activity of the ZPA. Cell, 1993. 75(7): p. 1401-16.

49. Shenai, J.P., Chytil, F., and StahIman, M.T., Vitamin A status of neonates with bronchopulmonary dysplasia. Pediatr Res, 1985. 19(2): p. 185-8.

50. Benjamin, J.T., Smith, R.J., Halloran, B.A., Day, T.J., Kelly, D.R., and Prince, L.S., FGF-10 is decreased in bronchopulmonary dysplasia and suppressed by Toll-like receptor activation. Am J Physiol Lung Cell Mol Physiol, 2007. 292(2): p. L550-8.

51. Benjamin, J.T., Carver, B.J., Plosa, E.J., Yamamoto, Y., Miller, J.D., Liu, J.H., van der Meer, R., Blackwell, T.S., and Prince, L.S., NF-kappaB activation limits airway branching through inhibition of Sp1-mediated fibroblast growth factor-10 expression. J Immunol, 2010. 185(8): p. 4896-903.

52. Bellusci, S., Grindley, J., Emoto, H., Itoh, N., and Hogan, B.L., Fibroblast growth factor 10 (FGF10) and branching morphogenesis in the embryonic mouse lung. Development, 1997. 124(23): p. 4867-78.

53. Burri, P.H., Structural aspects of postnatal lung development - alveolar formation and growth. Biol Neonate, 2006. 89(4): p. 313-322.

54. Mailleux, A.A., Kelly, R., Veltmaat, J.M., De Langhe, S.P., Zaffran, S., Thiery, J.P., and Bellusci, S., Fgf10 expression identifies parabronchial smooth muscle cell progenitors and is required for their entry into the smooth muscle cell lineage. Development, 2005. 132(9): p. 2157-66.

55. Perl, A.K. and Gale, E., FGF signaling is required for myofibroblast differentiation during alveolar regeneration. Am J Physiol Lung Cell Mol Physiol, 2009. 297(2): p. L299-308.

56. Boucherat, O., Franco-Montoya, M.L., Thibault, C., Incitti, R., Chailley-Heu, B., Delacourt, C., and Bourbon, J.R., Gene expression profiling in lung fibroblasts reveals new players in alveolarization. Physiol Genomics, 2007. 32(1): p. 128-41.

57. Smith, E. and Frenkel, B., Glucocorticoids inhibit the transcriptional activity of LEF/TCF in differentiating osteoblasts in a glycogen synthase kinase-3beta-dependent and-independent manner. J Biol Chem, 2005. 280(3): p. 2388-94.

58. Takayama, S., Rogatsky, I., Schwarcz, L.E., and Darimont, B.D., The glucocorticoid receptor represses cyclin D1 by targeting the Tcf-beta-catenin complex. J Biol Chem, 2006. 281(26): p. $17856-63$.

59. Gulino, A., De Smaele, E., and Ferretti, E., Glucocorticoids and neonatal brain injury: the 


\section{Chapter 7}

hedgehog connection. J Clin Invest, 2009. 119(2): p. 243-6.

60. Sweet, D.G., Huggett, M.T., Warner, J.A., Moss, T.J., Kloosterboer, N., Halliday, H.L., Newnham, J.P., Kallapur, S.G., Jobe, A.H., and Kramer, B.W., Maternal betamethasone and chorioamnionitis induce different collagenases during lung maturation in fetal sheep. Neonatology, 2008. 94(2): p. 79-86.

61. Welch, K.D., Panter, K.E., Lee, S.T., Gardner, D.R., Stegelmeier, B.L., and Cook, D., Cyclopamineinduced synophthalmia in sheep: defining a critical window and toxicokinetic evaluation. J Appl Toxicol, 2009. 29(5): p. 414-21. 


\section{Summary \& Discussion}

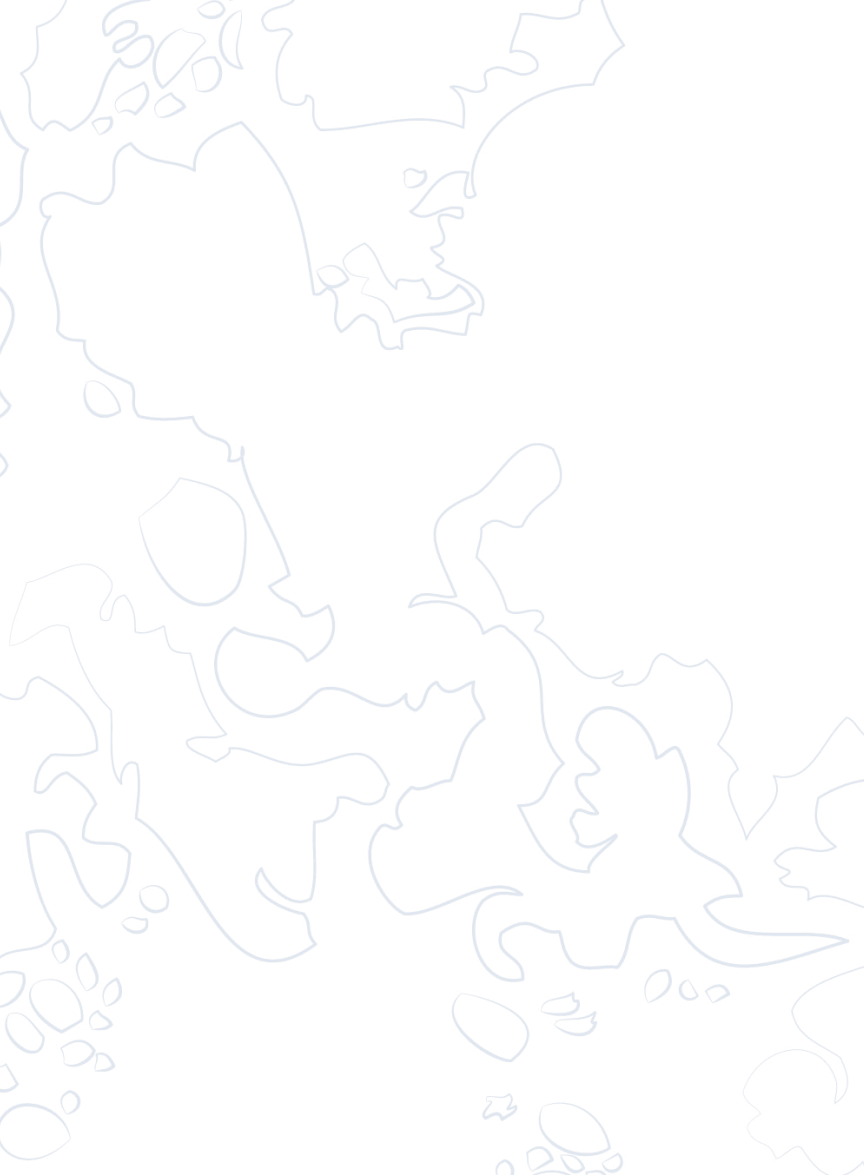




\section{Bacterial exposure and the fetal inflammatory response}

Contrary to popular belief, microbial invasion of the amniotic cavity is more likely the rule than the exception [1]. Microorganisms have been identified in tissues from fetuses throughout gestation, including those sampled from elective cesarean surgery at term [2]. In the majority of cases of preterm birth, however, an inflammatory response has been staged against these microorganisms by the fetus, which is diagnosed as histologic or clinical chorioamnionitis [2]. Analysis of the amniotic fluid of women presenting with PPROM led to the identification of a staggering 49 different bacterial species by PCR and culture [3]. Approximately $34 \%$ of the amniotic fluid samples harbored multiple bacterial species. An inflammatory response was seen in the majority of all preterm infants who were PCR and/or culture positive. This study illustrates how heterogeneous the intrauterine exposure to the fetus can be. But what determines if and how the developing fetal immune system responds to this exposure, particularly in the exposed developing lungs?

In this thesis, microbial invasion of the amniotic environment was mimicked by injecting either Escherichia coli LPS or living Ureaplasma parvum into the amniotic cavity of pregnant ewes (chapter $\mathbf{2}$ and $\mathbf{3}$ respectively). LPS is widely used in models of chorioamnionitis to elicit a fetal inflammatory response which is highly consistent and reproducible [4-9]. Although this allows detailed analysis of fetal immune responses to TLR4 activation (chapter 2) [10-16], it does not reflect the complexity and adaptability of bacterial colonization. Ureaplasmas on the other hand are highly adaptable bacteria, which activate TLR 1, 2 and 6 and are capable of evading the immune system through biofilm formation and rapid adaptation of their exterior, through the multiple banded antigen [17-19]. In chapter $\mathbf{3}$ we showed that the inflammatory response mounted by sheep fetuses against Ureaplasma parvum serovar 3 is markedly different from LPS. Contrary to LPS-induced inflammation [4, 14], there was no systemic response and only a mild up-regulation of cytokines in the fetal lungs after exposure to ureaplasmas. The most striking difference was the complete absence of a pulmonary monocyte/macrophage influx, which is one of the hallmarks of LPS-induced inflammation $[13,14,20]$. In a different study, chronic Ureaplasma exposure decreased immune responsiveness to LPS in fetal sheep of the same gestation, although short term Ureaplasma exposure was not sufficient to achieve this effect [21]. The fetal immune system was similarly paralyzed after repetitive LPS exposure, a finding which was recently confirmed in preterm infants which had been exposed to chorioamnionitis [13, 20, 22, 23]. Although this immune paralysis could well be protective against inflammation induced injury to the sensitive developing organs, it appears that infants exposed to chorioamnionitis are more likely to develop early onset sepsis $[23,24]$. Later on in life, it may also explain why preterm infants with BPD are more often admitted to hospital with respiratory infections [25]. 
A growing body of literature points out that the fetal immune system is fundamentally different to the adult immune system. The results discussed in this thesis regarding the fetal pulmonary inflammatory response support this concept. These differences in immune responsiveness likely protect the fetus and are adapted to life in utero, and like most other organs, the fetal immune system needs to make different adaptations for postnatal life.

\section{Effect of LPS or $U$. parvum induced inflammation on mediators of lung development and maturation}

Despite distinct differences in the composition of the immune response, both LPS and $U$. parvum models for chorioamnionitis showed pulmonary changes which are associated with lung maturation and BPD. LPS exposure led to increased production of surfactant in the fetal lungs and improved lung gas volumes (chapter 2 ). Pulmonary colonization with Ureaplasmas was accompanied by an altered and dysmorphic expression of extracellular matrix protein (chapter 3), which was similar to the lungs of BPD patients [26]. The major question posed in this thesis was which pathways mediated these developmental changes.

TGF $\beta$ has been suggested to be important in the development of BPD $[27,28]$, as it functions as a double agent for both inflammation and normal lung development and repair $[29,30]$. Induction of TGF $\beta$ caused a BPD-like phenotype in neonatal rat and mouse pups [31, 32], consistent with findings of elevated TGF $\beta$ levels in the bronchoalveolar lavage of ventilated infants that go on to develop BPD [27, 33]. The role of ventilationinduced injury in TGF $\beta$ induction should not be underestimated, as preterm infants are often ventilated [34]. Experimental studies using ventilated preterm animals report strong induction of TGF $\beta$ levels $[35,36]$. In our studies, 2 and 7 day LPS exposure only modestly increased TGF $\beta 1$ and 2 and its signaling mediators, pSmad 2 and TGF $\beta$ receptors 1 and 2 (chapter 4, 5 and 6). Interestingly, the downstream mediators were more strongly affected than TGF $\beta$ itself, including the negative regulator Caveolin-1 (chapter 4 and 5) and CTGF (chapter 5). Despite this modest involvement after LPS exposure, continuous or multiple exposures to LPS and/or ureaplasmas did not alter levels of TGF $\beta$ or downstream mediators. These findings do not undermine the importance of TGF $\beta$ in the pathogenesis of BPD, but merely point out that prenatal inflammation may not be its most important inducer. Chorioamnionitis could prime the immune system in such a way that a second hit like ventilation would cause injury-induced inflammation and a surge in TGF $\beta$ and remodeling (Figure 1)[37]. A clinical study by van Marter and colleagues confirmed the increased risk of BPD in neonates that suffered a second hit after chorioamnionitis, such as ventilation or sepsis [34]. Conversely, neonates exposed to chorioamnionitis and/or Ureaplasma spp. in utero that did not suffer a second hit 
were less likely to develop BPD [34, 38, 39].

Without exception, all other investigated pathways which play an important role in lung development and alveolarization were affected by intra-amniotic LPS exposure. In chapter $\mathbf{7}$ we found that the Shh-pathway was strongly suppressed after LPS exposure, which may have resulted in the increase in FGF10 and BMP4 gene expression.

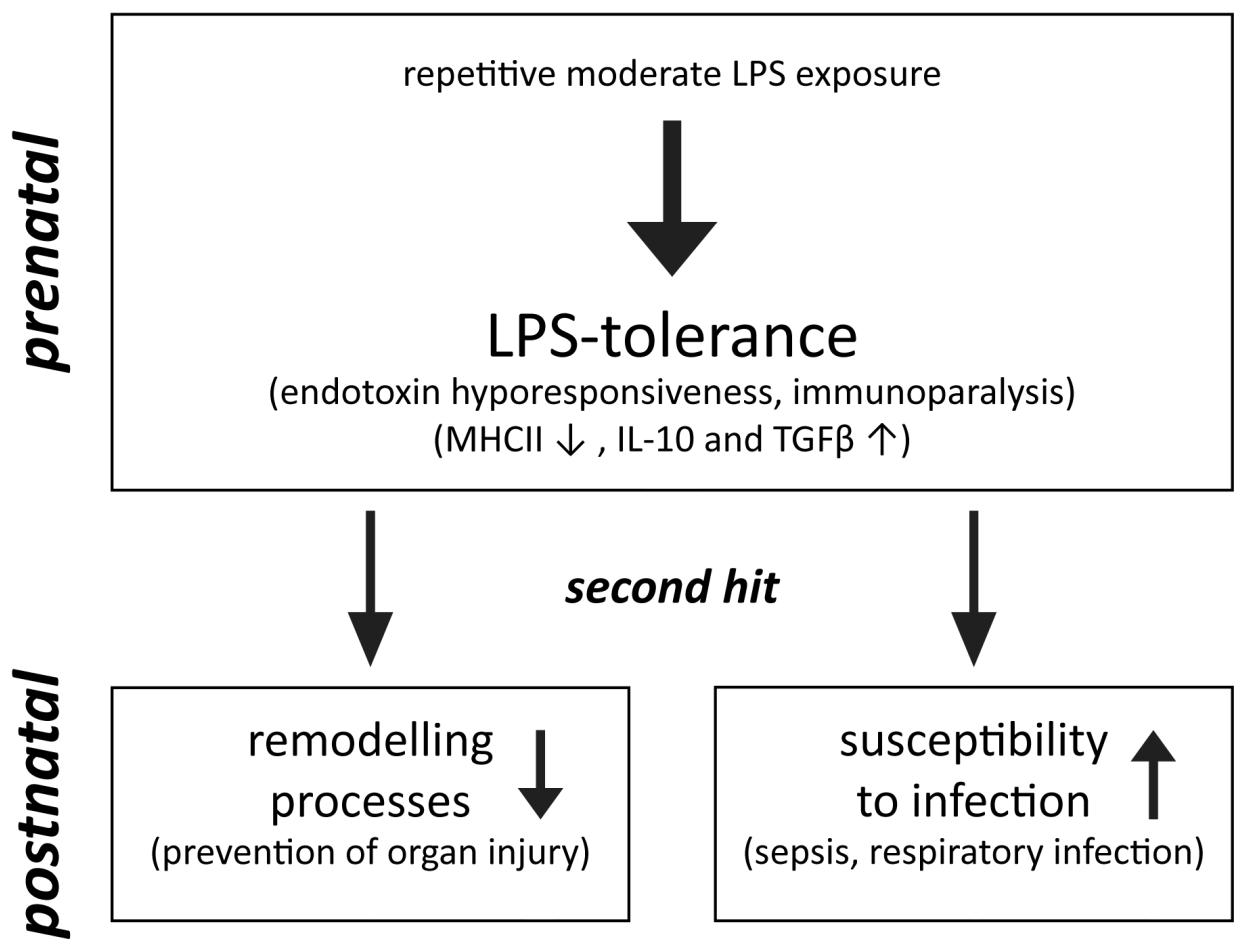

Figure 1: The second hit hypothesis of chorioamnionitis

Although there are no data available for Shh expression in the lungs of BPD patients, it has been reported that infants who go on to develop BPD have decreased levels of vitamin A [40]. Retinoic acid, which is a derivative of vitamin A, plays a crucial role in alveolarization and controls Shh expression [41-44]. Decreased levels of retinoic acid have also been reported in preterm sheep which had been exposed to LPS in utero [45]. Parallel to changes in TGF $\beta$ and Shh pathway mediators, components of the Wnt pathway were altered in the lungs of sheep fetuses exposed to intra-amniotic LPS (chapter 7). Wnt1, Wnt4 and Wnt5a, which represent different facets of the complex Wnt signaling family, were decreased in response to LPS exposure. Following this initial decrease, Wnt7b, and its downstream mediators Axin2 and c-myc, were strongly increased. Wnt signaling is needed for the regulation of alveolarization, particularly for the organization of the mesenchyme and smooth muscle cells $[46,47]$. The altered deposition of 
matrix proteins and smooth muscle layers around bronchi and vessels, as seen in both inflammation exposed preterm lambs (chapter 3, 6 and 7) and BPD patients [26], could therefore be the result of changes in Wnt and TGF $\beta$ signaling. Involvement of these pathways has also been reported in other lung diseases which involve remodeling, such as fibrosis and emphysema [48-51]. It is interesting to note that studies using hyperoxia based animal models of BPD consistently report a strong increase of TGF $\beta$, Shh and Wnt signaling $[35,52,53]$. Considering the different effects of inflammation and hyperoxia on these pathways, it would be interesting to see whether a two hit situation as described above would aggravate the effects seen after either hit alone.

\section{Inflammation and corticosteroids: partners in crime or rivals?}

Considering the incidence of chorioamnionitis and the widespread use of corticosteroids in preterm birth, a combined exposure of the fetus to inflammation and corticosteroids is very common $[54,55]$. Although the anti-inflammatory properties of corticosteroids might suggest an antagonistic effect when combined with intra-uterine inflammation, both factors combined actually enhance lung maturation in preterm sheep (chapter 2). This finding is supported by clinical observations that antenatal corticosteroids given to infants diagnosed with chorioamnionitis decreased the risk of adverse outcomes [56]. In clinical practice it is also possible that corticosteroids are administered before the onset of chorioamnionitis, instead of the other way around [54]. We found that the order of exposure to LPS-induced inflammation and maternal corticosteroids is significant with respect to the impact on fetal physiology. The strong additive effect of LPS and corticosteroid exposure was only seen in preterm lambs when LPS exposure preceded betamethasone administration. Consistently, an influx of inflammatory cells and an increase in the production of surfactant components were only seen in the lungs of lambs exposed to LPS before betamethasone (chapter 2). Although betamethasone administration before LPS exposure mostly prevented molecular changes induced by LPS, it did increase Wnt5a and TGF 32 levels, unlike any of the other exposures (chapter 5 and 7).

Despite the altered activity of the TGF $\beta$, Shh and Wnt pathways after LPS-induced inflammation, hardly any involvement of these pathways could be found in fetal lungs after sequential exposure to LPS and maternal corticosteroids (chapter 5 and 7). Other signaling pathways must therefore be responsible for maturation of surfactant production and subsequent lung function. Considering the decreased risk of BPD or RDS in chorioamnionitis exposed infants treated with maternal corticosteroids [56], it could be possible that this protective effect is mediated through the TGF $\beta$, Shh and Wnt pathways. Unfortunately, the inhibitive effect on alveolar septation was probably 
not prevented as sequential LPS and betamethasone exposure still caused a decrease in elastin foci (chapter 7). Other experimental studies observed similar structural and maturational effects $[57,58]$. Similar to our findings in the TGF $\beta$, Shh and Wnt pathways, betamethasone prevented the up-regulation of MMP9 after LPS exposure in fetal sheep [58]. Since the glucocorticoid receptor (GR) is capable of interacting with a wide array of molecules, it has a very potent effect on gene expression [59-64]. Co-activation of the GR with the transcription factor NF-KB during an inflammatory response can alter the regulation of many downstream genes, and is probably at least in part responsible for the alternate effects of LPS exposure combined with maternal corticosteroids [60].

\section{Clinical implications and future perspectives}

Biomedical research should always serve as a platform for the improvement of clinical outcomes, in particular if the research is aimed at elucidating basic biological mechanisms. In order to devise new preventive and therapeutic strategies for BPD, it is highly important to understand the mechanisms that drive normal saccular and alveolar development and how they are driven off course by the events that surround preterm birth. Only then should steps be made to take the new found knowledge from the bench towards the bedside, so that the lungs may grow and function as they were meant to. Now that the first generations of former preterm infants with BPD have reached adulthood, it is becoming clear that their lung function remains impaired $[25,65,66]$. Although perinatal care has changed and improved greatly in the last two decades, preterm infants are still exposed to a multitude of factors which lead to the diagnosis of BPD. It should however be stressed that most of these exposures, including maternal corticosteroids and mechanical ventilation, are first and foremost crucial for improved outcome and survival in the neonatal period. Important advances to improve pulmonary outcome have been made by changing ventilation strategies, so that they are gentler and induce less damage [67]. Further improvements to ventilation strategies and surfactant administration which prevent endotracheal intubation, such as nasal continuous positive airway pressure (nCPAP) and laryngeal mask surfactant administration, are promising to reduce the severity of BPD [67-69]. In the long run, a potentially revolutionary approach could be used to avoid ventilation completely by using extracorporeal membrane oxygenation (ECMO), which filters and oxygenates the blood directly and is already used in adults and term neonates [70, 71]. Optimizing other facets of antenatal management to prevent sepsis should also augment lung development and improve pulmonary outcome.

The association of chorioamnionitis with the development of several diseases of prematurity has given rise to the question whether microbial invasion of the 
amniotic cavity and subsequent inflammation can be prevented. It is hard to diagnose chorioamnionitis in pregnant women, as it is often clinically silent. Collection of amniotic fluid samples through amniocentesis creates risks of abortion. Research efforts to find biomarkers of chorioamnionitis in maternal blood has not yielded any reliable biomarkers [72]. This may be the result of the heterogeneity of the micro-organisms that have been found in chorioamnionitis, as they elicit very different immune responses [73]. Although prophylactic antibiotic treatment of pregnant mothers may seem a tentative option, broad spectrum antibiotics may not always cross the placenta in sufficient concentrations to achieve therapeutic concentrations in utero $[74,75]$. Moreover, the presence of bacteria commonly associated with chorioamnionitis, such as Ureaplasma spp., does not necessarily lead to preterm birth [2, 76, 77]. There may therefore be an inherent physiological or genetic component involved in fetuses that do mount an inflammatory response in utero compared to those who show immunologic tolerance [78-80]. Although intra-uterine inflammation can probably not be prevented, attention may be given to the overall prevention of preterm birth. This way, harmful postnatal exposures, such as ventilation, sepsis and antibiotics, may be delayed for as long as possible, in order to give the fetal organs a chance to mature as much as possible. Aside from smoking cessation and nutritional supplementation in pregnant women, a promising therapeutic intervention is the administration of progesterone to mothers who are at increased risk of preterm birth [81, 82]. Recent data from randomized controlled trials have demonstrated a marked decrease in preterm birth before 33-34 weeks of gestation in women treated with vaginal progesterone $[83,84]$.

In this thesis we found that intra-uterine inflammation can already affect normal lung development within days. Given the multifactorial character of BPD, a vast array of potential ways of treatment can be considered to bring molecular signaling pathways that direct lung development back on track. One readily available treatment option is supplementation with vitamin A. Vitamin A has been proven to be beneficial for lung function in children if the mothers took supplements before, during and after pregnancy [85]. In animal studies supplementation with vitamin $A$ improved alveolarization in neonatal rats and lambs $[44,86]$. In clinical studies, supplementation with vitamin $A$ in preterm infants significantly reduced the risk of BPD $[87,88]$. Unfortunately these studies have not lead to the adoption of vitamin A supplementation in clinical practice, as the benefits of treatment were deemed too small [89]. The finding of strongly decreased Shh expression in LPS exposed fetal lambs (chapter 7) may be a clue how vitamin A supplements could normalize developmental pathway signaling. More research into alternative administration directly into the lung, or improved metabolic uptake through retinoid acid receptor expression may improve the efficacy of vitamin A treatment. Next to vitamin A, other components of the TGF $\beta$, Shh and Wnt pathways 
should be considered as potential therapeutic targets to combat BPD [90]. Whether these pathways are best targeted one by one, or by using stem-cell based therapies to redirect alveolarization remains a focus of ongoing research [91, 92]. In all potential treatments, careful consideration should however be given to the effects on other organs, particularly those as vulnerable as the brain and the gut.

\section{Conclusion}

In this thesis we aimed to give insight into how the developing lung and the pathways that orchestrate lung development are affected by antenatal stimuli, such as inflammation and corticosteroids. Although our studies were performed in fetal lambs in which the developing lung is highly similar to that in humans, they were also inherently limited by their observational approach. To confirm the associations between inflammation, corticosteroids and pathways important to lung development which we have found, more in-depth mechanistic studies will need to be done. Nonetheless they have identified a potential link between intra-uterine inflammation and altered lung development, and should therefore provide a basis for future translational research towards understanding and treating BPD.

\section{References}

1. Kramer, B.W. and Jobe, A.H., The clever fetus: responding to inflammation to minimize lung injury. Biol Neonate, 2005. 88(3): p. 202-7.

2. Steel, J.H., Malatos, S., Kennea, N., Edwards, A.D., Miles, L., Duggan, P., Reynolds, P.R., Feldman, R.G., and Sullivan, M.H., Bacteria and inflammatory cells in fetal membranes do not always cause preterm labor. Pediatric research, 2005. 57(3): p. 404-11.

3. DiGiulio, D.B., Romero, R., Kusanovic, J.P., Gomez, R., Kim, C.J., Seok, K.S., Gotsch, F., MazakiTovi, S., Vaisbuch, E., Sanders, K., Bik, E.M., Chaiworapongsa, T., Oyarzun, E., and Relman, D.A., Prevalence and diversity of microbes in the amniotic fluid, the fetal inflammatory response, and pregnancy outcome in women with preterm pre-labor rupture of membranes. Am J Reprod Immunol, 2010. 64(1): p. 38-57.

4. Kallapur, S.G., Willet, K.E., Jobe, A.H., Ikegami, M., and Bachurski, C.J., Intra-amniotic endotoxin: chorioamnionitis precedes lung maturation in preterm lambs. American journal of physiology. Lung cellular and molecular physiology, 2001. 280(3): p. L527-36.

5. Vayrynen, O., Glumoff, V., and Hallman, M., Regulation of surfactant proteins by LPS and proinflammatory cytokines in fetal and newborn lung. American journal of physiology. Lung cellular and molecular physiology, 2002. 282(4): p. L803-10.

6. Prince, L.S., Okoh, V.O., Moninger, T.O., and Matalon, S., Lipopolysaccharide increases alveolar type II cell number in fetal mouse lungs through Toll-like receptor 4 and NF-kappaB. Am J Physiol Lung Cell Mol Physiol, 2004. 287(5): p. L999-1006.

7. Ikegami, T., Tsuda, A., Karube, A., Kodama, H., Hirano, H., and Tanaka, T., Effects of intrauterine IL- 6 and IL-8 on the expression of surfactant apoprotein mRNAs in the fetal rat lung. European journal of obstetrics, gynecology, and reproductive biology, 2000. 93(1): p. 97-103.

8. Sakai, M., Tanebe, K., Sasaki, Y., Momma, K., Yoneda, S., and Saito, S., Evaluation of the tocolytic effect of a selective cyclooxygenase-2 inhibitor in a mouse model of lipopolysaccharide- 
induced preterm delivery. Molecular human reproduction, 2001. 7(6): p. 595-602.

9. Abdulkadir, A.A., Kimimasa, T., Bell, M.J., Macpherson, T.A., Keller, B.B., and Yanowitz, T.D., Placental inflammation and fetal hemodynamics in a rat model of chorioamnionitis. Pediatric research, 2010. 68(6): p. 513-8.

10. Poltorak, A., He, X., Smirnova, I., Liu, M.Y., Van Huffel, C., Du, X., Birdwell, D., Alejos, E., Silva, M., Galanos, C., Freudenberg, M., Ricciardi-Castagnoli, P., Layton, B., and Beutler, B., Defective LPS signaling in C3H/HeJ and C57BL/10ScCr mice: mutations in T/r4 gene. Science, 1998. 282(5396): p. 2085-8.

11. Kawai, T., Adachi, O., Ogawa, T., Takeda, K., and Akira, S., Unresponsiveness of MyD88-deficient mice to endotoxin. Immunity, 1999. 11(1): p. 115-22.

12. Kawai, T., Takeuchi, O., Fujita, T., Inoue, J., Muhlradt, P.F., Sato, S., Hoshino, K., and Akira, S., Lipopolysaccharide stimulates the MyD88-independent pathway and results in activation of IFN-regulatory factor 3 and the expression of a subset of lipopolysaccharide-inducible genes. Journal of immunology, 2001. 167(10): p. 5887-94.

13. Kramer, B.W., Ikegami, M., Moss, T.J., Nitsos, I., Newnham, J.P., and Jobe, A.H., Endotoxininduced chorioamnionitis modulates innate immunity of monocytes in preterm sheep. Am J Respir Crit Care Med, 2005. 171(1): p. 73-7.

14. Cheah, F.C., Pillow, J.J., Kramer, B.W., Polglase, G.R., Nitsos, I., Newnham, J.P., Jobe, A.H., and Kallapur, S.G., Airway inflammatory cell responses to intra-amniotic lipopolysaccharide in a sheep model of chorioamnionitis. Am J Physiol Lung Cell Mol Physiol, 2009. 296(3): p. L384-93.

15. Kallapur, S.G., Nitsos, I., Moss, T.J., Polglase, G.R., Pillow, J.J., Cheah, F.C., Kramer, B.W., Newnham, J.P., Ikegami, M., and Jobe, A.H., IL-1 mediates pulmonary and systemic inflammatory responses to chorioamnionitis induced by lipopolysaccharide. Am J Respir Crit Care Med, 2009. 179(10): p. 955-61.

16. Kramer, B.W., Kallapur, S.G., Moss, T.J., Nitsos, I., Newnham, J.P., and Jobe, A.H., Intra-amniotic LPS modulation of TLR signaling in lung and blood monocytes of fetal sheep. Innate Immun, 2009. 15(2): p. 101-7.

17. Dando, S.J., Nitsos, I., Kallapur, S.G., Newnham, J.P., Polglase, G.R., Pillow, J.J., Jobe, A.H., Timms, P., and Knox, C.L., The role of the multiple banded antigen of Ureaplasma parvum in intra-amniotic infection: major virulence factor or decoy? PLoS One, 2012. 7(1): p. e29856.

18. Garcia-Castillo, M., Morosini, M.I., Galvez, M., Baquero, F., del Campo, R., and Meseguer, M.A., Differences in biofilm development and antibiotic susceptibility among clinical Ureaplasma urealyticum and Ureaplasma parvum isolates. The Journal of antimicrobial chemotherapy, 2008. 62(5): p. 1027-30.

19. Shimizu, T., Kida, Y., and Kuwano, K., Ureaplasma parvum lipoproteins, including MB antigen, activate NF-\{kappa\}B through TLR1, TLR2 and TLR6. Microbiology, 2008. 154(Pt 5): p. 1318-25.

20. Kramer, B.W., Joshi, S.N., Moss, T.J., Newnham, J.P., Sindelar, R., Jobe, A.H., and Kallapur, S.G., Endotoxin-induced maturation of monocytes in preterm fetal sheep lung. Am J Physiol Lung Cell Mol Physiol, 2007. 293(2): p. L345-53.

21. Kallapur, S.G., Kramer, B.W., Knox, C.L., Berry, C.A., Collins, J.J., Kemp, M.W., Nitsos, I., Polglase, G.R., Robinson, J., Hillman, N.H., Newnham, J.P., Chougnet, C., and Jobe, A.H., Chronic Fetal Exposure to Ureaplasma parvum Suppresses Innate Immune Responses in Sheep. J Immunol, 2011. 187(5): p. 2688-95.

22. Kramer, B.W., Kallapur, S.G., Moss, T.J., Nitsos, I., Polglase, G.P., Newnham, J.P., and Jobe, A.H., Modulation of fetal inflammatory response on exposure to lipopolysaccharide by chorioamnion, lung, or gut in sheep. Am J Obstet Gynecol, 2010. 202(1): p. 77 e1-9.

23. Azizia, M., Lloyd, J., Allen, M., Klein, N., and Peebles, D., Immune status in very preterm neonates. Pediatrics, 2012. 129(4): p. e967-74. 
24. Wolfs, T.G., Jellema, R.K., Turrisi, G., Becucci, E., Buonocore, G., and Kramer, B.W., Inflammation-induced immune suppression of the fetus: a potential link between chorioamnionitis and postnatal early onset sepsis. The journal of maternal-fetal \& neonatal medicine, 2012. 25 Suppl 1: p. 8-11.

25. Greenough, A., Long term respiratory outcomes of very premature birth ( $<32$ weeks). Seminars in fetal \& neonatal medicine, 2012. 17(2): p. 73-6.

26. Toti, P., Buonocore, G., Tanganelli, P., Catella, A.M., Palmeri, M.L., Vatti, R., and Seemayer, T.A., Bronchopulmonary dysplasia of the premature baby: an immunohistochemical study. Pediatr Pulmonol, 1997. 24(1): p. 22-8.

27. Kotecha, S., Wangoo, A., Silverman, M., and Shaw, R.J., Increase in the concentration of transforming growth factor beta-1 in bronchoalveolar lavage fluid before development of chronic lung disease of prematurity. The Journal of pediatrics, 1996. 128(4): p. 464-9.

28. Ahlfeld, S.K. and Conway, S.J., Aberrant signaling pathways of the lung mesenchyme and their contributions to the pathogenesis of bronchopulmonary dysplasia. Birth defects research. Part A, Clinical and molecular teratology, 2012. 94(1): p. 3-15.

29. Bartram, U. and Speer, C.P., The role of transforming growth factor beta in lung development and disease. Chest, 2003. 125(2): p. 754-765.

30. Massague, J., TGF-beta signal transduction. Annu Rev Biochem, 1998. 67: p. 753-91.

31. Vicencio, A.G., Lee, C.G., Cho, S.J., Eickelberg, O., Chuu, Y., Haddad, G.G., and Elias, J.A., Conditional overexpression of bioactive transforming growth factor-beta1 in neonatal mouse lung: a new model for bronchopulmonary dysplasia? Am J Respir Cell Mol Biol, 2004. 31(6): p. 650-6.

32. Gauldie, J., Galt, T., Bonniaud, P., Robbins, C., Kelly, M., and Warburton, D., Transfer of the active form of transforming growth factor-beta 1 gene to newborn rat lung induces changes consistent with bronchopulmonary dysplasia. Am J Pathol, 2003. 163(6): p. 2575-84.

33. Lecart, C., Cayabyab, R., Buckley, S., Morrison, J., Kwong, K.Y., Warburton, D., Ramanathan, R., Jones, C.A., and Minoo, P., Bioactive transforming growth factor-beta in the lungs of extremely low birthweight neonates predicts the need for home oxygen supplementation. Biology of the neonate, 2000. 77(4): p. 217-23.

34. Van Marter, L.J., Dammann, O., Allred, E.N., Leviton, A., Pagano, M., Moore, M., and Martin, C., Chorioamnionitis, mechanical ventilation, and postnatal sepsis as modulators of chronic lung disease in preterm infants. The Journal of pediatrics, 2002. 140(2): p. 171-6.

35. Dasgupta, C., Sakurai, R., Wang, Y., Guo, P., Ambalavanan, N., Torday, J.S., and Rehan, V.K., Hyperoxia-induced neonatal rat lung injury involves activation of TGF-\{beta\} and Wnt signaling and is protected by rosiglitazone. Am J Physiol Lung Cell Mol Physiol, 2009. 296(6): p. L1031-41.

36. Kunzmann, S., Speer, C.P., Jobe, A.H., and Kramer, B.W., Antenatal inflammation induced TGF-b1 but suppressed CTGF in preterm lungs. Am J Physiol Lung Cell Mol Physiol, 2006. 292: p. 223-231.

37. Speer, C.P., Neonatal respiratory distress syndrome: an inflammatory disease? Neonatology, 2011. 99(4): p. 316-9.

38. Lahra, M.M., Beeby, P.J., and Jeffery, H.E., Intrauterine inflammation, neonatal sepsis, and chronic lung disease: a 13-year hospital cohort study. Pediatrics, 2009. 123(5): p. 1314-9.

39. Berger, A., Witt, A., Haiden, N., Kretzer, V., Heinze, G., and Pollak, A., Amniotic cavity cultures, blood cultures, and surface swabs in preterm infants--useful tools for the management of early-onset sepsis? Journal of perinatal medicine, 2004. 32(5): p. 446-52.

40. Shenai, J.P., Chytil, F., and Stahlman, M.T., Vitamin A status of neonates with bronchopulmonary dysplasia. Pediatr Res, 1985. 19(2): p. 185-8.

41. Riddle, R.D., Johnson, R.L., Laufer, E., and Tabin, C., Sonic hedgehog mediates the polarizing activity of the ZPA. Cell, 1993. 75(7): p. 1401-16. 
42. Mendelsohn, C., Lohnes, D., Decimo, D., Lufkin, T., LeMeur, M., Chambon, P., and Mark, M., Function of the retinoic acid receptors (RARs) during development (II). Multiple abnormalities at various stages of organogenesis in RAR double mutants. Development, 1994. 120(10): p. 2749-71.

43. Frey, G., Egli, E., Chailley-Heu, B., Lelievre-Pegorier, M., Burri, P.H., Bourbon, J., and Tschanz, S.A., Effects of mild vitamin a deficiency on lung maturation in newborn rats: a morphometric and morphologic study. Biology of the neonate, 2004. 86(4): p. 259-68.

44. Massaro, G.D. and Massaro, D., Postnatal treatment with retinoic acid increases the number of pulmonary alveoli in rats. The American journal of physiology, 1996. 270 (2 Pt 1): p. L30510.

45. Kramer, B.W., Albertine, K.H., Moss, T.J., Nitsos, I., Ladenburger, A., Speer, C.P., Newnham, J.P., and Jobe, A.H., All-trans retinoic acid and intra-amniotic endotoxin-mediated effects on fetal sheep lung. Anat Rec (Hoboken), 2008. 291(10): p. 1271-7.

46. Cohen, E.D., Ihida-Stansbury, K., Lu, M.M., Panettieri, R.A., Jones, P.L., and Morrisey, E.E., Wnt signaling regulates smooth muscle precursor development in the mouse lung via a tenascin C/PDGFR pathway. The Journal of clinical investigation, 2009. 119(9): p. 2538-49.

47. Salazar, K.D., Lankford, S.M., and Brody, A.R., Mesenchymal stem cells produce Wht isoforms and TGF-beta1 that mediate proliferation and procollagen expression by lung fibroblasts. American journal of physiology. Lung cellular and molecular physiology, 2009. 297(5): p. L1002-11.

48. Kneidinger, N., Yildirim, A.O., Callegari, J., Takenaka, S., Stein, M.M., Dumitrascu, R., Bohla, A., Bracke, K.R., Morty, R.E., Brusselle, G.G., Schermuly, R.T., Eickelberg, O., and Konigshoff, M., Activation of the WNT/beta-catenin pathway attenuates experimental emphysema. Am J Respir Crit Care Med, 2011. 183(6): p. 723-33.

49. Konigshoff, M., Balsara, N., Pfaff, E.M., Kramer, M., Chrobak, I., Seeger, W., and Eickelberg, O., Functional Wnt signaling is increased in idiopathic pulmonary fibrosis. PLoS One, 2008. 3(5): p. e2142.

50. Khalil, N., O'Connor, R.N., Unruh, H.W., Warren, P.W., Flanders, K.C., Kemp, A., Bereznay, O.H., and Greenberg, A.H., Increased production and immunohistochemical localization of transforming growth factor-beta in idiopathic pulmonary fibrosis. American journal of respiratory cell and molecular biology, 1991. 5(2): p. 155-62.

51. de Boer, W.I., van Schadewijk, A., Sont, J.K., Sharma, H.S., Stolk, J., Hiemstra, P.S., and van Krieken, J.H., Transforming growth factor beta1 and recruitment of macrophages and mast cells in airways in chronic obstructive pulmonary disease. American journal of respiratory and critical care medicine, 1998. 158(6): p. 1951-7.

52. Dang, H., Wang, S., Yang, L., Fang, F., and Xu, F., Upregulation of Shh and Ptc1 in hyperoxiainduced acute lung injury in neonatal rats. Molecular medicine reports, 2012.

53. Alejandre-Alcazar, M.A., Kwapiszewska, G., Reiss, I., Amarie, O.V., Marsh, L.M., Sevilla-Perez, J., Wygrecka, M., Eul, B., Kobrich, S., Hesse, M., Schermuly, R.T., Seeger, W., Eickelberg, O., and Morty, R.E., Hyperoxia modulates TGF-beta/BMP signaling in a mouse model of bronchopulmonary dysplasia. American journal of physiology. Lung cellular and molecular physiology, 2007. 292(2): p. L537-49.

54. Goldenberg, R.L., Andrews, W.W., Faye-Petersen, O.M., Cliver, S.P., Goepfert, A.R., and Hauth, J.C., The Alabama preterm birth study: corticosteroids and neonatal outcomes in 23to 32-week newborns with various markers of intrauterine infection. Am J Obstet Gynecol, 2006. 195(4): p. 1020-4.

55. Carlo, W.A., McDonald, S.A., Fanaroff, A.A., Vohr, B.R., Stoll, B.J., Ehrenkranz, R.A., Andrews, W.W., Wallace, D., Das, A., Bell, E.F., Walsh, M.C., Laptook, A.R., Shankaran, S., Poindexter, B.B., Hale, E.C., Newman, N.S., Davis, A.S., Schibler, K., Kennedy, K.A., Sanchez, P.J., Van Meurs, K.P., Goldberg, R.N., Watterberg, K.L., Faix, R.G., Frantz, I.D., 3rd, and Higgins, R.D., 
Association of antenatal corticosteroids with mortality and neurodevelopmental outcomes among infants born at 22 to 25 weeks' gestation. JAMA : the journal of the American Medical Association, 2011. 306(21): p. 2348-58.

56. Been, J., Degraeuwe, P., Kramer, B., and Zimmermann, L., Antenatal steroids and neonatal outcome after chorioamnionitis: a meta-analysis. BJOG, 2011. 118(2): p. 113-22.

57. Joram, N., Launay, E., Roze, J.C., Caillon, J., Franco-Montoya, M.L., Bourbon, J., Jarreau, P.H., and Gras-Le Guen, C., Betamethasone worsens chorioamnionitis-related lung development impairment in rabbits. American journal of perinatology, 2011. 28(8): p. 605-12.

58. Sweet, D.G., Huggett, M.T., Warner, J.A., Moss, T.J., Kloosterboer, N., Halliday, H.L., Newnham, J.P., Kallapur, S.G., Jobe, A.H., and Kramer, B.W., Maternal betamethasone and chorioamnionitis induce different collagenases during lung maturation in fetal sheep. Neonatology, 2008. 94(2): p. 79-86.

59. Schaaf, M.J. and Cidlowski, J.A., Molecular mechanisms of glucocorticoid action and resistance. The Journal of steroid biochemistry and molecular biology, 2002. 83(1-5): p. 37-48.

60. Rao, N.A., McCalman, M.T., Moulos, P., Francoijs, K.J., Chatziioannou, A., Kolisis, F.N., Alexis, M.N., Mitsiou, D.J., and Stunnenberg, H.G., Coactivation of GR and NFKB alters the repertoire of their binding sites and target genes. Genome research, 2011. 21(9): p. 1404-16.

61. Smith, E., Coetzee, G.A., and Frenkel, B., Glucocorticoids inhibit cell cycle progression in differentiating osteoblasts via glycogen synthase kinase-3beta. J Biol Chem, 2002. 277(20): p. 18191-7.

62. Smith, E. and Frenkel, B., Glucocorticoids inhibit the transcriptional activity of LEF/TCF in differentiating osteoblasts in a glycogen synthase kinase-3beta-dependent and-independent manner. J Biol Chem, 2005. 280(3): p. 2388-94.

63. Ito, K., Barnes, P.J., and Adcock, I.M., Glucocorticoid receptor recruitment of histone deacetylase 2 inhibits interleukin-1 beta-induced histone $\mathrm{H} 4$ acetylation on lysines 8 and 12. Molecular and cellular biology, 2000. 20(18): p. 6891-903.

64. Takayama, S., Rogatsky, I., Schwarcz, L.E., and Darimont, B.D., The glucocorticoid receptor represses cyclin D1 by targeting the Tcf-beta-catenin complex. J Biol Chem, 2006. 281(26): p. 17856-63.

65. Wong, P.M., Lees, A.N., Louw, J., Lee, F.Y., French, N., Gain, K., Murray, C.P., Wilson, A., and Chambers, D.C., Emphysema in young adult survivors of moderate-to-severe bronchopulmonary dysplasia. The European respiratory journal, 2008. 32(2): p. 321-8.

66. Fawke, J., Lum, S., Kirkby, J., Hennessy, E., Marlow, N., Rowell, V., Thomas, S., and Stocks, J., Lung function and respiratory symptoms at 11 years in children born extremely preterm: the EPICure study. American journal of respiratory and critical care medicine, 2010. 182(2): p. 237-45.

67. Bohlin, K., Jonsson, B., Gustafsson, A.S., and Blennow, M., Continuous positive airway pressure and surfactant. Neonatology, 2008. 93(4): p. 309-15.

68. Abdel-Latif, M.E. and Osborn, D.A., Laryngeal mask airway surfactant administration for prevention of morbidity and mortality in preterm infants with or at risk of respiratory distress syndrome. Cochrane database of systematic reviews, 2011(7): p. CD008309.

69. de Winter, J.P., de Vries, M.A., and Zimmermann, L.J., Clinical practice : noninvasive respiratory support in newborns. European journal of pediatrics, 2010. 169(7): p. 777-82.

70. Arens, J., Schoberer, M., Lohr, A., Orlikowsky, T., Seehase, M., Jellema, R.K., Collins, J.J., Kramer, B.W., Schmitz-Rode, T., and Steinseifer, U., NeonatOx: a pumpless extracorporeal lung support for premature neonates. Artificial organs, 2011. 35(11): p. 997-1001.

71. Schoberer, M., Arens, J., Lohr, A., Seehase, M., Jellema, R.K., Collins, J.J., Kramer, B.W., Schmitz-Rode, T., Steinseifer, U., and Orlikowsky, T., Fifty Years of Work on the Artificial Placenta: Milestones in the History of Extracorporeal Support of the Premature Newborn. Artificial organs, 2012. 
72. Menon, R., Taylor, R.N., and Fortunato, S.J., Chorioamnionitis--a complex pathophysiologic syndrome. Placenta, 2010. 31(2): p. 113-20.

73. Menon, R., Peltier, M.R., Eckardt, J., and Fortunato, S.J., Diversity in cytokine response to bacteria associated with preterm birth by fetal membranes. Am J Obstet Gynecol, 2009. 201(3): p. 306 e1-6.

74. Kenyon, S.L., Taylor, D.J., and Tarnow-Mordi, W., Broad-spectrum antibiotics for spontaneous preterm labour: the ORACLE II randomised trial. ORACLE Collaborative Group. Lancet, 2001. 357(9261): p. 989-94.

75. Briggs, G.G., Freeman, R.K., and Yaffe, S.J., Drugs in pregnancy and lactation. 8th ed2007, Philadelphia: Lippincott.

76. Perni, S.C., Vardhana, S., Korneeva, I., Tuttle, S.L., Paraskevas, L.R., Chasen, S.T., Kalish, R.B., and Witkin, S.S., Mycoplasma hominis and Ureaplasma urealyticum in midtrimester amniotic fluid: association with amniotic fluid cytokine levels and pregnancy outcome. Am J Obstet Gynecol, 2004. 191(4): p. 1382-6.

77. Iwasaka, T., Wada, T., Kidera, Y., and Sugimori, H., Hormonal status and mycoplasma colonization in the female genital tract. Obstet Gynecol, 1986. 68(2): p. 263-6.

78. Romero, R., Velez Edwards, D.R., Kusanovic, J.P., Hassan, S.S., Mazaki-Tovi, S., Vaisbuch, E., Kim, C.J., Chaiworapongsa, T., Pearce, B.D., Friel, L.A., Bartlett, J., Anant, M.K., Salisbury, B.A., Vovis, G.F., Lee, M.S., Gomez, R., Behnke, E., Oyarzun, E., Tromp, G., Williams, S.M., and Menon, R., Identification of fetal and maternal single nucleotide polymorphisms in candidate genes that predispose to spontaneous preterm labor with intact membranes. American journal of obstetrics and gynecology, 2010. 202(5): p. 431 e1-34.

79. Resch, B., Radinger, A., Mannhalter, C., Horvath, B., Binder, A., Zenz, W., Walcher, W., Haas, J., Muller, W.D., and Pertl, B., Maternal interleukin-6 (-174) C/C polymorphism is associated with chorioamnionitis and cystic periventricular leucomalacia of the preterm infant. Journal of perinatology, 2010. 30(11): p. 712-6.

80. Holst, D. and Garnier, Y., Preterm birth and inflammation-The role of genetic polymorphisms. European journal of obstetrics, gynecology, and reproductive biology, 2008. 141(1): p. 3-9.

81. Flood, K. and Malone, F.D., Prevention of preterm birth. Seminars in fetal \& neonatal medicine, 2012. 17(1): p. 58-63.

82. lams, J.D., Romero, R., Culhane, J.F., and Goldenberg, R.L., Primary, secondary, and tertiary interventions to reduce the morbidity and mortality of preterm birth. Lancet, 2008. 371(9607): p. 164-75.

83. Hassan, S.S., Romero, R., Vidyadhari, D., Fusey, S., Baxter, J.K., Khandelwal, M., Vijayaraghavan, J., Trivedi, Y., Soma-Pillay, P., Sambarey, P., Dayal, A., Potapov, V., O’Brien, J., Astakhov, V., Yuzko, O., Kinzler, W., Dattel, B., Sehdev, H., Mazheika, L., Manchulenko, D., Gervasi, M.T., Sullivan, L., Conde-Agudelo, A., Phillips, J.A., and Creasy, G.W., Vaginal progesterone reduces the rate of preterm birth in women with a sonographic short cervix: a multicenter, randomized, double-blind, placebo-controlled trial. Ultrasound in obstetrics \& gynecology: the official journal of the International Society of Ultrasound in Obstetrics and Gynecology, 2011. 38(1): p. 18-31.

84. Cetingoz, E., Cam, C., Sakalli, M., Karateke, A., Celik, C., and Sancak, A., Progesterone effects on preterm birth in high-risk pregnancies: a randomized placebo-controlled trial. Archives of gynecology and obstetrics, 2011. 283(3): p. 423-9.

85. Massaro, D. and Massaro, G.D., Lung development, lung function, and retinoids. N Engl J Med, 2010. 362(19): p. 1829-31.

86. Albertine, K.H., Dahl, M.J., Gonzales, L.W., Wang, Z.M., Metcalfe, D., Hyde, D.M., Plopper, C.G., Starcher, B.C., Carlton, D.P., and Bland, R.D., Chronic lung disease in preterm lambs: effect of daily vitamin A treatment on alveolarization. Am J Physiol Lung Cell Mol Physiol, 2010. 299(1): p. L59-72. 


\section{Chapter 8}

87. Tyson, J.E., Wright, L.L., Oh, W., Kennedy, K.A., Mele, L., Ehrenkranz, R.A., Stoll, B.J., Lemons, J.A., Stevenson, D.K., Bauer, C.R., Korones, S.B., and Fanaroff, A.A., Vitamin A supplementation for extremely-low-birth-weight infants. National Institute of Child Health and Human Development Neonatal Research Network. The New England journal of medicine, 1999. 340(25): p. 1962-8.

88. Ambalavanan, N., Tyson, J.E., Kennedy, K.A., Hansen, N.I., Vohr, B.R., Wright, L.L., and Carlo, W.A., Vitamin A supplementation for extremely low birth weight infants: outcome at 18 to 22 months. Pediatrics, 2005. 115(3): p. e249-54.

89. Ambalavanan, N., Kennedy, K., Tyson, J., and Carlo, W.A., Survey of vitamin A supplementation for extremely-low-birth-weight infants: is clinical practice consistent with the evidence? The Journal of pediatrics, 2004. 145(3): p. 304-7.

90. Alapati, D., Rong, M., Chen, S., Hehre, D., Rodriguez, M.M., Lipson, K.E., and Wu, S., Connective tissue growth factor antibody therapy attenuates hyperoxia-induced lung injury in neonatal rats. American journal of respiratory cell and molecular biology, 2011. 45(6): p. 1169-77.

91. Alphonse, R.S. and Thebaud, B., Growth factors, stem cells and bronchopulmonary dysplasia. Neonatology, 2011. 99(4): p. 326-37.

92. Waszak, P., Alphonse, R.S., Vadivel, A., Ionescu, L., Eaton, F., and Thebaud, B., Preconditioning enhances the paracrine effect of mesenchymal stem cells in preventing oxygen-induced neonatal lung injury in rats. Stem cells and development, 2012. 


\section{Vereenvoudigde Nederlandse}

\section{samenvatting}




\section{Vroeggeboorte}

In de westerse wereld wordt 5 tot 13 procent van alle kinderen te vroeg geboren, waarbij vroeggeboorte wordt gedefinieerd als een zwangerschapsduur van minder dan 37 weken. In 2008 werd in Nederland 7,7\% van alle kinderen te vroeg geboren na een zwangerschapsduur van tussen 22 en 36 weken. Vroeggeboorte is de belangrijkste oorzaak van ziekte en sterfte onder zuigelingen, en veroorzaakte $75 \%$ van alle zuigelingensterfte in Nederland in 2008. In recente jaren is er niet alleen een geleidelijke toename geweest van het aantal vroeggeboortes, maar zijn ook de overlevingskansen van vroeggeborenen sterk verbeterd, waardoor er een sterke toename in overlevende vroeggeborenen is. Dankzij verschillende nieuwe behandelingen, zoals maternale corticosteroïden- en surfactant-behandeling bij de pasgeborene, kunnen meer vroeggeborenen overleven met minder complicaties die veroorzaakt worden door vroeggeboorte. Corticosteroïden worden toegediend bij aanstaande moeders die dreigen te vroeg te bevallen. Zowel corticosteroïden als de toediening van surfactant verbeteren de longfunctie van de baby zodat deze beter kan ademen. Zodoende verkleint dit ook de kans op andere complicaties.

Vroeggeboorte kan verschillende oorzaken hebben, maar een van de meest voorkomende is waarschijnlijk een bacteriële infectie van de baarmoeder. Aangezien de moeder doorgaans geen klinische symptomen vertoont van deze infectie, kan deze pas vastgesteld worden door de vruchtvliezen en het vruchtwater in een laboratorium te laten onderzoeken. Als de vruchtvliezen inderdaad ontstoken zijn, wordt er gesproken van een chorioamnionitis. De aanwezigheid van bacteriën in het vruchtwater hoeft niet persé te leiden tot vroeggeboorte, maar bacteriële infecties komen wel veel vaker voor bij vroeggeborenen dan bij voldragen zuigelingen. Het is niet duidelijk wanneer deze bacteriële infecties beginnen tijdens de zwangerschap, maar waarschijnlijk banen de bacteriën zich een weg vanuit de vagina naar de baarmoeder en door de vruchtvliezen. Er zijn tot nu toe al veel verschillende soorten bacteriën geïdentificeerd in het vruchtwater en de vliezen van zuigelingen met chorioamnionitis, maar de meest voorkomende zijn Ureaplasma bacteriën. Er is toenemend epidemiologisch bewijs dat een bacteriële infectie van de baarmoeder niet alleen kan leiden tot vroeggeboorte, maar dat er ook een verband is met de ontwikkeling van verschillende complicaties na de geboorte.

De gevolgen van vroeggeboorte zijn volledig afhankelijk van de zwangerschapsduur op het moment van geboorte, en zijn veel ernstiger naarmate de zuigeling minder ontwikkeld is. Omdat de organen van vroeggeborenen nog niet klaar zijn voor het leven buiten de baarmoeder, hebben deze zuigelingen vaak medische ondersteuning nodig. Het eerste probleem waar ze mee te kampen krijgen is ademen, aangezien het longoppervlak nog niet groot genoeg is om voldoende zuurstof binnen te krijgen. Naast de behandeling 
met corticosteroïden en surfactant, worden vroeggeborenen daarom vaak beademd om te zorgen dat er voldoende zuurstof in het bloed komt. Andere organen hebben ook vaak moeite met het leven buiten de baarmoeder. Omdat de huid, longen, darmen en het immuunsysteem nog niet volledig ontwikkeld zijn, treden er vaak ernstige infecties op. Doordat de organen nog onderontwikkeld zijn en ze nog niet om kunnen gaan met de invloeden van de buitenwereld, zoals infecties en (gebrek aan) zuurstof, treden er vaak complicaties op die grote gevolgen hebben voor het verdere leven van het kind. Veel kinderen die te vroeg geboren zijn groeien op met verstandelijke of motorische problemen, krijgen vaker infecties en ontwikkelen vaker astma.

Als zuigelingen te vroeg geboren worden zijn hun longen nog volop in ontwikkeling, en zijn de longblaasjes vaak nog niet volledig gevormd. Ondanks dat corticosteroïden zorgen voor een verbeterde longrijping en -functie, hebben ze het ongewenste neveneffect dat ze de longgroei en de vorming van longblaasjes remmen. Daarnaast worden deze longen vaak in de baarmoeder al blootgesteld aan een bacteriële infectie, en ook aan infecties en schade door beademing na de geboorte. Een van de meest voorkomende complicaties van vroeggeboorte is dan ook bronchopulmonale dysplasie (BPD), een afwijking in de longgroei waardoor er weliswaar minder, maar erg grote longblaasjes ontstaan. BPD patientjes krijgen niet genoeg zuurstof binnen omdat hun longoppervlak te klein is en moeten vaak met extra zuurstof beademd worden. Op dit moment is er geen behandeling mogelijk waardoor de longontwikkeling weer normaal wordt. De enige toegepaste behandeling is het toedienen van extra zuurstof, wat de longontwikkeling niet herstelt, maar uitsluitend de overlevingskans bevordert en het optreden van verdere complicaties voorkomt. Ondanks dat er veel bewijsmateriaal is dat bovenstaande infecties en schade door beademing vaak leiden tot de ontwikkeling van BPD, is het nog niet duidelijk hoe dit precies gebeurt.

\section{Dit proefschrift}

In dit proefschrift is onderzocht hoe veel voorkomende blootstellingen zoals infectie/ ontsteking en corticosteroïden de normale longontwikkeling beïnvloeden. Voor dit onderzoek is gebruik gemaakt van een schaapmodel, omdat de laatste stadia van de longontwikkeling van schapenfoetussen heel erg lijken op die van de mens. Ondanks dat zowel bacteriële infecties als behandeling met maternale corticosteroïden in de praktijk vaak voorkomen, is het effect van beiden op de ongeboren vrucht nauwelijks onderzocht. In hoofdstuk 2 wordt beschreven hoe het immuunsysteem van schapenfoetussen reageert op de blootstelling aan zowel ontsteking als maternale cortcicosteroïden, welke ook ontstekingsremmende eigenschappen hebben. Een interessant resultaat hierbij was dat corticosteroiden blootstelling vóór de ontsteking een heel ander effect had op het 
immuunsysteem en de longrijping dan blootstelling na de ontsteking. Daarnaast werd aangetoond dat ontsteking gevolgd door corticosteroïden de longrijping kon versterken terwijl de mate van ontsteking verminderd werd. In hoofdstuk $\mathbf{3}$ is aangetoond dat Ureaplasma bacteriën, die vaak gevonden worden bij te vroeg geboren kinderen, een ontsteking kunnen veroorzaken in de longen van schapenfoetussen wanneer de bacteriën in het vruchtwater worden geïnjecteerd. Daarnaast vertonen de longen van deze foetussen ook gelijkenissen met de longen van BPD-patiëntjes.

Een van de stoffen die aangetroffen is in longspoelingen van vroeggeborenen die BPD ontwikkelen is TGF $\beta$. TGF $\beta$ speelt een belangrijke rol bij zowel ontstekingsprocessen als longontwikkeling, en is daarom hoogstwaarschijnlijk ook betrokken bij de ontwikkeling van BPD. In hoofdstukken 4, 5 en $\mathbf{6}$ is gekeken naar de betrokkenheid van TGF $\beta$ in de longen van lammetjes die blootgesteld zijn aan ontsteking (hoofdstuk 4), ontsteking in combinatie met corticosteroïden (hoofdstuk 5) en ontsteking met en zonder Ureaplasma bacteriën (hoofdstuk 6). TGF $\beta$ was enigszins toegenomen in de longen van lammetjes die alleen blootgesteld waren aan ontsteking, maar niet bij corticosteroïden of Ureaplasma bacteriën, ondanks de aanwezige ontsteking of de veranderingen in de longstructuur. Deze bevindingen benadrukken dat blootstelling aan ontsteking in de baarmoeder waarschijnlijk niet de belangrijkste oorzaak is van de ontwikkeling van BPD. Het is goed mogelijk dat deze eerste blootstelling aan ontsteking het immuunsysteem zodanig voorprogrammeert dat een tweede blootstelling aan ontsteking (zoals na longschade door beademing) een sterke toename aan TGF $\beta$ veroorzaakt. Dit zou dan leiden tot een verstoring van longontwikkeling en vervolgens tot BPD. Deze theorie wordt ondersteund door klinische studies, die hebben aangetoond dat vroeggeborenen die blootgesteld zijn aan zowel chorioamnionitis als beademing een veel grotere risico hebben op het ontwikkelen van BPD.

Naast TGF $\beta$ zijn er ook verschillende andere stoffen die een belangrijke rol spelen bij het aansturen van de longontwikkeling. In hoofdstuk $\mathbf{7}$ is de invloed van blootstelling aan ontsteking en corticosteroïden op de aanwezigheid van deze stoffen in de foetale long onderzocht. Daaruit bleek dat al deze stoffen sterk verhoogd of verlaagd waren door ontsteking, wat kan duiden op een verstoorde longontwikkeling. Interessant was daarbij dat wanneer de foetussen ook blootgesteld waren aan corticosteroïden, al deze stoffen weer op normaal peil kwamen. Wat dit betekent voor de verdere longontwikkeling en functie is op basis van dit onderzoek moeilijk te zeggen, maar het is wel opmerkelijk dat longen die blootgesteld waren aan zowel ontsteking en corticosteroïden een versterkte longrijping ondergingen (beschreven in hoofdstuk 2). Verder onderzoek is nodig om te bepalen of de longrijping die veroorzaakt wordt door corticosteroïden de longontwikkeling permanent verstoort, of dat het effect slechts tijdelijk is. 
Conclusie

Biomedisch onderzoek dient er altijd naar te streven om inzichten te verschaffen waarmee betere behandelingen ontwikkeld kunnen worden, zelfs als het onderzoek zich buigt over de meest basale lichaamsprocessen. Opdat nieuwe therapiën ontwikkeld kunnen worden om BPD te genezen of zelfs te voorkomen, is er dringend behoefte aan kennis over de normale longontwikkeling aan het einde van de zwangerschap, en hoe deze verstoord kan worden voor, tijdens en na vroeggeboorte. Het onderzoek dat gepresenteerd wordt in dit proefschrift heeft hier aan bijdrage aan geleverd, door aan te tonen dat een veelvoorkomende blootstelling aan bacteriën in de baarmoeder al een effect kan hebben op de zich ontwikkelende long en de stoffen die deze ontwikkeling aansturen. In de toekomst zal er nog verder onderzoek nodig zijn om de verbanden tussen ontsteking en longontwikkeling beter te begrijpen en verder uit te diepen. Het onderzoek in dit proefschrift geeft een basis voor toekomstig onderzoek dat erop gericht zal zijn om BPD te kunnen begrijpen en uiteindelijk te genezen. 

Curriculum Vitae 
Jennifer Johanna Phyllis Collins was born on September 19th 1985 in Heerlen, the Netherlands. In 2003 she graduated from the Bernardinuscollege in Heerlen with honorable mention, and started her studies in Molecular Life Sciences at Maastricht University. After completion of her Bachelor's degree in 2006, she stayed in Maastricht to pursue a Master's degree in Clinical Molecular Sciences. In 2007 she did her junior internship, entitled "Volume trauma at resuscitation leads to epigenetic changes in preterm lambs" with Prof. dr. Boris W. Kramer at the Department of Pediatrics of the Maastricht University Medical Center. For her senior internship in 2007-2008 she travelled to New Zealand, where she did research on the outgrowth and first interactions of the nerve into the muscle tissue in the rat embryo with dr. Marilyn Duxson, at the Department of Anatomy and Structural Biology of the University of Otago in Dunedin. For this work she received an award for "Best master's thesis" from the Faculty of Health, Medicine and Life Sciences at Maastricht University. In 2008 she obtained her Master's degree cum laude.

At this point her interest in developmental biology was well established, and she decided to pursue this interest by starting a PhD project, on lung development after intra-uterine exposure to inflammation, under the supervision of Prof. dr. Boris W. Kramer and Prof. dr. Luc Zimmermann at the Department of Pediatrics and the School for Oncology and Developmental Biology (GROW). For this project, she actively participated in a (now) 22year ongoing collaboration with Prof. dr. Alan H. Jobe and Prof. dr. Suhas G. Kallapur from Cincinnati, OH, USA and Prof. dr. John P. Newnham from Perth, WA, Australia. Parts of her PhD research have been awarded with the GROW science day poster award in 2010, and considered "Best in Pediatrics" at the annual conference of the American Thoracic Society in 2011.

Since 2011 she is married to Daniël and will continue her research into pediatric respiratory research as a postdoctoral researcher with Prof. dr. Bernard Thébaud at the Ottawa Hospital Research Institute in Ottawa, Canada. 
List of Publications

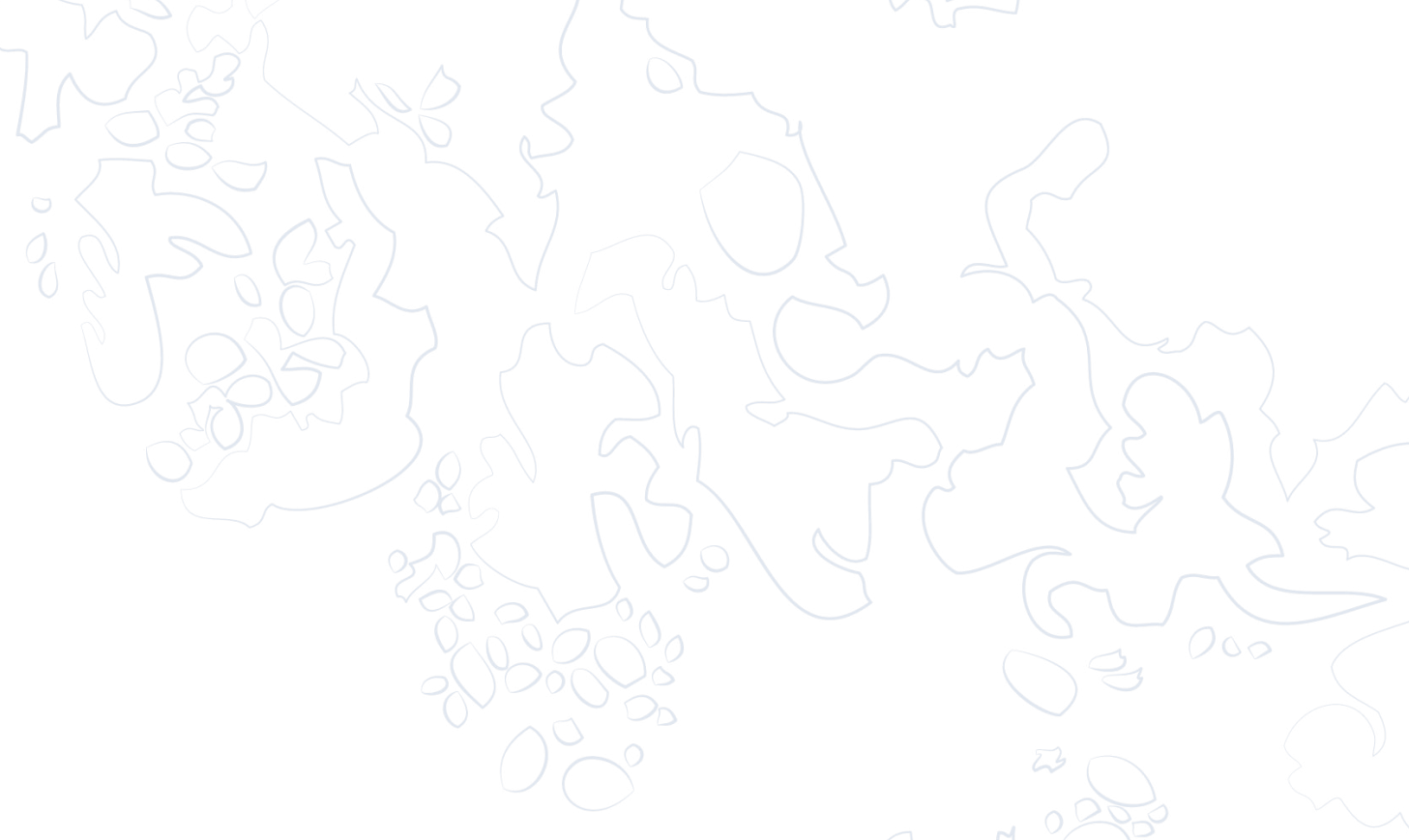




\section{International peer reviewed publications}

Engel M, Nowacki RME, Reiss LK, Uhlig S, Willems CHMP, Kloosterboer N, van Iwaarden JF, Sewing ACP, Seehase M, Lambermont VAC, Collins JJP, Zimmermann LJI, Vos GD, Kramer BW. Comparison of recruitment manoeuvres in ventilated sheep with acute respiratory distress syndrome. Lung 2012 Nov 2 Epub

Seehase $\mathrm{M}^{*}$, Collins JJP*, Kuypers E, Jellema RK, Ophelders DRMG, Ospina OL, Perez-Gil J, Bianco F, Garzia R, Razetti R, Kramer BW. New synthetic surfactant with SP-B and C analogues gives survival benefit in preterm lambs. PLoS One 2012;7(10):e47631. Epub 2012 Oct 16.

Collins JJP*, Kuypers E*, Nitsos I, Pillow JJ, Polglase GR, Kemp MW, Newnham JP, Cleutjens JP, Frints SGM, Gavilanes AWD, Kallapur SG, Jobe AH, Kramer BW. LPS-induced chorioamnionitis and antenatal corticosteroids modulate Shh signaling in the ovine fetal lung. Am J Physiol Lung Cell Mol Physiol 2012 Sep 7 Epub

Kuypers E, Collins JJP, Jellema RK, Kemp MW, Nitsos IN, Pillow JJ, Polglase GR, Newnham JP, Warda AS, Germeraad WTV, Kallapur SG, Jobe AH, Kramer BW. Ovine fetal thymus response to lipopolysaccharide-induced chorioamnionitis and antenatal corticosteroids. PLoS One 2012;7(5):e38257. Epub 2012 May 31.

Gantert M, Jellema RK, Heineman H, Gantert J, Collins JJP, Seehase M, Lambermont VAC, Keck A, Garnier Y, Zimmermann LJI, Kadyrov M, Gavilanes AWD, Kramer BW. Lipopolysaccharide-induced chorioamnionitis is confined to one amniotic compartment in twin pregnant sheep. Neonatology. 2012 May 17;102(2):81-88.

Schoberer M, Arens J, Lohr A, Seehase M, Jellema RK, Collins JJP, Kramer BW, SchmitzRode T, Steinseifer $U$, Orlikowsky T. Fifty years of work on the artificial placenta: milestones in the history of extracorporeal support of the premature newborn. Artif Organs. 2012 Jun;36(6):512-6.

Kuypers E*, Collins JJP*, Kramer BW, Ofman G, Nitsos I, Pillow JJ, Polglase GR, Kemp MW, Newnham JP, Gavilanes AWD, Nowacki R, Ikegami M, Jobe AH, Kallapur SG. Intraamniotic LPS and antenatal betamethasone: inflammation and maturation in preterm lamb lungs. Am J Physiol Lung Cell Mol Physiol. 2012 Feb;302(4):L380-9.

Kunzmann S, Collins JJP, Yang Y, Uhlig S, Kallapur SG, Speer CP, Jobe AH, Kramer BW. Antenatal inflammation reduces Cav-1 expression and influences multiple signaling pathways in preterm fetal lungs. Am J Respir Cell Mol Biol 2011 Nov;45(5):969-76.

Arens J, Schoberer M, Lohr A, Orlikowsky T, Seehase M, Jellema RK, Collins JJP, Kramer 
BW, Schmitz-Rode T, Steinseifer U. NeonatOx - A pumpless extracorporeal lung support for premature neonates. Artif Organs. 2011 Nov;35(11):997-1001.

Kallapur SG, Kramer BW, Knox CL, Berry CA, Collins JJP, Kemp MW, Nitsos I, Polglase GR, Robinson J, Hillman NH, Newnham JP, Chougnet C, Jobe AH. Chronic fetal exposure to Ureaplasma parvum suppresses innate immune responses in sheep. J Immunol. 2011 Sep 1;187(5):2688-95.

Kallapur SG, Kramer BW, Nitsos I, Pillow JJ, Collins JJP, Polglase GR, Newnham JP, Jobe AH. Pulmonary and systemic inflammatory responses to intra-amniotic IL-1 alpha in fetal sheep. Am J Physiol Lung Cell Mol Physiol. 2011 Sep;301(3):L285-95.

Collins JJP, Kallapur SG, Knox CL, Nitsos I, Polglase GR, Pillow JJ, Kuypers E, Newnham $\mathrm{JP}$, Jobe $\mathrm{AH}$, Kramer BW. Inflammation in fetal sheep from intra-amniotic injection of Ureaplasma parvum. Am J Physiol Lung Cell Mol Physiol 2010; 299: L852-860.

Deries M, Collins JJP, Duxson MJ. The mammalian myotome: a muscle with no innervation. Evol Dev 2008; 10 (6): 746-755.

\section{National peer reviewed publications}

Kunzmann S, Collins JJP, Kuypers E, Gavilanes AW, Kramer BW. [Effects of antenatal inflammation on the developing lung] Z Geburtshilfe Neonatol. 2012 Aug;216(4):177-85. Epub 2012 Aug 27.

\section{Submitted}

Collins JJP, Kallapur SG, Knox CL, Kemp MW, Kuypers E, Zimmermann LJ, Newnham $\mathrm{JP}$, Jobe $\mathrm{AH}$, Kramer BW. Repetitive intra-uterine exposures to inflammatory stimuli attenuated TGFB signaling in the ovine fetal lung.

Collins JJP*, Kunzmann S*, Kuypers E, Kemp MW, Speer CP, Newnham JP, Kallapur SG, Jobe AH, Kramer BW. Antenatal glucocorticoids counteract LPS changes in TGFB-pathway and Caveolin-1 in ovine fetal lung

Kunzmann S, Collins JJP, Kuypers E, Kramer BW. Thrown off balance: The effect of antenatal inflammation on the developing lung and immune system

Seehase M, Houthuizen P, Jellema RK, Collins JJP, Bekers O, Breuer J, Kramer BW. Propofol administration to the fetal-maternal unit reduced cardiac injury in late-preterm lambs subjected to severe prenatal asphyxia and cardiac arrest. 
Seehase M, Jellema R, Jennekens W, Zwanenburg A, Andriessen P, Collins JJP, Vles JSH, Steinbusch H, Gavilanes AWD, Kramer BW. Early propofol administration to the maternalfetal-unit improved fetal EEG and influenced cerebral apoptotic pathways in late preterm lambs suffering from severe asphyxia.

Wolfs TGAM, Kallapur SG, Knox CL, Thuijls G, Nitsos I, Polglase GR, Collins JJP, Kroon E, Spierings J, Shroyer NF, Newnham JP, Jobe AH, Kramer BW. Antenatal Ureaplasma infection impairs development of the fetal ovine gut in an IL-1 dependant manner.

*= authors contributed equally 


\section{Acknowledgements}


One of the reasons why I am fascinated with the human body is because so many different cells interact so perfectly with each other to coordinate the miracle that it is the human body. Processes that seem effortless and natural to us, like breathing, thinking and moving, are only possible because many different cells work together and communicate. While you are reading this, 40 different cell types are all working together in your lungs so that your body may be supplied with fresh oxygen and cleansed from waste gasses like carbon dioxide. In my four years of PhD research I have found that research is very much the same: you need to work together with many different people to obtain even the simplest result. Because of their invaluable help during my PhD research, I would like to dedicate some words to these people who come from every corner of the world.

When doing PhD research, you need good promoters and mentors to give guidance where you need it. So first of all I would like to thank my promotors and mentors: professors Boris Kramer, Luc Zimmermann, Suhas Kallapur and Alan Jobe.

Dear Boris, first of all a big thank you to you! Ever since we first met 6 years ago you have been a fantastic mentor, and I've always thoroughly enjoyed our scientific (and non-scientific) discussions. I'm very grateful for all the opportunities you have given me to develop as a scientist, and that you supported me in pursuing my scientific interests. Dear Luc, thank you very much for always being there during my presentations and to provide an independent critical view on my research and papers. Dear Suhas, you have always been closely involved in the inflammatory side of my research. Therefore l'd like to thank you for all your support and advice along the way! Dear Alan, you have taught me a great deal about writing scientific papers, and you have never ceased to amaze me with how fast you provide feedback to my latest writings. You are a true inspiration, and I think that you are the living proof that good science and good food are peas in the same pod! Thank you for being there for me!

I would also like to gratefully acknowledge the members of my assessment committee, Prof. Dr. Frans Ramaekers, Prof. Dr. Bernd Kremer, Prof. Dr. Emiel Wouters, Prof. Dr. Siddharta Bambang Oetomo and Prof. Dr. Irwin Reiss for their time and effort to critically judge this thesis.

During all the daily ups and downs that come with doing PhD research, it helps tremendously if you have nice colleagues who help each other in their time of need or who you can have a cup of coffee/tea/water with if you need to unwind. I would therefore like to give a warm thank you to all of my roommates, Reint Jellema, Matthias Seehase, Verena Lambermont, Yixuen Zhang, Elke Kuypers, Daan Ophelders and Maria Nikiforou for the good times we have shared! Elke, I would to express my heartfelt gratitude to you in particular. You started out as a Masters student under my supervision, 
and I am very glad you decided to stay for your own $\mathrm{PhD}$ research. Without you this thesis would have looked quite different, which is proven by the fact that you have become a co-author in nearly every chapter in this book! You've not only been my partner in crime during our daily work, but l'm very glad to have found a good friend and now paranymph in you. Thank you very much for all of your support! Also, I would like to thank all other colleagues who have been a part of the Pediatrics lab throughout the years, Tim Wolfs, Nico Kloosterboer, Lilian Kessels, Leon Janssen, Dennis Kruk, Coen Willems, Bea Zoer en Saskia van der Sterren, for all the good times and support. In addition, I would like to thank the other two principal investigators of our lab, Eduardo Villamor and Freek van Iwaarden, for all their constructive criticism and discussions about my research during our research meetings.

In (the planning of) research you often have dire need of administrative support, for which I am deeply indebted to Natascha Vrijhoeven-Pieters, Tamara Cauberg-Smits and Lea Lapré for their efforts. Moreover I would like to thank my "distant" colleagues of the Department of Pediatrics, Kim van de Kant, Ester Klaassen and Cynthia Gubbels, for all the fun we've had together the last few years!

Many ideas, protocols and papers in this thesis were able to mature because of the efforts of a fair number of under- and postgraduate students from the universities of Maastricht and Hasselt, and also the Fontys University of Applied Science in Eindhoven. Steffy Janssen, Sanne Lievense, Charelle Willems, Anne-Sophie "Anso" Warda, Manuel Noben, Irma Tindemans, Dennis Kruk, Erik Sarton, Mustafa Tahir, Nynke van den Hoogen, Jeroen Meekels, and especially Monique Willems, thank you very much for your hard work! I have always really enjoyed supervising you and I hope that I have been able to help you in your developing careers.

The one condition for this PhD-position was to go down under to Perth every year to lend a hand during the "sheep frenzy". It's therefore not surprising that my entire PhD research has revolved around these experiments, and all the data that resulted from it. I would like to give a warm thank you to the entire flock of sheep people in Perth at The University of Western Australia with whom I worked through the yearly "business time" craziness: John Newnham, Matt Kemp, Graeme Polglase, Ilias Nitsos, Jane Pillow, Masatoshi "Masa" Saito, Richard "Dickers" Dalton, Clare Berry, Jenny Henderson, Shaofu Li, Andrea Lee, Tom Cox, Christine Knox, James Robinson and all others. For their endless patience and willingness to troubleshoot my work with the FACSCanto II ("the Diva"), especially on Sunday mornings, I want to thank Kathy Heel, Tracey LeePullen and Paul Rigby from the Centre for Microscopy, Characterization and Analysis at The University of Western Australia. Also, l'd like to express my gratitude to the people at the Western Australian Institute for Medical Research for their hospitality when we 
did our yearly run of experiments there, particularly Kristen Nowak, Gina Ravenscroft and Nigel Laing.

Part of the fun of being a part of highly dynamic and international group is that I got the chance to get involved with other people and their projects, and to learn a lot from these people along the way. In Würzburg I would like to thank Steffen Kunzmann for the close collaboration and his expertise on the TGF $\beta$ papers; in Parma, Italy I would like to thank Roberta Razzetti and Federico Bianco from Chiesi Farmaceutici for the fruitful collaboration and recently published paper on our surfactant study; closer to home I would like to thank Mark Schoberer, Jutta Arens, Anne Lohr and Aileen Erben from Aachen for letting me be a part of their very interesting work to prevent ventilation in preterm babies by using a highly sophisticated artificial placenta. In addition, I would like to thank Markus Gantert for all the help, expertise and good company he has given us during the experiments in Maastricht. In Maastricht I would like to thank Monique Engel for all the knowledge she shared regarding ventilation strategies, which has been very helpful for my experiments in Maastricht! Additionally, I would like to thank the personnel of the CPV for their support, patience, but also their good company during our experiments.

As a researcher in a versatile group, every now and then you need to ask for help from specialized experts, who have a lot of experience in the research topic that you're trying to tackle. In this category I would like to gratefully acknowledge Nikki Reynaert, Irene Eurlings and Ramon Langen from the Department of Pulmonology, Jack Cleutjens from the Department of Pathology, Wilfred Germeraad from the Department of Immunology and Suzanna Frints from the Departments of Clinical Genetics/ Anatomy \& Embryology from Maastricht University for their advice and support.

Despite my involvement in all of the above mentioned projects, I wanted to make an effort for my fellow PhD students within GROW, my research Institute, during the last two years of my PhD research. Ton Hopman, Frans Ramaekers, Brigitte Custers, Tamara van de Laar and all active GROW PhD students: thank you very much for your support!

For designing the gorgeous cover and chapter page motif, I would like to thank my long time penpal and talented artist Sarah Butler. You did an amazing job!

Sometimes you really need to give your brains (and yourself) a break, because your brains refuse duty or because you need to let off some steam. At those times it's really nice to have some friends close by with whom you can share a coffee/tea/hot chocolate. Timo Rademakers and Jeroen Otten, I'm really going to miss our coffee breaks in Ottawa! Timo, thank you so much for your help as my paranymph, I'm glad to have you by my 
side.

At the end of the day, family and friends are the ones who are able to energize you to such an extent that you can give another $120 \%$ of yourself the next (working) day. Dear Inge Weyers and Hélène Weusten, I feel privileged that you are always there for me, even if there are times that I do not have the time or energy to meet up with you for months on end. Thanks also to my parents and sisters in law, Renee Hofstee, Paul, Annabelle and Hannah de Wolf, for giving me the chance to unwind whenever I come to visit.

Dear Mum, Daddy, Danielle and Oma, without you I wouldn't have come this far. Thank you for always believing in me, for encouraging when I had lost my confidence and for telling me to slow down when I needed to. Thank you also for your efforts as my "shadow paranymphs" because of my being in Ottawa! I love you very much!

Dear Daniël, this thesis would not be here if you hadn't been the silent force at home who could keep me balanced. More than once you have been able to slow me down when I wanted to do too much at once while I couldn't handle it, and more than once you had to endure a flood of biomedical terms with which you don't have any affinity being an IT guy. I am deeply grateful for your endless patience, support and love, and I am looking forward to brave our Canadian adventure with you by my side! 
